\title{
EPISTEMIC RESPONSIBILITY AND THE LITERARY JOURNALIST
}

BY

LINDSAY JANE MORTON

\author{
A THESIS \\ SUBMITTED TO VICTORIA UNIVERSITY OF WELLINGTON \\ IN FULFILMENT OF THE REQUIREMENTS FOR THE DEGREE OF \\ DOCTOR OF PHILOSOPHY
}

VICTORIA UNIVERSITY OF WELLINGTON 


\begin{abstract}
The primary purpose of this thesis is to examine the role of epistemic responsibility in the practice of book-length literary journalism. Literary journalism offers a powerful alternative to mainstream journalism. Its narrative mode and storytelling techniques open possibilities of representation often closed by traditional reporting practices. Subsequently, literary journalists have attracted criticism for unorthodox modes of representation and attendant "truth claims" in many texts. In this thesis I draw on the work of epistemologist Lorraine Code to highlight the tension between the branches of ethics and epistemology, and argue that holding them apart for the purposes of explication yields important insights into the practice of literary journalism. I argue that criticism of literary journalism has at times conflated ethical and epistemic concerns, resulting in censure of the practitioner on primarily moral grounds. While such a critique is often valid, I propose that it can mislabel problematic cognitive processes as moral deficiencies.
\end{abstract}

A re-examination of significant controversies raised by literary journalism shows disputed areas stemming from epistemic "blind spots". These "blind spots" are often characterised as ethical lapses, but I argue that framing criticism in this way inhibits progress in sound practice. Recurring controversies over works by practitioners such as Janet Malcolm and Australia's Helen Garner bear this out. I also offer close readings of three works of contemporary US literary journalism through their paratextual frames. The limits of transparency are demonstrated here, including the fact that disclosure can hide more than it illuminates. Code's "epistemic responsibilist" approach is subsequently presented as an important addition to literary journalism scholarship, as it offers a sound foundation for reflexive practice-for both writers and critics. Using this approach, I offer critical readings of the "truth claims" in three contemporary US texts: Adrian Nicole LeBlanc's Random Family (2003), Dave Cullen's Columbine (2009) and Rebecca Skloot's The Immortal Life of Henrietta Lacks (2010).

A secondary aim of this thesis is to characterise contemporary Australian book-length literary journalism. Using Code's concept of an "epistemic community", I propose that the nature of national discourse influences the voice of the Australian literary 
journalist, as revealed by anxiety over representation in the texts under analysis. These texts highlight the pressures of subjectivity on truth, which results in a destabilisation of "truth claims". In comparison with the US practitioners analysed, their three Australian counterparts analysed place less emphasis on disclosure transparency, and rely more heavily upon self-presentation as seekers, rather than discoverers, of knowledge and truth. I further maintain that these three texts represent a dominant national function of book-length literary journalism. Issues of national identity are bound up in the relationship between the land and its people, and are evident in the work of Margaret Simons, Chloe Hooper and Anna Krien, three of Australia's most notable literary journalists. Through the lens of a civic dispute, each of these practitioners join one of the most pressing cultural issues in contemporary national discourse, that is, to explore what it means to be "Australian". 


\section{ACKNOWLEDGMENTS}

This thesis has benefitted at every turn from the guidance of Professor Harry Ricketts and Dr Nikki Hessell. As supervisors, they have offered insightful, critical feedback in ways that always encouraged and renewed vision. As teachers and researchers they have modelled excellence in their fields and have facilitated the best possible introduction to the world of research for me. Thank you, sincerely, Harry and Nikki. It has been a privilege to work with you both. Thanks to Professor Matthew Ricketson of the University of Canberra, who has generously shared his time and knowledge, and whose continuing interest in my research has been appreciated. I would also like to acknowledge and thank Professor Michael Meehan of Deakin University, who was the first to turn my attention to literary journalism, and encouraged me to pursue research in this area.

My parents have been a great source of support in every conceivable way. Thanks Dad and Mum for Friday phone calls and the endless supply of encouragement from across the ditch. Belinda and Marlan, thank you for your stimulating discussions, sharp eyes, and for pointing out interesting books and stories along the way. Owen, Tamar, Jack, Jami, Great Ruth, Michelle, Liza, Kara, and especially Karli and Keira, thank you for your encouragement, strong shoulders and big hearts. I'm so grateful. And this project is dedicated to my Wicked Step-Mother, Val Brittain, who encouraged me at age 13 to chase my dream of becoming a doctor. I believe at the time I was heading towards a career in podiatry, but I don't think she minds the change in direction.

Finally, I would like to acknowledge the literary journalists whose work has inspired this thesis. Throughout the course of this research I have followed them into war zones, classrooms, treetops, science labs, witness boxes, boardrooms, villages, city streets, prisons and parliaments, and I have read about their private hopes and fears. Their dedication, talent, and heart are inspiring, and I hope that this thesis contributes in some way to the work that they do. 


\section{Table of Contents}

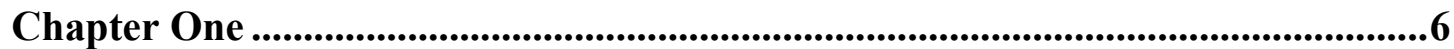

Terra Nullius: Exploring the Territory of Literary Journalism............................................ 6

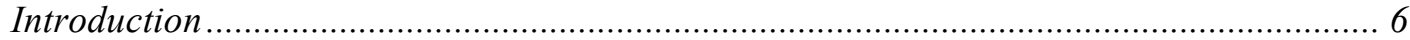

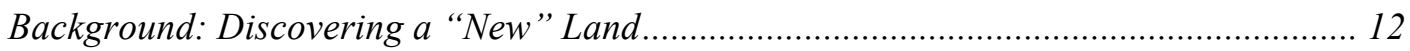

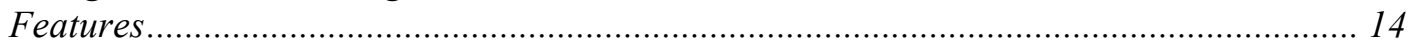

The Story Behind the Name (Or: The Name Behind the Story) ...................................... 18

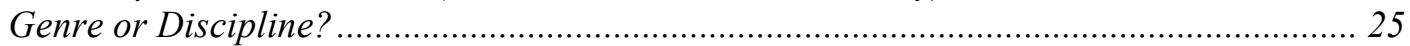

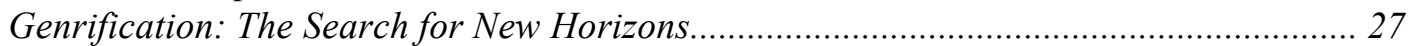

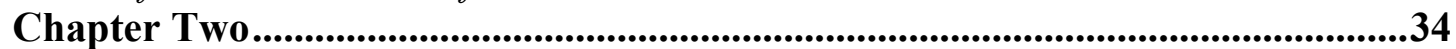

Negotiating Non-fiction: Taking Back Ground ……........................................................... 34

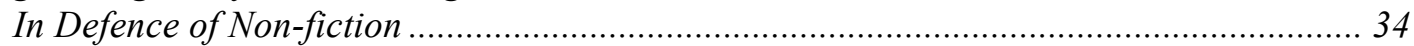

Narrative Features: Closure, Meaning, Reflexivity and Reification................................ 43

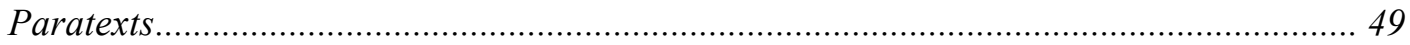

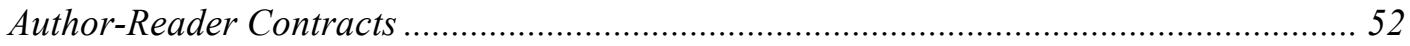

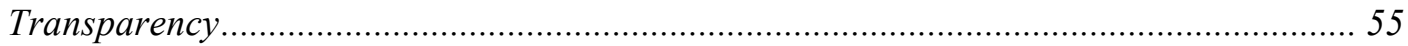

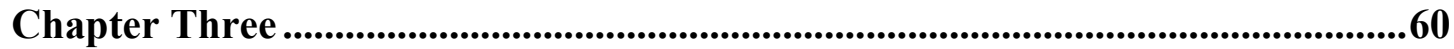

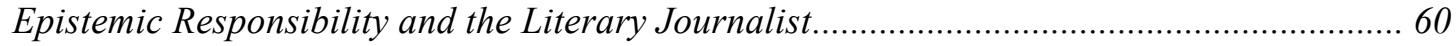

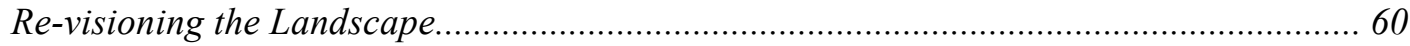

Epistemological Approaches: Foundationalism, Coherentism, and Responsibilism.......... 61

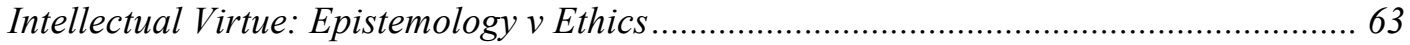

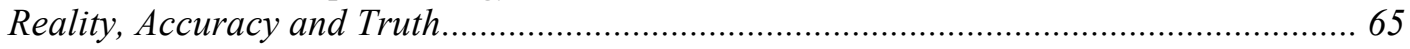

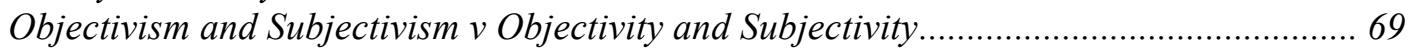

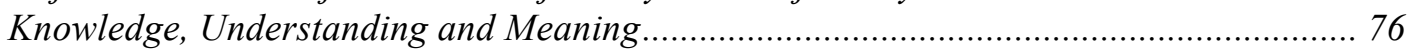

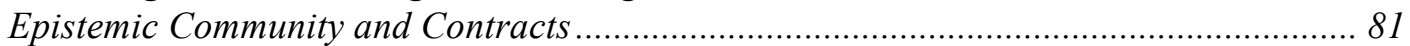

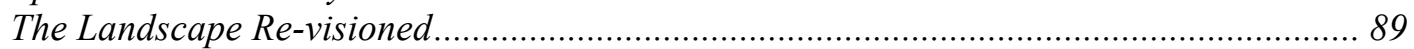

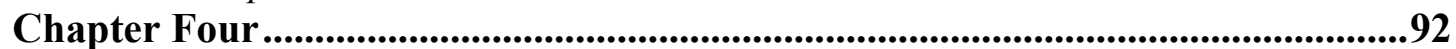

Contracts and Controversies: The Limitations of Transparency ......................................... 92

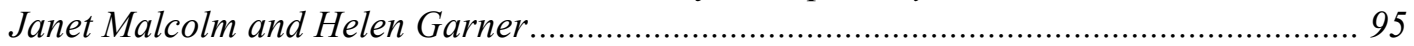

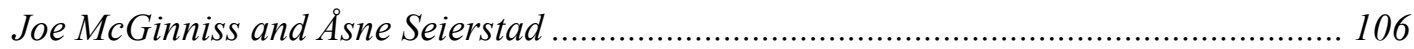

Richard Critchfield and Alexandra Fuller ............................................................... 115

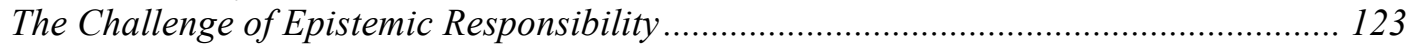

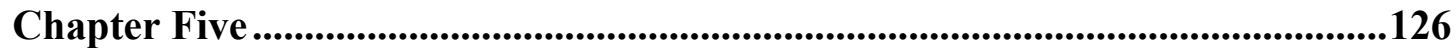

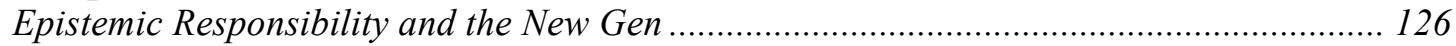

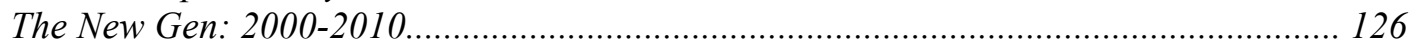

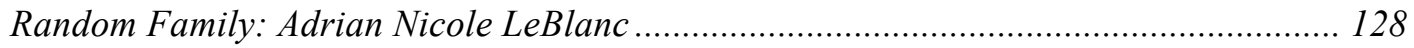

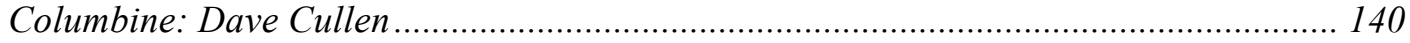

The Immortal Life of Henrietta Lacks: Rebecca Skloot ................................................. 152

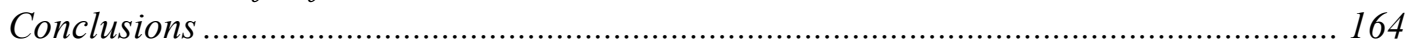

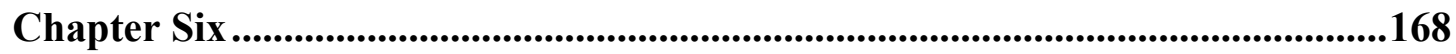

Contemporary Australian Literary Journalism ……................................................ 168

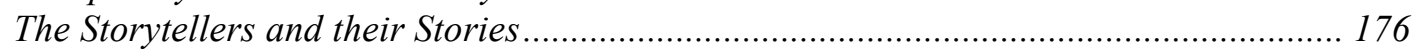

Epistemic Community and the Shaping of Australian Literary Journalism.................... 180

Australia's New Gen: On "Being Australian”............................................................ 197

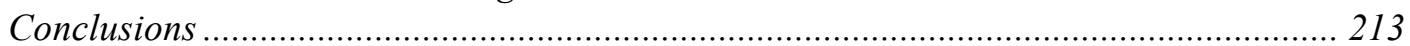

The "New Gen": History Makers, Future Shapers ...................................................216

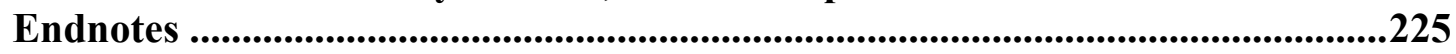

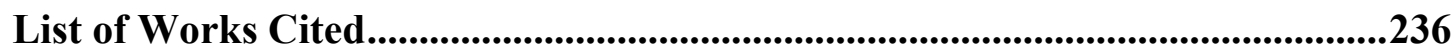




\title{
Chapter One \\ Terra Nullius: Exploring the Territory of Literary Journalism
}

\section{Introduction}

In 1997, the State of New Jersey took legal action against the State of New York over the jurisdiction of Ellis Island. Originally a three-acre dot of land between the two states, the island was claimed by New York in 1834, despite being on New Jersey's side of the state boundary. It is well-known today as the site of processing for millions of people immigrating to the United States. After 1891, the federal government began to build up the island with landfill to accommodate the growing need for processing space, to the point where today, approximately 24 acres - or nine-tenths - of the current island is new land. Evidently, this is not part of the original land upon which the States' agreement was made. New York's sovereignty over Ellis Island was legally contested in 1997, when the state of New Jersey argued in the Supreme Court that it had never been notified of New York's intention to claim the built-up areas, and that it had never acquiesced sovereignty of the new land to that State. In its final ruling in 1998, the Supreme Court invoked the term terra nullius to explicate the legal meaning of territorial sovereignty. The Latin phrase is used in international law to describe land that has never been occupied by any sovereign state, and may therefore be acquired. Terra nullius can be interpreted in a number of ways: as "emptiness"; as "absence of civilised society"; or as "uninhabited or barbarous country" (as under English common law); but in layman's terms, it simply means "no-man's land". At its core is the concept of a territory that has yet to be explored and settled. Justice Souter's opinion read in part:

\begin{abstract}
Even as to terra nullius ... a claimant by right as against all others has more to do than planting a flag or rearing a monument. Since the 19th century the most generous settled view has been that discovery accompanied by symbolic acts give no more than "an inchoate title, an option, as against other states, to consolidate the first steps by proceeding to effective occupation within a reasonable time" ("State").
\end{abstract}

The Court upheld New Jersey's claim to the new land, citing the State of New York's failure to notify its intention to extend the original agreement, and New Jersey's refusal to yield its rights over the 24 acres. Today, both States exercise jurisdiction over Ellis Island, with the majority lawfully belonging to New Jersey. 
Four elements pertaining to terra nullius can be inferred from the Court's written opinion: discovery, exploration, consolidation, and occupation. In this case, New York State's 64-year occupation was not, in legal parlance, considered "insufficient as a matter of general law" to claim sovereignty, but the Court's opinion cited a "conviction that in the interest of stability ... the present possessor should be considered the rightful owner of a territory" ("State"). Neither can "symbolic acts" ensure jurisdiction — giving "new" land a name and planting a flag on its shore are not sovereign acts. Time, stability and consolidation are all necessary for a claim over terra nullius, as is the hearing of all counter-claims and dissent by opposing parties. It is these elements that make the term such a rich metaphor for the scholarship on literary journalism. Similarly, contested jurisdiction over the new land added to Ellis Island prefigures issues faced by the New Journalists and contemporary literary journalists alike: ownership, control, purpose, and responsibility.

The International Association for Literary Journalism Studies (IALJS), founded in 2006, has begun to illuminate the areas researchers in this field could explore. To invoke the terra nullius metaphor, the practice of literary journalism-particularly in the United States - is well into the consolidation, and perhaps even occupation, phases. Scholarship, on the other hand, is still firmly in a period of exploration. The purpose of this thesis is to enhance this exploratory phase by contributing to the advancement of literary journalism scholarship in two areas. In the inaugural issue of the scholarly journal Literary Journalism Studies (2006), leading scholar Norman Sims outlined the need for "elucidating the form's international nature and how it relates to different national cultures, placing the form within the context of a broad time frame for its history, recognizing the role that practicing writers of the genre can play in reflexive critique, and the promise of online presentation as a vehicle for the form. Finally, there is the problem of ... the "reality boundary," which ... is central to such scholarship" ("Problem" 7-8 emphasis added).

Of these areas, this thesis primarily engages in the two highlighted above: namely, the "reality boundary", and exploration of the national character of Australian literary journalism. The "reality boundary", however, is somewhat of a misnomer for the perspective offered in this study. Here I contend that while attempts to assess literary 
journalism with established journalistic norms such as the "objectivity standard" and the "discipline of verification" are valuable, these attempts are often frustrated by texts' and practitioners' resistance to such norms. In practice, this is manifested in attempts to assess "truth claims" against epistemological categories such as belief and understanding. The fact that empirically verifiable data is always subject to individual perception and framing is also problematic for normative, objective standards. As a result, attempts to apply such standards can only offer limited assessments of the value of literary journalistic texts. It will be further contended in this thesis that some frustration proceeding from such analyses stems from a conflation of epistemological and ethical issues. In order to address this state and propose an alternative way to conceptualise and study literary journalism, I will draw on Lorraine Code's important work Epistemic Responsibility (ER). Code's approach has not been applied to literary journalism in a sustained way. In this thesis it illuminates aspects of the practice of literary journalism, and provides a language and framework through which epistemic issues can be discussed.

Complementing the assessment of a text's truth claims with an analysis of epistemic responsibility acknowledges the role of the literary journalist as something more than a "recorder" of reality - a supposition upon which the assessment of "truth claims" lies. To appropriate and apply Code's language to literary journalism, analysing the truth claims of a work of literary journalism independent from its epistemic foundations renders practitioners as abstractions, and closes off the possibility of significant epistemological scrutiny. For Code, "concentration upon end-states grants them an unwarranted finality, making them seem implausibly definitive, static, and removed from the flux of cognitive forces" (ER 8). Epistemic enquiry consequently places the literary journalist at the centre of the knowledge claims of a text. It asks whether or not a practitioner is in a position to make knowledge claims - knowledge that often cannot be parsed through normative processes of verification.

Epistemic Responsibility received a mixed reception amongst epistemologists. In an article titled "Responsibility and Rhetoric" (1994) published seven years after Epistemic Responsibility, Code notes the "uneasy" location the book occupies within the discourse of Anglo-American epistemology, and attributes its reception-ranging 
from admiring to ambivalent to critical - to a number of factors. ${ }^{1}$ She identifies the primary resistance to its premise, however, in the following way:

the book sits uneasily with epistemologists, I suggest, because such questions are thought not to be properly epistemological at all, but to belong to ethics, or to the softer fringes of everyday talk about knowledge, rather than to the hard center of serious epistemological analysis. My claim is that if epistemology is indeed about the scope and limits of human knowledge, then it needs to address such questions, and not just the more formal ones that have been its principal preoccupation ("Responsibility and Rhetoric" 3).

Code's work may lack a firm affiliation with an identifiable philosophical position, hence its tenuous position in the academy. But I argue that this weakness is actually a strength, in that it considers the phenomenological before constructing the theoretical. Code sets out to "adduce a set of claims about expectations and responsibilities" rather than proposing a theory to which human cognitive and communicative practices ostensibly conform. She continues:

In each case, a responsibility to know is at issue, and it is to that responsibility that I wish to draw attention. It is true that, in many of the cases, it is the action(s) based upon the inadequately or carelessly arrived at knowledge claims or beliefs that come under public scrutiny and that seem to invite moral and/or legal censure, for the consequences of being wrong are serious. But it is instructive, for epistemological purposes, to focus upon the assumed or alleged knowledge itself, to consider what is involved in the contention that there is, often, a responsibility to know, or at least to know better than one does (ER 2 emphasis in original).

Here Code identifies a crucial distinction between epistemology and ethics. Actionsor, in the case of literary journalism, narratives-may invite moral and/or legal censure, but in many cases the root causes of disputes originate from weak or unjustifiable epistemological foundations, from which (moral) errors ensue. This distinction illuminates a number of controversies that have been triggered over ostensibly ethical lapses, but I argue that they are primarily epistemic, and occur in the immersion stage of the reporting process. The crucial distinction here is that a literary journalist with a flawed epistemological base does not choose to write unethically, but that is the inevitable outcome of a flawed epistemology. In gathering and ordering knowledge to produce "truth claims", a practitioner may act irresponsibly, but this is only a choice if they are aware of sound and unsound epistemic practice. As literary 
journalism goes beyond the epistemological boundaries of "mainstream" journalism, ${ }^{2}$ practitioners can benefit from Code's responsibilist approach that encourages reflexivity and the best possible practice in an innovative field. In its application to literary journalism, Epistemic Responsibility finds "a readily available space within the discourse/rhetoric of epistemology" to test its interpretive potential ("Responsibility and Rhetoric" 5). ${ }^{3}$ The primary aims of this thesis, therefore, are to apply Code's approach to past and present works of literary journalism; to identify and isolate epistemic issues that have been obscured by ethical criticism or praise; to model reflexive epistemic questioning that leads to best practice; and, thus, to advocate a "responsibilist" approach to literary journalism.

Although to a lesser extent, Epistemic Responsibility will also support the secondary focus of this thesis; that is, the nature and function of Australian literary journalism. Here, again, terra nullius is a particularly apt metaphor. The term itself is controversial in both Australian political and public discourse. Although it is primarily used in the legal arena, the concept became familiar to many Australians in 1992 during a High Court case over land rights. Australia is the only Commonwealth nation not to have signed a treaty with its indigenous peoples, its settlers having invoked terra nullius to justify the acquisition of land at various times through the $19^{\text {th }}$ and $20^{\text {th }}$ centuries. Two decades ago, however, Eddie Mabo led a group of Meriam people from the far Northeast in legal action to recognise their possessory title over the land by reason of long possession. Judicial bodies had endorsed terra nullius in previous Australian cases where indigenous peoples sought to claim their traditional land back from British settlers, but the High Court found for Mabo in this landmark decision, ruling that there is a concept of native title to be found in common law. This finding effectively overturned terra nullius - legally recognising traditional ownership of the land for the first time. The effects of this ruling cannot be overstated. While subsequent cases modified the 1992 Mabo decision, this case was a touchstone event in Australia's "history wars", a term denoting two decades of deeply divisive public and political debate over the nature of British colonisation and the subsequent treatment of the country's first peoples. Historians, anthropologists and political parties polarised into camps that either supported or opposed the Mabo decision during the 1990s, dividing not only over Mabo but also a version of history that saw the British as settlers, occupiers, or invaders. Public opinion also split over the Mabo 
decision, and remains divided today. At the heart of the history wars, however, is a struggle common to all colonised nations: that of reconciling what it means to be a citizen in the wake of a nation's colonial past. It is this issue - the forging of national identity - that I propose is a central concern of contemporary literary journalism in Australia.

The dual focus of this thesis may initially seem incongruous; epistemic responsibility and national identity do not obviously occupy common ground. In the final chapter, however, these two elements achieve synthesis when the literary journalist's epistemic community_including subjects, readers, critics, publishers, publicists, and academics - is shown to impact upon the practice and unique features of Australian literary journalism. Whether or not this is the case for other national forms is beyond the scope of this thesis. But Australia's small population and celebrated national character, I argue, have laid the foundations for a deeply introspective form of literary journalism that exhibits anxiety over representation in the texts under analysis.

Before proceeding with the central arguments outlined above, the purpose of this chapter is to engage with key theoretical issues underpinning current international scholarship of literary journalism. It will discuss reportorial and textual features, definitions and nomenclature, before drawing on advances in genre studies to reconceptualise literary journalism in relation to other journalistic and fictional forms of narrative. These are standard discussions in literary journalism scholarship; however, not only does this chapter set up a critical framework within which to situate an analysis of primary texts, it also offers a brief overview of current scholarship to inform readers pursuing this field of study, a field that is largely unoccupied — or terra nullius - in Australia.

Chapter two seeks to meet the challenge to the fiction/non-fiction dichotomy and set a theoretical foundation for literary journalism as non-fiction. I employ Code's reading of Immanuel Kant, which offers an alternative theory of cognition to that relied upon by deconstructionists. Kant's concept of "the creative synthesis of the imagination" is critical for Code. By extension, it provides a philosophical foundation for this thesis's positioning of literary journalism as non-fiction. This chapter also defines important terms associated with epistemic responsibility, as they will be used for the remainder 
of the study, and works through issues in avenues of epistemic responsibility such as paratexts, author-reader contracts, and transparency. The third chapter lays out a full reading of Code's Epistemic Responsibility and applies her approach to the practice and criticism of literary journalism. Critical to this section is the separation of ethics and epistemic modes of enquiry; this is the starting point from which analyses in the following chapters will be performed. Chapter three will also suggest how Code's definitions of key terms such as knowledge, meaning, understanding, belief, balance, and truth, can be employed as a framework to assess literary journalism's claims. This theoretical framework will then be applied to a number of well-documented controversies in chapter four, including Masson v New Yorker, Helen Garner's literary journalism, and Åsne Seierstad's experience with the nexus between ethics and epistemology. Revisited through an epistemological lens, these analyses attempt to separate epistemic and ethical issues, at least for the purposes of explication, and identify pertinent areas for future analysis of literary journalistic texts and practice.

Chapter five moves away from well-documented controversies to contemporary, critically acclaimed works of book-length literary journalism. In this section I employ Code's approach to analyse three debut texts. My readings engage with critical responses to these texts, published in the United States between 2000-2010. Here I identify epistemological issues in acclaimed texts, demonstrate the limitations of transparency, respond to truth claims, and suggest areas for future literary journalism scholarship and criticism to consider. The final chapter also analyses epistemic responsibility in three contemporary book-length works of literary journalism. These Australian texts, also debuts published between 2000-2010, may not be representative of all literary journalism in Australia, but when analysed as a group they reveal an important relationship between the epistemic community within a relatively small population and its impact on literary journalistic practice. Not only do these analyses collectively illuminate this relationship, individually they also demonstrate what I suggest is the dominant function of contemporary practice in Australia, that is, to explore what it means to "be Australian".

\section{Background: Discovering a "New" Land}

In 1965 Truman Capote famously declared himself the author of a new creation: the non-fiction novel. Assiduously researched and written in narrative form, In Cold 
Blood began a wave of sensation as an example of journalism written with the artistic flair of a novel. Capote's claim, according to Tom Wolfe, caused a "status panic in the literary community" (The New Journalism 25): was it possible to create a work of non-fiction, at once "true" and "creative"? Today the wave of critical dissent begun over four decades ago is still rippling through the academic world - and at times - the wider public domain, as book-length works of narrative literary journalism continue to challenge the objectivity standard and what constitutes the representation of truth.

While scholarship clearly shows Capote's claim of creating something new to be optimistic at best (see Bak 1-3; Hartsock; Kerrane and Yagoda 17-19; Sims and Kramer 3-5), the term "non-fiction novel" was coined in the mid-1960s, an era closely associated with the rise of the New Journalism. Practitioners already experimenting with the form were further energised by the positive reception of In Cold Blood. Writers such as Wolfe (The Electric Kool-Aid Acid Test 1968), Hunter S. Thompson (Hells Angels 1966, Fear and Loathing in Las Vegas 1973), Joan Didion (Slouching Towards Bethlehem 1968) and Norman Mailer (The Armies of the Night 1968, The Executioner's Song 1980) similarly applied literary techniques to news articles and essays, creating divisions between critics who struggled with this "new" phenomenon in journalism. The features of this type of writing invite critical attention for many reasons. However, the seemingly irreconcilable fusion of factual content and narrative form remains a contentious feature in works written during this era.

The literary world has arguably seen the death of the "New Journalism" in the five decades since Capote's claim, and is currently witnessing the coming-of-age of what Robert Boynton would have his readers believe is its near-eponymous progeny. The somewhat playful title The New New Journalism (NNJ) (2005) refers to a growing number of contemporary North American works linked through their journalistic roots, immersive reporting practices and narrative approach. According to Boynton, the New New Journalism has "benefited enormously from both the legitimacy Wolfe's legacy ... brought to literary nonfiction, and from the concurrent displacement of the novel as the most prestigious form of literary expression" (NNJ xii). That the prestige of the novel has been "displaced" will not be debated in this thesis; however, Robert Vare's assertion in 2000 that narrative non-fiction in the US "shows every sign of being in the midst of something of a golden age" is a 
quantifiable reality. Among practitioners in this field are winners of the Pulitzer Prize for journalism, National Book Critics Circle Awards for general non-fiction, and numerous other honours. These best-selling works range from treatise to exposé to jeremiad-all products of intensively researched and painstakingly crafted investigative journalism. Indeed, it is the wide range of forms and practices represented by these texts that obscures a clear or simply definable canon for literary critics or the wider reading public to recognise. Works in this field can be labelled as diversely as politics, contemporary history, science, cultural studies, transportation, biography and urban studies. The dilemma of classification is perhaps most obvious with texts such as The Carpet Wars by Christopher Kremmer, the 2007 edition of which is labelled: "current affairs/social history/travel". Such diversity reflects the range and depth of literary journalism being practised today, as well as highlighting the lack of homogenous features of works in this field.

Boynton claims that recent movement away from New Journalism's controversial characteristics represents a "continued maturation of literary journalism" (NNJ xi), and observes that current practitioners' achievements are "more reportorial than literary" ( $N N J$ xii). His analysis is echoed by practitioner William Langewiesche, who states: "What's going on now is a new form of clean classicism." Langewiesche regards the more recent iteration of the form as "equally as deep" as New Journalism (Reynolds 66), evidently referring to the powerful thematic, political, cultural, and advocatory concerns of contemporary works. These judgments are supported by this thesis, in which six debut works of book-length literary journalism published between 2000-2010 are analysed. Hollowell observes that discussing literary developments without the clarity of perspective provided by time has inherent risks; the critic "may fall prey to the distorting proximity of a decade just past" (ix), but the value of my study relies in part on its timeliness. ${ }^{4}$ Surveys of contemporary practice reveal the state of practice; the results of the analyses in chapters five and six, then, are relevant for current and future practitioners, scholars and readers.

\section{Features}

It is perhaps unfortunate that the terra nullius analogy can apply equally well to the scholarship of literary journalism as to its practice. The core of the colonial project involves the appropriation of an area otherwise uninhabited - a virgin territory to be 
carved out, quantified, labelled and "tamed". The parallels with academia are clear. If the process of genrification is inevitable, however, it can be undertaken with sensitivity to the intentions of practitioners-particularly in this non-fiction field where the relationship between the author, subject and reader can have ramifications beyond the text itself.

The scholarship of an earlier form of literary journalism emerged in the field rather than the academy. In 1973, Tom Wolfe proposed his own framework for the practice of New Journalism. He posited the following features as characteristic of reportage, or journalism written with literary techniques: scene by scene construction; dialogue in full; third-person point of view; symbolic details of status life; interior monologue; and composite characterisation (The New Journalism 31-32). Many of these features can be found in contemporary works; however, at this point a divergence of opinion occurs regarding the use of certain narrative techniques in non-fiction, such as interior monologue and composite characterisation, some of which have caused controversy. Writers such as Gail Sheehy and Joe McGuiness are well-known for storms created over composite characterisation (see Sims, Literary Journalism 104, 115). More recent cases such as Australian Helen Garner's The First Stone are widely documented, and will be further discussed in chapter four. This does not mean such practices have been abandoned, however. Richard Preston uses interior monologue in The Hot Zone (1995), for example; but he is careful to defend his practice in the Foreword to the book. ${ }^{5}$ Other features such as third-person point of view are clearly not grounds for identifying or excluding texts from this field, as both heterodiegetic as well as homodiegetic narration is common in contemporary practice; however, authorial decisions about narratorial presence and technique have similarly proved contentious, such as in John Hersey's extended version of Hiroshima (1985) andmore recently-William Langewiesche's American Ground (2002) and Adrian Nicole LeBlanc's Random Family (2003). Clearly this field resists classification by specific features. As such, identification rests predominantly on the shared characteristics of exhaustive research of "real" entities, timeliness, and narrative mode.

Almost a decade on from Wolfe's attempt to characterise New Journalism, Norman Sims argued for historical roots Wolfe attempted to downplay. He proposed two active generations of literary journalists were practising at the time of writing, and 
cited - among others — James Agee, George Orwell and John Hersey as earlier literary journalists (Literary Journalists 5). From interviews with "new gen" writersRichard West, Mark Kramer, Sara Davidson, Tracy Kidder and Mark Singer-Sims derived six characteristics to create "the boundary of the form" (8): immersion (8-12); dynamic structure that does not conform to a journalistic formula (12-15); accuracy (15-16); individual voice (16-18); responsibility (to the subjects of the text) (18-21); and symbolism, or symbolic reality (21-25). Sims contended "literary journalism has been around just long enough to acquire a set of rules. The writers know where the boundaries lie" (5). This statement is as questionable now as it was in 1984 when The Literary Journalists was published, and indicates a more static conception of genre than is in current use - a point that will be explored later in this chapter. Sims extended the historicisation of the form in the first edition of Literary Journalism in the Twentieth Century (1990), although in the introduction he seems to loosen up from restrictive issues of definitions, noting "it seems easier and more definitive to cite examples" than to define literary journalism (xvii).

Another decade on, Thomas B. Connery went beyond Sims's study to propose three historical cycles of modern literary journalism: the 1890s, 1930s and the 1950-1960s (Sourcebook xii-xiii). Connery prefers more open boundaries, stating "immersion may or may not be an element of literary journalism; its use is not necessary for a work to be classified as literary journalism. Making immersion optional allows for a broader, yet legitimate application of the definition" (12 emphasis in original). Connery allows that immersion is crucial to longer, more complex articles or booklength works (13), but is wary of excluding texts on the basis of immersive reporting practices. Connery praises Barbara Lounsberry's proposed four constitutive features of literary or artistic non-fiction. They are: documentable subject matter chosen from the real world as opposed to "invented" from the writer's mind; exhaustive research; the scene; and fine writing: a literary prose style (xiii-xv). But again he goes beyond the scope of her analysis - Talese, Wolfe, McPhee, Didion and Mailer, who were all still closely associated with New Journalism - to represent the historical cycles of literary journalism.

Published in 2000, John C. Hartsock's A History of American Literary Journalism offers a preliminary definition of narrative literary journalism as "those true-life 
stories that read like a novel or short story" (22) before working through the difficulties inherent in such a definition. Hartsock focuses on the complexities of nomenclature rather than the identification of features to delimit the field, a focus consistent with his aim to acknowledge the scholarly discussion but move beyond it (12). The IALJS similarly avoids demarcating features to create boundaries. The Association does not currently endorse a single definition, instead offering six definitions of literary journalism to "establish a meeting ground for its critical study" ("Mission Statement"). The point here is not to create a comprehensive overview of features evident in scholarly studies. Rather the intention is to demonstrate how, over time, scholarship has moved away from imposing boundaries that exclude texts on the grounds of individual features, allowing for a more inclusive, text-driven body of analysis to emerge.

Taking the lead from this trend in scholarship, I will characterise the works surveyed in this thesis by their shared features: they are book-length non-fiction narratives written with literary techniques, resulting from immersive research of actual contemporary people and issues through the lens of contemporary events. In this definition the narrative mode differentiates works in the field from texts in which the dominant mode is expository or analytical. The term "contemporary" separates literary journalism from historical works. That is, while texts may divert into historical records to provide background information, the narrative is primarily concerned with issues and events occurring up to a ten-year period before the book's publication. This definition also distinguishes biography from literary journalism with the phrase "through the lens of contemporary events". A subject's life story may be relevant and thus referenced by practitioners, but here the primary journalistic focus is the event. "Practitioner" is also preferred over "journalist" in this thesis to acknowledge the varied professional backgrounds of writers featured in chapters five and six. While some theorists consider only former or practising journalists in their study of literary journalism, here the features of the work and process of gathering information are given precedence over the professional background of the writer. "Literary style" includes such features as a narrative arc; figurative language; symbolism; and the preference of narration over exposition. The term essentially differentiates between what Ronald Weber identifies as skilled factual reconstruction and non-fiction writing with a literary purpose (132). This "literary" descriptor signals 
a text's value beyond its informative function. Finally, shorter works are often featured in anthologies such as Sims's The Literary Journalists and share many features of book-length works, but considering short texts lies beyond the scope of this thesis.

\title{
The Story Behind the Name (Or: The Name Behind the Story)
}

One of the most controversial aspects of this field of study has been assigning a name to texts with such broad characteristics and loosely related features. This reluctance to label has been - and continues to be - a point of contention between some academics, authors, journalists and interest groups in the wider public domain. In 1990, Lounsberry posed the question: "If we live in an age of nonfiction, then why is critical appreciation of this work so rare? This is explained, in part, by the inevitable lag of the critic behind the artist, but also by the lack of a satisfactory name for this work" (xi). More than two decades later, her observation still accurately describes the uncertain nomenclature for what she herself terms "literary nonfiction"; however, critical appreciation of individual works is a thriving, and arguably urgent, field of study in the world of literary criticism. Lounsberry's accounting for the nameless state of "this work" nevertheless raises an important question: is there good reason for this lack of critical consensus? Corollary questions follow: does this work need to be named? And, if so, what effect does labelling texts have on academic and/or public reception of works bearing a common label?

In 2000, Hartsock suggested the state of scholarship in this area has altered little since the time of Lounsberry's writing. He also suggested this lack of development was linked to lack of consensus on a name:

\begin{abstract}
because there are only a few book-length examinations of literary journalism and the scholarship is generally meagre, the form's study lacks a critical or scholarly mass. Such a problematic conclusion might suggest in more traditional academic circles that literary journalism/nonfiction cannot be critiqued because it appears to lack focus and weight, with the result that such a position can only continue to marginalize the form. Yet as I attempt to demonstrate, the form - by whatever name - is alive and well given the ongoing critical acknowledgement of it (259).
\end{abstract}

Here Hartsock identifies a difference between the "lack of scholarly mass" and “ongoing critical acknowledgement", indicating positive reception of literary 
journalism among mainstream reviewers without a correlating reception among scholars. This was accurate in 2000, but the state is changing. If the practice of literary journalism is in the midst of a golden age, its scholarship is arguably also entering a golden age of its own. Despite the rapid development of the field, however, Jenny McKay argues that as recently as 2011, reportage remains "invisible" to the general public in Britain, partly out of neglect by the academy (Reportage 53). She writes:

it would be [heartening if] reviewers felt they could depend on their readers' knowledge about reportage through having read enough of it to equip them with a framework of critical reference other than that provided by fiction. This is not a trivial point. It is a use of words that helps to perpetuate the invisibility of a significant and important genre of writing. ... [A]nd so if something has no name, no verbal label, then it can comfortably be ignored (Reportage 54).

McKay's reference to a critical framework here is tied to the notion of "generic competence", or a knowledge set that "enables readers to decode a narrative, cocreating the story as a meaningful and coherent whole" (Pyrhönen 110). She concludes that this state of invisibility perpetuates reportage's low profile and limits would-be practitioners' access to resources: “There is money available, in the national press at least. It's just that it is being spent on astronomically high fees for personal columnists or their admittedly more serious and possibly more interesting to read commentarycolumn colleagues" rather than practitioners who investigate using immersion techniques ("Hidden Genre" 57). If writers do manage to support themselves, McKay contends, they will struggle to get their work published due to limited column space in magazines and newspapers ("Hidden Genre" 57). This is perhaps not the case in the US, where recognisable traditions still flourish in publications such as the New Yorker-and book-length narrative journalism is finding both mainstream and critical success. But for McKay, the invisibility of reportage in Britain is directly linked to a lack of funding, as is the absence of a critical framework through which readers can consume narrative forms of journalism. A similar state exists in Australia, and will be elaborated on in chapter six. Evidently, settling on a name has significant "real-world" benefits for scholars, practitioners and readers alike.

Despite a lack of consensus, some names have been gaining more currency than others. Norman Sims's use of "literary journalism" has gained traction in the 
academy, as evidenced by successive anthologies, historical studies, and the eponymous association and journal. Eisenhuth and McDonald note that many journalists distrust such terms: "Literary Journalism: Bunging It On?" (41), a position held by almost all Australian practitioners, as well as American writers such as Ron Rosenbaum who finds the term "self-consciously highfalutin" (in Boynton NNJ 339). The "Creative Nonfiction" movement has spawned textbooks, anthologies, a magazine-turned-journal and podcast. The stated aims of the Creative Nonfiction Foundation, or $\mathrm{CNF}$, are to: "provide a venue ... for high quality nonfiction prose (memoir, literary journalism, personal essay); to serve as the singular strongest voice of the genre, defining the ethics and parameters of the field; and to broaden the genre's impact in the literary arena by providing an array of educational services and publishing activities" ("The CNF Foundation"). The genre referenced in this manifesto is identified as "literary nonfiction"- "The [CN] Foundation pursues educational and publishing initiatives in the genre of literary nonfiction" ("The CNF Foundation") - a label to which "Creative Nonfiction" somewhat surprisingly seems to defer.

Boynton's title The New New Journalism draws on its predecessor's reputation for rigorous reporting, innovation and influence, although he defaults to "literary journalism" when invoking genre (The New New Journalism xxx). Other terms in use include "reportage" in John Carey's Faber Book of Reportage (1996), "personal reportage" (McDonald 269), "literary non-fiction" in Weber's The Literature of Fact (1985), and of course the "non-fiction novel" as promoted by Capote. Critics and theorists at times use these terms interchangeably. Caveats such as "I choose the term reluctantly" (Ricketson "Hitchhiking" 85) are not uncommon. Dispute over names continues in public and academic discourse; however, as scholarship advances, academics are, in fact, carving out fields with clear differences that often-but not always - reflect the biases of their backgrounds. Overlapping features can create diffuse expectations for readers, however; this is a difficulty to be addressed by all scholars in the wider field of narrative non-fiction.

Assigning a name is a daunting task in the light of historical constructions and divergences between fact and fiction, journalism and literature, and those who would uphold such distinctions. As identified by John Hartsock, the four main terms used in 
varying pairings_-"non-fiction", "narrative", "literary", and "journalism" (4) —are all problematic in their own way. As William Howarth notes, the label non-fiction is frustrating "for it says not what a book is, but what it is not. Since fiction is presumably made up, imaginative, clever, and resourceful, a book of non-fiction must not be any of those things, perhaps not even a work of art" (in Smith 209-210). The term "non-fiction" hence invokes the field in the negative instead of reflecting actual features, and, as McKay notes, in doing so "we imply that we attach much more value to the opposite - to fiction in this case" (Reportage 54). "Narrative" is a similarly problematic term, whether used in adjectival form or as a noun. While in common usage "narrative" usually connotes "story", Abbott's Cambridge Introduction to Narrative cites four definitions of narrative, ranging from Abbott's own-“simply put, narrative is the representation of an event or series of events" (13) - to MarieLaure Ryan's complex definition with eight criteria indicating variable degrees of membership. Ryan describes narrative texts as "a fuzzy set ... but [a set that is] centred on prototypical cases that everybody recognises as stories" (Towards 28). Such definitions may not inspire confidence in those wanting an accurate, defensible term in an emerging field of academic study. The question of narrative is pertinent to the study of literary journalism as a function of identifying the field of inquiry. Texts may be written in a narrative mode but contain extended passages of exposition, argument or simple description that does not add to the narrativity of the text. Many works cited in Boynton's The New New Journalism, for example Susan Orlean's The Orchid Thief (1999), Jon Krakauer's Under the Banner of Heaven (2003) and Richard Ben Cramer's How Israel Lost: The Four Questions (2004) are highly digressive, and contain long expository or descriptive passages. Narrativity is expressed to different degrees in each text, with Orlean's perhaps displaying the strongest narrative tendencies with multiple digressions, while Cramer's would be difficult to characterise as a narrative at all.

"Non-fiction" and "narrative", however, are arguably less controversial terms than "literary" and "journalism" when attempting to apply them to these texts with shared essential features. Phyllis Frus's historical outline of the term "literature" highlights the problematic nature of the term "literary" because of its association with fiction. Frus demonstrates that the term "literature" denotes fictional status and argues that: 
It is clear that narrative does give up its nonfictional status when it is enshrined in the canon of literature ... because nonfiction is thought of as the realm of discourse where true and false are important distinctions, and literature is thought of as the realm where, even when a work represents the world, its truth or falsity is irrelevant. Not so incidentally, this makes the term "literary nonfiction" logically contradictory, for under these notions of literature a narrative can be either nonfictional or literary, but not both (9).

Frus further criticises the application of "literary" to the definition as works in this field are often politically or socially charged; whereas, she finds the canon of literature "does not value political and historical narrative" (126). Finally, she contends that such terms as literary journalism/non-fiction "imply the existence of journalistic or factual discourses that are not literary; therefore, some way must be found to distinguish one category from the other, which leads to the imposition of what are invariably formalist criteria" (126); whereas, she argues, "texts do have inherent qualities, but literariness is not one of them" (16). This is a moot point. Dow, for example, understands the term as highlighting in literary journalistic texts "the literary and the 'factually unverifiable' in order to foreground (the contingencies of) ... authorial perceptions and truth claims" (133). But Frus's answer to this conundrum is to collapse the historical division of "literary" and "non-literary", essentially conflating all discourse into one category: literature. This enables a "reflexive reading", ultimately "[reinserting] a text, genre, or mode into the conditions which gave rise to it" (33), thus avoiding the fact-fiction question (48). This ambitious project does indeed avoid difficult territory; however, it also raises its own problems, none more so than how to convince the academy that a common news report can (and should) be redeemed and read as literature, if, as Frus claims, the academy is responsible for creating the division. From another angle, the objectivity standard observed by Western mainstream journalism is an intentional demarcation from other forms of non-fictional discourse. This is not the imposition of formalist criteria by critics, but the creation of boundaries of discourse by a historical, conscious process of exclusion.

Tzvetan Todorov, on the other hand, unpacks "literature" and in doing so exposes a conflation of the term's effect with its definition. He writes:

Literature is a fiction: this is its first structural definition. ... Is such a definition satisfactory? We may well wonder whether we are not about to 
substitute a consequence of what literature is for a definition of literature. Nothing prevents a story that recounts a real event from being perceived as literature. Nothing in its composition needs to be changed; we need only say that we are not interested in its truth value but are reading it "as" literature. A "literary" reading can be imposed on any text: the question of truthfulness will not arise because the text is literary. Rather than a definition of literature, we are offered here, in a roundabout way, one of its properties (3 emphasis in original).

Todorov offers that the "second great definition of literature, then, comes under the banner of the beautiful: here pleasing wins out over instructing" (5). He follows theoretical reconceptions of this definition over time, observing: "the notion of the beautiful is crystallized, toward the end of the eighteenth century, in an affirmation of the intransitive, noninstrumental nature of the work of art. Having once been identified with the useful, the beautiful is now defined by its nonutilitarian nature". This progression produces an understanding of literature as "a system, a language that attracts attention to itself through its systemacity alone, a language that becomes autotelic. This is its second structural definition" (5). But as with his first point, Todorov finds that these "two definitions allow us to account for a number of works ordinarily called literary, but not for all". He concludes: "We remain floundering in imprecision and vagueness" (9). If these are not definitions but descriptors, there is, as Todorov notes, nothing to prevent non-fiction from being literary. A feature of such texts, then, should be an internal systematic consistency in addition to correspondence with reality. Thus, literary journalism is bi-referential in nature.

Hartsock also tracks the development of "literature" in A History of American Literary Journalism. Here he shows the diverging paths of literature and journalism: "The concept ... of a transcendental literature largely derives from the nineteenth century, with roots in neoclassical rhetoric and oratory that provided universal forms even as literature was reacting against neoclassical rhetoric. Journalism never made a claim to such a transcendent universality" (218). Both Hartsock and Frus, supported by Connery (1990), show how objective journalism emerged as a result of positivist ideology during the second half of the nineteenth century-itself a reaction against Romanticism - creating an epistemological gulf at a moment of social and cultural transformation and crisis. Following shortly after, as a reaction against the objectifying and alienating effects of "objective journalism", the literary journalism of the 1890s emerged (Hartsock 6, 17, 20, 41, 42, 87; Frus 9, 54, 100, 103; Connery, 
"Third Way" 4, 6, 9). This sequence shows how literary realism/naturalism, objective journalism and literary journalism arose in opposition to each other, and in response to the effects of the previous movement, thus highlighting the difficulties of combining the terms "literary" and "journalism" to denote a type of discourse that grew out of opposition to both the (fictional) literary and (objective) journalistic traditions.

Each of these four terms, then, "non-fiction", "narrative", "literary" and "journalism" can be seen as problematic. They are, however, the most widely used in reference to this loosely linked body of works, and each has a reasonable claim to viability. "Nonfiction" denotes the externally verifiable content of texts in this field, but this element is arguably implicit in the form as labelled "journalism". As Connery contends, "Use of the word 'journalism' is preferred over 'non-fiction' because the works assigned to this literary form are neither essays nor commentary. It is also preferred because much of the content of the works comes from traditional means of news gathering or reporting" ("Third Way" 15). "Journalism" thus references the research element of the writer's practice as well as the timeliness of the account, and further delimits the field from historical works, biography and autobiography; as such it is both more specific and economical than "non-fiction". The terms "narrative" and "literary" ostensibly both reference the mode of writing: "Rather than standing alone, modes are usually qualifications or modifications of particular genres (gothic thriller, pastoral elegy, satirical sitcom) ... [T]hey specify thematic features and certain forms of modalities of speech, but not the formal structures or even the semiotic medium through which the text is to be realised" (Frow, Genre 65). While scholars and practitioners alike use the terms interchangeably, or, like Hartsock, as a compound such as "narrative literary journalism", in this thesis the term "literary" is preferred as it subsumes "narrative", differentiates the form from hard news reports that at times are written in a narrative mode, and arguably has a richer stylistic connotation-style being a feature of the form.

The term "literary journalism" is perhaps the term with the most traction in this field of study (Hartsock 4; see also Bak and Reynolds; Connery; Sims, True Stories). The term is a medium by which the stylistically rich, transcendent nature of literature and the practice of immersive journalism can merge. If indeed Frus is correct in assigning 
literature the capability of conveying universal truths and journalism belonging to the medium that reports everyday facts (53), literary journalism can be seen as the site where the everyday affairs of real entities take on a meaning that transcends the temporal and holds universal significance, if not truth. Christa Wolf argues that this has traditionally been the domain of literature, to create "a truth beyond the important facts of the world", as facts in themselves do not necessarily provide understanding (in Josephi and Muller 68). Viewed in this light, literary journalism offers an alternative to both objective journalism and fiction, and undoubtedly is a fertile field for scholarly inquiry.

\section{Genre or Discipline?}

Up to this point I have used the somewhat awkward terms "form" or "works in this field" rather than "genre". This has been intentional. Conceptualising literary journalism as a genre is the subject of critical debate, as previously noted. Many scholars use the terms "form" and "genre" interchangeably, as in Sims's call for international scholarship for literary journalism ("Problem"). Hartsock speculated in 2000: "Perhaps critical usage will eventually characterise such texts as a 'genre' but for the moment, I adopt the more conservative usage of 'form' $\ldots$ as an acknowledgement that our understanding of it is still very much emerging" (3). He uses the term "genre", however, in the 2008 preface to Sims's Literary Journalism in the Twentieth Century. More recently, Bak argues that both terms, "form" and "genre", limit the advancement of international scholarship. He writes:

Continually calling it a genre locks literary journalism into a subcategory of literature, alongside poetry and drama. Referring to it as a journalistic form sandwiches it somewhere between fiction and journalism. Suggesting that it is a subcategory of nonfiction dangerously sets it on even ground with biography, travelogues, policy analysis, history, cultural studies, and memoirs, some of which can be literary journalism but are not by that definition that alone (18).

I would suggest, however, that while the term "genre" is used in literary criticism, it has a much wider application and use than Bak has given it in this instance. The contractual "force" afforded by genrification, for example, is one consideration here, and will be further explicated in chapters two and three. But, as I have demonstrated, "literary" moderating "journalism" does not push texts into the fictional domain; nor 
is it, I would argue, situated somewhere between fiction and journalism. Bak's use of the term "dangerously" conceivably refers to - in layman's terms - the "poetic license" taken in memoir and biography particularly; further along the spectrum, history and cultural studies lack the interpretive potential afforded by literary narratives. But to set literary journalism on "higher ground", as Bak's statement here implies, is to burden it with expectations of verifiability it is not equipped to bear. Each of these subcategories of non-fiction have their unique attendant aims; the task of literary journalism scholars is in part to make clear the terms of reception for this genre.

Bak also introduces the term "discipline" into the discussion. He contends that "[r]aising literary journalism to the level of a discipline would institute a moratorium on the barrage of definitions and defenses that have hindered the advancement of literary journalism studies", and would "certainly reduce the pedagogical problems facing international literary journalism" $(18,19)$. It is questionable, however, that achieving disciplinary status would institute a moratorium on definitions and defences. Discussions among scholars might be less influenced by loyalties to one academy or another, but conceivably the "barrage" will not cease until critical agreement is reached-with or without disciplinary status. But if the discipline is formed and consensus is reached, boundaries that are currently porous and overlapping might become firm and necessarily exclude writers and texts deserving critical attention. At the level of practice, any attempt to delimit the field relies on a combination of research and writing processes (intensive/immersive reporting, independent writing, externally verifiable entities and events) as well as shared narrative techniques. As demonstrated in collections such as Boynton's The New New Journalism, however, the journalistic practices employed by practitioners are often as diverse as the works produced. Australian writer Chloe Hooper, for example, perceived herself to be working outside the traditions of both journalism and anthropology when investigating and writing her first work of literary journalism; many of Boynton's interviewees similarly consider themselves loosely linked to a tradition resembling literary journalism without belonging to it. Before a call for disciplinary status, then, consideration should be given to the trade-off between smoothing pedagogical problems and delimiting the field of study. To reinvoke the analogy of colonising unoccupied land, the movement from pioneering to settlement 
or occupation necessarily involves building boundaries and assigning territory, but can this be done without limiting the potential of the land, and excluding some of its inhabitants? For a field that is noted for its pioneering spirit, how will the formalisation of pedagogy affect a new generation of practitioners?

Bak's observations reflect an inflexible taxonomic certainty that the term "literary journalism" itself contradicts. Resistance to conceiving of the field as a genre on the grounds that it "locks literary journalism into a subcategory of literature" (18) disregards recent advances in genre theory that destabilise the idea of fixed boundaries and open genre studies to a broader function than classification and hierarchy. Swales notes that during the past decade "the genre movement has coalesced somewhat" to reconsider the function of genre (148); in the words of one academic, "Discourse as genre ... extends the analysis beyond the textual product to incorporate context in a broader sense to account for not only the way the text is constructed, but also the way it is often interpreted, used and exploited in specific institutional or more narrowly professional contexts to achieve specific disciplinary roles" (Bhatia 20). These functions of genre studies are particularly useful to the scholarship of literary journalism. As Sims suggests, works of literary journalism need to be examined on their own terms ("Problem" 8). This calls for analysis not only of the practice or construction of literary journalism, but also analysis of its reception and interpretation. Genre studies offers a broad framework through which scholars can analyse the claims literary journalism makes about itself, and utilise literary analysis to offer readings that examine those claims.

\section{Genrification: The Search for New Horizons}

The taxonomic function of genre is important in establishing a recognisable market for literary journalism, although its popularity is clearly not dependent on a label identifying it as such. Publishers and retail venues alike classify works of literary journalism in pre-existing genres, such as travel writing, politics, true crime or cultural studies. At times, bookstores do not know where to put works of writers such as Lawrence Weschler, although Weschler classifies his own works - independently labelled "Economics", "Psychedelics" and "Latin America"—as "writerly nonfiction" (Boynton The New New Journalism 404). This variance in labelling raises some critical questions: does this classification affect reader expectations? Could it inhibit 
or enhance the reading experience? Does it distort authorial intention? Will the audience receive the text differently according to the section of the bookstore they found the book in or in relation to other genre markers throughout the text? A book label on a dust-cover jacket is unlikely to prevent a reader from choosing to purchase or read a book; however, they may never discover a book if it is labelled and catalogued in an unexpected way.

Genre indicates how a reader might approach a book before they turn to the first page. Hans Robert Jauss explains that such indications create a "horizon of expectations and rules familiar from earlier texts, which are then varied, corrected, changed or just reproduced. Variation and correction determine the scope, alteration and reproduction of the borders and structure of the genre. The interpretative reception of a text always presupposes the context of experience of aesthetic perception" (13). Genre is also the first step in a negotiation of an author/reader contract. Pyrhönen asserts, "to understand the function of textual components and the reading experience, we should understand the rules governing the relationship between author and reader. These rules are grounded in generic practices, although they are not identical with them. Rather, they arise from a conjunction of generic conventions and interpretive strategies, enabling the reader's moves in a game played with and against the author" (115-6). The concept of an author/reader contract will be further explored in the next chapter. But the taxonomic function of genre has been attacked in the past. As Wai Chee Dimock has observed:

Theorists from Benedetto Croce to Jacques Derrida have long objected to the concept of genre, pointing out that something as dynamic as literature can never be anatomized ahead of time, segregated by permanent groupings. "[I]nstead of asking before a work of art if it be expressive and what it expresses," genre criticism only wants to label it, putting it into a pigeonhole, asking only "if it obey the laws of epic or of tragedy." Nothing can be more misguided, Croce says, for these "laws of the kinds" have never in fact been observed by practising writers (1377).

Indeed, interest groups such as scholars, students and publishers conceivably have more of a vested interest in establishing generic boundaries than practising writers. But to state that the laws of genre have never been observed by writers is a particularly broad generalisation - one that is difficult to substantiate, and perhaps equally as questionable as a claim that all writers are cognisant of generic boundaries in their 
writing process. Barbara Foley observes, "treating generic categorization as a framework imposed a posteriori by literary critics [rules] out the possibility that it may constitute a necessary basis for the contracts formed between actual writers and readers" (Telling the Truth 32). ${ }^{6}$ Perhaps a mid-point between these positions is most applicable to literary journalism. Anecdotal evidence-presented more extensively in chapters five and six-suggests contemporary practitioners depend in part on journalistic standards and narrative frameworks from their predecessors to define the scope of their enquiry and shape their narratives. But innovation is also a vital characteristic of literary journalism. A tension is evident here. What, then, is genre's role in mediating production and consumption of literary journalism?

Derrida's study "The Law of Genre" further critiques the effects of genrification. With some hyperbole he asserts that historically "as soon as genre announces itself, one must respect a norm, one must not cross a line of demarcation, one must not risk impurity, anomaly, or monstrosity" (57). An effect of "traditional" genrification, then, for Derrida is somewhat of a closing of ranks, a stagnation of form and a limit to a text's interpretive potential—ostensibly for critics a minimal loss in the trade-off for taxonomic certainty. Such a view, however, conceives of genre as a prescriptive power that controls writers and scholars alike. The history of innovative, boundary-breaking practitioners and the emergence of new genres show this to be an exaggeration of genre's function. Neither are scholars limited by generic conventions in their criticism: the most innovative literary criticism arguably results from the analysis of texts through unorthodox or unexpected critical frames.

Derrida goes on to posit a law of "participation without membership" (63), offering an alternative classificatory system where a text may belong to one or multiple genres without necessarily being demarcated (67). This concept has parallels with literary journalism, a field in which many practitioners participate while resisting membership. But in terms of genre, this "law" effectively loosens taxonomic and hierarchical structures. It recognises that texts can participate in multiple genres, thus does not limit their rhetorical potential. Works of literary journalism may also participate in genres such as travel writing, current affairs and medicine, for example, while corresponding to the definition of literary journalism. A difficulty here is conflicting expectations raised by genre assignation. 
For John Frow, following Derrida, genre has a "dynamic" function; this is reflected in the literary journalistic contract, which will be dealt with more fully in chapter two. Frow sees texts as performances of genre rather than reproductions of a class to which they belong. His theory represents "a shift away from an 'Aristotelian' model of taxonomy in which a relationship of hierarchical belonging between a class and its members predominates, to a more reflexive model in which texts are thought to use or perform the genres by which they are shaped" (Genre 25). This concept contributes much to an investigation in this field where there are "real world effects" in the production, reception and function of non-fiction texts. In works that represent actual events, entities and issues, a channel of communication between the "real" author and "real" reader is paramount. Genre is one function that facilitates this communication, shaping the expectations of the reader through the "performative structures that shape the world in the very process of putting it into speech" ("Reproducibles" 1632-3). Frow offers the following definition of genre:

Genre, we might say, is a set of conventional and highly organised constraints on the production and interpretation of meaning. In using the word "constraint" I don't mean to say that genre is simply a restriction. Rather, its structuring effects are productive of meaning; they shape and guide ... generic structure both enables and restricts meaning, and is a basic condition for meaning to take place (Genre $10)$.

Frow's definition implies two functions of genre. Firstly, genre is widely understood as a classifying structure that is composed of "conventional and highly organised constraints". These can be summarised as the taxonomic function-that identified by Derrida. In the broadest sense, these classifications can be seen in labels on shelves in bookstores, in DVD rental outlets and at the beginning of arts reviews in newspapers, and are widely understood to demarcate the content and style of one group of texts from another. As Frow contends: "Genre is, amongst other things, a matter of discrimination and taxonomy: of organising things into recognisable classes" (Genre 51). Thomas Beebee's assertion that genre is "primarily the precondition for the creation and the reading of texts" (250) supports Frow's definition; although the term "precondition" implies a static, fully conceived way of reading which is predetermined by the author, publisher or the librarian who determines where it is shelved. For Derrida, this is the law of genre that inhibits a text's agency. 
As stated, Frow's definition also ascribes a dynamic function to genre. He asserts that "texts work upon genres as much as they are shaped by them" (Genre 28). The effect of this function is to destabilise the notion of a static set of rules used to classify texts, and to posit a set of "actual and contingent forms rather than necessary and essential forms" ("Reproducibles" 1629). This dynamic nature of genre is supported by Dimock, who argues that:

Genres have solid names, ontologized names. What these names designate, though, is not taxonomic classes of equal solidity but fields at once emerging and ephemeral, defined over and over again by new entries that are still being produced. ...Far from being clear-cut slices of the literary pie, genres have only an on-demand spatial occupancy. They can be brought forth or sent back as the user chooses, switched on or off, scaled up or down. Each is one among several levels of resolution, with alternating features that can be read either as random detail or as salient pattern (1379).

In this way, texts can be said to perform genre, rather than have genre assigned to them. Significantly, genre's performative function opens the possibility of negotiation between the author and reader over how to interpret meaning-a possibility that echoes Derrida's law of participation without inclusion. Dimock's term “user" here invokes not only the writer, who employs genre to shape a text, but also the reader, who consciously or unconsciously uses elements of genre to inform and perform an interpretation of the text. Dimock assigns the reader with the power to "choose", "switch on or off" or "scale up or down" elements that signal genre. As such, genre can be understood as a dynamic site of negotiation between the author and reader, with the characteristics of genre: working on the text; being worked on by the text; informing the writer and reader; and being informed by previous experience and knowledge of the writer and the reader. Clearly there is more happening here than the drawing of a line of demarcation that cannot be crossed. Negotiating what the text is, then, is fundamental to deciding how to read and interpret the text. This phenomenon is a foundational element in the discussion of literary journalism because of its claim to non-fiction status in a mode that is often self-consciously subjective. Understanding this field's reliance upon genre and the expectations it creates is vital to-in Swales's words - the "better consumption and production" of texts, or in this case, of literary journalism. 
To date, the taxonomic function of genre as applied to literary journalism has produced much discussion but little consensus. In spite of this, perhaps movement towards a traditional form of genrification was inevitable. Frow's bi-functional model of genre as both taxonomic and dynamic, however, provides a theoretical framework within which a genre such as literary journalism may be conceived that does not rely on strict taxonomic boundaries, but exemplifies participation without membership. Rather than conceptualising the genre through commonalities of textual features alone, the "minimal traits" by which literary journalism should be recognised include those that represent its process: exhaustive research; presentation of externally verifiable entities and events; timeliness; narrative mode; and (for the purposes of this thesis) book length. While these traits are effectively taxonomic, they are also dynamic in that they signal to the reader particular messages about the way the text has been constructed, and thus initiate negotiations about how the text can be read.

In summary, Frow's concept of genre defines a field of study without delimiting it. It simultaneously allows texts to participate in-or perform-multiple genres at once, acknowledging that dominant features will predispose it to a primary genre assignation. Scholarship that conceives of literary journalism as a genre opens texts to be studied with the tools of both narrative and rhetorical analysis, and will produce a body of criticism that: equips readers with a framework of critical reference to approach texts (Reportage McKay); potentially enhances the market for works of literary journalism (Reportage McKay); provides the focus necessary to prevent the genre from being marginalised (Hartsock); spurs practitioners to new innovations (Swales); and illuminates the relationship between texts and their environments of production (Sims, "Problem").

To invoke the analogy of terra nullius once again, exploration in any field should be respectful of the individual inhabitants of unclaimed land. This is true of literary journalism scholarship. In this thesis I approach the criticism of contemporary US and Australian book-length literary journalism with an intent to illuminate the effects of textual and epitextual features that compromise practitioners' epistemic integrity, in order to inform contemporary practice and theory; I also engage with criticism of literary journalistic practice and defend practitioners where possible, on the theoretical basis set out in this, and the following, chapter. Further, I acknowledge 
that while this thesis identifies important thematic connections between texts, booklength works of Australian literary journalism do not represent a homogenous set of research or writing practices, neither do practitioners identify with membership in a group; this is typical of the field internationally. However, comparing characteristics of individual Australian texts does reveal an underlying cultural function consistent with contemporary international theory, and finally invites closer engagement with works in a field which, to date, is largely unexplored. 


\section{Chapter Two \\ Negotiating Non-fiction: Taking Back Ground}

\section{In Defence of Non-fiction}

Common to many works of literary journalism is a claim to non-fiction status. For readers, this classification may produce a range of responses, from a vague awareness of a text's referentiality to a strong, personal engagement with its subjects. For critics, literary journalism's particular claims about itself have often been the first point of reference for critical engagement. The concept of permeable borders becomes less tenable when "truth" is at stake; terra nullius is not likely to be invoked either by those who uphold, or those who conflate, the fiction/non-fiction dichotomy. As the following chapters examine knowledge and truth claims in literary journalism, the purpose of this chapter is to establish a theoretical foundation for the position taken in this thesis. I will discuss this central issue informing literary journalism scholarship, that is, the genre's status as non-fiction. After establishing a theoretical position, the remainder of this chapter will define key terms and engage with issues affecting epistemic responsibility, such as paratexts, author-reader contracts, and transparency.

Opponents of the New Journalism argued strongly against supposed "truth claims" of texts based on externally verifiable referents (Pauly, "Politics" 112). In the main, attacks were levelled against experimental forms of writing, for example the so-called "linguistic pyrotechnics" of Tom Wolfe within the discipline of journalism (Hartsock 195). Wolfe further provoked critics with contentious claims such as: "I am the first to agree that the New Journalism should be as accurate as traditional journalism. In fact my claims for the New Journalism, and my demands upon it, go far beyond that. I contend that it has already proven itself more accurate than traditional journalism" ("The New Journalism" 46). Gay Talese, widely recognised as another founding father, also lent his weight to the claims of New Journalism. He cited as its purpose: "to reveal a larger truth than is possible through the mere compilation of verifiable facts, the use of direct quotations, and adherence to the rigid organizational style of the older form" (vii), a role traditionally assigned to the domain of literature. As a result, critics such as Dwight MacDonald used terms such as "faction" and "parajournalism" pejoratively to discredit works of the nascent form. MacDonald 
wrote in 1965 that the New Journalism "seems to be journalism- 'the collection and dissemination of current news'-but the appearance is deceptive. It is a bastard form, having it both ways, exploiting the factual authority of journalism and the atmospheric license of fiction" (3). A number of key terms are at play here (accuracy, truth, fact, tradition and authority) without acknowledgement of the underlying assumptions that inform each individual's position. MacDonald implies that accuracy of atmosphere is not achievable; or, if it is, that it cannot be authoritative as it subverts traditional journalistic standards of truth. Such a critique avoids a critical discussion of the relationship between types of knowledge such as facts, accuracy, meaning and truth.

Literary journalism has attracted a new opponent since the volatile arguments over the New Journalism — one that attacks the foundation upon which its "truth claims" rest. The work of Jacques Derrida is standard in literary theory; his critique of Saussure's system of signs and signified meanings has destabilised logocentrism and brought into question notions of representation, meaning and truth in all forms of discourse. For Derrida, deconstructive criticism aims "to show that any text inevitably undermines its own claims to have a determinate meaning, and licences the reader to produce his own meanings out of it by an activity of semantic "freeplay"' (in Lodge 108). The implications for non-fiction are clear: the belief that a text can have a determinate meaning is central to any claim of presenting a "true" account of externally verifiable phenomena. The effect of mimetic representation is further called into question by this challenge. If discourse that claims to represent "reality" (or, more plainly, externally verifiable phenomena) is unable to present a fixed, or objective representation of such phenomena by virtue of its nature as discourse, all discourse can be said to be fictional. The "organic" nature of the dichotomy is exposed as a construction, and attempts to present discourse as "true" or "real" are discredited as naïve.

The postmodern project has not been entirely antithetical to literary journalism, however. One outcome of the attempt to reduce all discourse to fiction has been to subject so-called "non-literary" discourse to narratological investigation (Ryan, "Postmodernism" 177). Non-fiction's status has historically been subordinate to that of literature, resulting in what Gerard Genette terms a silent annexing of factual 
narrative from the study of narratology, "without investigation or justification" (Fiction 55). In A History of American Literary Journalism, Hartsock traces the rise of fiction, or "imaginative literature" in prose, through the late nineteenth century to its pre-eminence as a form of writing (204-245). He demonstrates how other forms of prose came to be classified in opposition to fiction, resulting in the negatively charged term "non-fiction" (12). The justification, it seems, was inherent in the belief that representations of the real and associated notions of objectivity did not merit the attention of literary theorists. The postmodern challenge has effectively brought nonfiction texts such as literary journalism out of fiction's shadow and exposed them to questions about the relationship between narrative discourse and reality. So the challenge for literary journalism not only remains but is heightened: what does the classification "non-fiction" mean?

The first defence for upholding the fiction/non-fiction dichotomy can be found, paradoxically, in historian Hayden White's writings. White challenges a naïve belief in historical realism in his poetics of historical discourse. In the introduction to Tropics of Discourse: Essays in Cultural Criticism (1978), White cautions against accepting mimetic texts as representations of "things as they are" (Tropics 3). He points out that the purest intention to employ mimesis necessarily fails as mimesis inevitably distorts reality. Such can be proven by competing descriptions of the same externally verifiable phenomena which may have more claim to realism, thus a stronger claim to being "faithful to the facts" (Tropics 3). White asserts that historical narrative is "not only a reproduction of the events reported in it, but also a complex of symbols which gives us directions for finding an icon of the structure of those events in our literary tradition" (Tropics 88 emphasis in original). Working towards a critique of objectivity, White here implicitly connects narrative with meaning. While the arguments come from different directions, both Derrida's and White's theories arrive at the conclusion that narrative is not a reliable vehicle for representing externally verifiable phenomena in a way that has traditionally been considered "objective". However, White does not appear to go as far as the deconstructionist's position, as the "fictive" process involved in interpretation does not necessarily produce a work of fiction. Narrative is, however, widely employed as a medium through which representations of historical events are conveyed, and as such must be 
reconsidered in the light of epistemological choices practitioners make as they write history.

The term "narrative" is itself a contested site of criticism, having been defined in multiple ways that emphasise particular characteristics of its form. Etymologically, the term "narrative" does not seem to belong exclusively to the domain of fiction; its origins are in the ancient Sanskrit "gna" meaning "know," and the Latin "gnarus" (knowing) and "narro" (telling) (Abbott 10). Subsequent definitions as simple as Abbott's "the representation of an event or series of events" (13) and RimmonKenan's "[narrative] represents a succession of events" (2) are helpful in that they open the field of narratological study, but are perhaps too permissive in their scope. Marie-Laure Ryan's definition lies at another end of the spectrum. She posits eight potential constitutive features of narrative, including: a signification transformation in the story-world caused by non-habitual events; the communication of something meaningful to the audience; and a unified causal chain that leads to closure ("Definition" 29). Significantly, none of these definitions precludes phenomenal reality as the subject of a narrative. The question that arises here is fundamentally epistemic: what does it mean to "know" and "tell"?

In "Narrativity in the Representation of Reality", White builds on an understanding of the effects produced by historical narrative by contrasting the non-totalizing nature of the annal and cumulative chronicle forms with narrative. The relevance of White's analysis here is that he shows how different forms of historical discourse reflect prevailing ideologies of meaning and reality, or "particular products of possible conceptions of historical reality" ("Narrativity" 5). The annal, for example, reflects prevailing beliefs in a history and future determined by an omnipotent and omniscient power through a purely objective, incomplete and somewhat deterministic account of events. In contrast, the chronicle approaches a narrative form as the writer is a selfconscious presence in the account, seeking a fuller account of reality, therebyparadoxically — decreasing the "objectivity" as a historical account ("Narrativity" 18). Ideology in the annal is revealed through its absence of commentary, whereas the chronicler approaches a more explicit sense of meaning by presenting his - albeit limited - subjectivity and alluding to the potential effects of chronicled events. Both of these forms lack closure, instead terminating without commentary or analysis. To 
"know" for annalists and chroniclers, was to observe, and to "tell" was simply to record.

In contrast to both the annal and the chronicle, White contends that meaning is immanent in any narrative account of real events and that narrative is dependent upon closure, which he suggests is "a demand ... for moral meaning" ("Narrativity" 20, 21). Here lies the crux of White's analysis of annal to narrative: historical discourse functions as a record of historical events, but in its narrative form it also moralises by producing meaning, and through closure creates a sense of totalisation. These are both products arrived at by "fictive" measures, that is, processes that are not found in history itself, but produced by the historian. White asserts:

[The] value attached to narrativity in the representation of real events arises out of a desire to have real events display the coherence, integrity, fullness, and closure of an image of life that is and can only be imaginary. ... Does the world really present itself to perception in the form of well-made stories, with central subjects, proper beginnings, middles, and ends, and a coherence that permits us to see "the end" in every beginning? ... And does the world, even the social world, ever really come to us as already narrativised, already "speaking itself" from beyond the horizon of our capacity to make scientific sense of it? Or is the fiction of such a world, capable of speaking itself and of displaying itself as a form of a story, necessary for the establishment of that moral authority without which the notion of a specifically social reality would be unthinkable? ("Narrativity" 24-5)

One potential response is that the natural world (as opposed to the social world) does indeed present itself to perception. Northrop Frye is one example of a literary critic who uses natural phenomena to inform his archetypal schemata; beginnings and endings can be seen in the systematic rotation of the seasons, while naturally occurring dichotomies such as night and day, cold and heat, and life and death do reveal some structure in a world that, for White, is essentially chaotic. An important point is made in this passage, however, when White refers to the human capacity to make scientific sense of the world. Here White invokes a dualism that I argue is at the heart of criticism that fails to thoroughly assess literary journalism thoroughly; that is, the application of scientific methodology to discover "facts" to the process of discovering "knowledge" and "meaning". But for White to label the possibility of narrative coherence, integrity, fullness, and closure of a representation of life "imaginary" is a bleak assessment. It somewhat belies the possibility of accurate 
representation in narrative, and discredits the roles of evidence and logic in the historical method for historians - and immersion reporting for literary journalists. White may not go as far as the poststructuralist critic; his analyses of the annal and chronicle forms highlight the possibility for him that language can represent reality without or with minimal interpretation, to the extent that it eschews causal explanations and remains "elements" rather than "story". The form and content of narrative, however, are inextricably linked through the "fictive" process of using "real" events to produce the narrative form.

Is the dichotomy that underpins literary journalism's truth claims collapsed, then, by the application of meaning to the recounting of past events? If meaning, which is always constituted rather than found, is mistaken for reality, which is always found rather than constituted, does the form of narrative make void the claims to reality it seeks to represent? Here the distinction must be made that White does not consider histories fictions, despite claiming that the process of producing history inherently involves acts of the imagination. This distinction becomes clear as White defends narrative as a vehicle for meaning production through historical experience:

In the historical narrative the systems of meaning production peculiar to a culture or society are tested against the capacity of any set of "real" events to yield to such systems. If these systems have their purest, most fully developed, and formally most coherent representations in the literary or poetic endowment of modern, secularized cultures, this is no reason to rule them out as merely imaginary constructions. ... In its origins, historical discourse differentiates itself from literary discourse by virtue of its subject matter ("real" rather than "imaginary" events) rather than its form. But form here is ambiguous, for it refers not only to the manifest appearance of historical discourses (their appearance as stories) but also to the systems of meaning production (the modes of emplotment) that historiography shared with literature and myth ("Question of Narrative" 44).

The first defence for upholding the fiction/non-fiction dichotomy can be found in this passage. He draws a distinction between texts that referentially represent the "real" or present the "imaginary". It is important to emphasise that in non-fiction all represented events are externally verifiable and thus are contestable, but that meanings are also open to contestation can further support the dichotomy. Even if "the production of meaning ... can be regarded as a performance", it does not follow that, as White asserts, "any given set of real events can be emplotted in a number of 
ways, can bear the weight of being told as any number of different kinds of stories" ("Question of Narrative" 44). This is to claim that events culminating in a natural response of grief can be emplotted as comic. The inverse is also logically true. But, as Code suggests, practitioners of non-fiction are finally limited in the ways they can represent reality. That literary journalism is established as non-fiction is fundamental not only to how it is read, but also to how it is produced. For Weber, an essential difference between fiction and non-fiction is the limit imposed upon practitioners of the latter. He observes: "The writer of literary nonfiction, like the writer of fiction, can take us deeply inside people and events and construct works that move beyond story to plot. But in neither case can he do this to the same extent that the fiction writer can. He is finally restrained by his commitment to the facts" (45). ${ }^{7}$

Referentiality is also a key feature of narrative non-fiction for Daniel Lehman in Matters of Fact: Reading Nonfiction over the Edge (1997). The "edge" here for Lehman is an acknowledgement that a non-fictional text contains entities and phenomena that "are ... available to and experienced by the reader outside the written artifact" (Matters 4)(Matters 4). His project is thus to encourage readers to read "over the edge", either by going outside the text for external verification or by reading with the knowledge that this is a possibility. Accordingly, reading in this reflexive or critical manner will "implicate" the reader, producing an experience of reading that is anything but identical to reading fiction (Matters 4, 32). At this point Lehman departs from Frus's concept of a "reflexive reading", as she ultimately denies any difference between the experiences of reading a fiction or non-fiction text (Frus 160). For Lehman, then, to claim non-fictional status is to invoke a text's referentiality. The critical difference between fiction and non-fiction is that readers of non-fiction live in the world represented by the text, and therefore have direct access to its constituents: an impossibility in the possible worlds of fiction. Eric Heyne centres his critique of Lehman's work on both the notion of reading over the edge and the corollary inference of a fixed boundary between fiction and non-fiction. Heyne contends that Lehman's trope of reading "over the edge" is a metaphor, and thus a poor substitute for critical theory on the relationship between author, text, reader and subject, and that his argument is "closer to ethical criticism than rhetorical criticism" ("Where Fiction Meets Nonfiction" 325). 
Lehman does not go so far as to assert an essential boundary between fiction and nonfiction within the text, however, preferring instead to demonstrate the complexity of reading texts that contain real world events and people as well as inventions and/or recontextualisations of such. Having restated the impossibility of equating "actuality" with non-fiction ("Mining" 335), Lehman is free to focus on his main concern: the relationships between author, text, reader and subject. The framework developed in Matters of Fact - "writer (outside text) to event; writer (through text) to event; reader (outside text) to event; reader (through text) to event; event arbitrated by text; text arbitrated by event and interpreted by writer and reader" (36) - highlights the fact that not only can a reader have access to the event without the text, but details of a writer's relationship to the event outside the text itself can also be known and influence how the text is received.

The two distinctions of referentiality and verifiability can be read as defining points between fiction and non-fiction, and are upheld by proponents of maintaining the dichotomy such as Marie-Laure Ryan, Eric Heyne and Daniel Lehman. Ryan, for example, contends that the shared versus unique reference world could provide a basis for a definition of reality: "In an ontological model encompassing a plurality of possible worlds, the real world is the only one that can function as the target of many texts and as the object of conflicting versions" ("Postmodernism" 167). Further, Heyne writes "we can recognize nonfiction by a concomitant recognition of competing versions" ("Where Fiction Meets Nonfiction" 330). Both Heyne and Lehman agree with Ryan that the distinction of forms is fundamental to our understanding of reality. But Ryan goes further. She pleads in favour of the fiction/non-fiction distinction as "it provides our only protection against the 'hyperreality syndrome' (to borrow Baudrillard's concept): the replacement of reality (of the masking of its absence) by the simulacra thrown at us by culture and the media" ("Postmodernism" 180). This indeed is a heavy burden for non-fiction to bear. The debate over the fiction/non-fiction status of texts is evidently a complex one, loaded with ideological, epistemological and ontological concerns, and is further complicated by the claims of literary journalism. Recognising the complexities of interplay between the world, language, meaning and the structures of the human mind does not, however, inexorably lead to the conclusion that all forms of discourse are 
fictions. As Ryan observes, "story is not tied to any particular medium, and it is independent of the distinction between fiction and non-fiction" ("Definition" 26).

At this point, the Kantian philosophy that underpins Code's approach can shed some light on key terms, as well as offering a companion conception of cognition to that posed above. Code holds that Kant's concept of the "creative synthesis of the imagination" is "one of the most important innovations in the history of philosophy" (ER 77). According to Kant, the cognitive processes of sorting and understandingfor White, fiction-making operations - are undertaken by the "imagination". Code acknowledges that the term "imagination" is not fortuitous, but it denotes the imageforming faculty of the mind for Kant (ER 102). Nevertheless, the cognitive arrangement of (tangible) empirical input and (intangible) concepts is limited by reason and logic. This process, synthesised by pre-existing schemata, signals an epistemic difference between invention and emplotment. For Code,

In consequence of [Kant's] innovation, it is possible to account for the creative nature of human cognition: a taking and structuring of experience, not a passive receiving and recording. Within the constraints imposed upon this creativity by the nature of the world and of human cognitive capacity, the subjective possibilities of making sense of experience are many and varied. There is a considerable degree of freedom in knowledge; hence, an adequate explication of human knowledge must give scope and grant respectability to subjective factors that structure the process of knowledge acquisition, while preserving an ideal of objectivity, or realism normatively construed. If the entire project is not to amount to an endorsement of an "anything goes" kind of relativism, there must be constraints upon subjectivity in the form of epistemic imperatives and criteria of epistemic confidence. If these cannot be separated from moral imperatives of the standard sort, the balance between subjectivity and objectivity cannot readily be maintained (77).

Both Code and White recognise creative elements in the process of cognition, and that narrative creates meaning. In fact, for Code, narrative is an essential genre for the characterisation of human action (ER 29). She writes, "It does seem to be true ... that one cannot hope to understand human action in isolation from lives, histories, contexts, and narratives, and I think it is equally true that one cannot hope to understand cognitive activity and intellectual virtue apart from lives, histories, and context" (ER 28). A telling difference between Code's and White's positions, however, may be that Code allows for the separation of meaning and understanding as 
epistemic categories from moral concerns, whereas White conflates them. Code asserts:

[I]t is not my intention to deny that "facts are what they are ... independently of us"; particularly if this statement means that the world has a certain nature that it is our central, cognitive purpose to discover and understand. ... I take exception [to] the "recorder-model" of human cognition. In my view, we are discoverers rather than recorders of how things are. Out of this discovery, we derive the information that forms the basis of our knowledge, belief, and understanding. It is our responsibility to perform this task with respect for how things are. ... One who has not been scrupulous in knowing cannot be scrupulous in doing (94-5).

In this passage Code gives her rationale for focusing on epistemic responsibility rather than truth claims as such; her position will be more fully explicated in the next chapter. For the purposes of this discussion, referentiality and verifiability as upheld by White, Ryan, Heyne and Lehman, are supported as indicators of non-fictionality by the theory of cognition underpinning Code's approach. A non-fiction text is indeed subject to verifiability, but empirically unverifiable knowledge or "truth claims" can be substantiated, or epistemically justified. Consequently, I proceed in this thesis with the understanding that non-fiction and fiction are ontologically distinct categories, produced by epistemically-guided processes of cognition.

\section{Narrative Features: Closure, Meaning, Reflexivity and Reification}

Having endorsed a philosophical ontological difference between fiction and nonfiction, I now reorientate the discussion to some key issues regarding representation in literary journalism. As both genrification and authorial decisions about representation produce a rhetorical effect, this discussion is predicated on an author's claim to have produced a work of non-fiction in a narrative mode. ${ }^{8}$

The representation of phenomenological events in non-fiction narrative forms creates myriad issues as specific as word choice and as broad as narrative structure, from the use of tropes to the presence of the author in the text. One of these key contentious features of literary journalism in relation to its non-fiction status is closure. Hartsock contends that narrative literary journalists have been influenced by a "critical articulation" that emerged from literary realism. Naturalism, especially, called for "an 
examination in which the material world would dictate its 'transcription.' ... [I]n the close examination of the material world, what became evident was that it was by no means a rational and orderly one- no matter how rigidly enforced by convention, whether social, scientific, intellectual, religious, or aesthetic" (46-7). Hartsock cites Hamlin Garland as one literary theorist who tried to "strike a balance between an acknowledgment of the existence of a phenomenological world, however contingent, and the existence of a world only perceivable through the fallibilities of a consciousness", and continues, "This is a critical stance that reflects remarkably the modus I suggest is at work in narrative literary journalism" (47). Hartsock then draws on the work of Mikhail Bakhtin to reconsider the relationship between phenomenal reality and narrative closure.

Bakhtin acknowledges as a starting point a shared human contemporary reality and "the living people who occupy it together with their opinions". He continues, "From this vantage point, from this contemporary reality with its diversity of speech and voice, there comes about a new orientation in the world and in time (including the 'absolute past' of tradition) through personal experience and investigation" (25). This reorientation is what Bakhtin calls the "inconclusive present-day reality" (39) or "inconclusive present", a term that reflects the fluidity and inconclusive nature of reality. Hartsock contends that the literary journalistic project grew from the recognition on some level of "the impossibility of ever adequately rendering a contingent world", and that the efforts of literary journalists have been "part of an attempt to resist unsustainable critical totalizations or closure because of that phenomenological fluidity" (42). For Hartsock, a practitioner signals their intention to come into contact with the real world by resisting closure, reification, or by drawing attention to the changing nature of phenomenal reality. He further demonstrates how the fictional novel "discovered" the inconclusive present, "something the nonfictional narrative was long indulging", thus as a result "it may be more appropriate to conclude that the modern fictional novel borrowed technique from nonfictional narratives and not the other way around" (118). While Hartsock's study of historical influences is illuminating, it is perhaps overstating to identify the absence of closure as a characteristic of (contemporary) literary journalism. Of the six book-length works of literary journalism analysed in this thesis, for example, each demonstrates a different level of commitment to closure, with some attempting to subvert closure 
completely, while other practitioners employ the feature to great-although not unproblematic - effect. The analyses in chapters five and six also demonstrate that contemporary literary journalists may attempt to avoid closure in their non-fiction narratives, but the form of narrative invites closure, thus creating tension between the intent and text.

Hartsock's claim that narrative literary journalism attempts to "strike a balance" between objective reality and subjectivity may more accurately apply to David Eason's conception of a "modernist" approach to the genre. Eason's theoretical differentiation of "modernist" and "realist" texts proposes that the latter organises "the topic of the report as an object of display," while "the reporter and reader, whose values are assumed and not explored, are joined in an act of observing that assures conventional ways of understanding still apply" (192). As such, closure is a narrative feature for realists, and can be expected (and found) in the work of: Tom Wolfe, Gay Talese and Truman Capote. Eason continues: "In contrast, modernist texts, most clearly reflected in the reporting of Joan Didion, Norman Mailer, and Hunter Thompson, describe what it feels like to live in a world where there is no consensus about a frame of reference to explain "what it all means"” (192). These types of texts resist closure, or rather, acknowledge the fluidity and inconclusive nature of reality. As Ricketson observes, however, "Eason does not appear to allow for the possibility of a practitioners being fully alive to the difficulties of representing events and people yet choosing to present their findings in a realist narrative mode. Conversely, a practitioner's self-conscious demonstrating of the difficulties of representation can have the effect of obscuring the subject or, consciously or otherwise, of foreclosing their inquiry" ("Ethical Issues" 153). The presence of closure in a work of literary journalism may, or may not, then, reflect an ideological position of a practitioner. Of the six texts analysed in chapters five and six, each displays a different commitment to closure, and the analyses suggest that each book produces a unique rhetorical effect. Eason's theory is helpful when characterising individual works of literary journalism, but less so when applied to practitioners. The discussion here raises an important question: if phenomenal reality is indeed fluid and inconclusive, how can the "validity" of closure be assessed in works of literary journalism? 
One argument made by White about the nature of this process is that any implication of causation or emplotment leading to narrative closure is essentially fictive. Code might rejoin that closure represents a category of knowledge that is subjective, but that relies on epistemic cognitive processes that produce understanding as a type of truth - that is, the type of closure offered is finally limited by "constraints upon subjectivity in the form of epistemic imperatives and criteria of epistemic confidence" (ER 77). As such, it would be difficult indeed to apply the discipline of verification when assessing closure in a work of literary journalism, but "validity" of a narrative's closure can be evaluated by consideration of the epistemic responsibility-or situation —of the practitioner, as outlined in the following chapter.

Some examples may demonstrate this point here. For some critics and practitioners, such as Hollowell (1977), Hellmann (1980), and Weschler (in Boynton 2005), a point of departure of literary journalism from non-fiction is located precisely in practitioners' intention to draw meaning from fact. Literary journalism is typically charged with using "fictional" techniques to impose meaning that cannot be "found" in phenomenal reality. Australian writer Helen Garner characterises this as "trying to arrange the material objects and events and dialogue on the page in such a way that they do the heavy lifting, so I won't have to interpret or pontificate" (in Eisenhuth and McDonald 165). Garner's methodology here has been contentious: is the arrangement of verifiable content an act of manipulation, in the term's most pejorative sense? It is certainly a type of rhetorical positioning that invites particular kinds of interpretation from readers. But as interviews with prominent Australian literary journalists reveal: "using the word fiction flies in the face of what practitioners ... believe they are doing" (Ricketson, "Ethical Issues" 150-151). That is, deriving meaning from fact may be a work of the imagination, but imagination here should be understood in the Kantian sense; as Code observes, it is "a mediating power or faculty between understanding and sensibility. It is the bearer of the schemata for the production of images that delimit a category, and permit its application to experience". Code uses terms and phrases such as "to form images", "to construct concepts", "mediating" and "production" to emphasize that "the knowing process is, above all, active in its creativity" (ER 102). 
While meaning in non-fictional texts is an indication of fictionalisation for some theorists, for others it is a defining and desirable characteristic for narrative nonfiction. For example, in The Literature of Fact, Weber states:

[I]t is my view that the literary quality of recent nonfiction is located precisely in the capacity of the writer to find in factual experience some "tissue of significances," some "resonant meanings." Such meanings may be less "totalizing" or grandly metaphysical than they once were, but they are as nonetheless present in nonfiction that seeks the level of art as in fiction, and works of literary nonfiction can be explored by examining how writers have used fictional techniques to reveal meaning and by trying to gauge the extent to which they have been able to do so (49).

A practitioner's intention to draw meaning from fact should not be equated with fiction through Weber's use of the misnomer "fictional techniques". Tracy Kidder, winner of a Pulitzer for general non-fiction, points out that techniques commonly held to belong to fiction writing did not originate there: "They belong to storytelling" (in Sims and Kramer 19). Nevertheless, as Weber states, the work of scholars in this area is to examine how writers may "totalize" meaning, and gauge the extent to which practitioners may do so. This might also give insight into the potential overuse of such techniques and provide theoretical case studies to guide future literary journalists. Further, Weber's perspective recognises the value of meaning in nonfiction, without conflating the genre with fiction.

One technique used to subvert what Weber terms "totalizing" or "grandly metaphysical" meanings is reflexive practice. Reflexivity in general is a "crucially important aspect of epistemic competence" for Code. She defines it as "insight into the extent of one's own cognitive capacities, to distance oneself as much as possible so one can be critical of one's own knowing" (ER 176). Reflexivity in literary journalism reminds readers of the subjectivity behind the text, and consequently its constructed nature. In this way many works of literary journalism differ from historical discourse, which rarely reveals the mechanics of its construction. Reflexive techniques have observably changed over time in response to dominant culture. James Agee, for example, is a much-quoted forerunner of this tradition. He used avantgarde, highly reflexive writing techniques with two main intentions: to critique objectivity in texts that reproduced the norms of representation in late nineteenth- 
century citizen-witnessing (Bartley). Agee's method guided the reader's consciousness to the constructed nature of the text; readers were consequently compelled to reflect on the real-world existence of subjects. He wrote, for example:

George Gudger is a human being.... I could invent incidents, appearances, additions to his character, background, surroundings, future, which might well point up and indicate and clinch things relevant to him which in fact I'm sure are true... [But] he is in those terms living, right now, in flesh and blood and breathing ... [I]t is essentially and finally a hopeless [thing], to try merely to reproduce and communicate his living as nearly as exactly as possible, nevertheless I can think of no worthier and many worse subjects to attempt (232-3).

The intention here appears to be to narrow the distance between the real and the represented by emphasising it. Frus supports this reflexive mode of representation, suggesting it "may be an effective way to challenge the reification implied by most mass-cultural forms" (180). She further contends that reflexivity encourages the "recognition of the hegemonic workings of society" (117). But Barbara Foley questions Frus's privileging of reflexivity in works of literary journalism, stating:

For what this means is that texts which problematize their own truth-claims and direct attention to their own conditions of production are intrinsically those best equipped to challenge, and break down, reification. Frus's "heroes" in this regard are Norman Mailer ... and Janet Malcolm ... who presumably repudiate positivist objectivism and grasp the textual construction of reality. Despite their self-conscious sophistication, however, these writers are, in my view, hardly unblinded by what I would call "ideology". ... [P]ropositions, set forth however "reflexively", still contain a "content" that calls out for assessment separate from the "form" of their articulation (Foley, "Politics" 346).

In an analysis of reflexivity in literary journalism, then, it is important to be aware that reflexivity may unsettle a determinate representation of reality, but that it can also mask an ostensibly transparent text. Reflexivity can thus be used both critically and constructively. As a critique it targets uncritical acceptance of modes of representation that attempt to represent the world; but simultaneously it can be used to produce a new kind of aesthetic experience that re-orientates readers back to the phenomenal reality it seeks to represent. 
Book-length works of literary journalism may or may not display reflexivity, resistance to reification and closure, but when employed, each of these features can contribute to creating an aesthetic experience for the reader that reorientates them towards the bi-referentiality of the text. That is, the text may be a cohesive narrative, but these features can also stress a text's correspondence to observable, phenomenal events - its claim to non-fiction status. But some texts do not rely on such narrative features. In such texts, the referentiality of the text is often established through paratextual features. Framing the narrative in this way produces not only a rhetorical effect, but also invests the text with what Genette terms a "contractual force" (Paratexts 11).

\section{Paratexts}

As early as the fifth century B. C., evidence can be found of writers offering explanatory notes as a way to prepare their readers, or instruct them in the text's epistemological background. In the introduction to his account of the Peloponnesian war, Thucydides's dedication to the methodology of truth articulates authorial intent and specifies the practices used to obtain information (in Kovach and Rosenstiel 70). The dedication further aims to establish the authority of the writer, and thus the authority of the historical account. In 1997, Genette coined the terms "epitext" and "peritext" to denote two areas of text used to convey "a commentary that is authorial or more or less legitimated by the author." Together the epitext and peritext make up the paratext, a site Genette refers to as the "fringe" but elsewhere has been called a “frame” (see Berlatsky 173-84; Frow 106-7; Derrida 70; Symes 19-25). Combined, these areas function as "a zone between text and off-text, a zone not only of transition but also of transaction: a privileged place of a pragmatics and a strategy, of an influence on the public, an influence that-whether well or poorly understood and achieved - is at the service of a better reception for the text and a more pertinent reading of it" (Paratexts 2 emphasis in original). Of course, Genette recognises that a "pertinent" reading is directly correlated to the author's desire for the text's reception (2), but for works of non-fiction this is an important point as the text's reception is directly influenced by a practitioner's claim to authority.

Thucydides's introduction comprises part of the peritext, the spatial zone closest to the text itself, which includes outermost elements such as the cover and title page, the 
book's material construction (including format, paper, typeface and so on) (Genette, Paratexts 16), as well as the introduction, dedication, foreword/afterword and so on. The second zone, or epitext, denotes "any paratextual element not materially appended to the text within the same volume but circulating, as it were, freely, in a virtually limitless physical and social space" (344). This zone includes the publisher's epitext which has a primarily promotional or marketing function and does not always involve the author in a meaningful way (347), semiofficial allographic epitext, which is "allography more or less 'authorized' by some authorial assent or even inspiration" (348), public authorial epitext which includes any authorial public response to the text or its reception directed at the public, such as interviews and public conversations (Paratexts 351) and private epitext, including letters, journals and oral confidences that shed light on the text (Paratexts 371).

The particular importance paratext holds for literary journalism has do with its potential illocutionary force. Genette contends that some paratextual elements may hold little - if any_significance, functioning simply "to communicate a piece of sheer information - the name of the author for example" (Paratexts 11), although he later states that an author's name is a "constituent element" in autobiographical works - or referential writing where the credibility of testimony rests largely on the identity of the witness or person reporting (Paratexts 41). ${ }^{9}$ Other elements more obviously communicate an intention of, or interpretation by, the author; make an assertion; create a commitment, or issue a command (Paratexts 11). It is the latter two functions - commitment and command - that have the most obvious illocutionary force and work to draw readers into a negotiation over how to read a work of literary journalism. As Heyne points out, the nonfictional status of a text does not always make a difference to how it is read, although it "can make a difference to those readers for whom it already makes a difference" ("Where Fiction Meets Nonfiction" 325). Elsewhere, however, he concedes that "in order to evaluate a complex nonfiction narrative, it is essential to understand the exact truth-claims being made and how they fit into the author's overall intentions" ("Toward a Theory" 488). Both of these sentiments are echoed by Abbott (30-31), Berlatsky (184), Darrel (266-67) and Frow, who argues that while "we cannot conclude ... that interpreters have licence to read whatever generic form they please into a text ... this is not to say that these guidelines must be respected." Further, "Readers and writers negotiate the 
generic status of particular texts but do not have the power to make their ascriptions an inherent property of those texts" (Genre 109).

Genette also takes the line that the illocutionary power of the paratext is potential rather than given, although he clearly sees authorial intention as valuable. He states that "valid or not, the author's viewpoint is part of the paratextual performance, sustains it, inspires it, anchors it", but that "the critic is by no means bound to subscribe to that viewpoint. I maintain only that, knowing it, he cannot completely disregard it, and if he wants to contradict it he must first assimilate it". Genette's conclusion that "To accept [the paratext]—or, for that matter, to reject it-one is better off perceiving it fully and clearly" (Paratexts 408-9) aligns with Heyne's; finally, any intentional reading of non-fiction must take into account the author and publisher's framing devices through paratextual markers. Choosing to disregard or read against them is the prerogative of the reader, but to do so without acknowledging their intended illocutionary effect is to direct one's interpretation away from what Heyne terms "a proper response" ("Toward a Theory" 480), a phrase that echoes Genette's "pertinent reading".

Genette describes paratextual cues as having different levels of influence; he also observes that the illocutionary power of paratexts is greatest in works of non-fiction. For genres such as autobiography, memoir or narrative history, Genette refers to a level of "commitment" as one possible indication from the author, with some authors choosing to create a higher level, or "more binding contractual force" (Paratexts 11 emphasis added). Arguably, the contractual force of paratexts of literary journalistic works should be some of the strongest, in light of their emerging generic status. While the label "non-fiction" signals a genre indication, the number of variables involved in literary journalism - for example, how the information was gathered, the relationship of the author to the subject, the extent to which names and information have been changed - raises questions in the mind of the reader that, left unanswered, have the potential to create an incomplete, false or misleading "horizon of expectations" (Frow, Genre 70) for the reader.

Paratextual information consequently becomes a central component in negotiating an author's intentions for how their book should be read. Paratexts cue a reader's 
expectations at the levels of questions and expectations, although "this is always a matter of interpretation, not of recognition" (Frow, "Reproducibles" 1630), and readers are not obligated to respond to such cues. Readers also undoubtedly bring their own understanding of a genre to a text as an initial step in negotiating how to read the text, and each of these paratextual features has the potential to refine expectations. In this way the author encodes the text with markers of intention, giving the reader the opportunity to supplement their understanding of what constitutes "nonfiction" with information to decode the text. This process is effectively a social transaction, the characteristics of which mirror to some extent the negotiation of a contract in legal or moral terms.

\section{Author-Reader Contracts}

Literary journalists working outside a news media organisation are neither bound nor protected by a normative set of journalistic practices. This state of affairs necessitates that each practitioner negotiate their own ethical epistemic practice on a text-by-text basis. Writers and - at times - theorists invoke the metaphor of a "contract" between an author and reader to describe the process of negotiation of a text's status. John McPhee, a leading practitioner of narrative non-fiction, comments on the use of composite characterisation to demonstrate his understanding of this negotiation: "If [using composite characterisation is] what they mean by the line blurring between fiction and nonfiction, then I'd prefer another image. What I see in that image is that we don't know where fiction stops and facts begin. That violates a contract with the reader" (in Sims, Literary Journalists 16). This comment may promote a simplistic understanding of non-fiction narrative in that it does not account for embedded meaning, inherent in narrative forms, that goes beyond factual statement of verifiable events (the annal or chronicle forms, for example). It does, however, reference the practitioner's intention not to invent facts or even to manipulate them-as in the case of composite characterisation - and as such highlights the need for some kind of negotiation between the author and reader to set up a "horizon of expectations".

For Genette "the genre contract is constituted ... by the whole of the paratext and, more broadly, by the relationship between text and paratext" (Paratexts 41). Theorist Mas'ud Zavarzadeh notes that throughout the 1950s and 1960s the term contract was used almost always with a disapproving tone by critics, one of whom writes of non- 
fiction novelists, "Their works are 'interesting', full of observation and talent and even wisdom, but as far as fictional faith goes we are left to make the effort by ourselves" (73). Pauly contends that the "crucial" political contribution of the New Journalism was that it "compelled us to reconsider the social rituals through which writers might declare themselves responsible rather than merely free" ("Politics" 123). This responsibility of the author to establish expectations of a text's status and practitioner's implication in the narrative may then be seen as a legacy from New Journalism to literary journalism, and the term "contract" understood as a social ritual through which such a negotiation may take place. ${ }^{10}$

The idea of a metaphorical contract between an author and reader is discussed by Heather Dubrow:

[The poet] is in effect telling us the name and rules of his code, rules that affect not only how he should write the work but also how we should read it. ... Through such signals as the title, the meter and the incorporation of familiar topoi into his opening lines, the poet sets up ... a contract with us. He in effect agrees that he will follow at least some of the patterns and conventions we associate with the genre or genres in which he is writing, and we in turn agree that we will pay close attention to certain aspects of his work while realizing that others, because of the nature of the genres, are likely to be far less important (31).

While Dubrow's assertions are made in reference to poetry, and, arguably do not apply to all forms, the same principles can be effectively applied to other types of discourse, and particularly book-length literary journalism. The title (and subtitle) may offer paratextual indications of the text's scope and intention, the narrative's structure may set up expectations at the levels of questions and expectations, and the literary style may also signal specific intentions of the practitioner. For literary journalism, it may be contended that the first negotiation of genre is the author's promise to deliver a work of non-fiction. As has been demonstrated, however, nonfiction is a problematic term in light of what it is and is not able to connote. The term non-fiction may produce an understanding between author and reader that the text will be based on facts or verifiable evidence, but the narrative form clearly precludes the text from being "factual" alone, thus prompting questions about the text's potential as an accurate representation of reality. The assertion of non-fictional status 
alone, then, may not offer enough information for a reader of literary journalism to approach a text in a way that an author intends it to be read.

The key characteristics of a legal contract are relevant to the process of negotiating a text's genre status. Perhaps the three that are most helpfully indicated by the term are expectation, responsibility, and trust. In a work of literary journalism, a practitioner assumes responsibility for representing real events and entities: this is the primary goal of non-fiction. Beyond that, the author has the opportunity to set reader expectations by disclosing reasons behind the investigative work, methodologies, writing techniques or any other information relevant to the writing of the text. Genette suggests that the factual narrative's requirement of truthfulness is "the obligation to report only what one knows - but at the same time everything that one knows, to provide all the information - and to state how one has come by that knowledge" (Fiction 67). Such disclosure would undoubtedly revolutionise historical and journalistic narrative; a more practical approach perhaps is that authors include salient information that they believe is necessary to inform the reading of their text. In this way, they accept responsibility, set expectation and set the terms of the reader's trust in their stated claims. As Frow states, "Credibility, authority, and emotional tone are effects of these rhetorical relations and their formal expression in the syntactic and intonational nuance of the discourse" (Genre 75). This is the domain of epistemic responsibility, which will be more fully addressed in the following chapter.

Of course the reader is under no obligation to accept — or even read — the terms set out by the author. But here again the notion of a contract is valuable as it exemplifies how perceived violations of the text can be validated or invalidated by the author's claims - or absence of them. Pauly observes, "Writers use conventional codes to convey truth, but such codes are themselves just one form of a larger series of social occasions during which interpreter and interpreted meet to argue their positions" ("Politics" 123). If a reader feels an author has violated their trust, an argument can be made primarily in reference to terms of the knowledge offered and claims made by the author. The negotiation may include information outside of the text and paratext of a particular work of non-fiction. The reader potentially brings to the text-and thus the contract - their knowledge of the author as a public figure, the author's previous works, information through marketing of the text, media coverage, critical reviews 
and so on. Thus, the types of knowledge and information a reader may bring to the negotiation of the text is often outside of the intentions and control of the author.

Authors and publishers of literary journalism are under no obligation to provide paratextual information that, for Genette, holds a contractual force. But the notion of transparency is increasingly being explored as a counter-balance for journalistic practices that have traditionally hidden the means of their production. In the wake of crumbling positivist ideologies, is transparency a viable currency in which literary journalists can trade?

\section{Transparency}

Literary journalism is not the only type of news media under scrutiny for its content and form. Mainstream journalism's so-called "crisis" wrought by the movement towards technocentric societies is well documented (see for example Curran; Young; van Tuyll), with the move from analogue to digital media systems opening news cultures that were previously closed to the public. As a result, leading media scholars have called for transparency to become the news value of the future (see Forde; Kovach and Rosenstiel; Plaisance; van der Wurff and Schonbach). The intention of such scholars is to increase the profession's legitimacy; establish jurisdiction in an increasingly competitive publishing environment; expose self-interest in journalists; and reinforce traditional journalism's standing in society (Allen). Kovach and Rosenstiel assert that:

Transparency ... signals the journalist's respect for the audience. It allows the audience to judge the validity of the information, the process by which it was secured, and the motives and biases of the journalist providing it. This makes transparency the best protection against errors and deception by sources. ... Transparency also helps establish that the journalist has a public interest motive, the key to creditability. The willingness of the journalist to be transparent about what he or she has done is at the heart of establishing that the journalist is concerned with truth. The lie, or the mistake, is in pretending omniscience or claiming greater knowledge than we have (80-81).

Literary journalism that produces a sense of omniscience is clearly problematic from this perspective. But peri- and epitexts are sites at which practitioners may defend their epistemic responsibility without compromising the aesthetic value-or rhetorical 
impact - of a narrative. Karlsson differentiates between "disclosure transparency" and "participatory transparency". The former is often paratextual. It makes clear the process of content selection, publishing links to original material and sources and revealing personal positions in relation to the news (537), while the latter "aims at getting the audience involved in the news production process in various ways" (538). Karlsson advocates both forms of transparency in journalism, but Allen argues that what Karlsson would characterise as "disclosure transparency" increases criticism rather than understanding; limits journalistic autonomy; can be employed to deceive an audience; and may ultimately undermine the very freedom transparency is intended to protect (325-6). Allen does not conclude that transparency has no place in journalism, but rather that it should exist as a normative standard rather than function as an "instrumental value enlisted to protect institutional legitimacy and stave off criticism" (324). Evidently, time is needed for transparency to develop as a universal norm rather than being employed as a preemptive action against criticism. But as the analyses in this thesis will demonstrate, Allen's arguments are particularly pertinent with regards to literary journalism, and careful consideration is needed before such a norm is adopted.

Disclosure transparency is directly related to the author-reader contract in literary journalism. Practitioners are able to choose the extent to which they reveal their sources, investigative methodologies, writing practices, and position in relation to their subjects. The argument between advocates and opponents of transparency in the journalism academy is highly relevant to literary journalism; in fact, the controversies outlined in chapter four suggest this argument surfaced in relation to literary journalism decades before it became an issue for mainstream journalism. That there has been no consensus on, or professional standards drawn, in relation to disclosure transparency for literary journalists indicates that there are no easy answers for either institution. As will be demonstrated with the analyses in chapters five and six, trends in contemporary US practice favour both disclosure and participatory transparency, but with varying results. In this economy, literary journalism has the potential to lead the way in modeling epistemic responsibility to mainstream journalism. As contemporary media faces a crisis of reinvention in the wake of a burgeoning online environment, contemporary literary journalists-with their tradition of challenging 
and being challenged by their audiences on epistemic responsibility - have a rich history - as well as a clean slate - to draw on.

The features of the Internet provide a new epitextual realm that is potentially far more accessible for readers than that of the New Journalists. Marie-Laure Ryan proposes four features of online media that are salient here: the Internet's immediacy, hypertextuality, multimediality and interactivity (Virtual Reality 4-7). These characteristics strengthen the epitextual frame because of their potential universal accessibility, and in many cases the author's crafting of the epitextual space. As Ryan writes, hypertextuality, multimediality and interactivity support—or perhaps even embody - the postmodern approach. By dismantling "grand narratives" and replacing them with "little stories" or even the "endless deferral of signification", readers are denied "the satisfaction of a totalizing interpretation", and are positioned to challenge "the epistemologically suspect coherence, rationality, and closure of narrative structures" (Ryan, Virtual Reality 7). For extended works of literary journalism there is growing a-perhaps unlikely - alliance between print and online media cultures. The former ostensibly promotes uniformity of narrative, the authority of the writer, and narrative coherence, while the latter functions to question authority, frustrate totalizing narratives and ultimately turn consumers into producers. However, as contended by some theorists, literary journalism seeks to avoid reification (Frus 180); resist critical closure (Hartsock 153); and ultimately respond to an epistemological crisis that calls into question notions of objectivity and authority (Hartsock 15). Thus, literary journalism and online media could make good bedfellows, despite the seeming incongruence between their static and dynamic forms.

That readers value "truth" and do access primary sources and resources —including the practitioner-as-source - is evidenced in the growing popularity of online "companion sites" for book-length literary journalism. While general or semi-allographic online epitext includes interviews, reviews, blogs, author channels on YouTube, academic critical analyses and more, "companion sites" arguably provide a narrative's central online presence on the Web. Such sites are central in that readers are often directed straight to companion sites from URLs in the physical text. Also, companion sites are most likely to be sanctioned by the author, thus act as "official" epitext. While they often contain links to other sites that promote or support the book, companion sites 
typically contain general information such as the author's biography, oeuvre, and contact information, as well as features specific to the text, such as primary source documents, reviews, public forums, teaching aids, video clips, photographs, and, increasingly, book trailers. For many authors and publishers, the primary purpose of such sites may be to market the text. Notwithstanding this motivation, companion sites have at least a dual function: that of promotion, and transparency — or epistemic responsibility. Online epitextual information not only establishes epistemic responsibility, but the potential immediacy of access increasingly strengthens its function as a frame.

The provision of online epitextual material suggests increased awareness of epistemic responsibility in current practice. While epitextual material has always had the potential to inform or modify a reading of a text, it has not always been potentiallyor simultaneously - immediate, hypertextual, multimedial, or interactive. The effect of these four qualities of epitext on the narrative creates a rich field of inquiry in the context of the author-reader contract. By offering resources online, do literary journalists surrender control of the narrative to the reader immersing themselves in primary and secondary epitextual sources? Or are book-length works of literary journalism reified to the extent that they frame epitextual matter, rather than the epitext framing the narrative? If the latter is the case, online epitext may be operating under a modus in opposition to the "mounting evidence" that denies the existence of a verifiable reality and affirms reality's social and cultural construction (Aucoin; Allen). Is transparency truly the news value of the future? And how can practitioners who seek to destabilize reified cultural stories protect the authority of their narratives without perpetuating the very state they are attempting to critique?

As contended in chapter one, it is valuable to use established journalistic norms such as the "objectivity standard" and the "discipline of verification" to assess literary journalism, but results of such analyses cannot attend to the questions above. Authorreader contracts offered through narratives and their paratexts can act as avenues for disclosure transparency; but these, too, have their limitations and weaknesses. In the next chapter I will offer Code's theory of epistemic responsibility as a framework with which to assess the knowledge - and truth — claims of literary journalism. Code's perspective builds on foundationalist and coherentist theories of epistemology to 
separate the moral and epistemic issues involved in knowledge acquisition and presentation. I argue that while Code's notion of a "responsibilist" approach does not eclipse the need for verification, it is complementary to such an assessment, and illuminates issues that trouble the theory and practice of contemporary literary journalism. 


\section{Chapter Three}

\section{Epistemic Responsibility and the Literary Journalist}

\section{Re-visioning the Landscape}

Pioneers bring familiar ways of seeing and working land to new territory. It is not uncommon for settlers to apply practices from a country of origin to new land in the discovery and exploration phases of settlement. Difficulties occur, however, when pioneers fail to take into account the unique features of an environment and attempt to impose "tried and true" methods of managing land from their home country on unresponsive — and, at times, hostile — terrain. James Aucoin (2001) has observed this phenomenon in relation to literary journalism. In his article, "Epistemic Responsibility and Narrative Theory", Aucoin contends that two scholarly approaches are evident in the 30-year critical debate over literary journalism. ${ }^{11} \mathrm{He}$ names Zavarzadeh (1976), Hellman (1981), and Heyne (1987) as scholars who have defended literary journalism as a genre of literature, and Sims (1984), Connery (1992), and Kramer (Sims and Kramer 1995) among those who "have attempted to legitimize literary journalism as a genre of journalism ... [and] have hinged their classification scheme on the criterion of verifiability" (6-7). Verifiability is a problematic standard for the genre, Aucoin argues, owing to three key reasons: "the mounting evidence from science and philosophy that denies the existence of a verifiable reality that can be described through logical-positivist empiricism and affirms that reality is socially and culturally constructed" (7); "the voluminous evidence that journalism constructs a truth that is based on culturally accepted conventions" (7); and "dominant narrative theory, which holds that any imposition of narrative is a moral act that results to some extent in a fictionalization" (8). Aucoin argues that literary journalism should not be subject to the discipline of verification, and therefore offers "a strategy of using narrative theory and epistemic ethics to judge literary journalism" (5-6).

In the previous chapter I engaged with dominant narrative theory and posited that there is, in fact, a case for separate ontological categories of fiction and non-fiction. Code's reliance on Kantian philosophy also produces an argument for locating knowledge - and, consequently, truth-within social interactions. But while the 
structuring of reality relies upon socially constructed "ways of knowing", reality also exists independent of such constructions. As Code writes, knowledge and community are dependent upon each other, but both are also subject to the constraints imposed by the phenomenal world. "The sum total of communal knowledge at any point in history is a product of personal efforts to tread an intricate path between a need to make sense of the world (in the sense of making it one's own) and a need to understand it in a communally viable way" (ER 114 emphasis in original). It follows that although consensus plays an important role in the synthesis of knowledge, it "is not the ultimate arbiter of truth or justification; there are areas of knowledge where disagreement is not only possible, but inevitable" (ER 115). Consequently, I continue in this chapter with the understanding that verifiability is an important constraint on potential and possible knowledge, while acknowledging that verifiability cannot account for different types of knowledge offered in works of literary journalism.

\section{Epistemological Approaches: Foundationalism, Coherentism, and Responsibilism}

Code's approach differs from two established epistemological traditions: foundationalist and coherentist. Foundationalists hold that there is "knowledge in the world which is so certain that no reasonable man could doubt it" (Code, ER 3), and that this knowledge forms a foundation for all other types and systems of knowledge. For coherentists, on the other hand, the "source of evaluation and justification of a belief or knowledge claim lies in its relations with other beliefs or 'knowns' within a system; explanatory relations or relations of probability or logic might be taken into account" (ER 4). The foundationalist and coherentist traditions are analogous to the traditions of literary journalism scholarship. Following Aucoin, scholars cited in the previous chapter broadly fall into two categories when attempting to articulate standards for the genre: those who primarily employ narrative theory to articulate standards, such as narrative coherence, verisimilitude and other literary criteria, and those who advocate the application of journalistic standards, such as accuracy and verifiable content, to works of literary journalism. Examples of those who perform literary readings include Hollowell, Weber, and Anderson, while scholars such as Lounsberry (xiii-xiv) and Kerrane and Yagoda (13) employ verifiability as a standard. ${ }^{\mathbf{1 2}}$ Standards of verification can thus be understood as part of the 
foundationalist tradition, while narrative theory has a correlation with coherentist theories of epistemology.

These distinctions are important in light of Code's project. She acknowledges that foundationalism and coherentism "represent the best efforts of epistemology so far to approach 'the problem of knowledge'", but also contends that enquiry is limited by the range of possible questions these approaches allow (ER 7). A complementary approach is necessary, Code argues, to widen the scope of epistemological investigation:

The persistent exemplary status of ... items in foundational and coherentist theories of knowledge obscures the extent to which there are genuine choices about how to know the world and its inhabitants, choices that become apparent only in more complex epistemic circumstances - for example, in knowing other cultures, negotiating an environmental policy, assessing the significance of certain actions and policies, or predicting the implications of tests and experiments. Such circumstances, and others like them, occasion questions about epistemic responsibility. In doing so they broaden the scope of epistemology to include considerations of credibility and trust, of epistemic obligations and the legitimate scope of enquiry ("Responsibility and Rhetoric" 3 ).

In the same way I advocate an additional—or complementary-mode of analysis to those offered by literary theory and the discipline of verification for literary journalism. This is particularly timely for what I contend is a dominant feature of contemporary literary journalism. Historically, key literary journalists such as Ryzyard Kapuściński have produced important texts that did not appear to place emphasis on journalistic standards of verification, attribution or transparency despite asserting their non-fiction status. But I propose in this thesis that a new generation of practitioners - those producing their first works of book-length literary journalism between 2000-2010 - aspire to the highest standards, both literary and journalistic. Critical reception can be mixed, as demonstrated in chapters five and six, but "New Gen" literary journalists such as Daniel Bergner (Soldiers of Light 2004), Suketu Mehta (Maximum City 2004), John Vaillant (The Golden Spruce 2005), Rajiv Chandrasekaran (Life in the Emerald City 2006), Andrew Westoll (Riverbones 2008), Alexandra Fuller (The Legend of Colton H. Bryant 2008), and Dave Eggers (Zeitoun 2009) demonstrate deep commitment to both literary aims and "traditional" journalistic standards such as verifiability, balance and accuracy. I further contend 
that Adrian Nicole LeBlanc (2003), Dave Cullen (2009) and Rebecca Skloot (2010), my central case studies in chapter five, are representative of these contemporary practitioners, who - in spite of increasingly blurred notions of reality-operate under a modus that holds reality to be discoverable, and whose texts represent their best effort to accurately capture such reality. ${ }^{13}$ As noted, this is a "new form of clean classicism" and is quite distinct from New Journalists' emphasis on the apocalyptic zeitgeist of the 1960s and attendant "hysteria" of life in that era (see Foley, Telling the Truth; Hellmann; Hollowell).

In keeping with Code's rationale, an epistemological responsibilist approach opens the range of questions that can be asked of literary journalistic practice. It can also illuminate literary readings of texts where meaning and truth are as important as the events from which they proceed. Reorienting epistemological focus from end points to processes, Code encourages would-be knowers to engage in "Socratic dialogue" over their knowledge claims (ER 28-9). Cooper gives examples of epistemic questioning that could inform literary journalistic practice such as: "Do I really know what I think I know?”; “Do I know enough to act as I do?”; "What don't I know?”; "What are the moral consequences of my knowing/ignorance?"; "Should I know more or acknowledge incomplete knowledge?" (86). Such questioning informs not just the practice but also the criticism of literary journalism. It emphasises the choices available to - and limitations imposed upon-practitioners in the way they represent reality, as well as their responsibility to "know well". Likewise, critics and scholars may ask these questions of practitioners to illuminate analyses, but they similarly have an obligation to know their subject well—well enough to judge as they do - as they also engage in a process of representing reality. This is both the challenge and opportunity of opening practice to assessment of epistemic responsibility.

\section{Intellectual Virtue: Epistemology v Ethics}

A "responsibilist" approach to epistemology is grounded in the notion of intellectual virtue. ${ }^{14}$ For Code, intellectual virtue is "about possessing a fairly constant and dependable set of qualities and capacities, manifested in one's orientation toward the world, toward one's knowledge-seeking self, and toward other such selves as part of the world" (ER 52). She continues: "Virtues, both moral and intellectual, have more to do with ways of relating to the world than with the 'content' of particular actions or 
knowledge claims" (ER 53). This division between moral and intellectual virtue is critical: "Here the demands of good moral conduct and good epistemic conduct are sharply divergent" (ER 186-7). Code emphasises that one can be intellectually virtuous (a knowledgeable practitioner) without being morally virtuous; con men and scandal-collectors are apposite examples. John D'Agata and Jim Fingal's The Lifespan of a Fact (2012), analysed later in this chapter, exploits this separation of epistemic and moral conduct. But here a differentiation will be made between believing "what works for me as long as it does not harm or adversely influence someone else" - almost a purely moral point - and "whether I can structure my epistemology so that it is wrong epistemically for me to hold certain beliefs because my epistemic principles will not allow it" (ER 47). Code observes that the separation of these domains of enquiry is complex:

The complexity arises because knowing well, preserving an appropriate degree of objectivity, thinking clearly, and being epistemically responsible are, in fact, moral matters. But they are not just moral matters; nor can they, as moral matters, be wholly subsumed under standard modes of ethical discussion. ... [T]hey are not amenable to adequate discussion under the rubric of any of the traditional approaches to ethics nor under any reasonable amalgam thereof (ER 68).

Indeed, the term "responsibility" belongs to the discourse of ethics. It is therefore important to acknowledge that the separation of an "ethics of belief" and "epistemic responsibility" will never be absolute. Code likens their relationship to strands of a thread, which, when parted, "show that it is not a unity, but composed of individual filaments that alone could not make up a thread" (ER 72). The rationale behind Code's project is thus summarised in the following passage:

Different cognitive capacities and epistemic circumstances create situations where experience is structured, and hence the world is known, quite differently from one cognitive agent to another. Each time a moral judgment is made, then, two parts of a situation must be assessed: the way it is apprehended and the action that is performed as a result. The former, the apprehension, is a matter for epistemological assessment, and the moral dimension of the situation is crucially dependent upon this epistemic component (ER 69).

Hence, "knowing well" is a matter of moral significance, not because cognitive processes are moral or immoral in themselves, but because actions borne out of 
epistemological practices are often judged ethically. I argue that conflating these categories has significant ramifications for the theory and practice of literary journalism. To the extent that they can be held apart for analytical purposes, ethics and epistemology should be evaluated separately to illuminate how ethical practice is dependent on a sound epistemic foundation. In the following chapter I (re)examine some literary journalistic texts using this rationale. The epistemic strand of intellectual virtue, however, is the focus of discussion for the remainder of chapter three.

\section{Reality, Accuracy and Truth}

An emphasis on epistemology invites an examination of conditions in which an individual can "know well". One starting point is the nature of reality. Code draws on Kantian philosophy again when she asserts

[t]he formal conditions of knowing, imposed by human cognitive structures, significantly (but not absolutely) determine the manner of the synthesis. In both Kantian and Piagetian terms, only what can be subjected to these formal conditions can become part of human knowledge. ... [I]t is reasonable to suggest that empirical (that is, phenomenal) reality is, by definition, coextensive with the (current) limitations of human cognitive powers, both actual and potential (ER 105).

This echoes Weber's point, made in chapter two, that potential knowledge in nonfiction is limited by phenomenal reality. But Code also explicitly acknowledges the limits imposed by actual and potential cognitive powers. The manner of an individual's structuring of reality "is dependent upon a knower's interaction with the world and will vary accordingly" (ER 105). The epistemic responsibility of a literary journalist can then be characterised as a responsibility to interact with the world in a way that enables a practitioner to "know well" - that is, to anchor the coherence of meaning to the correspondence of empirically verifiable reality. According to Code, objective knowledge is produced when cognitive processes synthesise with phenomenal reality:

There is no contradiction in claiming both that the world known to human beings is formed or created through the cooperation of active exploration, perception, thinking, and imagining and that knowledge is objective. For something to be an object of human knowledge, it must 
be amenable to this creative synthesizing; yet objects themselves (that is, real things in the real world), together with formal conditions imposed by human cognitive capacities, determine the manner of the synthesis. Although there are many ways of knowing legitimately socalled, evidence strongly favors the claim that these are ways of knowing one real world. The patterns that can be selected are limited in practice by the necessity that they conform, to some degree, to this objective reality. To this extent, objects dictate the nature of the synthesis (107).

The idea that objective knowledge is discoverable by individuals closely reflects, I contend, theory underpinning the practice of contemporary literary journalism represented in this thesis. Both anecdotal evidence from practitioners and current scholarship support such a contention. Mark Kramer, founding director of the Nieman Foundation for Journalism, for example, reflects on evidence from his discussions with literary journalists, which suggests that current practitioners share a tacit understanding with readers. This understanding is "so strong that it amounts to a contract: that the writers do what they appear to do, which is to get reality as straight as they can manage, and not make it up" (Kramer 25). Such comments reflect a belief that reality is "discoverable", and that there are "ways of knowing one real world" (Code, ER 107); literary journalists are part of a shared reality that can be objectively known. Importantly, Kramer also differentiates between the New Journalists' project and contemporary literary journalism. He relates the horizon of expectations set by Norman Mailer's The Executioner's Song (1979): “The dust jacket bore the odd description 'A True Life Novel.' Although such truth-in-labeling doesn't explicitly demarcate what parts are actual, it's a good-faith proclamation to readers that they've entered a zone in which a nonfiction writer's covenant with readers may be a tease, a device, but doesn't quite apply". ${ }^{15} \mathrm{He}$ asserts that this category of expectations "[fall] outside the modern understanding of what literary journalism is" (Kramer).

Theories that refute the possibility of representing reality are antithetical to the practice of literary journalism. "New Gen" practitioner Arnon Grunberg suggests "Doubt and skepticism about what constitutes reality are very healthy, but denying the distinction between fiction and reality ... points to an attitude that results from a lack of skepticism and doubt. Reality offers a few 'truths,' which leave not a lot of room for skepticism. Go and stand on a rail track for instance, and wait for the train to come" (in Harbers 79). Grunberg's point, although wry in tone, reflects what I argue 
is a dominant ideological position of contemporary literary journalists. It is certainly not, however, an argument for a facile relationship between humans and reality. Writing about Grunberg's Chambermaids and Soldiers (2009), Agnes Andeweg observes: "As the narrative ... shows, reality is multifaceted ... . That produces a third effect in Grunberg's journalism: he makes his reader question what reality is. Not in the sense that he would deny reality exists (as the misguided representation of postmodernism goes), but in the sense of how to make sense of different versions of reality" (63). In the passage under discussion, Grunberg shifts between political, psychological, and physical "realities". ${ }^{16}$ Andeweg believes that these three "different versions of reality chafe" (63), but I would argue that they are not, in fact, different versions of reality; rather, they represent different focal planes of the same reality. Grunberg's - or literary journalists' - ability to switch between multiple focal planes demonstrates a high degree of understanding of their subject in relation to other elements of knowledge. This point will be explicated further in a later discussion. Here, however, I posit that literary journalistic "truth" is discoverable in the spaces between different levels of reality.

Truth, in this sense, emerges from a process that moves from knowledge to understanding to the apprehension of meaning. If meaning can be reapplied to the conditions that gave it rise, it is possible to discern a "truth" in that (re)application of meaning. For example, Andeweg observes that Grunberg is "very aware of the gap between truth and reality":

Grunberg shows that "big" events break down into individual stories, into different realities, and that moral choices are never easy. A call for reality, or realism (factuality), does not necessarily bring us closer to the truth. Realism can be understood as the privileged access to truth only when truth is just conceptualized in terms of the correspondence between representation and fact. Truth and reality are two different things (63).

Andeweg implies here that truth is the product of process. It is not one end of a direct link between fact and truth; a more direct relationship exists between fact and accuracy. Morrison similarly prefers to distinguish between fact and truth rather than fiction, as "facts can exist without human intelligence, but truth cannot" (in Lehman, Matters 33). While still contending that Grunberg is working on multiple focal planes, rather than with different realties, I support Andeweg's assertion that "a call for 
reality, or realism (factuality), does not necessarily bring us closer to the truth." Truth can be a product of the correspondence between representation and fact, when facts are parsed through the process that renders them knowledge, moves to understanding, and allows the apprehension of meaning. Hartsock refers to part of this process when he writes: "facts can only be understood once there is a reflexive understanding of feeling or subjectivity that determines which facts are to be valued" (180). In the reapplication of meaning to reality, (a) "truth" is perceived.

My positioning of Grunberg as representative of dominant contemporary literary journalistic trends is supported by current scholarship. As recently as 2012, Keeble and Tulloch wrote that literary journalists "claim the real". This phrase signifies "an assertion about truthfulness to verifiable experience, an adherence to accuracy and sincerity which practitioners assert are the crucial features that distinguish their narratives from 'fiction'” (7). Keeble and Tulloch also acknowledge that this is problematic:

A demand for realism can be represented as an essentially conservative concept, aimed at repulsing the $20^{\text {th }}$-century postmodernist project in writing. ... In these terms, literary journalism can be presented as a throwback to the idea of a stable text and stable reality that can be narrativised, a refutation of the pretensions of modernism in which eager journalists penetrate to "the quick of what's happening." But many writers would now claim, with David Shields: "Story seems to say everything happens for a reason, and I want to say, No, it doesn' $t$ "' $(7-8)$.

These opposing positions demonstrate that a "demand for realism" takes on different meanings for different practitioners. "Claiming the real" for some literary journalists may mean representing "a phenomenal world that is fundamentally indeterminate" (Hartsock 51), but for others, reality is discoverable, and narrative form is alive to the possibilities of (re)presenting their discoveries. These divisions are recognisable as Eason's "modernist" and "realist" approaches. For the latter group, Keeble and Tulloch suggest "accuracy" and "some explicit reflection in the story about the reliability of information and how the journalist arrives at his or her account"- that is, disclosure transparency — as ways to exercise "a duty of care for the reader" (9). But is this advice effective for literary journalism written in an extradiegetic narrative mode? As contended in a discussion of Eason's study in chapter two, a work of literary 
journalism may or may not reflect a practitioner's ideological position. He or she may well be alive to the theoretical and practical implications of structuring reality in a narrative without signalling their concerns textually. Are first-person narrative modes, therefore, more epistemically responsible than third-person narrative modes that obscure subjectivity?

\section{Objectivism and Subjectivism v Objectivity and Subjectivity}

Works of literary journalism that appear to eschew subjectivity are evidently more susceptible to criticism of reifying and objectifying their subjects than openly subjective narratives. While subjectivity may be evident even in "objective" accounts such as John Hersey's Hiroshima (1946), this text has been criticised by a minority of reviewers-including Dwight MacDonald, Mary McCarthy, and Phyllis Frus - as sensationalist, morally deficient, and provoking condescension in readers because of its narrative mode (see Hartsock 185-7; Boyer 185-7). Frus's criticisms of Hiroshima include its tendency towards narration rather than discourse; a reluctance to interpret; unnaturally impersonal narration causing excessive detachment; lack of critical insight; its rejection of the contingent and historical; and Hersey's admission that he looked for “types" (90-98). Hartsock has observed, however, that Hiroshima's "narrative ambition is still pointed toward narrowing the distance between the subject and the object because of the rhetorical choices made". He continues: "In his own way, Hersey struggles in the direction of attempting to overcome the distance between subjectivity and objectification" (187). Hersey's approach can be accounted for by Code's definition of "objectivism". Not to be confused with "objectivity", objectivism

involves keeping in touch, as closely as one can, with ordinary experience: being humble rather than haughty toward it and taking care not to impose theoretical structurings where the fit between theory and world is not as good as it could be. ... Indeed, objectivism and realism thus construed are virtually synonymous. Objectivism gives the object full reign [sic]. It is directed to and conditioned by the object, and it peruses reality rather than aiming, peremptorily, to conquer it. It is a mode of contemplation: something of a secularized Platonic knowing. Likewise, a realist respects the nature of the object while (in self awareness) coming to know it as well as possible (ER 142-3).

At the heart of criticism aimed at third-person literary journalism is the disquiet brought about when readers lack the data they need to assess the practitioner's 
interaction with the world. This is equally true in the epistemic sense as it is in the ethical sense. But again, these two should not be conflated. Frus, for example, is critical of Hersey's lack of transparency regarding the politics of the narrative's construction as well as the use of his subjects as types; but she does not seem to question whether Hersey knew enough to represent his subjects as he did, and whether he considered (was aware of) the moral consequences of his knowing or ignorance. The text itself eschews such reflexivity, and was initially published in the New Yorker without any significant peritextual information. A publisher's note in Hiroshima's book form sheds some light on the text's epistemic foundation:

In May, 1946, The New Yorker sent John Hersey, journalist and author of $A$ Bell for Adano, to the Far East to find out what had really happened at Hiroshima: to interview survivors of the catastrophe, to endeavour to describe what they had seen and felt and thought, what the destruction of their city, their lives and homes and hopes and friends, had meant to them in short, the cost of the bomb in terms of human suffering and reaction to suffering. He stayed in Japan for a month, gathering his own material with little, if any, help from the occupying authorities; he obtained the stories from actual witnesses. The characters in his account are living individuals, not composite types. The story is their own story, told as far as possible in their own words ("Publisher's Note").

This disclosure indicates that Hersey's approach was objectivist; his narrative is "directed to and conditioned by the object, and it peruses reality rather than aiming, peremptorily, to conquer it" (ER 143). It is perhaps this aim - to avoid conquering the object - that drove Hersey to eschew his subjectivity. While self-awareness is not present in the narrative itself, it is evident in Hersey's approach that he was aware of the impact his subjectivity would have on the account, and that the decision to write "objectively" was made with knowledge of potential consequences, as well as adequate knowledge to represent his subject. Time has also proven this point. Writing forty years after Hiroshima's publication, Hersey reflected that he had been right in his choices of representation: "The flat style was deliberate, and I still think I was right to adopt it ... . A high literary manner, or a show of passion, would have brought me into the story as a mediator; I wanted to avoid such mediation, so the reader's experience would be as direct as possible" (in Boyer 208). In this way, Hersey demonstrates epistemic responsibility towards his subject and his narrative. 
An objectivist approach is also evident in five of the six texts analysed later in this thesis. $^{17}$ Of these, only two texts-those of Adrian Nicole LeBlanc and Dave Cullen-are written in third person. LeBlanc's and Cullen's approaches to transparency significantly impact the reception of their texts; this will be further explored in chapter five. Hiroshima's example, however, demonstrates that an objectivist approach manifesting in an objective mode of narration is not inherently poor epistemic practice - in fact, the opposite can be true. If a practitioner aims to produce an epistemically defensible text, the challenge is to manage the tension between preserving its rhetorical force and providing enough transparency disclosure to facilitate informed reading and analysis. A practitioner may choose not to defend their text's epistemic foundation, in which case it is difficult for critics to carry out their work of reviewing in an epistemically responsible way. To some extent, practitioners who choose this option must be prepared to accept consequent criticism, as critics and scholars understandably assess non-fiction on its paratextual claims.

As with "objectivism" and "objectivity", Code also clarifies the difference between "subjectivism" and "subjectivity":

[T] he former carries negative implications that do not attach to the latter. "Subjectivity" involves recognizing the full person-hood and epistemological centrality of knowing subjects, of which theory of knowledge needs to take account and acquire understanding. "Subjectivism," by contrast, is an outright denial of any normative force to realism; it is Protagorean relativism in its most literal interpretation. ... [It] seeks to conquer what it encounters in the world, aiming primarily to control rather than to understand. To this end, it applies ready-at-hand labels at the slightest indication that they must stick, without due consideration about whether they do, or ought to be made to, fit. Partial explanations are easy; they allow us to move readily about the world and to cope quite well at a superficial level. But they close off possibilities of understanding (ER 142-3).

Here a tension is clear between acknowledging subjectivity and a subjectivist approach. To appropriate Code's definition, literary journalists ought to recognise and acknowledge the full person-hood and epistemological centrality of both themselves and their subjects. Finding a balance here is an important element of epistemic responsibility, as analyses of Helen Garner's and Rebecca Skloot's literary journalism in this thesis demonstrate. In "The Legend on the License" (1989) Hersey captures the subjectivist approach to journalism in the following way: "the reporter [becomes] the 
center of interest rather than the real world he is supposed to be picturing or interpreting. A filter of temperament discolors the visible universe. The report becomes a performance. What is, or may be, going on in 'reality' recedes into a backdrop for the actor-writer; it dissolves out of focus and becomes, in the end, fuzzy, vague, unrecognizable, and false" (266).

Four of the texts analysed in chapters five and six of this thesis openly acknowledge subjectivity in their practitioners' use of first-person narration. A range of ideologiesand reasons - informs the use of first-person narration amongst the four practitioners. None of the approaches, however, could easily be characterised as subjectivist. Rather, an objectivist approach is dominant in each text. Margaret Simons (The Meeting of the Waters 2003) emphasises her subjectivity to demonstrate a larger truth about the relationship between culture and worldview, but ultimately is objectivist in approach. At the other end of the spectrum, Rebecca Skloot resisted writing about her role in her subjects' lives until compelled by her editor to acknowledge her subjectivity in the narrative. This strongly objectivist approach is problematic, however, as will be discussed in chapter five. Chloe Hooper (The Tall Man 2008) and Anna Krien (Into the Woods 2010) demonstrate a more moderate approach towards their subjectivity; but both utilise their subjectivity to guide their investigations and establish credibility with their readers. An author's presence in a narrative does not necessarily signal that they are fully aware of themselves, their motivations, or the effect of their presence in the text. Consequently, acknowledging subjectivity is not an inherently epistemically responsible practice.

This point is well illustrated by Helen Garner's literary journalism. The first major controversy over Garner's work will be explored in the next chapter, but here a discussion of her second book-length work of literary journalism demonstrates the limitations of first-person narration as an epistemically responsible practice. In Joe Cinque's Consolation (2004), Garner covers the criminal trials of Anu Singh and Madhavi Rao, two law students who were accused of murder and conspiracy to commit murder respectively. The victim was Singh's partner Joe Cinque, whom she injected with a lethal dose of heroin after a dinner party with friends. Typical of Garner's writing, her subjectivity is a feature of Joe Cinque's Consolation. Part Two of the narrative begins with Garner's motivation for following the story: 
I understand now that I went to Canberra because the break-up of my marriage had left me humiliated and angry. I wanted to look at women who were accused of murder. I wanted to gaze at them and hear their voices, to see the shape of their bodies and how they moved and gestured, to watch the expressions on their faces. I needed to find out if anything made them different from me: whether I could trust myself to keep the lid on the vengeful, punitive force that was in me, as it is in everyone - the wildness that one keeps in its cage, releasing it only in dreams and fantasy (Joe Cinque's Consolation 25).

This passage indicates that Garner was cognisant of "the full person-hood" and "epistemological centrality" of herself as a "knowing subject" (Code, ER 142) at the time of writing. It would seem that inclusion of such personal self-knowledge indicates epistemically responsible practice; that is, Garner tells what she knows at all costs. She confides in her reader, "I lay on the bed for a while thinking about Anu Singh and her distracted visits home from university. I wondered if $m y$ parents had guessed what was the matter with me, in 1964, when I took the train home to Geelong after I had had an abortion" (Joe Cinque's Consolation 33). And later, "Call that mental illness? She's just like me" (Joe Cinque's Consolation 38). In this way, Garner is the focaliser as she draws readers into her confidence. As Clendinnen has observed, Joe Cinque's Consolation "is lit by confessional introspections into her own darker self, which for her readers, as for Garner, clinch the authenticity and therefore the authority of her judgments" ("Making Stories" 6). But does knowing her self equate with knowing her subject—or the story—well?

While Garner's disclosures about her own life do not invite questioning — in this case she is the authority - her value-laden judgments about Singh's case and the broader issues of law can be queried. Garner's deft and, at times, caustic appraisals of the law and legal processes reveal an epistemic blind spot of her own. She asserts: "To read the record of [a committal proceeding] ... is to be flung back into the same story when it was in a much more sprawling, undignified state, before the Crown and defence teams had taken hold of it to smooth away its rough edges and trim off damaging or uncontrollable bits that did not fit their respective "case concepts" (Joe Cinque's Consolation 170). Here Garner is critical of legal process without engaging with the equally complicated construction of her own text. ${ }^{18}$ In an interview following the publication of the book, she demonstrates an awareness of epistemic choices without reflecting on the consequences: 
The art of it is in choice, but also a kind of inspired and totally legitimate mimicry. And there are times when you have to paraphrase, or the reader will die of boredom. I learnt this the hard way when I was writing Joe Cinque's Consolation-I précis a barrister's whole submission in a murder trial, but still make it sound like talking. Hardest work I've ever done. But it gave me a terrific sense of being in control (in Eisenhuth and McDonald 163).

While Garner's example necessitates - and indeed displays - a high degree of understanding in this situation, her language here suggests an approach closer to subjectivism than objectivism; as Code writes, this is "aiming primarily to control rather than to understand. ... [I]t applies ready-at-hand labels at the slightest indication that they must stick, without due consideration about whether they do, or ought to be made to, fit" (ER 143). The latter point is significant. Many of her critics take issue with the extent to which Garner employs archetypes:

[Garner] confides that her very first sight in a photograph of the young, beautiful woman on trial 'raised my girl-hackles in a bristle'. Behind this instant physical intuition lies the stuff of a hundred fairy tales: the evil lurking behind the fair, young, female exterior; the prickling thumbs which warn bitter men and ageing women that evil has taken fair form in our midst. ... For Garner the heroine of the case is Joe Cinque's mother. When Mrs Cinque cries out in protest in court, Garner says, "there rose from the depths of her a tremendous, unassailable archetype: the mother." ... The mythification of Maria Cinque is necessary, dramatically, for Garner's urgent story-making (Clendinnen, "Making Stories" 6-7).

Rooney also analyses Garner's use of archetypes, contending that Garner invokes the mythic and sacred to "[reproduce] mimetic rivalry before acceding, but only reluctantly and partially, to the antimythicizing Christian demand to exercise empathy with victims, be they sinners or not" (163). She is critical of Garner's use of archetypal narrative patterns and language, particularly the portrayal of Anu Singh as an archetypal witch-figure as Singh and her family refused to be interviewed for Garner's research. Rooney writes: "Immersion in the 'real' of non-fiction, moreover, may inhibit a writer's capacity or willingness to imagine all viewpoints fearlessly. It does seem fair, however, to question the vivid animosity of Garner's narrative against Singh, especially in view of its conversely passionate identification with the Cinques" (162). This is essentially epistemic criticism: did Garner know enough of Anu Singh to (re)present her in this way? Despite the text's strong subjectivity and reflexivity, 
there is no evidence-including her visceral reactions-that Garner had enough knowledge to warrant such a portrayal of Singh.

In a further example of Garner's selective knowledge, Dever cites the dismissal of domestic violence as an issue in the case. She observes: "[Garner] repeatedly dismisses out of hand Anu Singh's claim that she had been 'terrified' of Joe Cinque" (np). In this way Garner engages in the process she denounces in the courtroom: creating a narrative that will reach an audience as a controlled package. The confidential, confessional tone promotes her authority, but obscures Garner's own narrative construction - a smoothing away of rough edges. Joe Cinque's Consolation is a powerful and important book. It is not a source upon which legal judgment can be based, but it does provide a valuable platform for voices lost in the legal system, such as Nino and Maria Cinque. Finally, however, Garner has an epistemic responsibility to "know well", to be guided by all evidence offered in the course of the trial, and to acknowledge limitations in the construction of her narrative. At best, her subjectivity in Joe Cinque's Consolation obscures this responsibility; at worst, these are limits of which Garner does not seem aware, or chooses to ignore. Whether her position is at either of these extremes or somewhere in between, this case does demonstrate that exposing subjectivity is not a reliable indicator of epistemically responsible practice.

A practitioner's approach to their subject is, then, more important than measures taken to reveal the relationship between them. Epistemic responsibility begins with an approach to objects in the world best described by Code's term "objectivism": "keeping in touch, as closely as one can, with ordinary experience: being humble rather than haughty toward it and taking care not to impose theoretical structurings where the fit between theory and world is not as good as it could be" (ER 142). The extreme objectivity of Hiroshima juxtaposed against the strong subjectivity of Joe Cinque's Consolation demonstrates that revelation does not equate to reliability; neither does reflexivity equal transparency. These two examples, chosen for their practitioners' strong approaches, also show that transparency is only valuable when it is based on a responsibilist approach; that is, practitioners must be cognisant of the range of knowledge available — and unavailable — to them as they construct their narrative. As Code writes, "to strive for insight into the extent of one's own cognitive capacities, to distance oneself as much as possible so one can be critical of one's own 
knowing, is a crucially important aspect of epistemic competence" (ER 176). Roy Peter Clark also makes a connection between virtue and epistemology when he writes: "In a culture of media bravado, there is plenty of room for a little strategic humility. This virtue teaches us that Truth-with a capital $\mathrm{T}$ - is unattainable, that even though you can never get it, that with hard work you can get at it - you can gain on it" (np emphasis in original). Epistemic "blind spots" may be inevitable, but a practitioner's approach to the world, and to possible avenues of knowledge, creates a strong foundation for the truth in literary journalism.

\section{Knowledge, Understanding and Meaning}

The relationship between knowledge and understanding has important implications for the theory and practice of literary journalism. Code's approach to epistemic responsibility emphasises the process or effort to achieve end-states of cognition; thus, both knowledge and understanding are modes of interpreting experience (ER 135). Code writes that humans can "structure experience into reasonably coherent patterns of knowledge and understanding, even though we may not know the precise relation of these patterns to the reality they purport to reflect" (ER 133). This is in spite of the fact that "different aspects of what seems to be the same reality are coherent for different people in the same circumstances, and though our control over experience continually meets with limiting cases, reminding us that reality transcends our knowledge of it" (ER 133). Knowledge, then, is apprehended from interaction with the world, and structured into patterns of understanding that cohere with-and modify - previous knowledge and understandings. For Code, understanding is a process rather than a faculty (ER 148). It involves "tying one's knowledge down: relating it to a context, having some conception of the relation of this one 'bit' of knowledge to the rest of what one knows" (ER 150).

Understanding, then, involves a just apprehension of significance and endorses an ideal of seeing things "whole" in some sense. This characterization is somewhat paradoxical, given the unlikelihood or ever achieving perfect understanding, but seeing things "whole" is subtly different from seeing them completely, understanding them utterly. It has more to do with apprehending connectedness and significance. Indeed, one of the reasons understanding is so difficult and so neglected an epistemological concept may stem from its being always a matter of degree (ER 151). 
In this way, understanding, or seeing things whole, is a prerequisite for "right" apprehension and production of meaning. Connecting elements of knowledge produces meaning; that is, connectedness produces significance. Understanding is contingent upon new knowledge and must adjust in relation to it; this does not nullify the possibility of "right" understanding, but does introduce the concept of understanding in degrees.

The relationship between knowledge and understanding is exemplified in a number of literary journalists' reflections on their process of research and writing. Bill Reynolds's informative study of two practitioners, William Langewiesche and John Vaillant, illuminates the process involved in moving from knowledge to understanding and meaning. It also demonstrates that meaning is dependent on understanding. Over time new knowledge can modify understanding; consequently, the meaning of an event must be re-evaluated. The importance of correspondence and coherence is evident in this process. Reynolds bases his article on the contention that "[i]n long-form narrative, the story is rarely simply about the story-it is usually a metaphor for something much larger. While it is true that the best magazine pieces focus tightly on a theme, or in some cases multiple themes, there is always something else underneath the story" (60). He writes of Langewiesche's American Ground (2003) and Vaillant's The Golden Spruce (2005) that "the writers discovered, first in the field and then in front of the computer screen sculpting words from the raw material of fact, the true significance and meaning of their stories" (60). Reynolds's language here is significant:

As they searched for clues and assessed what they had found, the story began to reveal itself. It is only during this creative, artistic part of the process - the "Just what are we looking at here?" part, or the literary journalism part rather than the reporting and researching part-when their stories come to provide a worldview (60).

The terms "discovered", "searched" and "reveal itself" here indicate a belief that meaning is inherent in events and observable, shared reality. The phrase "true significance and meaning of their stories" similarly implies that there may be false, or inaccurate, signification and meaning applied in this process. However, Reynolds also describes the processes of assessing as the "creative, artistic part of the process". Are these ideas incongruous? Is meaning being created here? Or is it being discovered? 
Code's use of the "creative synthesis of the imagination" again helpfully illuminates the beliefs implied in Reynolds's article, and is worth repeating in full:

[Using Kant's concept] it is possible to account for the creative nature of human cognition: a taking and structuring of experience, not a passive receiving and recording. Within the constraints imposed upon this creativity by the nature of the world and of human cognitive capacity, the subjective possibilities of making sense of experience are many and varied. There is a considerable degree of freedom in knowledge; hence, an adequate explication of human knowledge must give scope and grant respectability to subjective factors that structure the process of knowledge acquisition, while preserving an ideal of objectivity, or realism normatively construed (ER 77).

Here "creative" is not synonymous with invention, but rather signifies the process of structuring according to "many and varied" possibilities. The term "artistic" refers to the level of meaning to be attained: abstracting significance and truth requires higher cognitive processes than apprehending and recalling facts. Reynolds indicates as much as he notes Langewiesche's story is simple to start with. It can be summarised in a sentence: "Two very large buildings collapse and a cluster of men spend several months on the cleanup". However, "this deceptively simple story ... suddenly becomes maddeningly complex" (63). Langewiesche describes his framework for finding meaning as derived from his experience as a pilot. The following passage reveals an objectivist approach to the world and to literary journalism:

The aerial view is something entirely new. We need to admit that it flattens the world and mutes it in a rush of air and engines, and it suppresses beauty. But it also strips the façades from our constructions, and by raising us above the constraints of the treeline and the highway it imposes a brutal honesty on our perceptions. It lets us see ourselves in context, as creatures struggling through life on the face of the planet, not separate from nature, but its most expressive agents. It lets us see that these patterns repeat to an extent which before we had not known, and that there is a sense to them (in Reynolds 65).

There is a sense here that Langewiesche attempts to give the object full rein, but is aware that objectivity is limited by perception. This observation is supported by the "Afterword" in American Ground, where Langewiesche writes:

It has been suggested that I must have been glad to be the only writer with free access to the inner world of the Trade Centre site, but the 
opposite is true. There was obviously more happening there than I alone could know or describe. ... The presence of the daily press would have served the useful role not only of informing the public but also clarifying the participants' views of themselves (210).

The metaphor of an aerial view is invoked here again, this time in the form of the daily press as outsiders who are able to provide a wider perspective, and promote reflexivity amongst those immersed in their work at Ground Zero. This metaphor is a helpful one for literary journalists in its implication that perspective can be lost in immersive situations. It is important, for Langewiesche, that practitioners remove themselves from the situation for a time - or seek perspective from other sources - in order to "know" the landscape "well".

The narrative scope for Langewiesche was "readymade", according to Reynolds, "with the attacks [on the World Trade Centre] at the beginning and a ceremony nine months later acting as natural bookends. But still, Langewiesche needed to find the story within these generous parameters" (65). Narrative theorists such as White would perhaps take issue with the term "natural bookends", but the point is that the attack marked the beginning of the World Trade Centre's deconstruction, and the ceremony marked the end of that particular process. Evidently, these points have been chosen by Langewiesche to start and end his narrative, but they could be considered neither arbitrary nor random when considering their impact on narrative closure. Reynolds writes that five weeks after the twin towers fell, Langewiesche "began to see the unfolding drama as a positive story in the midst of so much misery. ... Buried underneath a mountain of man-made junk was the will to create a new world" (67). Langewiesche recalls: "It was obvious to me that we were looking at much, much more. That view came from being on the inside; it was not an external view at all. ... An amazing experiment was happening before our very eyes. ... [Telling this story exposed] to us (the observer, the writer, and then the reader) who we are" (in Reynolds 67). The accumulation and apprehension of knowledge, then, structured into coherent patterns of understanding, produced, for Langewiesche, meaning or significance about the nature of US citizens. The process of understanding and signification, however, did not end there. 
Interestingly, Langewiesche later modified his understanding of the meaning signified by the events he witnessed. Reynolds writes: "He decided he had been too absorbed in the tiny world of Ground Zero during those months of intense, on-site reporting to pay much attention to the George W. Bush administration's exploitation of patriotism and 9/11 for its own ends" (67). This situation illustrates Code's proposal that understanding is a matter of degree (ER 151). Langewiesche's position on Ground Zero afforded him a "whole" view in the sense that he "apprehend[ed] connectedness"- or understood how the elements affected each other in coherent patterns. But his perspective was limited by his position on the ground; time, distance from his subject and new knowledge modified his understanding, which produced a new significance from the events he researched. This example not only demonstrates the transition of knowledge to meaning, but also the importance of both correspondence and coherence to apprehension of meaning. Langewiesche's knowledge accurately corresponded to external, observable reality. It was cohered into patterns that produced significance. However, it was also subject to changes of perspective and developments of knowledge over time. Knowledge is not, therefore, a static end-state of cognition, but subject to the modifying influences of new discoveries, different contexts and changing perspectives.

Reporting does not necessarily end with an end event, but rather a tipping point where a practitioner's knowledge becomes understanding. Asked when he finishes the reporting stage, William Finnegan replied: "When the story seems to have a beginning, middle, and end. When I think that the action, the narrative arc, is complete. But I'm often wrong about that, and more action often takes place while I'm writing. New endings appear. New beginnings, even" (in Boynton NNJ 96). Anna Krien, whose Into the Woods is analysed in chapter six, still felt like more research needed to be done after publication. But, she states, the reporting was finished "when I went back to the island, probably for the third or fourth time, and all of a sudden I could have proper conversations with people. ... [Before that] I was not really understanding" (in Attwood). An analysis of epistemic responsibility should take into account the extent of reporting, and assess the rhetorical situation of a practitioner according to knowledge potentially accessible at the time of writing. ${ }^{19}$ Code makes the point that beliefs are grounded because of what happens in the world: "the practical consequences of holding certain beliefs have considerable bearing upon the 
reasonableness [for an individual at a particular point in time], of holding the belief" (ER 41). An associated point here is that literary journalists are not alone subject to the requirements of epistemic responsibility. The wider epistemic community also has a mandate to approach and analyse literary journalism in an epistemically responsible way; that is, to acknowledge the inherently static nature of books in their consideration of literary journalists' epistemic responsibility.

\section{Epistemic Community and Contracts}

Code identifies community as a fundamental precondition of knowledge. She illustrates the dependence of knowledge-seekers upon community in the following way:

The wolf boy of Aveyron knows little, if anything, of what the "average" human being knows. His ignorance cannot be explained by saying that the world is not there for him to experience and know; nor can it adequately be explained by his not having human language. The most important fact in accounting for his ignorance is that he has had no access to a human community of knowers. I am not suggesting that he knows nothing: clearly he knows a good deal of what wolves know. I cite the example to illustrate the vital dependence of knowledgeseekers upon the epistemic community (ER 65).

Humans are, Code observes, dependent upon each other for apprehending possible and potential ways to structure reality. Yet, "the epistemological importance of this commonplace occurrence is too frequently obscured by assumptions about cognitive autonomy" (ER 192). Epistemic communities are essentially bound by trust. Truthtelling at its most basic level is a primary assumption; to opt out "is to deliberately opt out of a shared form of life" (ER 181). Code also writes that certain epistemic endeavours and circumstances inhere higher standards of responsibility and accountability than others (ER 62). Literary journalism's engagement with phenomenal reality and consequent "truth claims" place it firmly in this category. The epistemic community of a literary journalist may include, but is not confined to: their subject(s), their subjects' communities, fellow practitioners (past and present), critics, scholars, editors, publishers, policy makers, grant committee members, and, of course, readers.

A key point concerning epistemic community is that it needs to be taken into account when considering the "truth claims" of a text. Code writes that "the nature of the 
knower and of his/her environment and epistemic community are epistemologically relevant, for they act as enabling and/or constraining factors in the growth of knowledge, both for individuals and for communities" (ER 26-7). Mainstream journalism has a well-established, clearly defined community with boundaries around what constitutes knowledge. As the previous chapter demonstrates, the literary journalist's epistemic community is still very much developing. Constraints upon what constitutes knowledge, and how it can be delivered in an epistemically-as opposed to ethically_responsible way are still being developed. Consequently, responses from the epistemic community will be taken into consideration when analysing texts in the next three chapters. A corollary but often overlooked point here is that not only the literary journalists, but each of the individuals or groups that constitute the epistemic community also has a mandate to "know well" in the same way that literary journalists are bound by epistemic responsibility.

Code invokes the notion of a contract to explicate the function of an epistemic community. She writes:

The contract analogy is helpful in understanding central features of the way epistemic communities function, but its usefulness does not depend upon its having any discernible, or convincingly speculative, origins. ... I do not conceive of an epistemic contract as an event which creates obligations but rather as a model for understanding the structure and workings of epistemic interdependence. ... This model is useful in explaining the outrage that occurs when trust is violated. It helps account for the conviction that something tangible was violated and that the violator is thereby accountable. ... Legislation preventing false advertising shows that, in the public domain, it is not enough for such agreements to remain tacit. Our sense that it is reasonable to assume that people will provide accurate information, to the general agreement to do so, even where the law is not involved (ER 179).

In the previous chapter I used the analogy of a contract in a similar way. I drew on Genette's term "contractual force" to argue that paratexts can be dynamic sites of negotiation for a literary journalistic contract. Again, Genette emphasises that a reader is not bound to enter into an agreement about how to approach a text, but maintains "only that, knowing it, he cannot completely disregard it, and if he wants to contradict it he must first assimilate it" (Paratexts 408-9). Genette concludes that whether a reader accepts or rejects the negotiation offered, "one is better off perceiving it fully 
and clearly" (Paratexts 409). This is in fact a matter of epistemic responsibility. A reader may be "better off" for perceiving an author's intention, methodology and aims. But readers, and critics in particular, are also responsible for understanding the epistemic foundation of a work of literary journalism as they approach it and offer criticism or praise. Questions such as: "Do I really know what I think I know?”; "Do I know enough to write as I do?"; "What don't I know?"; and "Should I know more or acknowledge incomplete knowledge?" are equally applicable to the criticism as to the practice of literary journalism.

In a general application, Code observes that there are better and worse ways of observing the terms of a contract. For example, an individual displaying exemplary epistemic practice will go beyond

the bare minimum required by the (unwritten) letter of the contract. They would not, for example, disclose only the barest facts when asked if they know about something (the epistemic analogue of working to rule); rather, they would take cognitive interdependence to be a value worth some effort to sustain. The contract model has the scope to account for such qualitative differences. Although the notion of a contract implies a conventional, arbitrary construct, which might well take a form other than it in fact does, this could be true of an epistemic contract only to a point. The degree of possible arbitrariness within a workable epistemic contract is small indeed (ER 179).

This small degree of "arbitrariness" is evidently owing to the limitations imposed by the nature of reality, possible and potential ways of knowing, and arbitration by the epistemic community. In relation to literary journalism, there is, perhaps, a danger that upholding a "small degree" of epistemic "room to move" might constrict or confound one of its defining features: innovation (Sims and Kramer; Kerrane and Yagoda 14). The question arises: Can literary journalists push boundaries in an epistemically responsible way? Code's responsibilist approach suggests that individuals not only can but also should eschew caution and conservatism at times in order to explore new possibilities. "There must be room," she argues, "within the larger sphere where good knowers live, for the Socratic gadfly and for those who take outrageous stances to keep the epistemic community on its toes, to prevent it from settling into complacency or inertia. ... Catalysts of cognitive change play as vital a role in communities of knowers as do conservers of established practice" (ER 56 emphasis in original). While the New Journalism movement as a whole has been 
characterised as carrying out this role within the journalism establishment (see Pauly "Politics"), there are individuals within what I characterise as a comparatively conservative contemporary era, who carry out this role of "keeping the epistemic community on its toes".

An apposite example of two people playing out this role can be found in John D'Agata and Jim Fingal's The Lifespan of a Fact. Published in 2012, the book's genre classification is "Literature/Essays", leading almost all reviewers to treat it as a work of non-fiction (Silverman). The publisher's website promotes the book in the following way:

How negotiable is a fact in nonfiction? In 2003, an essay by John D'Agata was rejected by the magazine that commissioned it due to factual inaccuracies. That essay-which eventually became the foundation of D'Agata's critically acclaimed About a Mountain-was accepted by another magazine, The Believer, but not before they handed it to their own fact-checker, Jim Fingal. What resulted from that assignment was seven years of arguments, negotiations, and revisions as D'Agata and Fingal struggled to navigate the boundaries of literary nonfiction. This book reproduces D'Agata's essay, along with D'Agata and Fingal's extensive correspondence. What emerges is a brilliant and eye-opening meditation on the relationship between "truth" and "accuracy" and a penetrating conversation about whether it is appropriate for a writer to substitute one for the other ("The Lifespan of a Fact" emphasis added).

The blurb on the cover of the book offers almost the same information, but omits the italicized sentences above, and replaces "what resulted from that assignment" with "what emerges is a brilliant and eye-opening meditation on the relationship between 'truth' and 'accuracy' and a penetrating conversation". After the book's publication, it emerged in an interview with the authors that the initial correspondence between D'Agata and Fingal took between six months and year, after which the idea of publishing a book was formed. Fingal continues: "The rest of the ' 7 years' were really the conversation that arose out of that decision, as we elaborated on the material and started having/composing the out-and-out debate that we never really were able to have within the confines of the pseudo-professional relationship we had during the stint at the magazine" (Cutter). Fingal also states: "I must clarify that you should consider the 'Jim' and 'John' of the essay to be characters enacting a parallel process/discussion from the one John and I actually had during the factchecking 
process" (Cutter). The Lifespan of a Fact is thus not the original correspondence between Fingal and D'Agata, but a planned and constructed exchange based on their experience of the initial fact-checking process.

Silverman notes that one of the four reviewers he contacted regarding the book was aware that the exchange was created to attain and fulfil a book contract, that it is "by definition not a reproduction, since the book is primarily made up of text that did not exist prior to the authors embarking on a book project" (Silverman). Interestingly, the one reviewer who "knew the book was not always factual" explained that one signal of its constructed nature was that " $D$ 'Agata has a real history of these sort of literary tricks" (Silverman). This echoes Lawrence Weschler's injunction that readers need to be "intelligent" and "[follow] a person over years. Then you begin to get a sense of that writer, their voice. And you approach it as an adult encountering another adult in the world" (Garfield). But this case also highlights the deficiency of Weschler's explanation: the other three reviewers have no less apparent claim to intelligence, and as none were familiar with D'Agata's work, they read the publisher's blurb as a claim to non-fiction status. The hybrid nature of the genre assignation appeared to have been clarified by the peritext in this case, whereas in fact both the peri- and epitext misled their expectations. Is this a case of epistemic irresponsibility on the part of the authors (and publishers)? Or can this case be considered an effective means of pointing out the epistemic responsibility of reviews to know their subject-and practitioners - well? Are these two positions mutually exclusive?

The paratext enacts the issues raised by the content of the book in this way. The “character" in the exchange, John D'Agata, is striving to create an essay that delivers a genuine experience with art. D'Agata's fact-checker, Jim Fingal, protests against replacing numerous verifiable facts with inaccuracies, such as "four" for "eight" (17), "pink" for "purple" (39), wind direction (24), the phase of the moon (25) and statistics on suicide (52). The latter is particularly pertinent, as the original article recreates the last day of Levi Presley, a 16-year-old young man whose suicide is its subject. "D'Agata" here embodies the intellectually virtuous (knowledgeable) practitioner without displaying moral virtue. He argues that non-fiction is an inadequate term for what he is doing - creating a work of art — and not one that he would apply to his essay. The exchange continues in part: 
John: What we're dancing around here is the idea of moral responsibility in nonfiction. And that's why this sort of conversation always gets me peeved - and why the conversation always ends up in circles - because the moment we start judging a form of art in terms of its "moral value" is the moment we stop talking about art. Just by having this conversation and raising these issues we are disenfranchising nonfiction as literature. And this is frustrating, because we would never be having this conversation about a work of poetry or fiction or drama. Those are literary genres that we recognize, without any question, as literary. As artful. But nonfiction has been struggling to distinguish itself as art for decades in our culture.

Jim: Well, those are literary genres that don't make explicit claims of factual accuracy. Right or wrong, John, people are going to have different expectations of something that's called "nonfiction." There's a perceived difference in the intentionality behind nonfiction and fiction, because nonfiction is supposed to have its feet firmly planted in reality. Isn't that the definition of "nonfiction"? (111)

D'Agata's refusal to capitulate to the expectations set by the term "essay" and the (verifiable) subject matter of his text is based on his intention to produce an experience for the reader that he claims is not dependent on factual accuracy:

John: ... What the term "essay" describes is not a negation of genre-as "nonfiction" does - but rather an activity, 'an attempt, a trial, an experiment.' ... An essay is not a vehicle for facts, in other words, nor for information, nor verifiable experience. An essay is an experience, and a very human one at that. It's an enactment of the experience of trying to find meaning - an emotional meaning, an intellectual meaning, a political meaning, a scientific one, or whatever goal that artist has set for the text (111).

When Fingal suggests that D'Agata give readers "a wink or a nod" (disclosure transparency) to signal his intentions, D'Agata responds: 'I've been giving readers winks and nods for my entire career, Jim. I've edited anthologies, I've written essays, I've given lectures, I've taught courses ... all about this issue. At some point the reader needs to stop demanding that they be spoon-fed like infants and start figuring out on their own how to deal with art that they disagree with" (110). This is clearly intentionally inflammatory, but it summarises D'Agata's position: that non-fiction is a constructed category with which he fundamentally disagrees as it limits the possibility of creating a meaningful experience for the reader. Consequently, he does not feel 
bound to disclose factual inaccuracies to the reader, as he does not identify his work as non-fiction.

The exchange is entertaining, but the original article contains a twist as D'Agata acknowledges that he has replaced facts for rhetorical effect, to imbue them with significance they do not inherently hold. After building a theme around the number nine, based on the (inaccurate) fact that Levi Presley fell for nine seconds to his death, the article finally reveals:

I think we knew, however, that he really fell for eight. ... At some point it came clear that while I was visiting the Presleys that in fact I had not spoken to their son the night he died. It was clear as I left Vegas that some other boy had called. Clear that if I point to something seeming like significance there is the possibility that nothing real is there. Sometimes we misplace knowledge in pursuit of information. Sometimes our wisdom, too, in pursuit of what's called knowledge (99).

D'Agata is not, here, reversing his position and demonstrating that accuracy is important after all. He is underscoring the point that whether facts are distorted or not, it is part of the human condition to imbue details with meaning, which, he believes, is ultimately a work of imagination. Facts, by this reasoning, become negligible, and D'Agata's commitment to his reader is to provide a greater truth than facts alone.

Underlying the arguments made by "D'Agata" in the exchange with his fact-checker is a belief that is not explicitly dealt with by either the character or the author outside the book: that accurate facts cannot be artful. Interestingly, however, the epigraph of The Lifespan of a Fact is split over two pages that inform the text: "True words are not beautiful" (7) and "Beautiful words are not true" (9). These two quotations can be read as opinion or factual statements, but it soon becomes apparent that these lines form the underlying premise of the book. Throughout the exchange, "D'Agata" makes it clear that the facts are not aesthetically pleasing to his sensibility, thus he changes them to provide his prose with rhythm and style. It must be ventured, however, that while he felt the accurate facts limited his style, it could equally be the case that "D'Agata's" style might have changed to accommodate the facts. The premise that stylish prose cannot arise from verifiable fact is subject to opinion-or, perhaps, skill. As one practitioner writes, 
Like other literary journalists, I've found that, in fact, annoying, inconsistent details that threaten to wreck a scene I'm writing are often signals that my working theories about events need more work, and don't quite explain what happened yet. Not tweaking deepens understanding. And getting a slice of life down authentically takes flexibility and hard labor (Kramer).

"D'Agata" also reminds "Fingal" a number of times that he is not a journalist, thereby excusing his lack of notes, attribution of sources, and gaps in his research. However, that he made an effort to base his essay on the phenomenal reality of Levi Presley's life and death, rather than making up an entirely fictional character, suggests that he is aware of the rhetorical power of non-fiction and that he intends to trade on it, regardless of the label applied.

Epitextually, in an interview, (the real) John D'Agata reflected on the fact-checking process of the original article and writing the book, stating:

I think I'm a little more willing to acknowledge that there is a line somewhere that one shouldn't cross, but at the same time, I would still insist that it's a line that only we as individual writers can draw, only we can determine where it is, but that we should look for it. We should be on the lookout for moments when we might be overstepping what's appropriate (Strainchamps).

Should that line be acknowledged in works of non-fiction? The "D'Agata" of the text would argue not. The Lifespan of a Fact plays with questions such as these, but particularly: "What are the moral consequences of my knowing?" Each "character" represents various viewpoints throughout the book, but "D'Agata's" main thrust is that moral consequences are negligible in art, and that epistemic defence and attempts at transparency belie the intention of the non-fiction narrator. One actual consequence of the ambiguous generic status of the book was that many reviewers incorrectly reviewed the book as non-fiction. Interestingly, this is a point the real D'Agata was more willing to concede than his publishers. A wider consequence may be to discredit the genre, and, by extension, practitioners who carefully consider and negotiate their epistemic responsibility. This example also points out that some practitioners may set out to intentionally set a false or misleading set of expectations for their readers. This may be to make a point - as D'Agata and Fingal do here - or in order to garner authority for their text that they have not earned through the research process. But 
finally, The Lifespan of a Fact does challenge boundaries. It has opened a discussion - not least among those who reviewed it as non-fiction- that amounts to an investigation of both practitioners' and critics' epistemic responsibility. D'Agata's approach exemplifies that of "the Socratic gadfly". Code observes that

it is hard to accommodate this kind of thinker within a responsibilitybased theory. No one is inclined to doubt their interest in knowing well; rather, the conceptual problem arises because such projects invite the paradoxical conclusion that it could sometimes be necessary to be epistemically irresponsible, at least in the eyes of the community, to be responsible. Epistemic rebellion, and seemingly outrageous thought experiments subversive of "received" discourse, cannot, therefore, simply be condemned as treacherous or dismissed as irrational by knowers who are responsibly and openly committed to making the best sense of the world (particularly if "best" can be aligned, to come extent, with "creativity" and "inventiveness") (ER 56).

By ending this discussion with such an example, I do not intend to advocate the approach of "D'Agata" as an epistemically responsible one. It does, however, perform an important role in literary journalism's epistemic community. The Lifespan of a Fact illustrates several points central to this discussion: that literary journalists need to be epistemically responsible towards their epistemic communities; that epistemic communities must also maintain a "responsibilist" approach to practitioners (and works) of literary journalism; and that a contract exists between members which can define the terms by which epistemic responsibility may be judged.

\section{The Landscape Re-visioned}

At the beginning of this chapter I identified Aucoin as the first to apply Code's epistemic responsibilist approach to literary journalism. The framework offered here, however, differs from Aucoin's in two important ways. Firstly, I contend that epistemic responsibility should be understood as a complementary approach to literary journalism scholarship, alongside both literary and journalism criticism. The limitations of the discipline of verification are not grounds to discount its usefulness, as demonstrated in Garner's writing. Rather, I argue that verification is critical, not only to substantiate individual texts, but also the field as a whole. Literary readings are similarly vital for the growth of the field as they illuminate embedded aspects of texts and practices that can be overlooked without sustained scholarly attention. Consequently, a theory of epistemic responsibilism offers a balancing function for 
scholarly approaches, rather than eclipsing them. It takes into account both the journalistic and literary aims of a text, and uses a practitioner's knowledge claims about the world as a starting point, rather than a distrust of observable phenomenal reality.

Secondly, my approach differs from Aucoin's in that I recognise the fiction/nonfiction dichotomy; Aucoin finds it problematic at best, arguing that literary journalism should not be subject to the discipline of verification. Consequently, I read Code's comments about "literature" as applicable only to fiction, while Aucoin's theoretical perspective allows him to apply her discussion of fictional works to literary journalism. He uses, for example, the following statement from Code's chapter "Literature, Truth and Understanding" to support his thesis:

Where actual, historical events or characters play central roles in a work, one expects that the research has been done accurately; but there is no outright obligation upon writers, given the long tradition of poetic license, to tell things as they were rather than as they might have been. The onus is thus upon the readers to be sure that any claims they make are responsible (ER 214).

Code's comments here are made in the context of Jane Austen's, George Eliot's, and Charles Dickens's writing. I do not read Code's point in reference to non-fiction's claim to reality; however, Aucoin uses it to support his contention that a writer "is situated as an independent moral agent, responsible for what he writes, and readers, as independent moral agents, must independently decide whether to believe him" (Aucoin 15). While the latter point holds, it does not release a journalist - or literary journalist-from their responsibility to accept the limits placed upon them by phenomenal reality, or to subject their practice and texts to analyses that test those limits. This is one example of several which critically differentiate my approach from Aucoin's: where he advocates narrative coherence and epistemic responsibility, I argue that correspondence and verifiability are equally important.

The "inevitable lag of the critic behind the artist" (Lounsberry xi) has been a major factor in the controversy surrounding literary journalism during the past five decades. The epistemic community has, at times, lapsed in its own epistemic responsibility, but more often the struggle is to understand epistemological foundations on which 
pioneering practitioners base their texts. In this chapter I have endeavoured to revision the contemporary literary journalistic landscape by articulating Code's approach to epistemology, and applying a number of her key ideas to examples of literary journalistic practice. My purpose has been to examine the unique epistemic foundations of literary journalism through the lens of intellectual virtue. A discussion that considers the relationship between knowledge, understanding and meaning, and reality, accuracy and truth, clarifies terms and processes, as well as illuminating rationale behind practice. As Code writes, "Shifting the focus of epistemological enquiry to a study of intellectual virtue and epistemic responsibility will enhance the confidence that can be lent to knowledge claims, even when absolute certainty is taken to be impossible" (ER 67). Code's approach is an important branch of scholarship for literary journalism studies - a branch that has the potential to enhance confidence in the genre's claims to responsibly represent reality. The next chapter (re)examines seminal controversies within the genre. In it I apply Code's responsibilist approach, laid out in this chapter, to better understand the epistemological causes behind perceived lapses in ethics. 


\section{Chapter Four}

\section{Contracts and Controversies: The Limitations of Transparency}

Relativism, representation and the nature of reality are central concerns to narrative theory and the academy. But when an author claims to have produced a work of narrative non-fiction, with all of the implications such a claim carries, theoretical concerns are supplanted by the most elemental and essential of questions: Did she get it right? Is that what really happened? Matthew Kieran writes, "the quest for truth is tightly linked to procedural matters such as checking the authenticity and trustworthiness of one's sources, following up claims made to see if they bear out in fact, constitute plausible if unproved speculation or downright lies, attempting to discover if there are any motivations at work other than those presented" (152). This process is as relevant for subjects as it is for practitioners. As it unfolds, issues of memory, the relationship between writer and subject, investigative methods and writing practices may be scrutinised. The factual status of a text may be challenged on any or all of these grounds. In daily news reports, disagreements over facts or figures are often resolved quickly by confirmation, retraction or correction; lengthier disputes may take longer to resolve but often can be done without intervention by a mediator. ${ }^{20}$ The depth, complexity and bi-referential nature of literary journalism, however, create a distinctive set of issues that are much harder to resolve than by straightforward factual verification. Book-length works further compound epistemic issues, as the sheer enormity of time spent in immersive reporting situations generates and proliferates possible versions of verifiable experience, and potentially deepens an author's sense of their own subjectivity.

Traditional codes of journalistic practice fail to address some of these issues, particularly those of an epistemological nature. There is considerable overlap of the ethical and the epistemological in journalistic standards developed by organisations such as the Society of Professional Journalists (SJP) in the United States and the Media Entertainment and Arts Alliance (MEAA) in Australia. ${ }^{21}$ But as noted in chapter two, these are not binding on book-length works of literary journalism. Indeed, there has been no consensus on, or professional standards drawn for, the 
practice of literary journalism in this respect (see McKay, “Åsne Seierstad” 178). Independent texts also fall outside of the jurisdiction of independent media regulatory bodies, such as the Australian Press Council (APC), which adjudicate complaints when standards appear to be broken. ${ }^{22}$ This of course does not prevent practitioners from adopting their principles. Ricketson observes that Jon Krakauer is the only exception to nineteen leading American practitioners, interviewed by Boynton for The New New Journalism, who endorse professional codes of ethics for daily journalism, and John Bryson is the only exception to Ricketson's own six Australian interviewees who endorse the MEAA's code of ethics ("Ethical Issues" 16). But this observation belies the fact that some practitioners do not consider themselves journalists or bound by conventional codes of practice. One example is the Australian novelist Chloe Hooper, whose experience contrasts with those mentioned above. When researching her first work of literary journalism, she understood herself to be working "outside" the traditions of anthropology and journalism, and had her own code of conduct. She explains, in "every sentence there's a weight that's there. ... At the end of the day, I just felt that I had to tell the truth, and I hope that I've done that the right way" (Warhaft, In Conversation).

Book-length literary journalism is consequently a "no-man's land" in that practitioners have support neither from an institution, such as a newspaper or magazine corporation, nor an established or universal code of practice. As veteran practitioner John McPhee states in The Literary Journalists, "Nobody's making rules that cover everybody" (in Sims, Literary Journalists 15). Nicholas Lemann also notes that many journalists writing their first books are shocked to learn that "Books, unlike newspapers and magazines, often aren't edited or even vetted for accuracy" (in Sims, Literary Journalists 192). Texts are not produced in a vacuum, however. Each new project represents the opportunity for a practitioner to examine their epistemic responsibility and set reader expectations accordingly. Where, then, can literary journalists look for guidance when considering their epistemic responsibility?

Thomas Lake's short work of literary journalism, “The Last Heavy Footfalls of Doc Hullender" (2009), invites an interesting discussion in relation to standards of epistemic responsibility. The article, published in the online magazine Atlanta, is approximately 6,400 words and billed as "How a kid from Gwinnett County became 
an Army medic, served on the front lines of two wars, and faced a question as old as the Earth" (see "The Last"). The subject of the article is the death of Michael "Doc" Hullender, an army medic deployed in Iskandariyah, Iraq, in 2007. Hullender's death is portrayed as futile, as he was running to treat an injured soldier who had already been attended by a medic. This was his first attempt to treat a soldier's wounds in battle, despite nearly nine years in the Army. But the refrain running through the narrative, “Am I my brother's keeper?” produces a polemical quality in the piece; Iraqis are marginalised in the narrative and portrayed as subverting attempts at peace, which subtly raises the question of why was Hullender - an all-American boy-in Iraq at all? Accompanying the narrative is a hyperlink that invites the reader to "read about this story", and links to another webpage in the magazine, where Lake outlines in approximately 1,800 words his sources for the piece (see Lake, “About”). These range from background information, such as "Babylon was a major city on the Euphrates River in what is now southern Iraq", to disclosure of sources, "Kyle told the story of their meeting", to empirical evidence supporting peripheral detail: "Chad said ten Miller Lites was a typical night. One Miller Lite has 96 calories, so ten would contain 960 calories" ("The Last"). Lake demonstrates a clear commitment to disclosure transparency here; his practice reflects the importance of verifiability of the narrative, and at least an equal emphasis given to correspondence as to coherence. But is such a practice viable for long-form narrative literary journalism? Is it necessary? Or even desirable? Readers may or may not choose to explore the link. If they do, does the abundance of detail undermine the rhetorical effect produced by the piece? And, finally, does such emphasis on epistemic defence distract the reader from acknowledging the author's embedded yet powerful pro-American and anti-Iraqi rhetoric — one feature of the piece that is factually unverifiable?

Literary journalism's emphasis on the subjectivity of experience-the practitioner's, the subject's, or both-is clearly a double-edged sword. It sweeps away the illusion of a quantifiable reality produced by objective reporting, but simultaneously opens itself up to criticism on the grounds that its epistemic foundation does not correlate to mainstream journalism's objectivity standard. Here, Code's Epistemic Responsibility provides a strong basis for epistemic enquiry. It has been applied to both journalism and literary journalism in limited ways (see for example Cooper; Meyers; Aucoin), and in this chapter will be applied to controversial cases to assess the epistemic 
responsibility of the practitioners involved. Code advocates reflexive questioning when determining or assessing epistemic responsibility. As Cooper notes, this type of questioning is generalised in the sense that it applies to all human discourse (87), but he employs Code's method specifically to assess mainstream journalistic discourse. It is also applicable to literary journalism - arguably even more so, given that literary journalists must often consider and defend their authority in a way daily journalists do not. In this chapter, questions evaluating practitioners' epistemic responsibility will be applied to various controversies. Questions such as: "Do I really know what I think I know?"; "Do I know enough to act (as I do)?"; "What don't I know?"; "What are the moral consequences of my knowing [or] ignorance?"; and "Should I know more or acknowledge incomplete knowledge?" (Cooper 86) illuminate the epistemic roots of some ostensibly ethical controversial practices. I argue that Code's approach can be employed as a useful framework to guide literary journalists through the process of negotiating their own epistemic responsibility.

The relationship between the author-reader contract and transparency is also emphasized here. As noted in previous chapters, calls for transparency in mainstream media have proliferated in recent years. Plaisance, for example, writes that the Kantian notion of transparency needs to take centre stage in media ethics. In the struggle to "find rational ways to balance competing interests and values, the concept of transparency ensures that all the players, or stakeholders, are speaking the same language" (191). However, the following analyses pose the question introduced at the start of this chapter: is transparency the cure for controversy? And if not, to what extent should contemporary literary journalists adopt transparency as a standard? These cases bring into focus the relationship between knowledge, reality, truth, narrative, transparency, paratexts and author-reader contracts. The analyses in this chapter finally establish an analytical framework for subsequent readings of booklength literary journalism in this thesis.

\section{Janet Malcolm and Helen Garner}

Perhaps the most widely recognised case in which a literary journalist's interpretation of "non-fiction" clashed with the subject's was publically tried between 1984 and 1996 in Masson v. New Yorker. In this case, Jeffrey Moussaieff Masson sued Janet Malcolm, a writer for the New Yorker magazine, for libel over claims that Malcolm 
had both doctored and invented quotations in a profile of Masson for the magazine. The crux of the case was ultimately a discrepancy between Malcolm's and Masson's definition of what constitutes a quotation, and the limitations governing journalists when they represent speech. Malcolm's own interpretation of the case was that it degenerated into a "farcical squabble" about "the degree to which a journalist may function as a writer rather than a stenographer" (The Journalist 157), although the publicity the case attracted suggests that more was at stake than whether a quotation should be transcribed verbatim or not. As Kathy Roberts Forde summarises, the crucial issue involved "the legitimacy of various professionally acceptable methods available to the press in representing reality." She continues:

In a press married to the ideal of objectivity - an ideal underpinning the notion that verbatim quotation is both possible and necessary in the accurate and truthful portrayal of the world as it is-Janet Malcolm's understanding of quotation was ethically suspect. According to the received terms and norms of objectivity, to believe that some kind of translation must occur between speech and the written word was to disbelieve the journalistic premise that a report could correspond objectively and naturally to reality (57).

Malcolm's "understanding of quotation" is framed here as a moral charge: her understanding is "ethically suspect". I would argue that at play here is a conflation of ethics and epistemology, or "semantic overlap" (Code, ER 45). "It is one thing to assert," Code writes, "that we defend our beliefs and conclusions in ways very similar to those in which we defend our moral actions. It is significantly different to assert that our epistemic principles are moral principles tout court" (ER 48). Code's aims are to show that epistemic concepts are not reducible to ethical concepts, and that humans structure epistemological reasoning on an analogy with moral reasoning. "This does not amount to an insistence that we separate the moral from the epistemic uses of terms such as 'right,' 'wrong,' 'good,' 'bad,' 'justified,' 'unjustified'. The point is to understand the similarities and differences in the reasoning processes that warrant the application of these terms" (ER 48). The result of collapsing these categories into each other is an emphasis on the ethical over the epistemic. In fact, the way Malcolm understands quotation is primarily an epistemic issue. In this case, charging Malcolm with an ethical breach obscured the epistemic core of the issue. If her practice was suspect, the charge should be an epistemic misdemeanour; Malcolm in fact acted ethically by acting out her principles. 
This situation invites the question: Can a belief be judged ethically unsound? Code does not insist on separating moral and epistemic uses of terms, but some unpacking is helpful when considering this question. The terms "right" and "wrong" can be used in an ethical sense, working almost synonymously with "good" and "bad". These are essentially value judgements. Epistemically, however, "right" and "wrong" are more closely aligned with the terms "accurate" and "inaccurate", which suggest empirical validity. I would therefore argue that the "semantic overlap" has wrongly indicted Malcolm on a breach of ethics. As Forde demonstrates with a historical analysis of North American literary journalism, Malcolm was acting within a parallel branch of epistemology that is justifiable, if marginalised. ${ }^{23}$

Malcolm articulated her epistemic foundation in the "Afterword" of The Journalist and the Murderer (1990). In a much-quoted passage, she wrote, "This world is not the world of journalistic discourse. When a journalist undertakes to quote a subject he has interviewed on tape, he owes it to the subject, no less than to the reader, to translate his speech into prose. Only the most uncharitable (or inept) journalist will hold a subject to his literal utterances and fail to perform the sort of editing and rewriting that, in life, our ear automatically and instantaneously performs" (The Journalist 155). While the phrase "he owes it to the subject" invokes the ethical dimension of this transaction, the root of the issue here are the cognitive processes of understanding and the apprehension of meaning. This is primarily an epistemic issue. Further explication of Malcolm's position can be found in the trial transcript, where she states: "I think it's wrong to make up quotes if you're writing non-fiction ... I mean, that's one of the rules of the genre ... It's one of its pleasures, too" (in Fakazis 9). The articulation of Malcolm's epistemic foundation, which establishes her belief that "the literally true may actually be a kind of falsification of reality" (The Journalist 154), can be considered what Genette terms a "delayed" epitextual item (Paratexts 330). Clearly, had these beliefs been articulated before the interviewing process began, Masson might not have agreed to participate in the article. Use of this information at the time of publication might have affected its reception; although, along with the New Yorker's established editorial standards, readers' familiarity with, and expectations of, the New Yorker's style were not considered in the trial. ${ }^{24}$ 
Regarding transparency, the Supreme Court found that the Masson profiles offered the reader "no clue that the quotations [were] being used as a rhetorical device or to paraphrase the speaker's actual statements" (Forde 45). In this, the Court correctly identified a lack of peritextual information necessary to negotiate a reading of the article, but it also disregarded Malcolm's belief along with the ideological foundation of the magazine, which arguably functions as epitext for its articles. Readers familiar with the New Yorker's style would arguably not have expected verbatim quotations and understood that literary style necessitates editing and refinement of speech into prose. But, in spite of this, the Supreme Court found for the plaintiff in 1993, concluding that falsity existed in quotations that were altered "so as to change materially the original meaning" (Forde 150). A mistrial was declared when the jury could not decide on damages, and in a subsequent Ninth Circuit court trial, the jury found for Malcolm. The case was finally dismissed by the appellate court in 1996, bringing to an end a twelve-year dispute, but the verdict did little to narrow the breach between mainstream journalistic and alternative, ideologically divergent practices.

From one perspective, a case such as Masson v. New Yorker highlights how-in a court of law at least - the author's intentions, narrative technique and reporting practices are central to a non-fiction text's interpretation and meaning. It also shows the potentially dire consequences of not offering an author-reader contract. In this case, the reader had no peritext to draw upon to inform their reading (or, to define the contract). Written epitextual information was at best general to the publication as a whole, rather than specific to articles or practitioners who were presumably working under the same editors, but operating from different epistemological bases. Perhaps one of the most illuminating aspects of this case was that it was tried in the Supreme Court under the "actual malice" standard, a test which states that false and defamatory factual statements receive constitutional protection unless they are published with knowledge of falsity or reckless disregard for the truth (Forde 85). In both cases, it is the author and/or publisher's knowledge and regard or disregard for the truth that is on trial. This places the author's epistemic foundation in a central position-but in the initial finding against Malcolm, the validity of her belief was disregarded. 
Interestingly, Forde notes that many observers attributed Malcolm's ultimate win "at least in part to her rehabilitated look and demeanor. ... Charles Morgan, Masson's lawyer, told [Forde] that he was not able to convince the second jury, as he had the first, that Malcolm deliberately changed Masson's language to make him look badprimarily because Malcolm presented herself so much better in the second trial" (193). Although it is only possible to speculate here, it is reasonable to draw a connection between the actual malice standard and the jury's trust in the defendant's integrity or character. Forde notes that press coverage of the first trial had described Malcolm as having a "severe bearing" and a "prickly demeanour" which were softened in the second trial by a "more colourful appearance - tailored dresses in soft pinks and greens, white stockings, brown suede pumps, and the absence of gray hair" (193). This is interesting in the light of Code's contention that "intellectual integrity counts as a significant part of the evidence in much the same way as, in moral matters, a person's moral integrity is a determining factor in decisions as to whether she or he should be trusted" (ER 39). Increased emphasis on actual malice in the second trial, accompanied by Malcolm's more engaging look and demeanour, suggests that the jury may have been influenced to consider the issue in terms of the trustworthiness of the defendant.

A year after publication of the disputed article, William Shawn, editor of the New Yorker, claimed that the reporting in the magazine was "as close to being scientific in its objectivity as reporting can be", that the magazine tried to have "no advocacy, to have no prejudices" and that "at the New Yorker not only accuracy but truthfulness is sacred" (in Kornstein 130). Such claims come under Genette's definition for substantial epitext - that is, textual, accessible epitext as opposed to ephemeral "reputation". In the light of disgraced reporter Alastair Reid's claims and the controversy surrounding both Reid and Gail Sheehy, Shawn's comments suggest that he had a blind spot to some practices by New Yorker employees. ${ }^{25}$ These claims were subsequently misleading. Malcolm's narrative techniques may not have been outside the New Yorker's non-fiction tradition, but compression of quotations and altered scenes do not represent "objective" reporting practice, if the goal of objectivity is consistent, reliable, replicable results (Kovach and Rosenstiel 72, 81). 
Throughout this case, Malcolm did not demonstrate evidence that she had considered the moral consequences of her knowing-but not disclosing-her epistemic foundation. Clearly there are ethical issues here in that Malcolm had developed a relationship with Masson without disclosing her opinion or characterization of him in her profile. But as a standard of epistemic responsibility, did keeping both her narrative technique and ideology regarding quotations opaque constitute a break of faith with her potential readers? The final verdict suggests not. The literal consequences in this case were a libel suit and a twelve-year legal proceeding, but the scrutiny of Malcolm throughout this case was evidently damaging to her, both personally and professionally.

Interestingly, Janet Malcolm is cited amongst the strongest influences of Helen Garner, whose first work of literary journalism brings epistemic limitations into question. Arguably Australia's most notable literary journalist, Garner's highly subjective, boundary-pushing non-fiction has provoked critical debate and received both censure and praise from leading Australian intellectuals. Turning to freelance journalism and writing after being fired from a secondary school under controversial circumstances, Garner's first novel was commercially successful but critically reviewed as a thinly veiled autobiography_an assessment she contested until recently (see Byrne). The First Stone: Some Questions About Sex and Power, Garner's first work of book-length literary journalism, was published in 1995. Immediately following its publication, the book caused a highly public controversy over a number of issues, including the author-reader contract, the illocutionary power of the term "non-fiction" and the limitations of journalistic practice. But Garner's book was controversial for reasons beyond these. Firstly, the content of The First Stone was particularly sensitive, being a sexual harassment claim of two young women against the Dean of Ormond College - a prestigious hall of residence at Melbourne University. Secondly, as Malcolm later wrote in a New Yorker review, Garner "showed her hand too early" ("Women at War") by writing the Dean a sympathetic letter before beginning her investigation, before, in an inevitably futile attempt to preserve his anonymity, giving the Dean the evocative pseudonym "Colin Shepherd". Thirdly, as one reviewer contends, Garner's response to the case "was too complex to survive translation into journalism, a danger that the two young women seem to have realised long before Garner when they chose not to speak out" 
(Giles). Willa McDonald also observes that The First Stone pushed boundaries that had not been tested before in Australia. She writes that Garner's work has "provoked censure when it has refused to follow traditional journalistic conventions; chosen not to establish a clear contract of intention with its readership; privileged the exploration of the writer's emotions over intellectual frameworks; and challenged traditional notions of subjectivity and objectivity" (260). And finally, the controversy over Garner's book figured heavily in the culture wars playing out on a national scale. Closely related to the "history wars" cited in the first chapter of this thesis, the "culture wars" called into question hegemonic ideologies and values. Proponents on both sides of the history wars weighed in on The First Stone controversy as it created the perfect storm of issues: the role of subjectivity and interpretation in history/journalism; patriarchal hegemonic dominance in Australian academic/high culture; and the role of journalism in the construction of identity-both metaphorical and literal.

While Garner was — rightly — charged with a number of ethical lapses in her research and writing on the Ormond case, it is again instructive to separate some of these breaches from their epistemic roots. For Code, "The process of acquiring knowledge is as open to evaluation as are its outer, publicly observable products, for 'it is a task to come to see the world as it is'. The manner of performing this task determines the quality of knowledge achieved" (ER 137). This stance is one of epistemological realism, where the goal is "right" perception and cognition (ER 137). It was contended in the previous chapter that Garner carried out her research for Joe Cinque's Consolation with a subjectivist approach. This is also evident in The First Stone. Garner initially framed The First Stone as "an extended work of reportage", but close critical appraisal quickly found that the expectations set by the term "reportage" were not met in the text. Scrutiny of the text began after academic Jenna Mead revealed in a public speech that Garner used six different characters to represent her in The First Stone. Not only was this ethically suspect, claimed Mead, but it created and supported an illusion of a "feminist conspiracy" against the alleged perpetrator of the sexual harassment charge and his supporters - who included Garner (Mead 123). This, and Mead's further accusations, caused a furore amongst academics, journalists and the general public, which was fuelled by vitriolic talkback radio commentary, editorial pieces and scholarly journal articles. 
After rigorous questioning of narrative techniques such as reconstructed dialogue and lack of attribution of sources, Garner was forced to include an author's note at the beginning of seven successive reprints of the book between 1996 and 2005. This, however, did not assuage public anger at the perceived break in faith. Others simply read the book as fiction. One critic, Ann Curthoys, explicitly linked the lack of disclosure transparency as a form of contract in itself. She writes of The First Stone:

I read it from the beginning as a semi-fictional account, based on real events, the fictionality, I thought, being indicated by the dialogue, and the lack of any indication of the relationship of the text to its sources. This, I thought, was immediately obvious: The First Stone adopted the protocols of citation and referencing of neither the journalist nor the historian. I was surprised both by Helen Garner's own claims in various interviews that it was 'nonfiction', and by the shock many people felt later on learning that one person ... had formed the basis for several different characters. To me, it was always clearly a novel, albeit alluding quite openly, as many novels do, to well-known 'real' events (191).

Curthoys was not alone in reading the book as a work of fiction (see Ricketson, "True Stories" 163). The author's note in subsequent reprints conceivably went some way towards clarifying the book's epistemic roots, but for some it caused even more confusion. In it, Garner writes: "I ... encountered obstacles to my research which forced me, ultimately, to write a broader, less 'objective', more personal book. They also obliged me to raise the story on to a level where, instead of its being just an incident specific to one institution at one historical moment, its archetypical features have become visible" (The First Stone np). There is still no mention here of Mead's character being split into at least six; Garner's "less objective, more personal" disclaimer does not engage with the fact Mead exists, and the reference to the story being raised to another level may account for those who read the work as fictionagainst the intention of the author.

Garner's later introduction to True Stories (1997) includes a reflective statement on the author-reader contract. She writes that a writer's non-fiction contract with a reader is different to that of fiction:

A reader of nonfiction counts on you to remain faithful to the same 'real' world that both reader and writer physically inhabit. As a nonfiction writer you have ... an implicit contract with your material and with the people you are writing about: you have to figure out an 
honourable balance between tact and honesty. ... You have a responsibility to the 'facts' as you discover them, and an obligation to make it clear when you have not been able to discover them ("The Art of a Dumb Question" 7-8).

This objectivist statement, however, belies Garner's actual epistemic approach to her subject. Firstly, her interest in the Ormond Case can be evaluated. Code asserts that the question: "Who cares?" is epistemological in the same sense as the question: "Who knows?" She writes that a position of caring (Garner's point of departure for her narrative) "operates from a presumed ... knowledge that the situations in question are appropriate sites for the practice of care; that their participants ... need or want this kind of care; and that the presumptive carer(s) know(s) them well enough to provide the care they require". Further, the question of who cares "calls upon selfproclaimed carers to elaborate the epistemic qualifications - how they have informed themselves, what their interests are - that entitle them to intervene in these people's lives, here and now" ("Who Cares?" 106). Did Garner have access to knowledge about "Colin Shepherd's" needs? Or the complainants'? In the book, Garner almost immediately informs her readers of her epistemic qualifications: "One morning in August 1992 I opened the Age [newspaper] at breakfast time and read that a man I had never heard of, the Master of Ormond College, was up before a magistrate on a charge of indecent assault: a student had accused him of having put his hand on her breast while they were dancing." Garner recounts the "jolt" she got from this "desolate little item", and remembers thinking: "Has the world come to this?" (The First Stone 15). Her first reaction was not to call the newspaper, or Shepherd, to whom she evidently had access, but "women friends of my age, feminists pushing fifty. They had all noticed the item and been unsettled by it" (The First Stone 15). This first step arguably demonstrates a questionable choice in terms of defining an epistemic community. While she had not yet perhaps decided to write on the case, Garner's responsibility as a "knower" is complicated here; her actions also belie the position of care she establishes in the narrative for her subjects and for discovering the "full" story.

I also argue that Garner's practice suffered not from a lack of transparency, but from asking questions that would lead to "right" perception and cognition. She did make clear when she was not able to discover facts-for example, Garner was quite open 
about not having access to the young women who pressed charges. However, she is not reflexive about the way she creates "knowledge". As with Joe Cinque's Consolation, The First Stone is highly introspective; the creation of knowledge relies heavily on Garner's senses. Consider the following the following passage:

Stepping in from the beautiful gardens, with their flowering lines and spring foliage, I felt the halls in their grandeur to be overwhelmingly masculine: spartan, comfortless, forbidding. I had to pinch myself to remember that Ormond College, though originally established for men and their needs, had been admitting women as resident students for almost twenty years. To a passing observer, the presence of women seemed to have left no mark (The First Stone 22).

Mead's blunt assessment reads:

The book substitutes hearsay and innuendo for fact and evidence. Analysis of the events and their consequences is displaced in favour of [Garner's] own fantasies about what might have happened, accounts of her dreams, muddied transcripts of interviews, bits of documents, uninformed attempts at understanding sexual and institutional politics, caricatures of feminism and foggy dates (122).

A similar criticism notes "Garner's description on pages 20-22 of Ormond College itself is long on atmosphere but light on relevant facts" (Ricketson, "Hitchhiking" 95). The "rendering of felt detail" is typical of literary journalism (Connery, Sourcebook 3), but in the absence of critical facts, Garner relies too heavily on such details to create a coherent narrative. Subsequently, and of central importance to this discussion, Garner offers her perceptions as knowledge. This is not inherently irresponsible: Code writes that

for the intellectually virtuous, self-knowledge is as important as, and indeed complementary to, knowledge of the world. To achieve it, one must, presumably, be good at introspection, and this capacity ... can be cultivated in oneself, even though there are crucial conscious and unconscious limitations upon the extent to which self-knowledge can be achieved and/or claimed, even through introspection (ER 57).

The problem here, as Mead has identified, is presenting self-knowledge as a substitution for inaccessible knowledge. Given the lack of access she had to three of the four main parties involved in the Ormond case - the two complainants and Jenna Mead - this is epistemically irresponsible. Evidently, breaches identified by Garner's 
critics were indeed ethical, but I argue that they were the logical product of poor epistemic practice and a lack of reflexivity in vital areas. These can best be characterised as "epistemic blind spots", and stand as cautions to future practitioners.

In summary, these cases highlight Garner's problematic epistemological practice. Rhetorical techniques used in both The First Stone and Joe Cinque's Consolation suggest that Garner did not act epistemically responsibly. Reflexively applying the questions "What are the limitations on my knowledge?"; "Do I really know what I think I know?" and "Have I made claims that I cannot substantiate?"; immediately illuminates epistemic deficiencies. Furthermore, Garner's failure to disclose her practice clearly in initial and subsequent paratextual material lessened the epistemic defensibility of her book. If Code's approach to epistemic responsibility is applied to these cases, it becomes evident that these situations were avoidable. As Cooper states of epistemic responsibility, "In thinking more fully, more deeply, more carefully, we may anticipate and prevent damaging consequences, and evoke an enlightening atmosphere" (100).

Both Malcolm's and Garner's cases demonstrate that while alternative journalistic traditions exist quite legitimately and defensibly alongside mainstream journalism, they do not yet have the weight of recognition necessary to bridge the distance between expectations set by generic labels. In the cases above, writing techniques such as the compression of quotations, split characterisation, name suppression (and choice of pseudonym) as well as the role of subjectivity were contested. The reporting processes of both practitioners were called into question. This process of acquiring knowledge is "a task to come to see the world as it is" (ER 137 emphasis in original). In both cases, the quality and accuracy of the practitioners' knowledge was challenged. Neither Malcolm nor Garner had access to a generic term that accurately set expectations for the narrative techniques they employed, but neither did they provide epistemic defence to bridge the gap between expectations set by generic cues and actual narratives. The Malcolm case itself produced a great deal of epistemic defence for the New Yorker's practices, literary journalism in general, as well as being a catalyst for Janet Malcolm's own manifesto in The Journalist and the Murderer. In Garner's case, The First Stone struck a number of sensitive cultural, moral and ethical nerves, and her lack of disclosure was widely criticised in the 
media. ${ }^{26}$ Each situation did, however, act as a catalyst for the practitioners involved to reflect on their practice and adjust accordingly, with varying degrees of success. ${ }^{27}$

\section{Joe McGinniss and Åsne Seierstad}

If Malcolm's and Garner's cases highlight issues stemming from a lack of paratextual information, the controversies surrounding Joe McGinniss's The Last Brother: The Rise and Fall of Teddy Kennedy (1993) and Åsne Seierstad's The Bookseller of Kabul (2003) illustrate how the opposite can also be true. In the midst of calls for increased journalistic transparency, the following cases demonstrate that disclosing research and writing practices does not necessarily result in decreased controversy. Allen's cautions about the function of transparency inform this discussion. He warns that while disclosure transparency is intended to increase legitimacy and function as a system of accountability, it can also increase criticism rather than understanding (323); it can provide reasons to challenge the authority of the text (326); it may become a substitute for moral reasoning (332), and can be employed to deceive (325) - the last two of which are evident in the following example.

The amount of paratextual information in The Last Brother suggests that McGinniss has gone to great lengths to inform the reader of his intentions, and to defend what he acknowledges may be a controversial rendering of Edward Kennedy's life. McGinniss sets the tone for his narrative with an allographic epigraph from Adrienne Rich's Diving into the Wreck: "I came to explore the wreck... / I came to see the damage that was done ... / the wreck and not the story of the wreck / the thing itself and not the myth / the drowned face always staring towards the sun" (11). Here McGinniss invokes Genette's second and most canonical function of the epigraph, which "consists of commenting on the text [as opposed to the title], whose meaning it indirectly specifies" (Paratexts 157). His intention is to demythologise "the thing itself" — ostensibly Teddy Kennedy — with his book. Much is made of the Kennedy myth throughout the lengthy introduction $(13,20,22,26)$ and particularly the fourpage author's note at the end of the book where McGinniss writes: "Teddy Kennedy is far more than simply a seasoned United States senator from a prominent family. He is our last living link to the Kennedys of Camelot ... Whatever else he may be, Teddy remains the embodiment of the central secular myth of our age ... It has not 
been enough for him to be simply Teddy" (619-20). McGinniss reinforces his intention of dispelling the myth in the author's note, writing "it was in the hope of examining the effect of this phenomenon on the dutiful, resilient, flawed but willing Teddy Kennedy that I undertook to write this book. ... This is my view, and perhaps mine alone, of what life might have been like for Teddy-especially during the 1960s, when he was forced to be not only man but myth as well" (621). The irony here is evident; in undertaking to expose the "real" man, McGinniss has produced yet another "version" or "myth" of Senator Kennedy—his own.

This judgment is reinforced by the narrative techniques McGinniss uses to portray the subjectivity of Teddy Kennedy, including recreated dialogue, free indirect thought report and interior monologue. By the time of The Last Brother's publication in 1993, New Journalism had been out of fashion for almost two decades, but those who remembered the New Journalists' exploration of subjectivity would most likely have remembered claims attending the use of controversial techniques. Defending interior monologue, for example, John Sack explained that "the writer merely had to ask" to know what his or her subject was thinking at any given moment. And in the context of reporting dialogue, he stated, "I hate to use the word reconstructed because [it] means that I make up the conversation ... . But I just mean that ... every conversation is something somebody told me they said"' (in Weingarten 160). From McGinniss's introduction, however, it is evident that he only met his subject once briefly in 1968, spent six days with him in 1973 or 1974, and briefly again on the campaign trail in 1988, without ever having obtained an interview in which these events or dialogue were discussed. ${ }^{28}$ Aucoin questions McGinniss's claimed "stylistic right to leap inside Teddy Kennedy's head" on other grounds, observing that it would not be unreasonable "for a reader to mistrust McGinniss's work, particularly when his ethical lapses from past writing assignments are considered as part of his MacIntyrean accounting” (17). Aucoin is referring to McGinniss's ethical lapses as outlined by Janet Malcolm in The Journalist and the Murderer. Aucoin here invokes professional reputation as epitext that a reader may rightfully employ to inform their reading of McGinniss's work. But are these reasonable grounds to distrust a would-be "knower"? Code asserts that the intellectual character of an agent is of central relevance to how a knowledge claim will be judged, in a process analogous to judgment of moral actions according to the moral character of an agent 
(ER 29 emphasis in original). One might argue that intellectual and moral character are inseparable, but the point was made in the previous chapter that an individual can, indeed, be intellectually virtuous without being morally virtuous. My point here is not that Aucoin's critique is unfounded; rather, that conflation of the categories is common and easily overlooked. At times an ethical critique may be warranted, but in other cases caution must be exercised to differentiate between intellectual and moral virtue. In this case, when epitext, peritext and the narrative itself are combined, it is reasonable to contend that McGinniss not only based his writing methods on flawed epistemological foundations, but, in doing so, he also failed to fulfil his own stated intention, thus defaulting on the extensive author-reader contract proposed in the peritext.

As Jack Fuller notes, critics condemned the 1993 book variously as "an illustration of just how corrupt and decadent our cultural, intellectual time has become," "shameless", "licentious", and "a textbook example of shoddy journalistic and publishing ethics" (News Values 149-50). Fuller further observes that the "intensity of the reaction to McGinniss's book was peculiar, since McGinniss was just a little more candid about his method than most" (News Values 150). Indeed, the peritextual notes form somewhat of a defensive argument for the techniques used and liberties taken. The central issue here is not that the contract established was ambiguous, but rather that it was established on a poor epistemological basis. Despite, or because of, the lengthy justification, McGinniss's aims are both contradictory and misleading. However, I would contend that the (ethical) criticisms of McGinniss as "shameless", "corrupt", and "decadent" are at least contestable on the grounds that McGinniss had justified his practices - initially to himself, and then the reader. His justifications are clearly epistemically unsupportable, but McGinniss's lack of intellectual virtue should be the target of criticism and improvement, rather than his moral integrity.

Another way of reading the negotiation between author and reader in this situation is to see the paratext — specifically, the peritext — as lessening the rhetorical force of the narrative itself. As reader-response theorist James Phelan writes,

In reading, we are, strikingly, both passive and active, as the text acts upon us and we act upon it; the text calls upon - and we respond withour cognitive, emotive, psychological, social and ethical selves (though 
of course different texts will engage some of these selves more fully than others). When I speak of 'experiencing the text,' I refer to this twosided, multi-dimensional, multileveled activity (711).

In a non-fiction contractual negotiation, the paratext acts upon the reader-that is, applies illocutionary force in the manner it instructs or commands-but the reader has the ability also to act upon it. That is, readers create their own framework when they read reflexively. Despite - or, again, because of - the length and scope of McGinniss's peritextual defence, its illocutionary force is arguably lessened with the result that a reader may approach the book within the frame of non-fiction, while retaining a healthy amount of scepticism about the possible accuracy of McGinniss's insights — or the truth value of the book.

McGinniss's project brings into question its status as non-fiction. In The Art of Fact, Lounsberry argues that non-fiction must be solely composed of "documentable subject matter chosen from the real world as opposed to 'invented' from the writer's mind" (xiii). She further asserts that "when the factual accuracy of a work is questioned, or when authorial promises are violated, a work of literary nonfiction is either discredited or transferred out of the category" (xiv). Lehman calls this "rigid police work" (Matters 17) and expresses concern at approaches that "welcome" some texts and "disqualify" others ("Mining" 340). Code's writing on realism and understanding highlights a value judgement inherent in these different approaches: “To construe 'realism' normatively is to declare that the value in knowing and understanding how things are is greater than, and subsumes, the value of holding to favoured theories and cherished views of how they must be" (ER 136). McGinniss's stated aim, in his words, to convey "my view, and perhaps mine alone, of what life might have been like for Teddy" (621) reveals a concerning epistemic foundation, and accounts for the "peculiar" reactions to his frank, transparent disclosures. The "peculiarity" can be accounted for in that objections were not made against the coherence of the text or the value of the disclosure; rather, criticism responded to a flawed epistemic foundation and McGinniss's openness about his methods. Correspondence to reality, in this case, was sacrificed for narrative coherence. This is not a sound epistemic foundation for non-fiction. As Code writes, "One is to be guided in cognitive enterprises by an aim to understand how things really are, however difficult it may be to achieve such understanding. One should not rest 
content with partial, simplified, or distorted accounts when, with greater effort, more adequate and more accurate ones can be achieved" (ER 136). Despite the cases of Malcolm and McGinniss, where no action was taken by publishing houses to reclassify or market the texts as anything but "radical" or "controversial and compelling", subsequent controversies over texts published as non-fiction suggest that public opinion is - to a great extent - with Lounsberry.

Disclosure transparency failed again in a high-profile work of literary journalism in 2003. Despite an extensive author-reader contract, a dispute arose when one of the central subjects of The Bookseller of Kabul (2003) "stepped out from its pages and repudiated the book" (Hill). ${ }^{29}$ The libel claim had multiple aspects that were considered breaches of journalistic ethics. However, here again it is possible to separate the ethical and epistemic strands of the case to gain greater insight into the interplay between the two categories, and reflect further on the impact of epistemic foundations on ethical considerations of literary journalism.

An eight-year dispute against Åsne Seierstad began after The Bookseller of Kabul was published in 2003 and soon became the bestselling non-fiction book in Norwegian history (Topping). The subject of the narrative was a family living in Afghanistan in 2002, whom Seierstad stayed with for four months after obtaining permission to write about their lives. After publication, however, the book's central subject, Shah Muhammed Rais, objected to Seierstad's portrayal of his family and vowed to discredit the book. A lawsuit was eventually filed after Rais rejected a private settlement offer from the publishers (Naughtie). al Yafai notes that "Rais's criticism brings up a range of issues, from breach of trust and invasion of privacy, to a lack of cultural understanding. The questions are whether Seierstad truthfully reported what Suraia [Rais's wife] was thinking (whether it was true) and also whether she accurately reflected Suraia's story (whether it was accurate)" (np). The court initially ruled against Seierstad in July 2010. The judge cited negligence in reporting practice, but the actual finding of guilt concerned a breach of privacy. At the end of 2011, however, an appellate court judge overturned the finding, and Seierstad and her publisher were accordingly cleared of invading the family's privacy and of factual inaccuracy. Following the outcome of the appeal, critics still had concerns about The Bookseller. As al Yafai asked, "How do you accurately reflect a society that isn't your 
own?" (np). Questions such as this signal the cultural gap between the experience of Seierstad - the daughter of a prominent Norwegian feminist - and that of her Afghani subjects. It also brings into focus how the methods of arriving at a belief (epistemology) unavoidably affect the moral product (ethics) of a situation.

Along with al Yafai, McKay (2012) also identifies a number of issues arising from this case. These include the complexities of translation-both linguistic and cultural; the relationship between observer and observed; the technical and practical meanings of informed consent; representation of non-Western societies by western reporters; a journalist's duty of care to their subject(s); and the problems inherent in shaping subjects into characters to promote reader engagement (“Åsne Seierstad” 177-183). McKay recognises that these issues are part ethical-in that they concern the relationship between journalists and their subjects - and part "literary", "since they involve the question of how writers write about other people's experiences" ("Åsne Seierstad" 175). My approach is in keeping with Code's where she asserts that "Moral questions, then, have a central epistemic core that is commonly, but mistakenly, taken to be of a piece with the concerns submitted to moral scrutiny. This confusion tends to obscure a complexity that must be acknowledged" (ER 69). Here I seek to identify how Seierstad's epistemological foundation precedes and informs her literary practice, thus distinguishing between epistemic and ethical considerations while demonstrating their interconnectedness.

One of the significant issues arising out of this case is the use of third person point of view. While this has been cited by al Yafai as a moral issue, the core of its validity is an epistemic matter. Jack Fuller writes of extradiegetic narration: "Of all the techniques [Tom] Wolfe listed that blur the distinction between journalism and fiction, writing from the point of view of another person conflicts most sharply with the truth discipline. Without some intimacy with the characters, newswriting cannot create the feel of a traditional, realistic novel. But with too much intimacy, newswriting accepts a standard of truth that is far too low" (News Values 143). Fuller is responding here to Wolfe's defence of third person point of view, including interior monologue and free indirect discourse-or slipping in and out of a subject's consciousness without overt signalling. In the introduction to The New Journalism, Wolfe explains: "Yet how could a journalist, writing nonfiction, accurately penetrate 
the thoughts of another person? The answer proved to be marvellously simple: interview him about his thoughts and emotions, along with everything else" (The New Journalism 32). Wolfe's defence_-like Sack's—was straightforward, but deceptively so as this case illustrates.

Seierstad immersed herself in the family's life for four months, was purportedly scrupulous in her gathering of information, and, like McGinniss, demonstrated a clear commitment to disclosure transparency. The peritext of The Bookseller contains a seven-page Foreword where the author describes the circumstances under which she met the bookseller and gained permission to write about his family. Seierstad also provides lengthy defence of narrative techniques used, some of which is reminiscent of Sack's and Wolfe's: "When I describe thoughts and feelings, the point of departure is what people told me they thought or felt in any given situation. Readers have asked me: 'How do you know what goes on inside the heads of the various family members?' I am not, of course, an omniscient author. Internal dialogue and feelings are based entirely on what family members described to me" (3). But this simple explanation belies the fact that Seierstad's point of view is effectively hidden by the omniscient narrative mode. It reveals itself only in a reflexive reading. The appellate court did find that Seierstad accurately reported Suraia's thoughts (Topping), but it did not take into account that her thoughts were contextualised according to Seierstad's point of view — one that Rais claims is not held by Suraia. This is an area that even an extensive author-reader contract failed to cover, as the gap between a thought and its expression was implicitly filled by point of view. Here Allen's argument that transparency can be employed as a substitute for moral reasoning can be seen in action (332). The gap was acknowledged in retrospect by Seierstad as a blind spot. ${ }^{30}$ But even if Seierstad had engaged with this issue in the extensive peritext, such discussion would arguably neither have changed the rhetorical effect of the technique in the narrative, nor prevented the claim from being brought against her in the libel suit.

Seierstad's epistemic defence here, that all internal dialogue and feelings were based on descriptions from her subjects, is solid. Between the gathering of information and its presentation, however, is Seierstad's process of understanding — or forming coherence from these facts - apart from the point of view of her subjects, which 
inevitably changes the meaning (and subsequent truth) of the subjects' experience. Seierstad explains in an interview that her decision to represent the family in "a literary way" was intended to "force the reader into the story" and avoid a focus on her own reaction to the extremes of life in Afghanistan (Naughtie). This decision is primarily epistemic: Did the writer know enough to act in the way she did? Unlike Garner's case, Seierstad was epistemically responsible in that she could defend her practice with her research - a position upheld by the legal finding of the case. However, as contended earlier, this mode of representation is ethically questionable, particularly given Seierstad's strong views and the cultural gap between herself and her subjects. As one reviewer wrote, Seierstad's "outrage at the way women are treated in the book crackles on every page" (Hill). Seierstad has every right epistemically and ethically to present her own point of view-but presenting it through the lens of her subjects is morally questionable.

Another interesting epistemic point the culture gap raises is how point of view affects the meaning of facts. A 2010 interview with Seierstad and Rais highlighted divergent understanding of the term "bride price" between the author and her subject (Bennett Jones). Asked if he paid his father-in-law $\$ 300$ for his wife, as the book states, Rais responded that such accusations were "impolite" and "defamed the honour" of himself and his brothers. When pressed, he emphasised that the fact of the $\$ 300$ was not true at all; he paid over $\$ 20,000$ but that constituted costs of the entire wedding, or "expenses and gifts to my wife". Rais's objection to the "very much impolite" assertion that he and his brothers had paid for wives might be grounds to conclude that the dispute was an attempt to defend his honour. But his explanation was that the “payment" (Seierstad's term) was for wedding expenses; in civilian Kabul "they don't sell and buy wives for themselves" (Bennett Jones). Seierstad responded that this point was not disputed in the court case, and demonstrated that her notes showed a direct quote from Rais regarding a \$300 "bride price" She explained: "He [Rais] doesn't like my expression of buying and selling. But when you read the book and you read about the discussions they have, that is how it happens in Afghanistan" (Bennett Jones).

Cowlishaw writes that 'terms such as 'accuracy', 'the facts' and 'a disjunction between knower and known' are not neutral or unambiguous ideas but represent 
culturally and historically specific values. The prevailing value placed on measuring accuracy in quantitative, spatial and temporal terms may preclude the accurate representation of the meaning of an event to the differently positioned historical participants" (211 emphasis in original). Indeed, the term "buying and selling" used here is culturally specific and value-laden. The "truth" it carries for Seierstad coheres with her observations of gender inequity in Afghanistan. Similarly, Rais's explanation is consistent with the way he understands Afghan society and women-the "bride price" is providing for his wife and her family rather than buying them. Correspondence and coherence here are both evident here. The "meaning" of the $\$ 300$, however, is in dispute. In this case, Rais and Seierstad viewed the facts from different positions, affecting coherence, or "the interpretive procedures that allow a reader to transform the details of a text into larger meanings" (Rabinowitz 203). Should Seierstad be held accountable for presenting her interpretation of the bride price's meaning and not Rais's? Her position is epistemically valid. And as there is no standard of practice for literary journalism that calls for balance, if Seierstad is convicted of the truth of her assertion, and the facts are epistemically defensible, she does have a right to represent them as she perceives them. Careful consideration should be given, however, to imbalance caused by the rhetorical force of her own name as author and the disputed narrative techniques. In 2007, Rais also exercised his right to present his point of view by publishing Once Upon a Time There Was a Bookseller in Kabul, essentially a reply to Seierstad's work of literary journalism.

These two cases involving McGinniss and Seierstad bring into question the value of an extensive paratextual contract. In McGinniss's case, the lengthy transparency disclosure was intended to defend the legitimacy of his narrative, whereas it actually leads the reader to the conclusion that McGinniss did not have sufficient access to Kennedy to perform the reconstructions and interior monologue in the narrative. The narrative frame was invalidated by a faulty epistemic foundation and compounded by poor journalistic practices. McGinniss's paratextual defence did not validate his use of techniques such as interior monologue; in this way disclosure transparency failed. He did not have sufficient access to his subject to warrant his "stylistic right to leap inside Teddy Kennedy's head"; thus his defence was unsuccessful. Disclaiming incomplete knowledge of the Kennedy family and Ted Kennedy's situation ("This is my view, and perhaps mine alone") also does not justify poor practice; again, his 
limited access to his subject suggests that the authority often conferred by immersive reporting situations was not conferred to McGinniss. ${ }^{31}$

In Seierstad's case, an extensive author-reader contract contributed to the transparency of the text, but the narrative can still be contested on the grounds that her paratextual disclosure could not counter the rhetorical effect created by omniscient point of view. For Seierstad, the question: "What are the moral consequences of my knowing?" was not considered until after the libel suit. When knowing is more responsible, it is possible that the action might have been different (Code, ER 73). Seierstad later acknowledged that she had not considered the moral implications of (re)presenting the consciousness of Afghani women embedded within the construction of a Western, female reporter. But an examination of her epistemological foundations is also necessary. Seierstad concludes: "Journalism is moving into a different world where we are held to almost impossible standards. In everything I write, ever again, I need to make sure I am 100\% accurate. A journalist can get away with this sort of controversy once, but I can't survive it again” (Hill). This cases raises the corollary question of whether or not literary journalists "own" the stories they tell-a question that will be explored further in the following chapters.

To summarise, an extensive paratextual defence does not necessarily equate to good epistemic or ethical practice; neither does a seemingly thorough disclosure account for the (contested) rhetorical power of a narrative. Possible effects produced by extensive paratextual disclosures are more fully explored in the three analyses in the following chapter, as well as Margaret Simons's The Meeting of the Waters: The Hindmarsh Island Affair (2003) in chapter six. Each of these debuting literary journalists demonstrate far more of an awareness of epistemic responsibility than Malcolm and Garner, but as McGinniss and Seierstad's cases show, disclosure transparency must be carefully considered in terms of what it is hiding, as much as what it illuminates.

\section{Richard Critchfield and Alexandra Fuller}

The limitations of verification are explored in Miles Maguire's article on the literary journalism of Richard Critchfield. Maguire argues that the discipline of verification frustrates the analysis of truth claims in literary journalism scholarship, and highlights 
what Code would characterise as a largely irresponsible epistemic community. According to Maguire, Critchfield's case "provides an occasion to consider the need to find ways to evaluate the quality and accuracy, i.e., the truth, of the journalism that is presented as literary journalism. ... [O]ne of the central principles of journalistic accuracy, the notion of a 'discipline of verification', can lead to serious error and needs modification" (10). The critic's role is a third issue arising here. The epistemic community's response to Critchfield's literary journalism was largely irresponsible, Maguire observes, again because of the limitations of verification. While agreeing with Maguire's underlying premise, I argue that rather than modifying the discipline of verification, Code's responsibilist approach to epistemology offers an additional and effective approach for both the practitioner and critic to assess the truth claims of a work of literary journalism.

In "Richard Critchfield: 'Genius' Journalism and the Fallacy of Verification" (2009), Maguire relates how Critchfield dedicated himself to "village reporting", a form of immersion journalism, late in his career (9-10). This era was highly successful—with the exception of Shahhat: An Egyptian (1978), a book that attracted "a withering academic critique" and credible accusations of plagiarism (10). Maguire notes Critchfield's sincerity and dedication to his field, observing, "if sincerity and craft, [or] good intentions, are not enough to ensure that the journalism half of the literary journalism equation holds up, then proponents of this genre may need to reconsider whether it can be viewed as a form of fact-based journalism" (10). While a number of accusations were made by Timothy Mitchell, a political scientist, Maguire names the "most troubling charge" as one against Critchfield's claim to provide insights into an entire society through the experience of an ordinary family (16). Were the subjects of his book representative? Did Critchfield's observations bear out the paratextual claims that his research subject was "typical of the great mass of poor Egyptians" and that Shahhat's challenges were "exemplary"? (Critchfield xivi) After initially denying the charges, and several years of reflection, Critchfield eventually conceded that these accusations had merit and later wrote that he spent five hours walking through Wimbledon Common trying to figure out what had gone wrong in his reporting: "After all, if you've done a book about the Egyptian character and then discover you haven't understood it at all, it makes you think" (in Maguire 17). 
Maguire observes that systems to ensure truthfulness in literary journalism-such as being transparent, not inventing detail, and being truthful (see Kovach and Rosenstiel; Cunningham; Clark) — had no effect on this case (17). Essentially, the discipline of verification failed here, as it does in other works of literary journalism. Maguire's conclusion is worth quoting at length:

Critchfield's case illustrates a significant gap in the methodological protocols that are used by journalists to get at the truth. The problem with the idea of a "discipline of verification" may be that it encourages journalists to reinforce their own prejudices rather than seeking to overcome them. ... Verification is most often a process of confirmation, so that facts that are verified or confirmed are included and those that are not confirmed are set aside. ... Missing from the discipline of verification, as practiced by Critchfield and others, is an explicit acknowledgment of limits. ... But rare is the reporter who provides such an estimate. After all, journalists are trained to report what they know, not what they don't know (18).

What Maguire identifies as missing here is deeper than peritextual disclosure; he has previously established Critchfield's commitment to transparency (see Maguire 15). Rather, Critchfield lacked awareness of his epistemic limitations. It is his failure to reflect on his epistemological foundation that resulted in a faulty truth claim: that his subject's life was typical of an Egyptian peasant's experience. The questions: "Do I really know what I think I know?" and "Should I know more or acknowledge incomplete knowledge?" would have cast Critchfield's research in a different light and produced a different truth claim. The narrative conceals, for example, the thriving tourism trade occurring in and around Shahhat's village. According to Mitchell, the invisible reporter is a part of this trade (144-5). Critchfield had a responsibility as a researcher to consider the consequences of this knowledge-essentially, that the tourist trade perpetuated a westernised, reified concept of “the peasant". In Mitchell's words, Critchfield's narrative conceals "the multiple ways in which peasants continue to be organized as producers for nonpeasant consumption" (145).

The epistemic community is also a target of Mitchell's critique. Analyses performed on Critchfield's work failed to find fault with the factual adequacy (correspondence) of his work because both Critchfield and his epistemic community failed to ask the right-epistemic_questions. Mitchell lists a number of favourable reviews of Shahhat, which read much like praise of contemporary literary journalism. Some 
examples include: "an excellent dramatization of peasant life"; "enjoyable and readable"; as capturing "the vividness and passionate intensity of Upper Egyptian life"; and "one of the most absorbing accounts of peasant life I have ever read ... it illuminates and confirms the points anthropologists have made about peasant society" (145-6). What the epistemic community failed to consider, however, was how Critchfield's immersive situation facilitated confirmation of his prior beliefs, rather than constituting a process of discovery. 'His 'realism' in the portrayal of the peasant has been supported ... by a mass of reviewers, editors, publishers, development experts, policymakers, grant committee members, and university teachers" (Mitchell 146). Mitchell's criticism of the epistemic community's blind spot is justifiable. Critchfield's approach appeared to be objectivist, but essentially was subjectivist in the application of "ready-at-hand labels" without due consideration about whether they fit, and subsequently closed off possibilities of understanding (Code, ER 142-3). Maguire concludes that "Critchfield's frame of analysis was skewed and there was no way for him to correct for this error within the methodology that he was using" (18). This is particularly problematic for literary journalism, writes Maguire, as books in this genre particularly are not subject to the scrutiny of editing processes that exist at newspapers and magazines (18).

Writing of the relationship between epistemic community and truth, Pauly asserts: "To say a report is true is to affirm that it speaks the consensus of some actual community of interpreters, who read the social conditions in which the story was produced as well as its narrative strategies" ("Politics" 122). This case demonstrates the inverse reality of this statement: consensus can reinforce error in the same way it affirms truth. Again, the value of disclosure is that it offers the community of interpreters a wide scope to assess the conditions of a text's production. But in this case, of all of the epistemic community members assessing Critchfield's work, Mitchell was the only one who asked reflexive questions about the text's construction and exposed faults in its epistemic foundations. The resulting critique revealed a reified, "racist stereotype of the Third World peasant, with all colonial history removed and all the effects of neo-colonialism made invisible" (Mitchell 145). Epistemic communities therefore have a responsibility to be rigorous in their critical practice. 
The relationship between truth claims and epistemically responsible practice is also raised in Alexandra Fuller's first work of literary journalism. Her book did not create significant public controversy despite its ambiguous peritextual frame and her use of disputed narrative techniques. However, the its mixed critical reception and limited commercial success in comparison to Fuller's earlier Scribbling the Cat: Travels with an African Soldier (2004) and the award-winning Don't Let's Go to the Dogs Tonight: An African Childhood (2003) have been directly attributed to questionable use of narrative techniques (see Burrough; Forna; O'Grady). Interestingly, these two earlier books are categorised as autobiography, memoir and travel, genres that arguably lack the illocutionary force embedded in the journalistic label. The Legend of Colton H. Bryant (2008) has been variously marketed as biography, memoir, and literary journalism. Investigated from the oil fields of Wyoming while Fuller was freelancing for the New Yorker, the story of Bryant's life and death on an oil rig has been compared to Truman Capote's narrative style (see Finlayson). But it has also been assessed by Bryan Burrough, a New York Times reviewer, as cheating, although "not ... in the sense that plagiarism is cheating". Burrough continues: "I don't believe Fuller has committed a major felony here, but it's clearly a misdemeanor, even if she comes out and admits it" (np). Whether Fuller has cheated or not, a critical analysis of the paratext and narrative itself highlights issues that are not resolved - and may in fact be heightened-by the divergence between paratextual cues and narrative strategies. Unlike The Bookseller and Shahhat, the paratext of The Legend of Colton H. Bryant reveals epistemic deficiencies rather than setting a solid horizon of expectations.

Marketed by Borders bookstore as "literary non-fiction" and publisher Simon \& Schuster as "biography/literature", the book's strongest initial indication of genre is "non-fiction" (although "literature" possibly complicates that by its association with fiction). Fuller attempts to clarify the book's factual status in an author's note at the end of the book. This position causes it to function as a postface, consequently performing a curative or corrective function rather than framing an initial reading (see Genette, Paratexts 238-9):

This is a work of nonfiction, but I have taken narrative liberties with the text. I have emphasized certain aspects of Colton's life and of his 
personality and disregarded others. I have re-created dialogue and occasionally juggled time to create a smoother story line. ... I must emphasize, however, that Colton's friends and family were never less than honest and open with me and they were endlessly patient and understanding with my questions ... (Legend 204).

Whether the "narrative liberties" are those listed or additional, the "certain aspects" emphasized and disregarded may confuse rather than clarify. Fuller's method in recreating dialogue is not articulated, nor is the reason for anachrony. Further, competing against the book's non-fiction status is a number of paratextual and textual elements. The aim seems to be raising the generic status to - at least - an archetypal American cowboy story. Colin Symes states that a function of a text's title is to provide "signposts to its possible directions and thematic orientations" (20). Under Genette's classification, The Legend of Colton H. Bryant is both rhematic and thematic, in that it indicates genre as well as the central theme or subject. The incongruence here is between the status of legend and non-fiction. The legendary or mythic element is suggested by the sepia tones of the cover which imitate parchment or an old document; similarly, the archetypal status is supported by the stock photograph of father and son (not the subject and his father) in cowboy attire on a dusty road. The archetype is reinforced in the penultimate chapter: "It's as if Colton and his grave stand in for every boy who died too young from the violence of Wyoming's way of life" (Legend 195).

These indicators are further complicated by a list of the book's subjects entitled "Cast of Characters" directly after the contents page. The first intertitle, "A Western", is also a genre marker, which paradoxically fulfils both of Genette's stated purposes for an intertitle, in that it both settles and unsettles generic status (Paratexts 303). Fuller also includes the lyrics to one of Colton's favourite songs, "Feed Jake", as a peritextual element. For the reader who is already aware of Colton's fate, this can be read as an elegy in the tradition of the mournful Country and Western ballad. Each of these elements reinforces the narrative as a "Western", the archetypal nature of Colton and, arguably, the mythical status of his life and death. Juxtaposed against the acknowledgements page (again placed at the end of the book, after the author's note), the cumulative force of peritextual features further complicates the book's status as non-fiction. 
The narrative itself reinforces the mythic dimensions of the text. Fuller establishes an omniscient presence through extradiegetic narration, reconstructed dialogue, interior monologue, analepsis, prolepsis and present tense narration. A sense of immediacy is created by the present-tense mode, decreasing the distance between event and narration, encouraging the reader to be "present" in the role of an observer, and, paradoxically, increasing the authority of the author. The paradox lies in the reflexive reader's awareness that Fuller has never met Colton, nor witnessed any of his childhood, yet she makes observations such as: "Here is Colton H. Bryant at eight years old pedalling so pitiful fast through the streets of Evanston, Wyoming, that his legs look like eggbeaters" (5) and "he took your breath away with those eyes so unnaturally blue they went straight through you and came out the other side knowing more than when they went in" (51). Fuller also includes insights into his thoughts such as: "Colton stared at his plate of meatloaf and wished it had been made by Melissa" (147), a statement that can not be epistemically supported.

The text is structured around two main narrative strands: major life events such as Colton's first hunting trip (10-13), graduation from community school (68-71), meeting his partner (114-18), being employed on the oil rigs (120-24), getting married (144-45); and vignettes of events which caused Colton to reflect on his mortality. The latter events largely occur at the end of chapters and are often punctuated by what John Hersey calls "tag lines". These are "touches of prose, nearly always final lines" from "within the point of view of a character" which hold significance beyond the knowledge of the one who utters them. For Hersey, "this is not reporting; it is projection. And the cumulative force of the projections pushes [books] right out of the country of journalism" (261). Here the problem is not so much with the effect of the tag lines, but with the possibility that they are accurate. A salient example is Colton's exchange with a noisy raven, which ends with Colton throwing a stone at it. The raven continues to gargle in response, and Fuller records: "Colton cocked his fore and middle finger at it. 'Pah!' he said. 'You're dead"' (51). The allusion to death in this sequence is powerful; however, the scene takes place on a hunting trip in which Colton is the only person awake, Jake being "still asleep with his sleeping bag pulled up to his eyes" (50), raising the question of how Fuller came by this information. This is an example of what Heinze terms "paralepsis", or the phenomenon of a narrator 
knowing or sensing something to which they could not have access (282). This is a useful technique in fiction, but is epistemically unsupportable in non-fiction.

The lack of verifiability here lessens the authority and hence illocutionary force of the narrative. This illocutionary force is often characterised as an ambiguous but almost tangible power unique to non-fiction narratives. John Carey calls this "the power of the real" (xxxvi), but it is also referred to by Wolfe (31), Hersey (267), Lehman (Matters of Fact 27, 39), and Harrington (83). According to theorists such as Phelan and Heyne, readers have the potential to subsume such observations through the narrative's coherence; a lack of verifiability does not necessarily negate the authorreader contract. But the point here is that if instances such as these draw the attentive reader out of the narrative, the paratext does not offer helpful guidance as to how the narrative corresponds with reality. Fuller's failure to orientate the reader may account for her book's lack of that elusive power and, thus, its poor popular reception.

The purposes of this genre of writing are many and varied, but Fuller's intention here seems to be most closely aligned with John Hartsock's claim that literary journalism's "purpose is to narrow the distance between subjectivity and the object, not divorce them" (132). Guiding the reader towards a higher level of engagement with the subject, however, without providing appropriate explanations as to how the information was gathered, potentially disengages - or to use Hartsock's termdivorces the subjectivity and the object as the subjectivity is questioned. If Fuller's intention is to evoke a "willing suspension of disbelief" through the generic markers, placing the reader in the story with immediacy and omniscience, the reader's experience is actually complicated by Fuller's claim to non-fiction status. Again, it should be emphasised that it is not the use of individual techniques, or their cumulative force, that potentially affects this break. It is rather the contradictory claims in the peritext — and narrative itself — which activates metatextual questioning and may divorce the text from its subject.

In the cases discussed above, practitioners offered epistemic defence, but the disclosures offered a faulty or contradictory horizon of expectations. Fuller's disclosure was ambiguous and, as such, essentially worked against the validating effect both practitioners were attempting to achieve. That both attempted to provide a 
statement of transparency indicates that the practitioners were cognisant of their responsibility to acknowledge their epistemic responsibility, but neither author's notes bridge the gap exposed by the question: "Do I know enough to act as I do?" The most obvious consequence of this gap between knowledge and the content of their narratives is that readers will approach such texts as fictional, or "based on a true story" as Curthoys and others read Garner. Another concern for practitioners might be poor reviews or critical reception, although this does not inherently affect a book's popular reception, as Critchfield's case demonstrates.

\section{The Challenge of Epistemic Responsibility}

A number of questions were posed at the beginning of this chapter. Kathy Roberts Forde, writing on the Masson v. New Yorker case, has stated that "transparency, not objectivity, may well be the news value that we most need in our postmodern age" (218). Is transparency the cure for controversy? And if not, to what extent should contemporary literary journalists adopt transparency as a standard, if at all? Thomas Lake's article about the death of a US army medic demonstrated a commitment to disclosure transparency that would be difficult to emulate for many practitioners, and virtually impossible for practitioners of book-length literary journalism. The cases in this chapter demonstrate that disclosure transparency does not indicate epistemic responsibility. Indeed, transparency is not the cure for controversy. In some cases paratextual disclosures can obscure poor journalistic practice, mislead or confuse readers about the truth claims of the text, or interrupt a reader's engagement with a text. Conversely, non-fiction texts without author-reader contracts leave readers without a frame of reference with which to guide their reading experience.

In each of the cases in this chapter, I have examined the epistemic responsibility apart from the ethical charges made by critics. Malcolm's case highlights the fact that it is possible to have a sound, defensible epistemic foundation, but failure to disclose or defend practice can manifest in a charge of poor ethical practice. Malcolm had sufficient access to her subject to make her truth claims, and was eventually vindicated in her assertion about Masson's character and the meaning of his disclosures. Garner's The First Stone demonstrates what I have called here "epistemic blind spots"; that is, failure to be reflexive about the way knowledge is created. By drawing on her own experience to fill the holes left by inaccessible 
subjects, Garner creates a coherent narrative that clearly lacked correspondence with the reality of the young women's situation. Similarly, Joe McGinniss lacked access to his subject, but, unlike Garner, attempted to render his process as transparent as possible. Disclosure transparency cannot, however, remedy a faulty epistemic foundation. Åsne Seierstad showed an awareness of both her ethical and epistemic responsibility in the paratext of The Bookseller. The controversy over this book demonstrates that she had not considered the relationship between the two strands. And although she stands by her book as an accurate portrayal of life in Afghanistan for the bookseller's family, she is wary of using a literary form in such a reporting context again.

Richard Critchfield's Shahhat similarly demonstrates the deficiency of an extended author-reader contract, as well as highlighting the responsibility of a practitioner's epistemic community. The book's first detractor, Timothy Mitchell, had the same amount of information to draw from as other experts in this field, yet he was the only reviewer to ask questions that ultimately rendered Critchfield's "truth claims" unsupportable. And finally, Alexandra Fuller's first work of literary journalism is an instructive example of an ambiguous contract. It shows how paratextual elements such as titles, intertitles, and epigraphs need to be consistent with any epistemic defence (such as author's notes) and the narrative itself. Coherence between text and paratext is consequently as important as the narrative's correspondence to reality.

These cases also show that readers are not limited to paratextual disclosures to inform their reading of a text. They may also consider wider sources such as personal reputation, as in the case of Joe McGinniss; publication status, such as the New Yorker magazine's famed fact-checking reputation; as well as subjects of the books themselves, as demonstrated by Shah Muhammed Rais's libel claim against Åsne Seierstad and Jenna Mead's fierce and very public vilification of Helen Garner. All of these elements help to compose the reader's horizon of expectations. How, then, can literary journalists fulfil their epistemic responsibility? On what can first-time writers, in particular, draw to negotiate the author-reader contract?

The starting - and perhaps most obvious - point is that practitioners must first want to produce an epistemically defensible text. Readers should not assume that this is 
always the case. But for those who would attempt to determine whether their text is based on a firm epistemic foundation, it is contended in this chapter that reflexive, Socratic questioning forms a useful framework to work through this process. The answers to questions such as "Do I really know what I think I know?"; Do I know enough to act as I do?"; and "Should I know more or acknowledge incomplete knowledge?" reveal gaps in the epistemic foundation of a text, which then can guide the practitioner's disclosure transparency in the paratext. The point here is not to, as Cooper puts it, "force a rigid prescriptive epistemic ethic" upon practitioners (86). Rather, the intention is to acknowledge the inherent tension in each unique work of literary journalism that needs to be resolved, and to propose a way for practitioners to reflect on — and defend - their epistemic responsibility.

As such, these questions will guide the analyses in the following chapters. The discussion about the texts from the United States in chapter five, and Australia in chapter six, will consider the extent to which epistemic defence is an issue for contemporary literary journalists at a deeper level. The readings of these texts against their paratextual frames will provide case studies to inform pedagogy and practice for future literary journalists_ — and their epistemic communities. 


\section{Chapter Five \\ Epistemic Responsibility and the New Gen}

\section{The New Gen: 2000-2010}

At the 2000 Lukas Prize Project Conference, Robert Vare of The Atlantic Monthly and the Nieman Foundation addressed scholars, writers and students. He stated that while the magazine industry was weakening in the US, "prospects for narrative nonfiction writers in the other traditional source, book publishing, are exceptionally strong right now, as any glance at the weekly bestseller list over the last five or 10 years will attest." He continued, "if the 1980's defined a streamlined razzle-dazzle newspaper era of USA Today-style news bites and factoids and charts and graphs, where the sidebar became the main event, the hallmark of the last decade has been a growing fascination with long-form storytelling" (Vare). In the decade since, a new generation of writers has taken up the mantle of literary journalism. Among the book-length works of literary journalism published by American authors between 2000-2010, Adrian Nicole LeBlanc's Random Family (2003), Dave Cullen's Columbine (2009), and Rebecca Skloot's The Immortal Life of Henrietta Lacks (2010) represent both the influence and the spirit of the New Journalists, in that they seek to engage their readers with social realities through both the content and form of their narratives-albeit more conservatively than their predecessors. Movement away from techniques such as composite characterisation, experimental vocabulary and design, and heavy symbolism employed by practitioners such as Wolfe, Mitchell and Didion signals a more careful, widely appealing style of literary journalism for the twenty-first century.

If the New Journalists were "settlers" (Whitt xii) in an area they believed to be terra nullius, the "New Gen" of literary journalists might be seen as occupying the territory settled a generation ago. This is not typically a comfortable occupation. Issues manifested in (post)colonial experience are reflected in contemporary literary journalism: ownership of the land (or ownership of the story); the relationship between the land and its first and colonising peoples (or the relationship between story, subject and writer); and negotiation of colonial authority over the land (or the practitioner's authority over the story). In this context it is easy to see how literary journalists have a moral responsibility to carry out in relation to both people and their stories. But what 
is the epistemic responsibility of contemporary literary journalists? Objectivity rituals are accepted ways of achieving legitimacy in mainstream journalistic truth-telling; they define and normalise the scope of epistemic enquiry (Karlsson 536). How, then, can literary journalists understand their relationship to the nature, sources and limitations of what can be known? Does it require, as Kramer suggests, an implicit covenant with readers and sources about accuracy and candour (1995)? Is it, as Aucoin proposes, disconnected from the standards of accuracy and verifiability (2001)? Or is “internal vigilance" —which Jane Singer claims is journalists' preference- the best way to ensure accountability and protect truth claims? The previous chapter examined epistemological issues in a number of well-documented controversies, and I contended that these must be considered in addition to-rather than as part of-ethical considerations. In this chapter I explore how American practitioners, who are representative of a contemporary conservative movement of literary journalism, negotiate epistemic responsibility, given the genre's controversial past and the proliferation of platforms for epistemic defence. I offer readings of three author-reader contracts, engage with critical responses to the texts, and suggest how these analyses can inform current and future practice of literary journalism.

The "New Gen" faces cultural and technological issues that could not have been imagined by the New Journalists of the 1960s and 1970s. As noted by journalism scholars, contemporary advances in technology are changing how journalists fulfil the democratic public service function (see Fuller 2010; Gans; Schudson 2010). A new communications culture necessitates that journalists provide a different kind of context and explication of issues for readers:

As citizens encounter an ever-greater flow of data, [readers] have more need - not less - for identifiable sources dedicated to verifying that information, highlighting what is important to know and filtering out what is not. Rather than expand the time they spend sorting through information themselves, a task that becomes increasingly timeconsuming as outlets expand in number, people need sources they can go to that will tell them what is true and significant (Kovach and Rosenstiel 48 emphasis added).

These two issues, truth and significance, are central to the theory and practice of literary journalism. Writing about "first wave" practitioners Stephen Crane, Lincoln Steffens and Hutchins Hapgood, Connery notes that a literary journalistic account "did 
not just record and report, it interpreted as well" ("Third Way" 6). Practitioners "gave 'passing things' meaning and context by going beyond the facts, beyond the expectations and requirements of daily journalism and newspaper copy editors" ("Third Way" 9). But newspapers and magazines, literary journalism's traditional sites of publication, offered few avenues for paratextual information. Historically, epistemic defence has largely been embedded within narratives, difficult to access epitextually, or even hidden from readers, as evident in the Masson v. New Yorker case. Although epistemology was a central concern for the New Journalists, there was no consensus on how-if at all-practitioners disclosed their epistemic foundation, methods of gathering information, writing practices and position in relation to their subject. Pauly observes that while conventional journalism pursued cosmopolitan ideals such as objectivity, the alternative press privileged writer-reader relationships and connected itself to readers in specific local worlds ("Politics" 124). He uses the term "communitarian" to describe the covenant New Journalists had with their readers ("Politics" 124). This convention remains. But controversies outlined in the previous chapter indicate that if literary journalism challenges assumptions of how the phenomenal world should be perceived, consideration should be given to alternative ideological foundations. "New Gen" literary journalists increasingly reflect an awareness of this need. As this chapter demonstrates, contemporary American practitioners use multiple paratextual avenues to offer epistemic defence for their narratives, including online platforms which make participatory transparency possible.

Small samples may inhibit the possibility of drawing totalizing conclusions; however, the texts analysed in this chapter are representative in that they exemplify a range of differences typical of literary journalism. These include the practitioners' backgrounds; authorial intention; mode of narration; chronology; structure; peritextual features; and epitextual features such as online companion sites. They also highlight epistemic issues triggered by immersion reporting, a crucial feature of literary journalism practice when considering epistemic responsibility.

\section{Random Family: Adrian Nicole LeBlanc}

In 2003, Adrian Nicole LeBlanc joined reporters such as Steffens, George Orwell and Leon Dash in the powerful tradition of advocacy journalism. Random Family: Love, Drugs, Trouble, and Coming of Age in the Bronx follows the lives of four Puerto 
Rican youths, Jessica and Boy George, Cesar and Coco, growing up in New York. A product of over a decade of immersive journalism, Random Family was named one of the ten best books of the year by The New York Times Book Review, was a finalist for the National Book Critics Circle Award, and won the Anisfield-Wolf Book Award for non-fiction in 2004. The book was conceived in the late 1980s while LeBlanc was reporting for The Village Voice on Boy George's rise and fall as a heroin dealer. Fascinated by the extraordinary success of the "Kid Kingpin" and the women in his life, LeBlanc immersed herself in a poverty-stricken sub-culture for the next decade to try to understand the subjective experience of individuals behind the statistics.

Authorial intention is one feature that distinguishes LeBlanc's narrative from Steffens's, Orwell's and Dash's. As LeBlanc explains, "What interested me was less the details of the drug business, but what it felt like to be a young Puerto Rican kid from the Bronx who was able to fly to Hawaii with his girlfriend at the drop of a hat. ... I wanted to know what happened when these different worlds knocked up against each other" (Boynton, The New New Journalism 236 emphasis in original). Her desire was not only to know, but also to convey phenomenal reality from the perspective of the subject. Literary journalism scholar and LeBlanc's mentor, Mark Kramer, states that the point of immersion is to "comprehend subjects at a level Henry James termed 'felt life' - the frank, unidealized level that includes individual difference, frailty, tenderness, nastiness, vanity, generosity, pomposity, humility, all in proper proportion" (23). For this reason, LeBlanc writes in an extradiegetic mode of narration, prompting reviewers to observe that Random Family reads "like a novel" (see Wypijewski; Horst). While experience is mediated through the writer's sensibility in Steffens's The Shame of the Cities (1904), Orwell's Down and Out in Paris and London (1933), and Leon Dash's Rosa Lee (1996), LeBlanc's extradiegetic narrative mode emphasises the experience of her subjects. As discussed in the following analysis, this mode raises epistemic questions about the possibility of representing the truth of others' experience, rather than one's own.

LeBlanc's responsibility to disclose the scope and limits of her knowledge would seem strong given this narrative mode. Her presence is eschewed in Random Family despite the fact that she spent ten years in an immersive reporting situation. This is, perhaps, unsettling for some readers and critics, given that LeBlanc intermittently lived with 
her subjects, "shuttling children to welfare appointments" and becoming a part of the increasingly random family (Farley). A feature of the book's epistemic defence, however, is its brevity and general nature compared to The Immortal Life and Columbine. Dust-cover reviews variously describe the book as "a seminal work of journalism", "a painstaking feat of reporting", and "a non-fiction Middlemarch of the underclass". Non-fiction status is also made explicit in the author's note where the terms of the contract are defined:

This is a book of nonfiction. I was present for much of what is depicted here; some scenes were recounted to me. Hundreds of hours of written and tape-recorded interviews were supplemented with other research, including court transcripts; medical, academic, financial, legal, police, and prison records; and personal letters and diaries. ... Some of the dialogue has been taken from government wiretaps transcribed by me. Recollected experiences and exchanges were assembled through primary- and secondary-source interviews and visits to locations. In those cases where someone is said to have "thought" or "believed" something, those thoughts and beliefs were described and recounted to me by that person. There are no conflated events or composite characters in this book. Only the names of some individuals have been changed (405).

LeBlanc widened the epistemic scope of her research by studying criminal law, drug policy and sentencing guidelines, and interning at a New York State court that handled A-1 felonies, all of which are disclosed in the author's note (405).

The interplay between the peritextual disclosure transparency and narrative is not, however, straightforward. The statement that sheds light on the verifiability of dialogue, for example, is complicated by narrative techniques such as indirect thoughtreport with limited-perspective narration, blurring point of view and producing a sense of objective omniscience. The question raised here: "Whose knowledge is this?" is of primary analytic importance, according to Code. When working with a concept of knowledge as a construct produced by "cognitive agents within diverse social practices and positions of differing power and privilege, epistemological pretentions to disinterested objectivity have to be re-examined and deconstructed" ("Who Cares?" 105-6). While paratextual information suggests that disinterested objectivity does not describe LeBlanc's approach, the mode of narration invites this type of analysis. The following passage illustrates this point: 
Sister Christine wanted to tell Coco, Get away from your family. But she couldn't. Not everyone could clamber onto a lifeboat from a sinking raft. You either made your way by hardening up, like Iris, or you stayed stuck. Coco didn't see a choice. She admired Iris's accomplishments, but she couldn't live like that. Nor could she be like her older brother, Manuel, who dressed himself better than his children. Coco couldn't ignore the people she cared for, which is why Foxy and her little brother Hector turned to her first for help. The word that came to Sister Christine's mind whenever she thought of Coco was enmeshed. Coco would have said that she had heart (148).

In this passage, thoughts of the subjects and judgements made by the author/narrator are seemingly impossible to tell apart. The author's note clarifies somewhat: "thoughts" and "beliefs" were described and recounted to LeBlanc by the person who held those beliefs (405). Read in this context, this entire passage reads as indirect thought report of Sister Christine, with the exception, perhaps, of the last sentence. Is this a despairing acknowledgement from Sister Christine, or an authorial rebuttal of LeBlanc's? This is unclear. However, that "Coco would have said that she had heart" coheres with Coco's characterisation, and given both Sister Christine and LeBlanc's intimate knowledge of Coco and her history, either interpretation is epistemically supportable. This example of thought and speech report is typical of LeBlanc's seamless transitions between observation and focalisation; however, some passages are more difficult to differentiate. The following extract is an apposite example:

Cesar complained about prison, but it sometimes seemed easier and more fun than Coco's life. Cesar had no children to feed and bathe and dress; he had no worries about basic necessities; he lived in a dorm with his friends. ... Coco's limitations were her failures; but Cesar's immobility was the prison's fault. And Cesar still dictated the terms of the relationship — to choose her or cast her aside (153).

LeBlanc's disclosure does not cover narrated passages such as these. The ideas are insightful, but it is unclear whose knowledge is represented, or who is making judgments here. Is this problematic? Code suggests it is. "Questions about who knowers are, how they are located with respect to 'objects' of inquiry, are integral to analyses of the production and justification of knowledge claims" ("Who Cares?" 106). The preceding paragraph is clearly LeBlanc's voice. She reports: "Coco composed long letters in reply. She also copied by hand letters Cesar sent her to forward to his incarcerated friends. ... These communications suited her indirect style" (153). However, the passage in question could represent Cesar's judgment of Coco: 
his critical attitude towards her is a motif throughout the narrative. It could also be Coco's, as she would likely have reflected on the differences between her hardships and Cesar's to LeBlanc. But the absence of indicators of indirect thought report also suggest these might be LeBlanc's observations. The question remains: Are these LeBlanc's, Cesar's, or Coco's judgements? Whose knowledge is offered here? This is finally ambiguous.

Questions of "truth value" result in passages like this throughout the narrative. From the disclosure in the author's note, the reader cannot verify that the "knowledge" on offer - that Cesar's incarceration was preferable to Coco's day-to-day living in the Bronx; that Coco's limitations were her failures; that Cesar's immobility was the prison's fault (rather than a result of his own behaviour) — is LeBlanc's. Is it accurate? Is it truthful? I suggest that the former question applies if this knowledge is being reported from Cesar's or Coco's perspective; the question of "truthfulness" comes into play if it is LeBlanc's knowledge on offer here. The ethical question raised in the last chapter by Seierstad's case is also at work here: Does LeBlanc have the (moral) right to represent the experience of others in passages such as these? But the project in this thesis is to examine the epistemological foundation of literary journalistic texts: Is LeBlanc's representation epistemically responsible and defensible? If this is indeed her knowledge, does her scope of enquiry legitimate such knowledge and judgments? Or simply: Does she know enough to report as she does? When attempting to answer these questions, the author's note does provide a solid epistemic defence. Ironically, the section on "thoughts" and "beliefs" is not helpful. But the scope of LeBlanc's research - the decade of immersion with Cesar's and Coco's families - indicate that LeBlanc indeed has access to such knowledge, and is in a position to make judgements such as these. The depth and complexity of reported relationships, events and their meanings throughout the narrative further deepen the authority and increase the defensibility of its epistemic foundation. This brief example demonstrates that where the discipline of verification fails, questions of epistemic responsibility can be effective to judge the "truth value" of knowledge offered.

The necessity of asking "Whose knowledge is this?" indicates that LeBlanc's presence is discernable in the book, despite the narrative mode. For Weber, the absence of "I" is a matter of appearance in prose, but specifically literary non-fiction. Selection and 
arrangement of material reflects the reporter's presence-the writer is a "reporting angel" (see 73-88). Code similarly asserts "there is no good reason to believe that knowledge as product could fail to bear the mark of its producers, or of the process of its production" ("Who Cares?" 106). In this case, the reader must rely on the observations and subsequent analyses of LeBlanc as a reliable narrator, without extensive notes to verify the narrative, such as used in Columbine. The effect of Cullen's notes section will be analysed later in this chapter. But here the illocutionary force of the contract calls for the reader to trust LeBlanc if, indeed, analytical passages are not directly sourced from the thoughts or dialogue of the reader. In this sense, compared to Cullen's and Skloot's texts, LeBlanc relies least on paratextual explanation, and consequently most heavily on trust. But this is not necessarily prohibitive. Allen quotes Onora O'Neill when he suggests that an increase in transparency does not necessarily lead to an increase in trust. In fact, O’Neill contends that "trust precludes rather than requires transparency" (in Allen 325). This is a moot point. But in the absence of clear indicators of a text's production, "Questions about who knowers are, how they are located with respect to 'objects' of inquiry, are integral to analyses of the production and justification of knowledge claims" (Code, "Who Cares?" 106). Here LeBlanc follows in the footsteps of her predecessors, including Jacob Riis, Susan Sheehan and Alex Kotlowitz (Boynton, The New New Journalism 230), who rely on their reportorial practices and professional reputation rather than paratextual disclosures to defend their knowledge and truth claims.

At other times, LeBlanc's authorial voice is clearly discernable, as is her "location" with respect to her subjects (Code, "Who Cares?" 106). These are rare passages of narrative transparency, but all the more rhetorically powerful for their thematic and symbolic value:

[Cesar] smothered [his daughter's] hurt feelings with hugs, making it into a game, drowning out her crying with laughter and kisses and silly smooching sounds. In the subtle tyranny of that moment beat the pulse of Cesar's neighbourhood - the bid for attention, the undercurrent of hostility for so many small needs ignored and unmet, the pleasure of holding power, camouflaged in teasing, the rush of love. Then the moment passed, and Cesar's three-year-old daughter walked back out into the world and left him behind (162). 
Here the literary journalist's presence is briefly exposed in the narrative. In the bleakness of the moment, the reader becomes aware that this is LeBlanc's experience, too. A sense of helplessness pervades the scene; LeBlanc cannot intervene. Here she is the perceptive critic as well as the "reporting angel"; the ability to create her own subtly analytical moment and let it pass without pontificating is a strength in a narrative that has been criticised for its lack of interpretive analysis.

This criticism has been made by JoAnn Wypijewski, herself a practitioner of both daily and long-form journalism. In her review of Random Family, Wypijewski is primarily concerned with the ethical issues raised by the author-subject(s) relationship, but she also is critical of LeBlanc's extradiegetic narrative mode of representation. She contends that LeBlanc "wrote herself out of the story, becoming in the process its most provocative character: the voyeur who is everywhere and nowhere, watching and telling as things fall apart ... It is only by accident, in the acknowledgements, that the book finally confronts the reader with the "American experience of class injustice' that is ostensibly its subject" (np). Wypijewski's comment here again illustrates Genette's caution about the "curative" or "corrective" function of author's notes placed at the end of a narrative (see Genette, Paratexts 238-9). It betrays what is perhaps a common perception of the value of paratextual information; the author's note is treated more as an afterthought than a framing device that negotiates how to read a text. The phrase "it is only by accident" paradoxically reinforces the importance of the contract to the text's reception - the author's note is evidently not important to Wypijewski. But the position of the author's note is in keeping with LeBlanc's aim to convey the lived experience of her subjects (Boynton, The New New Journalism 236). In an interview published in The Guardian, she defends her rationale: "I didn't want it to be the white girl's journey into the ghetto: there have been other books like that. I didn't want to bounce the reporting off that. This is a subject worthy of close scrutiny on its own" (Bedell np).

Although LeBlanc's presence is largely imperceptible in the narrative itself, she commits to an authorial position in relation to her subjects by framing the narrative with an epigraph taken from William Blake:

Some say that Happiness is not Good for mortals \& they ought to be answerd that Sorrow is not fit for Immortals \& is utterly useless to any 
one a blight never does good to a tree $\&$ if a blight kill not a tree but it still bear fruit let none say that the fruit was in consequence of the blight (vii).

The epigraph here has the same function as in fiction. In the absence of a first-person narrative voice, the frame cautions the reader: there is nothing noble in the circumstances this family finds itself in, but the virtues portrayed are not a result of the blight (poverty, lack of education etc). Rather, they are evident in spite of the circumstances - that is, the blight is not a natural part of the tree. This frame clearly signals LeBlanc's advocatory role for those who experience class injustice. It works with the author's note to elaborate LeBlanc's epistemic qualifications-how she has informed herself, what her interests are (Code, "Who Cares?" 106) - that entitle her to offer knowledge about her subjects. Such a reading is consistent with the narrative as LeBlanc offers multiple perspectives from which Jessica's and Coco's situations can be viewed, including the example of Sister Christine and Coco. She records the impact of Coco's (mis)management of money, adding the caveat: "[b]ut to Coco, nothing was more important than family, and family included Cesar and Lourdes and friends, both old and new" (148). LeBlanc's desire to highlight the humanity of her protagonists is also evident in the closing words of the narrative, where Cesar reassures his daughter he will not drop her: "Listen, you light as a feather to me" (404). And it is finally reinforced at the end of the author's note, where LeBlanc concludes: "The hardships of these young people and their families are not unusual in their neighbourhoods. Neither are their gifts" (406).

The effect of disregarding the author-reader contract is evident here, but so is the rhetorical effect of disclosure transparency post-narrative. LeBlanc has demonstrated an awareness of her epistemic responsibility: her rationale is consistent with her aim and her practice, which allows the reader room for interpretation. As Matheson writes of journalism without a critical frame: "The lack of overt interpretation allows the listener to encounter these people less as symbols of something larger or as instances of a wider narrative, than as specific people in a concrete world. In the encounter, an interpretative space is opened up in which wider questions ... become available. The questions specific listeners ask are likely to be different" (410). In this way, LeBlanc's choice reinforces the outward orientation of her narrative, and encourages the reader to perceive her subjects in addition to - rather than solely defined by - their 
situation. Coco and Jessica are not just symbols; they are autonomous individuals open to the reader's own interpretation. But there is evidently a tension between guiding a reader's interpretation of a text, and emphasising the subjectivity-and autonomy—of one's subjects.

This point is a central (epistemic) criticism of Wypijewski's. She does not take issue with LeBlanc's factual accuracy, but critiques the cumulative truth effect of the narrative as a whole. Initially, she asserts that the "truths" in the text are drowned in "the onrush of personal detail” (np). These include: “"even living right was just another precarious hold'; that 'success was less about climbing than about not falling down'; ... and family generosity, however defeating, might be the only bulwark between awfulness and horror" (np). Further, "It seems the destiny of Jessica's and Coco's daughters to follow in their paths. It seems the destiny of young Puerto Rican men to go to jail (and, judging from Cesar's maturity there, seems a not half-bad solution). It seems the destiny of the whole community to live with extraordinary drama" (np). This assessment echoes Frus's critique of the extradiegetic narrative mode:

In general, the use of impersonal narration implies that all accidents of chance or fate have meaning simply because they are told, explained in a story. ... The absence of reference to the narrative situation in the historical narration, coupled with the illusion of realistic representation and the tendency to reconcile the contradictory elements in a roundedoff ending, fixes the world the way it is depicted here, and the reader tends to accept it as presented (25).

The argument here is that any type of reportorial practice reifies its subjects, which in turn creates an illusory (or "fictive") sense of verisimilitude. I would argue that LeBlanc resists reifying her subjects' experience by attempting to subvert closure; the final chapter is a reconstructed scene without great significance to the "plot." Both Wypijewski and Frus have a point regarding the cumulative truth effect produced by the extradiegetic mode and narrative structure, but an assessment of epistemic location suggests LeBlanc's knowledge, understanding and truth claims are justifiable.

While Random Family does not follow a narrative arc in a typical sense (it is atypical in that the complication (poverty) is thematic), the narrative does display 
"completeness," one of the eight Aristotelian elements of literary plot. Marsh identifies this element as inherently structural: the assignation of a beginning, middle and end signifies completeness (see Marsh 302). For Frus and White, this fixes the world and imposes meaning on random events. From LeBlanc's perspective, however, the facts she has gathered and subsequent knowledge she has accumulated produce meaning and truths, in the sense Code proposes. Understanding involves "tying one's knowledge down: relating it to a context, having some conception of the relation of ... knowledge to the rest of what one knows" (ER 150). The coherence in Random Family is primarily facilitated by structure. LeBlanc begins the narrative with Jessica, a sixteen year-old who becomes pregnant in the first chapter, and ends with her daughter Serena's sixteenth birthday. This passage both completes and begins a new cycle of teen pregnancy:

Serena worked herself up into a frenzy: "They are so worried about me having sex. She has fourteen grandchildren. Why $m e$ ? They don't care if their sons do it, only their daughters. If I was a grandson, do you think they would all be pressuring me?" she cried. "If I want to have sex, I'm going to have sex. Everybody has sex. They all want me to change. I don't care what my family, friends, or nobody says about me, I am the way I am and I don't care!"

She would be pregnant within six months (397).

This is the "coming of age" referred to in the book's subtitle. Despite the phenomenal reality of the situation, LeBlanc's structural choices do create a layer of meaning. The proleptic tag-line provides extra emphasis - a glimpse at the sensibility behind the narratorial voice and a sense of inevitability about Serena's situation. That this occurs in the penultimate chapter places Serena's sixteenth birthday as the climax of the narrative, and a fulfilment of the expectation set by the subtitle. What it means to "come of age" then takes on increased significance through this frame, and is reinforced by the scene's position in the text. LeBlanc recounts the following limousine ride, a gift from Serena's mother to her as she crosses the threshold into adulthood:

They wanted to leave the familiar world behind, but no one knew the direction out. "Mister," Josh asked the chauffeur. "You must know everything. You been everywhere. Where should we go? The waterfront?" ...

"Tremont," Tabitha said. She still lived there, in Rocco's old building. ... Jessica fumed when she learned about the stop on Tremont: "I 
wouldn't have paid for a limo if they wanted to go for a walk." Even if they wanted to go for a walk, why pick Tremont? And if they had to choose Tremont, why walk east? "Anthony? Mount Hope? That's a drug-infested block, there's shootings there," Jessica said. "They could have at least walked in the opposite direction, by the Concourse" (399).

This scene illustrates both the literal and symbolic dilemmas for three generations of Jessica's family. Serena and her friends want "to leave the familiar world behind" but no one knows the direction out; similarly, Jessica wants more for Serena than Serena wants for herself, but, significantly, does not have a frame of reference outside of the Bronx. That this exchange occurred on the night of Serena's sixteenth birthday may seem serendipitous. However, a critique might suggest its structural placement and symbolic power disregards the subjects' agency and the potential for alternatives for Jessica and Serena. Despite the formal lack of closure - no problems are resolved, and in the final chapter Cesar is still in jail - the passages recounting Serena's birthday do seem to offer a conclusion: that this cycle of poverty is destined to repeat itself. Is this a "truth"? Can this be verified? Embedded within the narrative structure, and subject to future events which LeBlanc cannot foresee, verification is - at this stage - an impossibility. Here the critic can turn to an assessment of epistemic responsibility. Appropriate questions then become: What was LeBlanc's location in relation to her subjects? Did she have appropriate access to her subjects to infer this meaning? Are her truth claims justifiable, given the evidence available to her at the time? That LeBlanc personally witnessed this cycle with two generations, and wrote extensively about Lourdes's (Jessica's mother's) similar experience suggests these questions can all be answered in the affirmative.

While not addressed in the peritext of the book, LeBlanc obliquely speaks to this concern in an epitextual source. When asked if the kind of journalism she does can lead to truth, she answers:

I don't know about truth, but I believe journalism can lead to a moment of real human connection between the reader and a world that they would not otherwise know. And with luck it will be a lasting connection. I always tell the people I write about that I'm writing about their world, but that it will be my story. So the truth will be my truth, not necessarily the truth that they believe (Boynton, The New New Journalism 48-9). 
Here LeBlanc acknowledges the subjective nature of perception and reality, and implicitly defends her text against criticism that it is "fixed." For LeBlanc, the truth of her representation accurately reflects her knowledge, understanding and perceptions of phenomenal reality. The print medium in which she is quoted (Boynton's The New New Journalism) is far less accessible than online material, however, and will consequently only act as a frame for a limited - and predominantly specialist_audience.

As calls for transparency in journalistic practice strengthen and venues for epistemic defence proliferate, LeBlanc's narrative has very little online presence. As of 2012, LeBlanc's professional website features only a photograph of the book's cover and a link to Amazon.com where the book can be purchased. Further, in comparison to The Immortal Life and Columbine, other online epitextual sources regarding Random Family are largely comprised of reviews. The discrepancy between the amounts and types of epitextual resources made available by LeBlanc and later practitioners Cullen and Skloot may be attributable to privacy issues. The use of pseudonyms for her subjects suggests LeBlanc's desire to protect them from public recognition; release of primary sources would clearly jeopardize their anonymity in a way not called for in Cullen's and Skloot's texts. LeBlanc's subjects' decisions to reveal their identities are then their own responsibility (see Writing Inside, Writing Outside), and do not compromise her commitment to their privacy, but provide one way to account for the lack of epitextual sources available. Otherwise, LeBlanc's book represents an anomaly in what might be characterised as a trend towards transparency in contemporary literary journalism, but one that does not significantly damage the validity of her narrative or, indeed, the power of its message.

LeBlanc has contracted with her readers to produce a narrative that is consistent with externally verifiable evidence. Her decision not to make sources available either perior epitextually opposes trends towards transparency, but in some ways, the lack of available epitextual sources protects Random Family from close scrutiny. The peritextual contract negotiated asks the reader to rely on the authority of the reporter, gained by the exhaustive research on her subjects' lives. The overwhelmingly positive critical and popular reception of Random Family suggests that LeBlanc's densely 
detailed narrative and ten years of immersive reporting have earned her the trust and respect of her readers.

The area for which LeBlanc has perhaps been most strongly criticised, the fixing of experience, is one that needs careful consideration for future literary journalists. As Frus posits: "Emphasizing the relationship between narrator or journalist and reader may be an effective way to challenge the reification implied by most mass-cultural forms" (180). Exposing the subjectivity of the author is a hallmark of literary journalism, but for practitioners such as LeBlanc who suppress their subjectivity for the higher objective of conveying the experience of their subjects, the paratext could be more fruitfully employed to perform the role homodiegetic narration carries out in other works of literary journalism. For first-time authors, particularly, the online environment offers opportunities to establish epistemic responsibility in a way that is immediate, engaging, interactive, and open to a web of information that can validate or contradict authorial claims. As the next two analyses will demonstrate, online media can be a powerful, multifunctional medium through which epistemic responsibility can be established. It can also, however, create conflicting frames that call a practitioner's epistemic defence into question.

\section{Columbine: Dave Cullen}

Dave Cullen's Columbine received enormous critical acclaim in 2009. While perhaps not enjoying the same widespread popularity as Skloot's The Immortal Life-the paperback version of Columbine spent only five weeks on The New York Times best seller list and peaked at number 10 ("Best Sellers")—Cullen's first extended work of literary journalism received almost universal critical praise. In the tradition of literary journalists, Cullen has been described as "a cultural translator" ("Dave Cullen's Biography"). Prior to Columbine his journalism covered Evangelical Christians, gays in the military, Barbie doll collectors, or "anyone on the margins" ("Dave Cullen's Biography”). Primarily a freelance journalist, Cullen has contributed to the New York Times, Washington Post, The Times of London, Slate, Daily Beast, the Guardian and online arts and cultural magazine, Salon. As LeBlanc's Random Family began as an article for The Village Voice, Columbine grew out of a smaller assignment for Salon. Cullen initially covered the Columbine High School shootings in Littleton, Colorado, 
for the magazine. His concern for media practices catalysed what would become his first book-length work of literary journalism. As a result, Columbine invites discussion about the practices of mainstream reporting of unfolding news; but the form and content of Cullen's own choosing also raise questions regarding the extent to which exhaustive investigative reporting can — or should — produce a definitive version of truth. Consequently, the epistemological limits of literary journalism are raised here. I will also argue that the author-reader contract — the narrative and paratextual framing of Columbine-reveals inconsistencies in ideology and practice, inviting careful consideration of how works of literary journalism are framed by peritextual and online epitextual sources, and how apparent transparency can lead to reification of text and subject. Finally, the question: "Where are you coming from?" informs this analysis. This question refers to the "implicit importance of the knowers or would-be knowers and what we might call their epistemic 'location' - in a time, a place, and in epistemologically relevant circumstances" (Code, ER 38). Code explains that it elicits "autobiographical answers, memoirs, testimony; performatives that produce and affirm allegiances, or commitments presented for critical-political analysis" ("Responsibility and Rhetoric" 1). For this analysis, the question refers to the literal location of the reporter in regards to the subject, but in a metaphorical sense, it also asks what kinds of expectations lead the literary journalist. Because Cullen eschews his own presence in the narrative, epistemic questions arise regarding the types of knowledge he withholds from readers, and the reasons for withholding it.

A native of Colorado, Cullen was one of the first reporters on the scene at Columbine High on April 20 ${ }^{\text {th }}$, 1999. In promotional interviews after the publication of his book, Cullen describes how he spent the afternoon and evening at the scene and posting his first_- "uncorrupted"-story for Salon. He then drove home listening to the radio coverage of the tragedy and followed network coverage well into the night. Media coverage included the first pieces of speculative information that would later become widely accepted myths surrounding the massacre. Cullen continues:

The pack mentality is powerful. Your peers are pretty smart, so when they're all going in one direction, and everybody's listening to each other, you tend to do that. ... I inserted all the junk the next morning ... I assumed I was wrong ... Whether you're covering the campaign trail, or anything, it's really hard to be that lone wolf. ... I had this pristine story with almost none of the myths, and I buckled, and inserted the 
myths. And as I should, I have the story now showing that I got it wrong, because I buckled the next morning and got it wrong, but it didn't have to be that way (chuckpalahniukcult).

The issue here is both ethical and epistemic: Cullen uses media as a source of knowledge rather than verifying facts himself. The epistemic question "Do I really know what I think I know?" (Cooper 86) is not easily considered when working to deadline. Columbine is an attempt to correct this. Frank ("These Crowded Circumstances"; see also Berkowitz) has written about the implications of journalists distancing themselves from pack journalism by writing about it. He identifies this practice as "boundary-work rhetoric", or "the rhetorical strategy of one group wishing to distinguish itself from another" ("These Crowded Circumstances" 448). Interestingly, Frank concludes that "distanced reflexivity" offers a way around the demands of objectivity. "By adhering to the third-person rhetoric of objectivity, the writer can make 'the media' an Other. 'The media' have become part of the story; this reporter has not. Such a strategy enables reporters to separate themselves from the pack and align themselves with the pack's critics" (456). Written in third-person narrative mode, Cullen's Columbine illustrates such "distanced reflexivity", and indeed makes the media an "Other" while Cullen clearly shows in the paratext that he was part of the pack. This sets Cullen up as an authority on the Columbine shootings, and given his ten years of reporting and research, this is warranted. But I also argue that the combination of distanced reflexivity and the rhetorical force of the media as "Other" sets up reader expectations that are epistemically untenable.

So where is Columbine coming from? The book functions in part as a correction of the record and a polemic against the practices of syndicated mainstream journalism. These purposes are introduced in the publisher's peritext — specifically, six pages of critical praise for Columbine. While promotion of the book is a primary aim, these pages also set the reader's horizon of expectations. Here the book is framed as "media criticism," showing "how truth was obscured by myth," "a correction of the record," "mythbusting" and letting "the truth contradict many popularly embedded ideas" (Cullen, Columbine ii-viii). This frame is reinforced epitextually online: Rachel Maddow of MSNBC commends the book for "meticulously disassembl[ing] the stories that make up so much of the country's collective understanding of that tragedy." Speaking on the tenth anniversary of the school killings, she advises her audience that: 
Today's anniversary can be an opportunity not only to remember and honour the victims, but also to get the Columbine story right. If there are going to be national lessons learned from that tragedy...it makes sense to base them on what actually happened, not on the stories we have told ourselves to try to make sense of it all, despite their distance from the facts (Maddow).

That Cullen's book is another story attempting to make sense of the shootings is not acknowledged; in fact, the book is marketed as a "definitive account" (dust cover). Cullen reinforces this in an author's note on sources that precedes the narrative: "In the great media blunders during the initial coverage of the story, where nearly everyone got the central facts wrong, I was among the guilty parties. I hope this book contributes to setting the story right" (Columbine xiv). That there is "a" right story, waiting to be discovered, is implicit here; Cullen equates correct facts with truth in a way that other literary journalists may not. The peritextual evidence cited above suggests Cullen's contribution has been accepted by critics as "the definitive account," and, as paratext, functions to create that expectation for the reader.

Interestingly, in the narrative itself, Cullen strongly rejects the idea of one story being the "true" version. In a chapter entitled "Media Crime", he writes: "It is an axiom of journalism that disaster stories begin in confusion and grow clearer over time. Facts rush in, the fog lifts, an accurate picture solidifies. The public accepts this. But the final portrait is often furthest from the truth" (Columbine 150). Skloot also recognises that artful arrangement makes facts "take on different weight" (Cavanaugh), disconnecting factual accuracy from truth value. Given the truth claims of both books, the practitioners' failure to engage with this idea in reference to their own narratives is somewhat concerning, but particularly so in a book marketed as a definitive account. As Code writes, “to strive for insight into the extent of one's own cognitive capacities, to distance oneself as much as possible so one can be critical of one's own knowing, is a crucially important aspect of epistemic competence" (ER 176). But Cullen extends his thesis: "Journalists were not relying exclusively on 'students.' The entire industry was depending on the Denver Post.... It did not single-handedly create any of the myths, but as the Post bought into one after another after another, each mistaken conclusion felt safe. The pack followed" (Columbine 152). Cullen here sets his narrative up in opposition to mainstream media reports. Nestled between densely 
detailed reconstructions and vivid flashbacks, "Media Crime" not only raises questions about the mainstream media's poor handling of this one event, it also produces a disquieting question: what chance does anyone have of "getting it right"? Questioning the media works here to validate Cullen's own version of events.

Code's call for recognition of epistemic limits is salient here. The immersive reporting element of literary journalism may impose "standards of intellectual achievement over and above those expected of persons simply as persons" (Code, ER 62 emphasis in original). However, Code also encourages "[e]xploration of cognitive experiences where evident efforts are made to arrive at a right sense of the situation offer a way of seeing what kind of attitude of mind is appropriately realistic in recognizing the sovereignty of the object and the limitations of human cognition" (ER 141). One of Cullen's only critics in the mainstream media, Janet Maslin, undertakes this task by questioning the epistemic validity of his narrative. The New York Times journalist asks in an online review: "What does Mr. Cullen's claim to pre-eminence really mean? How much of it is backed by his book and how much by the sheer volume of research in which he immersed himself? In some ways this author's notes are more revealing than his text" (np). This suggests that Maslin does take the paratext seriously, but has juxtaposed the narrative critically against the peritext rather than using the peritext as a frame. Rather than reinforcing his truth claims, Maslin argues, the notes section represents "misplaced confidence from his arduousness ... and hair-splitting precision [of detail]"' (np).

While not disputing the accuracy of Cullen's "facts," Maslin questions the possibility of Columbine fulfilling its claims. Crucial to the assessment of Cullen's epistemicrather than ethical-responsibility, Maslin notes that the last sealed depositions containing primary source information will be released in 2027 . This, along with the fact that Cullen never met the killers, or their families, suggests that Maslin's criticism is not without foundation. The extensive peritext — which acts as epistemic defenceoffers verifiability, but does not reflect on the epistemic limitations of Cullen's knowledge. In another example, an online epitextual source shows Cullen describing how after the first five years working on the book, his "characters" Eric Harris and Dylan Klebold were "completely different" to the characters as they appear in Columbine (Ulin). While clearly attempting to represent his journey towards "the 
truth", Cullen perhaps paradoxically demonstrates here the fluidity of representation built on facts.

Maslin's criticism also raises the question of ownership. This issue is one that has long been a concern to literary journalists. While it is inherently ethical, the question "Who owns the story?" is worked out epistemologically, as knowledge of the subject belongs to the literary journalist. As Helen Garner has stated: "The story is not a story until a writer tells it" (An Evening). This stance places the literary journalist as the owner of their work of literary journalism, without appropriating the right of the subject to tell their own story, or have it told by another practitioner. It also reinforces Code's injunction that the writer must have a "right" sense of the situation (ER 141), in that they are (morally) responsible for the amount, type and quality of knowledge that informs their narrative.

The three practitioners in this chapter approach ownership quite differently. LeBlanc's choice to elide herself from Random Family reflects the aim for her subjects to speak for themselves. Nevertheless, she acknowledges that the narrative is her own: "I always tell the people I write about that I'm writing about their world, but that it will be my story. So the truth will be my truth, not necessarily the truth they believe" (in Boynton, The New New Journalism 247). Skloot, as will be demonstrated, raises the issue both in the narrative and paratextually. She signals her concern and acknowledges her epistemic and ethical responsibility as a participant in her subjects' story, but maintains it is not her story-she is the conduit (WKNOPBS). Cullen's position seems most problematic, as paratextual frames emphasise that this is "the" story - a position that is reinforced by the narrative mode.

Cullen's extradiegetic mode of narration arguably adds a degree of difficulty to the defence of epistemic responsibility. Unlike Skloot's text, which is mediated by an authorial presence, Cullen's produces an illusion of omniscience. This is not unusual, however, in literary journalism. Tom Wolfe noted of the New Journalism that "most of the best work in the form has been done in the third-person narration with the writer keeping himself absolutely invisible, such as the work of Capote, Talese, the early Breslin, Sack, John Gregory Dunne, Joe McGinniss" (The New Journalism 42). Cullen's choice not to represent his own subjectivity in the narrative is not articulated 
beyond a passing reference in the author's note: "To avoid injecting myself into the story, I generally refer to the press in the third person" (Columbine xiv), but he does not articulate why this is important for him as a practitioner. Unlike the effect in LeBlanc's text, which is to produce a self-effacing narrator, the tone and extradiegetic mode in Columbine combine to create an authoritative narrator-a rhetorical situation vital to the truth claims of the text. This stance is evident from the opening paragraph of the book:

He told them he loved them. Each and every one of them. He spoke without notes but chose his words carefully. Frank DeAngelis waited out the pom-pom routines, the academic awards, and the student-made videos. After an hour of revelry, the short, middle-aged man strode across the gleaming basketball court to address his student body (Columbine 3).

Another product of this narrative stance is that Cullen frequently offers analysis without attribution. This is a powerful rhetorical device, and one that the extensive notes section following the narrative is intended to qualify. Jack Fuller notes that "the journalistic discipline of attribution often comes into conflict with a writer's use of sophisticated literary techniques" (News Values 157), but can be accomplished to reestablish a simple relationship between the reader, the narrator, and the writer (158). Frank similarly notes that "literary journalists do not want to compromise the artistic integrity of their work by mucking it up with attribution" ("You Had To Be There" 155), but concludes that while "writers of reconstructive narrative are doing good journalism, some of the best around", they "need to do a better job of letting ... audiences understand how good journalism is made" (157).

This is ostensibly Cullen's concern. Where he disguises his physical presence in the narrative, it is identified in the notes section; for example, a passage beginning, "When a journalist stopped by" is cited in the notes section with annotation "I was the journalist" (Columbine 408). The intended effect here is clearly to attribute or validate the scene without interrupting the rhetorical effect of the passage. It is also intended to establish Cullen as a transparent practitioner, deepening the narrative's verifiability and thus its reliability. The extensive documentation of sources and explanatory notes in the paratext is intended to validate the accuracy of the narrative - and clearly succeeds for most critics. But does Cullen's assertion that "the final portrait is often 
furthest from the truth" (Columbine 150) apply here? Is the final version the truth? As stated, literary journalism grew out of a journalistic endeavour that relies fundamentally on the writer's subjectivity, seeking to decrease the distance between subject and object (Hartsock 42). Embedding subjectivity in paratextual frames emphasises the objectivity of the research process, but positions readers to focus on what are represented as facts, rather than acknowledging the epistemic gaps that destabilise truth claims.

Positioning readers in this way is not an exclusively literary function: standard or expository non-fiction is subject to the same pressures and effects of selection as literary non-fiction. As Lehman contends:

The standard news writing form that lies at the source of much nonfiction writing in contemporary America reveals how authors quietly manipulate many readers of nonfiction. In these narratives, subjective decisions such as access to sources, whom to quote and in what order, and what details to highlight normally are hidden from the reader in favor of a style and structure that insists on nominal objectivity ("Mining" 338).

The elements identified here by Lehman are clearly also at work in mainstream journalism, the main difference here being that the general structure is pre-ordained from over a century of practice, thus also largely hidden from the reader through familiarity. That covert positioning occurs in other genres, however, does not preclude the importance of a discussion of structure's effect in literary journalism. The extent to which reader positioning affects representation of primary documentation is important to consider. In a lecture Cullen gives on structure in Columbine, he reports:

One of the slightly manipulative things that I did, was I knew that I wanted to introduce several different things before the murders, and have some of [the subjects] die, and some of them live, and not have you know which ones... and it would affect you in a certain way; it would also make you more glad and value the fact that some of the people you were rooting for lived, and made it ... I think it makes it more real and more intense (Ulin).

Cullen partly achieves his aims through the structure of the narrative, which is divided into three main elements. The first element is coverage of events leading up to the shootings, the second is the massacre itself, and third covers the ongoing effects on 
survivors and survivors' families. These elements provide the core structure while analeptic, occasional proleptic, and descriptive digressions interrupt the progression, creating tension, and producing questions and — eventually_-answers that intensify the reading experience. This cycle of questions and answers works as a self-verification mechanism. One concern here-and one that The Immortal Life, for example, avoids - is that Cullen's research and opinions are largely indecipherable; thus he presents his own conclusions as fact. Perhaps the most salient example is Cullen's characterisation of Eric Harris - the instigator of the plot behind the shootings - which builds towards an assessment of Harris as a psychopath.

One of the framing questions that propels the narrative is what drove Eric and Dylan to plan and carry out the attack on the school. Agent Dwayne Fuselier is used to develop this line of questioning, to interpret the data left by the killers, and ultimately, to give the answer. Interestingly, as the narrative develops, Fuselier's voice is fused with the narrator's. Fuselier is introduced in the narrative as a parent of a Columbine High School student, Brian. His role as an investigator, however, becomes apparent, and soon Fuselier has hard evidence with which to make a diagnosis:

His big break came just a few days after the murders, before he saw the Basement Tapes. Fuselier heard an ATF agent quoting a ghastly phrase Eric Harris had written.

"What you got there?" Fuselier asked.

A journal. For the last year of his life, Eric Harris had written down many of his plans in a journal. Fuselier zipped over and read the opening line ...

"When I read that first sentence, all the commotion in the band room just ended," he said later. "I just zoned out. Everything else faded." Suddenly the big bombs began to make a lot more sense. ... Eric would prove the easier killer to understand. Eric always knew what he was up to. Dylan didn't (Columbine 169-70).

Cullen does not reveal Fuselier's assessment at this point; in fact, it is alluded to three more times before the diagnosis is revealed, first emphasising its accuracy before articulating it with "Dr. Fuselier was not surprised by the notes. Very cold-blooded" (Columbine 208). And again: "Fuselier read the stories. He shuddered. All the conclusions were reasonable — and wrong. ... By this time, Fuselier had read Eric's journal and seen the Basement Tapes. He knew what the media did not. There had been no trigger" (Columbine 209). By the time Fuselier's diagnosis is revealed, the 
reader has been positioned to accept it as an answer to "why" these killings occurred. "Fuselier spent the next twelve weeks contesting his theory. That's how he approached a problem: develop a hypothesis and then search for every scrap of evidence to refute it. ... If it withstands that, it's solid. Psychopathy held" (Columbine 239). Fuselier's process here has been mimicked by Cullen; information has been offered but diagnosis withheld until "it's solid," and the reader is not offered the opportunity to assess for themselves. Fuselier's assessment is confirmed as "textbook" on page 247 where a report is given at a major FBI summit, functioning again to confirm the positioning of facts and carry out a self-verification function. Anomalies within the diagnosis are dealt with multiple times in the following way: "It's not clear exactly what Eric was up to with Dr. Albert. ... 'I would be very surprised if Eric was being honest and straightforward with his doctor,' Fuselier said. 'Psychopaths attempt to, and often succeed, in manipulating mental health professionals, too"' (Columbine 261). Here Cullen notes details that are incongruent with the diagnosis, but they are dismissed by Agent Fuselier. In light of the selfverifying structure to this point, there is no space for the reader to contest this representation. If questions do arise for the reader, Cullen again situates the reader as an outsider, reliant on Fuselier for perspective:

Eric outdid Dylan with apologies. To the untrained eye, he seemed sincere. The psychologists on the case found Eric less convincing. They saw a psychopath. Classic. He even pulled the stunt of self-diagnosing to dismiss it. "I wish I was a fucking psychopath so I didn't have any remorse," Eric said. "But I do."

Watching that made Dr. Fuselier angry. Remorse meant a deep desire to correct a mistake. Eric hadn't done that yet. He excused his actions several times on the tapes. Fuselier was tough to rattle, but that got to him (Columbine 328).

At this point, Cullen still focalises through Fuselier, but towards the end of the text as Cullen recreates the scene at the time of the shootings, focalisation is dropped as Cullen assumes the expert role:

They roamed aimlessly upstairs. To civilians, it seems odd that they stopped shooting and entered this "quiet period." It's actually pretty normal for a psychopath. They enjoy their exploits, but murder gets boring, too. Even serial killers lose interest after a few days. Eric was likely proud and inflated, but tired of it already. Dylan was less predictable, but probably resembled a bipolar experiencing a mixed episode: depressed and manic at once-indifferent to his actions; 
remorseless but not sadistic. He was ready to die, fused with Eric and following his lead (Columbine 350).

Columbine's bibliography demonstrates that Cullen has gone to great lengths to gain background knowledge here. His assertions beginning "It's actually pretty normal for a psychopath" can be upheld by his extensive research into psychopathy. But the question remains about the diagnosis for Eric - and Dylan. Over one hundred pages previously have created a path to this conclusion, buttressed by Fuselier's diagnosis and Cullen's extensive research.

Narrative techniques such as those demonstrated here verify the conclusions the author has made through extensive research, but again, there is no room in the narrative for questioning the "definitive" nature of the account. One way this is acknowledged is that the peritext points the reader to Cullen's own website (see "Columbine Online") where primary documents are accessible; although, arguably, by the time the reader accesses them, the narrative will already act as a frame through which the primary sources will be viewed. Nora Berning's discussion about the interplay between print and electronic media is illuminating here. She argues that Mark Bowden's Blackhawk Down companion website is

a crucial resource through which readers can retain a degree of autonomy from 'the tyranny of the author.' The appropriation of the text takes place according to the reader's own discursive rules. The text itself becomes a structural component for the formation of cultural capital which eventually translates into a critical perspective on culture (Berning).

But in Columbine's case, the reified narrative conceivably resists the plurality of meanings online epitextual sources are intended to open. As with The Immortal Life, the peritext of Columbine directs the reader to the companion website, effectively creating a complex multimedia text, and again, complicating the boundaries of the narrative. Of his official site "Columbine Online," Cullen writes in the peritext:

The sheer size of the Columbine evidence is overwhelming. And most of the early reporting on why it happened was wrong. I culled through thousands of police files, pictures, journals, videos, interviews, 911 calls, crime scene photos, etc. As I organized the information, I decided to share my research online. For this site, I compiled the most significant evidence and tried to make it easy to find. I hope this helps 
you navigate the maze of myths, distortions and the truth. Good luck on your search ("Columbine Online").

I would argue, however, that the author-reader contract as negotiated through the paratextual frames of the narrative does not offer the reader degrees of autonomy, nor does it allow for appropriation of the text. The narrative itself frames the online component of the text, closing off the potential plurality of meanings and reinforcing the authority of Cullen's version.

Berning also acknowledges that the features of the Internet can work against authenticating the meaning of a text. This is undoubtedly a result of the juxtaposition of frames in a sequence or structure unmediated by the author; in this case, an image read in isolation delivers a different idea to that proposed within the context of a narrative. Of the Blackhawk Down companion website Berning writes:

The electronic properties have unintended consequences and convey a message that stands in stark contrast to what Bowden exposes in his writing. For instance, the author deconstructs and criticizes the notion of American heroism and the ideology behind it. The multimedia elements, however, evoke the image of the American soldier as a hero, ignoring the disastrous course of events denounced in the story. Hence, instead of increasing the credibility and authenticity of a literary reportage, the features of the Internet can have a distorting effect (np).

Here I argue a difference between the framing devices of narratives is evident: the peritext of Columbine dominates and frames the online epitext, while for Berning, Blackhawk Down's peritext is compromised by dominant images in the epitext.

Columbine is undoubtedly an important, extensively researched work of literary journalism. Cullen's combination of research and rhetorical narrative strategies fulfil his aim of bringing characters alive, and evoking powerful emotive responses from his readers. The extensive paratext reveals a deep commitment to transparency, in the same way that his aim of "setting the story right" indicates a responsibilist approach to journalism. As this analysis demonstrates, however, the combination of extradiegetic narration and extensive paratextual notes in fact closes the narrative, and reinforces the "definitive" claims made by critics and the publisher. Other accounts of the Columbine tragedy offer both powerful and plausible explanations for Eric Harris's and Dylan Klebold's motivations, however, which call into question the epistemic 
foundation of Columbine. ${ }^{32}$ Did Cullen have access to enough information to create his narrative? Undoubtedly. But is there more (unavailable) information that could inform his questions of why the boys killed? Indeed there is. For Code, "[s]hifting the focus of epistemological enquiry to a study of intellectual virtue and epistemic responsibility will enhance the confidence that can be lent to knowledge claims, even when absolute certainty is taken to be impossible" (ER 67). The point of this analysis, however, has been that indicators of epistemic responsibility can obscure as well as illuminate a text's epistemological foundation. Conditions for "knowing well" may be an open-ended set (ER 39), but Maslin's critique defined the field of inquiry, and found the truth claims of Columbine to be untenable. Cullen's effort is extraordinary, but this analysis exposes a tension between immersive reporting, the limitations on the possibility of "knowing well", and attendant claims that can be made about literary journalism.

\section{The Immortal Life of Henrietta Lacks: Rebecca Skloot}

As of December 4, 2011, Rebecca Skloot's The Immortal Life of Henrietta Lacks still held second place as a New York Times bestseller-this, after 36 weeks on the prestigious list. While this is an extraordinary achievement for any debut work, it is perhaps even more unusual that science writing has garnered such a wide readership and sustained popularity. The book's enormously positive reception may in part be attributed to Rebecca Skloot's strong presence in the media, but its success has also been attributed to its thematic concerns, compelling narrative form, sympathetic treatment of its subjects and extensive paratextual support. In short, its features recommend it as an important work of literary journalism.

Originally a science major, in 2008 Skloot obtained a MFA in Creative Nonfiction and combined these interests to write her first book. The Immortal Life is Rebecca Skloot's narrative of an African-American woman who unknowingly produced the world's first "immortal" cell line; that is, human cells that reproduce infinitely. Like Columbine, the book follows three narrative strands: the life and death of Henrietta Lacks; the appropriation of her cells and subsequent rise of the lucrative biogenetic industry; and the story of Henrietta's family, but specifically her daughter, Deborah. Skloot uses her own research journey as a through-line to hold the narrative together. It is "the story behind the story" and has both authenticating and validating functions. The narrative is 
bookended by a prologue in which Skloot describes the first time she heard about Henrietta Lacks and the HeLa cells, and, in the final chapter, her reaction to Deborah's death in 2009, shortly before the book was published.

Skloot's relationship with Deborah is consequently central to the narrative. It provides the narrative drive: Will Deborah open up to Rebecca? How will it happen? Will the rest of the family accept this new development as Deborah has? Can one reporter help repair years of damage by intrusive and unfeeling media? It also provides opportunities for Skloot to reflect on the ethical implications of her role as a reporter on the family, her impact on the story, and the family's impact on her own ideologies and beliefs. Significantly, however, Skloot resisted including herself in the narrative in early drafts of the narrative (Pitzer). This resistance slowly gave way throughout the revision process at the urging of her editor, but it does raise an interesting epistemological issue. If Random Family triggers the primary question: Whose knowledge is it? and a reflexive reading of Columbine asks: Does the scope of enquiry legitimate knowledge and judgments offered? The Immortal Life poses the following: Does a practitioner have an epistemic responsibility to reveal how their own experience shapes the narrative? How might a text be read differently depending on its epistemic defence? Ethical considerations are dealt with extensively by Skloot; in the following analysis, the epistemological implications of shaping narratives will be considered.

According to Code's definitions of objectivism and subjectivism (ER 142-3) and paratextual sources of The Immortal Life, Skloot demonstrates an objectivist approach to reporting. The paratext of The Immortal Life initially signals a strong commitment to epistemic responsibility. But the ethical dimension of the story and issues it raises take centre stage. In a section entitled "A Few Words About This Book," Skloot writes: "The history of Henrietta Lacks and the HeLa cells raises important issues regarding science, ethics, race, and class; I've done my best to present them clearly within the narrative of the Lacks story" (The Immortal Life $\mathrm{x}$ ). This frame is reinforced in the Afterword, which contains a discussion regarding the ethics of tissue ownership and research. Skloot's stance is encapsulated here in a direct address to the reader: "How you should feel about all this isn't obvious. It's not as if scientists are stealing your arm or some vital organ. They're using tissue scraps you parted with voluntarily. 
Still, that often involves someone taking part of you. And people often have a strong sense of ownership when it comes to their bodies. Even tiny scraps of them" (The Immortal Life 317). The issue of informed consent is also raised in the Afterword. Here, the terms "disclosure", "unknown" and "confusion" are epistemological. But being embedded within a discussion of ethics, epistemic concerns are opaque. This privileging of ethical analysis is evident throughout the book, but also applies to the epistemic community's wider discussions of the text.

The narrative's paratextual frames are supported by a high degree of disclosure transparency, beginning with Skloot's motivation for researching and writing the story. The peritext highlights issues of truth, perspective, beginnings, endings, and borderlands of narrative. Skloot also tentatively offers an explanation for including herself in the story: "I did eventually meet Deborah, who would turn out to be one of the strongest and most resilient women I'd ever known. We'd form a deep personal bond, and slowly, without realising it, I'd become a character in her story, and she in mine" (The Immortal Life 7). Here Skloot employs narrative as a metaphor to bridge the gap between text and experience. Deborah, in many ways the book's protagonist, also uses language that frames her experience in narrative terms. Skloot quotes Deborah verbatim when she writes: "[Deborah] laughed and said, 'I tell you one thing - the story's not over yet. You got your work cut out for you, girl! This thing's crazy enough for three books!" (53); "There's two sides to the story, and that's what we want to bring out. Nothing about my mother is truth if it's about wantin to fry the researchers. It's not about punish the doctors or slander the hospital. I don't want that" (250); and "'It's too late for Henrietta's children,' she told me one day over the phone. 'This story ain't about us anymore. It's about the new Lacks children'” (302). That Deborah is quoted as perceiving herself and her role in the context of a narrative adds an authenticating layer to Skloot's project. The reader is reminded that the story is unfinished, but there is also an indication that it is being shaped to bring them to certain conclusions ("It's about the new Lacks children"). LeBlanc offers no such guidance; as Wypijewski observed, the narrative mode of Random Family precludes direction to the "bigger" story. But both narratives engage their readers' subjectivity in the lives of their subjects. While readers of Random Family may find themselves immersed in the world of Coco and Jessica without interruption, the reflexivity of The Immortal Life functions to remind readers of the subjects' phenomenal reality. 
This process is also enacted in subtle ways in the narrative. Mary Kubicek, a laboratory assistant at the time of Henrietta's death, was present at the autopsy. Skloot recreates the scene from her perspective. Mary stands in the doorway, panicking and concerned that she might faint, but also compelled to do her job. Henrietta's body is dehumanised-Mary is in the room "with a corpse". She wants to "run out of the morgue and back to the lab", but approaches the body and greets Dr. Wilbur, the pathologist. Then, to avoid looking at Henrietta's "lifeless" eyes, she turns to look at the bare feet at the other end of the table. Skloot recounts:

"When I saw those toenails," Mary told me years later, "I nearly fainted. I thought, Oh jeez, she's a real person. I started to imagine her sitting in her bathroom painting those toenails, and it hit me for the first time that those cells we'd been working with all this time and sending all over the world, they came from a live woman. I'd never thought of it that way" (The Immortal Life 90-1).

Whether calculated or not, Mary's reaction here enacts a process Skloot is trying to facilitate for the reader. Her experience suggests that Henrietta was an abstraction for Mary, until her bright red toenails, immaculately kept during Henrietta's lifetime, were viewed during the autopsy. The detail brings Henrietta to life. In the same way Skloot aims to reorientate the reader from the narrative's internal to external referentiality, or reality, through verifiable detail. To use a visual metaphor, Skloot makes the reader look at Henrietta, rather than through her. The combination of content and form of literary journalism facilitate this bi-referentiality: the story is compelling at the level of narrative, but "the power of the real" (Carey xxxvi) is at play both in Mary's and the reader's experience. Representation of fine detail (such as the shoe Skloot finds in Henrietta's dilapidated family home) deepens narrative coherence and correspondence, and verification authenticates other-less empiricalknowledge. Although Skloot does not appear in the scene, her authorial presence tangibly guides the reader to an awareness not only of the materiality of the text, but also the reality of the subject. While LeBlanc authenticates her narrative through similar use of fine textual detail, the lack of paratextual frames and reflexivity support the narrative's inward referentiality. This promotes a level of engagement similar to a novel, perhaps to the detriment of the advocatory role of the text. 
This "power of the real" is intensified through the discipline of verification. In an online interview, Skloot expresses her surprise at comments made online or at readings that question her claims to the verifiability of narrative detail. She states that she is repeatedly asked: “'So how much liberty did you have to take?' Not did you take any, but how much? There's this assumption that it's impossible to recreate history in a way that reads like a story" (Pitzer). As this is clearly dealt with in the peritext, reader comments here betray the same scepticism of the truth and power of paratextual contracts in LeBlanc's book. Both authors include statements outlining their reportorial practice in the peritext, both of which are demonstrably either discounted or disbelieved by their readers. However, while LeBlanc offers very little epitextual framing, online epitext offers Skloot a chance to expand her defencepotentially with immediacy - and reiterate her commitment to the "facts":

In the opening scene it's raining, and the room looks a certain way, and her husband is parked outside under an oak tree. The weather came from the weather bureau. I saw archival pictures of the tree and took it to an expert, who said "Yes, that's an oak." I saw archival photos of the room. Rebuilding that kind of narrative uses historical documents and interviews where you cross-source it. There's just one moment in the book that only had one person who recalled it, and I said that in the book. But other than that, multiple sources verified all the information. I think it's interesting that people assume that when they read dialogue that took place in the $1950 \mathrm{~s}$, it was made up, because I wasn't there. But in fact there are ways you can recreate that accurately in reporting. It is absolutely possible to recreate nonfiction in a narrative way and still be factual. It takes a heck of a long time, but it's worth it (Pitzer).

Skloot's defence is reminiscent of fellow literary journalist Walt Harrington's, who demonstrates a similar research ethic, and maintains that verifiability is a choice to be made, not an unattainable goal (see The Writer's Choice). "Incredulity" (88) at the possibility of reconstructing scenes accurately, expressed by Harrington's audience, mirrors that of LeBlanc's and Skloot's, suggesting that the role, value and potential power of paratextual defence needs to be given greater attention and prominence in works of literary journalism. With only one exception, Skloot claims that all information is verifiable by multiple sources, and she invites her readers to test this claim by the inclusion of primary audio, visual and documentary sources in the book's online companion website (see Skloot, "Special Features"). 
The scientific emphasis in the narrative parallels the claim that "Every detail in the story is verifiable in various ways" (WKNOPBS). Skloot's background in science has undoubtedly informed her research process and underscores the value she places on verifiability. On the area of science, scholar Jack Fuller argues:

Journalism is supposed to illuminate matters of public concern, and this includes the job of discovering significant information that otherwise might be hidden. So journalism must approach science (and other specialized disciplines that command large amounts of public money and deal with grave public issues) with the same disciplined scepticism with which it approaches the activities of a city council or a governor (News Values 172-73).

There is certainly a degree of disciplined scepticism in The Immortal Life. Ethics and finances surrounding the industry of tissue research are the subject of the Afterword, again framing the narrative with theoretical and statistical information. This frame is also reinforced epitextually, with Skloot highlighting the ethical and financial issues brought up in her book in online forums (AgendaStevePaikin; Garness; Henry; WKNOPBS; Pitzer). Yet Skloot actively seeks to humanise, rather than demonise, the scientists involved with the development of HeLa cells. Henrietta's, Deborah's and the cells' stories are interwoven into a tripartite narrative framework, demonstrating "that there are human beings behind every biological sample in a laboratory, but that there are also human beings behind every scientist" (Henry). The complex relationship of the three narrative strands is belied by "facts" or statistical representation alone. It is in fact Skloot's subjectivity that guides the reader to see the facts in the light of the human story, eschewing scepticism, instead infusing verifiable facts with perspective and compassion.

While it may initially seem paradoxical, Skloot's perspective-and empathy for the subjects of her book-is not at odds with a scientific approach to research, or objectivity. In fact, if Skloot's claims to verifiability of every detail in her narrative are true, she has practised what Kovach and Rosenstiel consider the original meaning of objectivity. As they argue in their book, "being impartial or neutral is not a core principle of journalism," and "impartiality was never what was meant by objectivity" (95). Rather, 
[w] hen the concept originally evolved, [objectivity] was not meant to imply that journalists were free of bias. Quite the contrary. The term began to appear ... out of a growing recognition that journalists were full of bias, often unconsciously. Objectivity called for journalists to develop a consistent method of testing information-a transparent approach to evidence-precisely so that personal and cultural biases would not undermine the accuracy of their work ( 72 emphasis added).

Michael Schudson supports this interpretation of "objectivity" to some extent, defining it as "at once a moral ideal, a set of reporting and editing practices, and an observable pattern of news writing" ("Objectivity Norm" 149). Schudson quotes Walter Lippmann's treatise from the early 1920s, arguing that objectivity is "the unity of method, rather than of aim; the unity of the disciplined experiment" ("Objectivity Norm" 163). Skloot's epistemic defence claims to reproduce the standard of transparency intended by the prescribed form of daily journalism. Where daily journalists write in an observable pattern to signal personal disinterest and thus transparency, a notion Jack Fuller describes as "hopelessly naïve" (News Values 14), the combination of reflexivity, homodiegetic narration and paratextual framing perform the same function in literary journalism. In this light, Skloot's research method seems to be the embodiment of objectivity. As noted, she claims "There's just one moment in the book that only had one person who recalled it, and I said that in the book. But other than that, multiple sources verified all the information" (Henry). Effectively, Skloot's claim means that other journalists researching Henrietta's life could potentially replicate her research. For Kovach and Rosenstiel, this is the journalistic goal:

In science, the reliability of an experiment, or its objectivity, is defined by whether someone else could replicate the experiment. In journalism, only by explaining how we know what we know can we approximate this idea of people being able, if they were of a mind to, replicate the reporting. This is what is meant by objectivity of method in science, or in journalism (81).

Skloot claims the highest verification standard for the content of The Immortal Life, at times revealing her research process in passages such as: "He grabbed my tape recorder from the centre of the table, handed it to Day, and said, 'Okay, Miss Rebecca got questions for you, Pop. Tell her what you know.' Day took the recorder from Sonny's hand and said nothing” (The Immortal Life 164), and “"This is Rebecca', she 
told the librarian, bouncing on her toes again. 'She's writing about Henrietta Lacks!'” (The Immortal Life 74).

A key point in this thesis, however, is that the discipline of verification does not solve all epistemic problems. Code is writing about fiction when she states: "Acquiring an accurate, right sense of a situation is a primary epistemic task, then, just as a writer's attempt to find a right form of expression is, in large part, an epistemic problem" (ER 141 emphasis in original). But this comment also applies to literary journalism. Connery notes that writers have long "grappled with finding the most effective form of prose discourse to make like comprehensible. ... [The search] usually has signified a persistence in discovering ways to relate language and text, and a desire to discover the limitations of the printed word in recording and depicting reality" ("Third Way" 5). For Skloot, finding the right form of expression was a long process, and her epitextual disclosure highlights some significant issues. In an online interview, Skloot discusses her initial reluctance to include herself in The Immortal Life:

I teach writing, and I often say to my students, you know, "Stop inserting yourself into other people's stories ... where you don't belong." ... I actually get annoyed with writers who put themselves in stories. So I was very resistant to doing it ... I kept saying, it's their story, it's not my story, and then at some point I realised that I had actually become a character in their story. It wasn't that it was my story of trying to get the story, but I was yet another journalist, or person who had come along, and had a big effect on them, in some cases positive, in some cases pretty dangerous. There are a lot of things the book is about, and one of them is this undercurrent of ... the effect that journalists can have on people's lives, whether they mean it or not, or whether they are even aware of what they're doing (WKNOPBS).

Ethics and epistemology are again conflated here, with the terms "effects", "positive", "dangerous", "realised" and "aware" used in the context of journalists' engagement with their subjects. But how important is a literary journalist's own subjectivity when writing in a first-person narrative mode? According to Code, subjectivity "involves recognising the full person-hood and epistemological centrality of knowing subjects, of which theory of knowledge needs to take an account and acquire understanding" (ER 142). Skloot clearly recognises the subjectivity of the Lacks family members, but is she epistemically responsible about self-representation? 
Skloot extends her explanation in another interview, reinforcing the ethical strand of representation: "In the end, I realized it would be dishonest of me to leave myself out of the book. It wasn't about me inserting myself into their story, it was about admitting that I had become a character in their story without realizing it. It was, in a sense, disclosure" (Henry). Skloot has been widely applauded for her transparent, ethical practice, but it is instructive to return to her resistance to "inserting herself into other people's stories" to assess the epistemic implications of finding "a right form of expression" (Code, ER 141).

The scene Skloot refers to in the interview mentioned earlier is one of the most dramatic in the narrative. The year is 2001 , and there has just been a breakthrough in the search for Deborah's sister, Elsie. Elsie "never went past a child in her head" (The Immortal Life 270), according to Deborah, and spent five years in Crownsville State Hospital, where she was likely used as a subject for medical research before her death in 1955. After their discoveries, Skloot and Deborah decide to continue their journey and are staying in a hotel when Deborah, prone to volatile mood swings, reacts violently to a misinterpretation of Skloot's smile. She starts yelling, begins packing her sister's medical records into canvas bags, then suddenly rushes toward Skloot and slams her up against a wall (The Immortal Life 283). Referring to this event, Skloot later recounted that during the drafting process:

At first, I was barely present in any of the first-person parts of the book, because I was really holding back and not wanting to have it be about my emotions. It took a lot of revising to let myself have some reactions. Some of that was my editor. When she read the first version that I gave to her, she was like, "OK, you seem like a psychopath in this scene, because Deborah just threw you against the wall, and she's screaming at you, and you don't react. You have to react." My editor drew out a little of that emotional stuff that I was really hesitant to put in (Pitzer).

The phrase "A little of that emotional stuff", however, downplays Skloot's reaction to Deborah. This scene climaxes in the following way:

"Who sent you? Who's paying you?" she yelled, her hand still holding me against the wall. "Who paid for this room?"

"We've been through this!" I said. "Remember? Credit cards? Student loans?"

Then, for the first time since we met, I lost my patience with Deborah. I jerked free of her grip and told her to get the fuck off me and chill the 
fuck out. She stood inches from me, staring wild-eyed again for what felt like minutes. Then, suddenly, she grinned and reached up to smooth my hair, saying, "I never seen you mad before. I was starting to wonder if you was even human cause you never cuss in front of me" (The Immortal Life 284).

This passage raises some interesting - if demanding - points regarding epistemology, representation and a "right" form of expression. The first and most obvious point arising from this scene is that Skloot's reaction was not initially represented at all. She had knowledge of this event, factual and emotional, yet during the narrative's construction, acted on her objectivist belief that this story was about Deborah, not herself. This decision was arguably made according to Skloot's ideological foundation, manifesting as journalistic ethics. She explains:

[Y]ou don't learn anything about my backstory unless it's relevant to Deborah or to the family's story in some way. In the prologue, you learn that I didn't come from a religious background, that I came from the Pacific Northwest, and that I'm white-and those are specifically juxtaposed against Deborah. You don't really learn that much about me as a character outside of their story. That was what I constantly had in my head, that it only belonged if it was something relevant to their story (Pitzer emphasis added).

Juxtaposed against Skloot's acknowledgement, "I realized it would be dishonest of me to leave myself out of the book" (Henry), this statement raises the question: What knowledge belongs in a story? And further, what criteria should be used to define this? Skloot clearly has a standard: is this information relevant to Deborah or the family's story in some way? This is, perhaps, a sound ethical criterion. But is it epistemically defensible? The effect of Skloot suppressing her reaction to Deborah's violent attack suggests not. According to her editor, representation in that case would have caused her to "seem like a psychopath". The injunction: "You have to react" discounts the point that the event has passed. More explicit, accurate feedback might have indicated Skloot had to reveal her reaction. Is this disclosure transparency? Or is it sculpting a narrative? Can these two be separated? This example suggests not. It also shows how epistemic considerations are regularly superseded by more obvious ethical demands. A practitioner's duty of care to their subject and their story is high indeed, but the literary journalist's obligation to represent reality as it is - despite how theoretically fraught that phrase may be-is at least of equal importance. This example demonstrates how "cherished beliefs pose formidable bastions of opposition to epistemic change" (Code, 
$E R$ 251), and highlights the tension between ethical and epistemic concerns in the representation of "real" events.

Fuller acknowledges that authors may choose to restrain emotions for personal or professional reasons, but claims that "these complexities decline in importance when the writer establishes his presence clearly throughout the narrative" (News Values 159). I would argue, however, that this example illustrates how epistemic complexities increase in importance when a practitioner represents him or herself. Skloot acknowledges that she has modified her practice - in opposition to her personal and professional belief, and this can be assessed as transparency disclosure. But that she was compelled to modify the scene by her editor, against her own judgment, suggests that there is room for some reflexive epistemic questioning in Skloot's practice. In this case, the epistemic community can be seen as working reliably; that is, her editor identified the nexus between Skloot's objectivist approach to her subject, and her epistemic responsibility to faithfully represent reality. This tension is one that must be carefully managed, as further analysis of this passage demonstrates.

The way dialogue is used to build dramatic tension throughout this scene is also noteworthy. Both direct and indirect speech are employed in this passage where Deborah's rage escalates while Skloot desperately tries to convince her that she is wrong. In the exchange of direct dialogue, Deborah "snaps" and then "yells", Skloot "tells" and then "yells", which builds to what should arguably be the climactic moment. Here it is worth including this dialogue again in full:

"Who sent you? Who's paying you?" [Deborah] yelled, her hand still holding me against the wall. "Who paid for this room?"

"We've been through this!" I said. "Remember? Credit cards? Student loans?"

Then, for the first time since we met, I lost my patience with Deborah. I jerked free of her grip and told her to get the fuck off me and chill the fuck out (The Immortal Life 283).

The inquit tag "said" here seems anomalous in such a volatile situation, particularly when used in conjunction with the exclamation mark. But the indirect representation of Skloot's own speech diffuses the climactic moment of the exchange. Had the final sentence of dialogue been represented directly, the passage would peak here. But, Skloot's - possibly exasperated, possibly desperate - cry is the last tone directly 
conveyed, before she loses patience and the scene ends in an anti-climax. For the rest of the chapter and well into the following chapter, Skloot is silent, apart from indirect representation of her thought and speech. The point here is perhaps hypercritical. But the purpose is to draw attention to the epistemic effects of skewing a narrative to emphasise the experience of the subject. In trying to give Deborah's experience "full [rein]" (Code, ER 142), Skloot does not offer the reader knowledge that accurately reflects her own experience. This example is also interesting in that Skloot sets the highest standard in the peritext - verbatim representation-for reproducing dialogue. She appropriates the rationale of one of Henrietta's relatives: "If you pretty up how people spoke and change the things they said, that's dishonest. It's taking away their lives, their experiences, and their selves" (The Immortal Life ix). While Skloot is particular about verbatim dialogue, she adopts the second part of this rationale for her subjects, but not for herself. A similar case occurs in the chapter entitled "Soul Cleansing”, where Skloot is present and records her reaction to Deborah's breakdown in the following way:

I'd been watching all this from a recliner a few feet away, dumbfounded, terrified to move or make noise, frantically scribbling notes. In any other circumstance I might have thought the whole thing was crazy. But what was happening between Gary and Deborah at that moment was the furthest thing from crazy I'd seen all day. As I watched, all I could think was, Oh my god ... I did this to her (The Immortal Life 292).

The ethical issue is clear here: Skloot is experiencing the fulfilment of her initial concerns that she was one more reporter imposing herself on the lives of the Lackses. She went ahead nonetheless, and in doing so pushed Deborah to her limits. This situation achieves some narrative closure in a following chapter, where Skloot is called up the front of Deborah's church and cheered by the congregation for her role in revealing Henrietta's story. Here, it seems, is justification-if not redemption-for Skloot. But for the rest of the chapter "Soul Cleansing", all of the dialogue represented belongs to Gary and Deborah, the other two people in the room; Skloot is again silent.

One could argue that Skloot's limited subjectivity combined with her objectivist approach is more epistemically responsible than mainstream journalistic practice, which often hides both process and perspective. Again, Kovach and Rosenstiel argue that the use of "the neutral voice" is a form of deception (74). Their statement echoes 
Kathy Roberts Forde's contention that "transparency rather than objectivity may well be the news value we most need in our postmodern age" (218), as well as a 2009 study which revealed "one striking new element [which] is the norm that the journalistic process be transparent-for both sources and the audience" (van der Wurff and Schonbach 412). Each of these journalism scholars might identify Skloot as an epistemically responsible practitioner by this standard, but as the analysis has demonstrated, apparently transparent texts can hide epistemic concerns.

Media ethicist Sandra Borden argues that the professional value of objectivity calls on journalists to "keep their feelings out of their stories," and where this is impractical or impossible, "professional standards encourage them to declare their empathy with a source or conflict of interest" (223). This analysis demonstrates that epistemic responsibility is reliant on more than a declaration. Skloot's debut work is one example of how literary journalism can merge facts, figures, statistics, emotions and perspectives without compromising a commitment to the highest standards of verifiability. But does this guarantee a sound epistemic foundation? First-person narration may seem to be less problematic in that it allows disclosure transparency in both research practice and ethical responsibility throughout a narrative. This would not have been possible had Skloot used an omniscient, extra-diegetic narrative mode such as that employed by LeBlanc or Cullen. Clearly, however, epistemic responsibility must be carefully assessed in spite of narrative techniques used. A balance is required between the objectivist goal of giving the object "full [rein]" and acknowledging one's subjectivity. Code explains that "to enjoin objectivism is to enjoin sensitivity to subjectivistic attitudes both in oneself and, where it touches one, in others" (ER 143). The point in this case is not the literary journalist's inattention to their subject, but to themselves as a subject of the narrative.

\section{Conclusions}

At the beginning of this chapter I proposed that issues manifested in (post)colonial experience are reflected in contemporary literary journalism. These include ownership of the land (or ownership of the story); the relationship between the land and its first and colonising peoples (or the relationship between story, subject and writer); and negotiation of colonial authority over the land (or the practitioner's authority over the story). People's stories are not terra nullius; at times they are highly contested sites of 
personal experience and representation for subjects and practitioners alike. This type of reflection invites ethical examination, but in this chapter I have identified epistemic implications involved in telling other people's stories. While "it is not possible to devise a rule of thumb for assessing the epistemic responsibility of other persons" (ER 175), Code nevertheless advocates enquiry into individuals' epistemic responsibility. In these analyses I have applied the types of reflexive questioning encouraged by Code, in order to assess the truth claims of three contemporary works of literary journalism. LeBlanc, Cullen and Skloot are not merely members of an epistemic community. To appropriate Code's terminology again, these practitioners are both "conservers and modifiers" of literary journalism. As such, they have a "constitutive role" to conduct their "moral and intellectual life so as to contribute to the creation and preservation of the best possible standards appropriate to the practices within which one lives" (ER 194). Each practitioner is clearly cognisant of this responsibility, and demonstrates a high degree of epistemic responsibility. The purpose of these analyses has been to highlight both strengths and gaps in literary journalism's epistemic foundation, to reflect on current practices, and suggest areas of improvement for future practitioners.

LeBlanc's Random Family invites epistemic questioning that asks: Whose knowledge is this? Is representation epistemically responsible and defensible? Does the scope of enquiry legitimate such knowledge and judgments? At times the answers to these questions are opaque in LeBlanc's narrative. But an analysis of Random Family suggests that where the discipline of verification fails, an evaluation of epistemic responsibility provides a strong evaluation of the "truth value" offered. Code's assertion that a "knower's" location with respect to the object of their inquiry is integral to the production and justification of knowledge claims" guides this analysis (ER 106). There are substantial differences between LeBlanc's and Cullen's access to sources, types of knowledge (personal, communal, relational, generational), and truth claims, indicating that there are distinctions between types of immersion journalism and the knowledge they can offer. Immersion is, however, the key characteristic of epistemically responsible practice.

Cullen's book raises the issue of the media as a source of knowledge rather than seeker of knowledge, but complicates its strong critique by participating in the same 
process it condemns. Columbine is a painstakingly researched reconstruction of a national tragedy, and deserves the critical praise it has garnered. But the analysis of Cullen's epistemic responsibility suggests that, like other practitioners, Cullen has epistemic "blind spots" that simultaneously produce strong truth claims and destabilise his version of events as the definitive account. Again, for Code, the ability to be "critical of one's own knowing is a crucially important aspect of epistemic competence" (ER 176). But in Columbine the potential fluidity of representation built on facts is not acknowledged. In the same way, "facts" which do not cohere with Fuselier's and Cullen's diagnosis of psychopathy are glossed over. This raises the questions: Are the knowledge and truth claims of Columbine epistemically justifiable? Is Cullen, to appropriate Code's words, "in a position to know" that his truth claims are definitive ( $E R$ 39)? Or is this, finally, Cullen's story? Alternate versions of the Columbine tragedy suggest that this is indeed Cullen's story, but the combination of narrative mode and paratextual framing lead readers away from this conclusion. Rhetorical devices and lack of attribution hide Cullen's subjectivity in a way that, I argue, paratextual disclosure is unlikely to rectify. The cyclical structure of questions and answers works as a self-verification mechanism for the narrative that further reifies this version of events and reinforces Cullen's personal judgmentsalbeit judgments based on extensive, immersive research. The online epitext is offered as disclosure transparency, but I have argued that the effect is a closing off of potential plurality of meanings as the narrative itself frames the online research resources. Again, Cullen's research effort is extraordinary, but this analysis exposes the tension between definitely "truth claims" and the epistemological possibility of "knowing well" with limited access to sources and resources.

And finally, Skloot's narrative has been praised for its depth of research, the emotional depth it evokes, and the quality of the reporting. Indeed, this acclaim is well deserved. But analysis of epistemic responsibility triggers the question: what is a literary journalist's epistemic duty to reveal how their subjectivity shapes the narrative? I have argued that the first-person narrative mode conceals epistemological concerns that need to be addressed in the process of constructing a narrative. Ethical issues are undoubtedly central to The Immortal Life of Henrietta Lacks, but I argue that the emphasis on these precludes rigorous epistemic questioning. The metaphor of narrative-Deborah and Skloot both employ this lexicon-adds an authenticating 
layer to the story; this inclusion seems to suggest that Skloot has considered problematic issues of representing her subjects in a narrative mode, but the anticlimactic ending to her altercation with Deborah suggests that further reflection is needed in this area. This scene also raises issues of how a practitioner's selfknowledge is represented in literary journalism-is an emphasis on a subject's experience detrimental to the "truth value" of a text? This analysis suggests the answer is yes. The Immortal Life harnesses "the power of the real" to produce an emotionally engaging, vividly rendered narrative. It is indeed "a heroic work of cultural and medical journalism", a "moving" story of "modern medicine and bioethics" and "full of poignancy and humanity" (dustcover). But it also raises important epistemic questions that are useful for the continued theorisation and practice of literary journalism.

There is no doubt that between 2000-2010, Rebecca Skloot, Dave Cullen and Adrian Nicole LeBlanc all established themselves as powerful new voices in contemporary media. While already relatively successful in their freelance work, publication of book-length works of literary journalism has placed them as politically, socially and culturally significant interpreters of our time. Skloot and Cullen's narratives are arguably as important for what they say about the media and modern forms of storytelling as for their compelling investigation of contemporary issues. The differing narrative modes, frames negotiating the author-reader contract, research methods and narrative styles employed by these three practitioners are typical of the range of practices represented in literary journalism — although nowhere near exhaustive. They also represent, however, the "new form of clean classicism" that signals maturation from the days of New Journalism, and further suggests that contemporary literary journalists are aware of the increasing importance of transparency in practice. The readings undertaken in this chapter reveal the complexities initiated by online access to epitextual sources, and suggest that writers must carefully negotiate the intratextual, peritextual and epitextual claims of their narratives to avoid sending contradictory messages to readers, undermining research efforts, or making unsustainable truth claims. 


\section{Chapter Six}

\section{Contemporary Australian Literary Journalism}

In his 2009 call for international scholarship on the discipline, Norman Sims acknowledges that literary journalism is not only an American phenomenon, but that it appears in other cultures with variations. He writes: "International forms that are akin to what we call literary journalism often put more stress on social usefulness than on artistry, which may be one of many marks that distinguish them from the North American varieties" ("Problem" 10). While LeBlanc's Random Family, Cullen's Columbine and Skloot's The Immortal Life of Henrietta Lacks have been acclaimed for their style or artistry as demonstrated in the previous chapter, this does not preclude or diminish their social function. Issues of race, class and violence focalised through the lens of individuals' experiences do represent, and to some extent encourage reflection upon, wider social problems in the United States. However, the limited range of subjects - or "hyper-personalisation"-of such issues does tend to over-simplify "enormously complex histories [while] diverting attention from other important social, political, geostrategic, religious and environmental factors" (Keeble 84). By focusing on individual experience rather than sites of group conflict, is North American literary journalism offering a way to understand the complexities of the social world? Or does it privilege individual experience? John Pauly takes up this theme in his 2011 keynote address to the International Association for Literary Journalism Studies, asserting, "Literary journalism, at least in the United States, has typically preferred the cultural to the civic. It discovers its most profound stories in humans' quest for meaning, rather than in the civic drama of news" ("Drama" 79). Pauly contends that this focus on the cultural is to the detriment of meaningful reporting on civic life. He asks: "Is it possible for literary journalism to describe a social field, in which individuals are not the entire focus but moments in a larger social process, in the way that cultural studies and sociology regularly attempt?" ("Drama" 79)

While literary journalism in the United States "has typically preferred the cultural to the civic", civic issues predominate in Australian literary journalism. Cultural concerns underlie many Australian works of literary journalism, but they are often 
explored through the lens of civic life and group conflict. From Guy Rundle's Hunter S. Thompson-esque election coverage to David Marr's narrative exposés into political crises, and from Paul McGeough's coverage of the Middle East to Malcolm Knox's critique of the jury system, Australian practitioners are deeply concerned with understanding the meaning of group life, responsibility, and civic conflict. ${ }^{33}$ In 2003 Mark Mordue observed the beginning of "a renaissance in Australian non-fiction" that featured "a radical hybridisation of style and content." He also suggested that this might be a result of readers seeking "recognition and identity in the non-fiction form" when it is lacking in fiction (Mordue). As will be argued in this chapter, concern with civic life in fact performs this function in landmark works of Australian literary journalism: that of examining and developing national identity.

An apposite example is John Bryson's 1985 classic Evil Angels. Bryson's book is arguably Australia's most recognisable work of literary journalism. Of the seven books written about Azaria Chamberlain's death, it unquestionably had the greatest impact in shifting public sentiment toward Lindy Chamberlain, who was accused of killing her nine-week-old daughter at Ayers Rock in central Australia in 1980. Like In Cold Blood, Evil Angels is written in an omniscient mode, features fully reconstructed scenes and dialogue in full, as well as narrative devices to contextualise the Chamberlains' religious background. Penny Pether has compared Evil Angels with In Cold Blood in that both represent "judgments about law and society, and thus about nation" (45). Pether further observes that Evil Angels and David Marr's and Marian Wilkinson's more recent Dark Victory (2004), share an interest in the role that legal actors, judges and lawyers play in "the epic of Australian national identity". She writes that Bryson,

a lawyer by training and at his best as a writer in the genre of literary journalism, uses ... characters ... as stalking horses for his dissection of a grim pettiness and hostility to people who are "not like us" that characterize Anglo-Australia at its worst, and of how the law becomes complicit in and compounds this moral failing of the dominant national culture when due process is no more than ... "surreal epistemology" (45).

Dark Victory, a narrative investigating the plight of asylum seekers in Australia, similarly depicts what happens when "the potent fictions of the rule of law become no more than cynical sham" and how "ancient fears of invasion by immigration... become 
the dominant cultural story, and circumscribe the vision of how the nation's past might shape its future" (Pether 45). Evil Angels and Dark Victory are stylistically dissimilar. If Bryson's work can be compared with Capote's, a helpful comparison can be made between Dark Victory and Woodward's and Bernstein's All the President's Men (1974) in both style and function as political exposé. These two books reflect the diverse characteristics of literary journalism, as does their content. But does this diversity preclude any guiding sense of purpose? Is there any evidence that literary journalism performs a cultural or political function in Australia comparable to that of the New Journalism?

The underlying concerns of these two books are consonant with those analysed in this chapter. In fact, I contend that a significant amount of Australian literary journalismthe subjects of which range from murder trials to asylum seekers, Royal Commissions to deaths in custody, and sexual harassment claims to old-growth forest logging-is concerned with the question: what does it mean to be Australian? This is manifested in various ways: How does a country with a colonial past come to understand itself as a postcolonial society? How can Indigenous, Anglo, and "other" Australians identify with each other? Who has power? How can it be shared? And if a homogenous notion of "being Australian" does exist, why is it so hard to relate to "others" who are "not like us" (Pether 45)? The stories Australian literary journalists tell about the land and people's relationship to it represent an effort not to rewrite the history books, but rather to make sense of a fragmented contemporary society, and to challenge established constructions of national identity perpetuated by mainstream media.

Terra nullius is an apt metaphor to describe the current state of scholarship on Australian literary journalism. In 2003 Mark Mordue identified a critical need for dialogue between journalism, the academy and Australia's literary fraternities given the lack of traditional outlets for long-form literary non-fiction (n.p.). But as recently as 2011, Sue Joseph has observed there is still a "dearth of research" into emerging forms of non-fiction in Australia ('Creative Non-fiction' 32). If there is currently a discussion taking place, Joseph writes, it is only happening among a small number of practitioner/academics in various universities, and to date it does not hold any sort of cultural gravitas (“Australian" 38). Yet literary journalism, itself a "no-man's land" for so long, is a powerful medium through which Australian stories can be told. The 
discussion in chapter one shows that scholars of literary journalism have learned valuable lessons about the importance of inclusiveness, honoring differences, the effects of labelling, and, most recently with the emergence of international scholarship, the power made available by open dialogue and a willingness to learn from other traditions (see Bak). These are lessons both practitioners and scholars can bring to the contemporary practice of Australian literary journalism. Literary journalism is largely unexplored territory in scholarship for a number of reasons, not least of which is the historic divide between the literary and journalistic communities. Here the metaphor of "no-man's land" in the sense of contested — but unoccupiedground in a war is particularly apt. The literary establishment in Australia considered mainstream journalism a disreputable profession well into the twentieth century (Hirst 89), a situation comparable to Tom Wolfe's standoff with "Literary Gentlemen in the Grandstand" in the US. In turn, Australian journalists have traditionally regarded themselves "great destroyers of intellectual pretensions" (in Conley 50), leaving those who practise the self-conscious or "highbrow" tradition of literary journalism without a home. While conditions have thus been historically unfavourable for the practice of literary journalism, Ricketson notes that the current "vibrant" state of book-length mainstream journalism in Australia is quantifiable through commercial and critical success. In the same study he also contends that contemporary practice outstrips the scholarship surrounding it (“Book-length Journalism” 76).

Robert Boynton's The New New Journalism (2005) thus does not have an equivalent in Australia. However, Joseph's paper titled: "Australian Creative Non-fiction" (2011) contains interviews with twelve practitioners, six of whom have produced a book-length work of literary journalism as it is defined in this thesis. This article provides some useful connections and contrasts between North American and Australian contemporary literary journalists. While Boynton's interviewees more readily identify themselves with a tradition than their Australian counterparts, practitioners from both countries have demonstrated a reluctance to be labelled in a specific field. Joseph notes that her interviewees are almost of one accord in questioning the need for labelling what they do. She further observes that there is something idiosyncratically Australian about this response: "idiosyncratic because the dismissive nature of the responses carry ... a 'larrikin' element - they really go against the gravitas accorded the discussion in the USA and UK" ("Australian" 49). 
While this may be so, resistance to labelling is demonstrably a global issue, and the "larrikin" element perhaps is more indicative of some antipathy towards the academy rather than the seriousness with which Australian practitioners approach their work. Nevertheless, in spite of the absence of a readily identifiable canon, consensus on a name, or a perceived need for a name-all issues Australia shares with the field worldwide - a new generation of literary journalists not only exists, but is also making a powerful impact on Australian national identity and culture.

The relatively short history of the nation since Federation in 1901, combined with its colonial past, has produced different conditions for the production and reception of literary journalism to those in the US. These conditions have arguably been influential in shaping its production and function. The first can be characterised as a lack of an identifiable tradition of Australian literary journalism, combined with the paucity of resources to sustain one. This is a catch-22 situation: without a strong tradition, resources are unlikely to be allocated, but without resources, a tradition cannot develop. There are, however, exceptions. Some scholars contend that Australia did not have the wave of New Journalism the US had (Josephi and Muller 72), but Denis Cryle argues that the Nation Review, established in 1972, represents a "home grown" form of what was taking place in the US during that decade (see also Joseph, "What If"). Rather than imitating American trends, Cryle contends that the iconoclastic, satirical, "larrikin" characteristics of that publication were "pre-eminently anti-British and anti-respectable rather than modelled on American trends" and aimed to "redefine the relationship between writers and readers to break down the aura of impersonality" (np). He also cites the "new nationalism of the period" as a catalyst for the emergence of the publication, whose editor listed the need "to explore the possibility of being Australian" (np) as a prime objective. In this, Cryle aligns his analysis with Hartsock's understanding of literary journalism as a response to social transformation (193), although MacCallum emphasises that "Australian New Journalism was much more evolutionary than its often revolutionary and celebrated American equivalent" (in Cryle np). This evolutionary quality is still evident in contemporary works, as the analyses in this chapter demonstrate.

Importantly, it has also been noted that while the mainstream press was commercially driven, Australia's wave of literary journalism was enabled by "the largesse of liberal 
millionaire, Gordon Barton," who "gave the Review and its talented contributors unprecedented freedom to engage in political parody and to challenge the moral certainties of conventional and daily journalism" (Cryle). The impact of the Nation Review, however, was limited. Pauly is one of many who identify New Journalism as a turn towards questions of culture in order to capture that era's sense of its own experience ("Drama" 77). But without the steady, influential presence of publications such as the New Yorker, Esquire, Harpers, the Village Voice and Rolling Stone, Australian literary journalism has not received either the institutional or public recognition it has in the US. Ricketson notes that, along with Nation Review, "Magazines like Australian Society and the Independent Monthly ... sometimes ran literary journalism but either did not have the money to support the research time literary journalists needed or the know-how to train journalists in this demanding form. It has largely fallen to individual journalists to do their own experiments" ("True Stories" 156). Subsequently, without funding for sustained investigative work, Australian practitioners did not have the resources afforded the "prose poets of the quotidian" (Boynton, The New New Journalism xv), hence they applied the discipline of narrative literary journalism to current affairs, politics and civic drama.

This civic focus remains dominant in Australian literary journalism. Between 2000 and 2010, three Australian practitioners produced their first book-length works. Margaret Simons's The Meeting of the Waters: The Hindmarsh Island Affair (MOTW) (2003), Chloe Hooper's The Tall Man: Death and Life on Palm Island (2008) and Anna Krien's Into the Woods: The Battle For Tasmania's Forests (2010) all explore power relations between citizens and authorities through the prism of a "civic drama". Significantly, cultural or ideological clashes give rise to group conflict in each case, thus cultural concerns are also central in each text. Conflict located at the intersection between culture and civic responsibility exposes power imbalances, thus the relationship between the two domains is largely symbiotic. Consequently, a common thread running through these texts is an analysis of society where personal (and national) identity, beliefs and practices clash with civic duties and their enforcement. While literary journalism's historical tradition of providing a voice for the marginalised is manifested in these texts, each practitioner attempts to provide a range of perspectives around the conflict, including those of business stakeholders, members of government, law enforcers and media personalities. These are events in 
which "individuals are not the entire focus but moments in a larger social process" (Pauly, "Drama" 79), or as Margaret Simons puts it, she is writing about "figures in the landscape" (MOTW 294). A deeper question then underscores the narratives: what do these stories reveal about what it means to be a figure in Australia's national landscape?

Along with Simons, Hooper and Krien discredit the idea of "an" Australian national identity. All demonstrate the myth of collective identity through the exploration of group conflict. Each of the practitioners also writes with an implicit awareness that they are both deconstructing and shaping national identity, a process that is mirrored by their own personal journey of reflection and discovery. A significant implication of this theme is that, while "outsiders", all three also consciously place themselves within the conflict by virtue of their relationship with their subjects and highly reflexive first-person narrator voices. This decision impacts on each narrative in different ways, but a shared anxiety is evident in the texts over the representation of events and concomitant issues regarding epistemic responsibility.

This anxiety may be due to a number of factors, but the strongest is arguably the influence of the epistemic community. Again, for Code, communities of "knowers" are "epistemologically relevant [in assessing truth claims], for they act as enabling and/or constraining factors in the growth of knowledge" (ER 26). Australia's relatively small population results in national media coverage for many significant or ongoing events. The three issues represented in these narratives - a dispute over the building of a bridge in South Australia, an Aboriginal death in custody and subsequent riot on Palm Island, and the logging of Tasmanian forests-have all attracted national media coverage over extended periods of time. Critics and the wider reading public are therefore often familiar with the "facts" of cases and conceivably take a position on events before book-length literary journalism is produced. For example, referring to the death in custody that is the subject of Hooper's The Tall Man, Queensland academic Cheryl Taylor writes, "Like most Australians, I knew of the events ... only through the media reports. These rarely revealed the experiences and attitudes that underlay the actions of the police and the Indigenous people involved" (36). Consequently, these three Australian literary journalists not only construct narratives to explicate the meaning of events, but must also work in 
opposition to ideologies ingrained in the national consciousness and reinforced by stereotyping in mainstream media. The "backyard effect"- the sense that events with national significance happen in close proximity to all Australians-increases the vulnerability of texts to competing narratives and emphasises the role of epistemic responsibility for the literary journalist.

An associated factor contributing to anxiety over representation is that of Australia's recent, colonial history. An "outsider" knowingly and intentionally trespassing on established or occupied ground has deeply resonant overtones for a country still coming to terms with its colonial past. Knowledge - or truth claims - about "others" are equally fraught. Practitioners must tread carefully to avoid alienating their readership, many of whom may have a personal investment in —or connection to - the events represented in their narrative. Manifesting as the "history" and "culture wars", ongoing dialogue over (post)colonial issues such as identity, citizenship, ownership of - and relationship to - the land are often passionate and polarising. Australian journals such as Meanjin, The Monthly, Quarterly Essay, The Sydney Papers and The Griffith Review regularly engage with issues related to national identity, often through the lens of controversial issues such as those represented in this chapter. Further, as independent practitioners, Simons, Hooper and Krien do not have access to the authority invested in reporters who are supported by a media institution. As suggested in chapter three, literary journalists are not protected by the boundaries afforded mainstream journalists, such as the critical distance offered by the objectivity standard. Therefore, readers familiar with the events will likely have a vested interest in knowing practitioners' motivations and agendas. For literary journalists endeavouring to shed light on national consciousness, the recasting of facts in narrative form is indeed a complex and sensitive task.

The purpose of this chapter, then, is twofold. Firstly, I investigate how these three practitioners negotiate epistemic responsibility. Using Code's notion of epistemic responsibilism, I read the paratextual contracts juxtaposed against the rhetorical effect of the narrative itself. The narrative voices in these works of literary journalism are analysed, and I demonstrate how the anxiety over representation can be read as an effect produced by an increasingly polarised, cynical epistemic community. And secondly, in the absence of substantial scholarly work examining the character of 
Australian literary journalism, this chapter suggests that one way of conceptualising contemporary practice is to explore what it means to be Australian. The following section will give background to the texts, before moving into an analysis of epistemic responsibility.

\section{The Storytellers and their Stories}

On July 19, 1995, a Royal Commission inquiry began into what became known as The Hindmarsh Island Affair, a dispute over whether or not a bridge should be built connecting the mainland to a small island in Lake Alexandrina, South Australia. Effectively, two main groups of local residents emerged in the investigation: those who supported the building of the bridge, and those who opposed it on grounds that the river is sacred. Some indigenous opponents of the bridge claimed that building the bridge would interfere with the "meeting of the waters" 34 where salt and fresh water mixed in the Goolwa estuary, which would have adverse effects on female fertility. The details of how or why this would happen, however, were only revealed incrementally over the course of the Royal Commission inquiry, a process that was taken by some as evidence that the purported traditions were fabricated. Of most significance to the case, however, were the protestors' claims that the traditions could not be made known to men. This gave rise to the moniker "secret women's business", a phrase which has entered the Australian lexicon to connote suspect activity. Those who supported the building of the bridge, known as the "dissident women", 35 claimed knowledge of neither the secret traditions of Hindmarsh Island, nor the relationship between the meeting of the waters and female fertility. The Commission was hampered by the inaccessibility of "factual" evidence, a poor initial investigation as well as vast divides in ideological and epistemic foundations. But it found that sufficient evidence was not available to justify protecting the site as sacred, and ordered that the building would proceed. This finding was effectively overturned in 2001 by the Federal Court of Australia, but by that time the bridge had already been built. A huge rift had also opened up in public opinion regarding the authenticity of the "secret women's business", and the larger issue of Aboriginal land rights. The Hindmarsh Island controversy proved to be a watershed for indigenous affairs as the battle between competing narratives played out in Australia's mainstream media. 
South Australian journalist Margaret Simons was initially drawn to the Hindmarsh Affair after reading a book by journalist Chris Kenny, who had covered the story to date and was sceptical of the proponent women's claims. ${ }^{36}$ Kenny initially broke the news that the dissident women denied the existence of secret women's business, and was critical of the "political correctness" he perceived as overwhelming "common sense among anthropologists and journalists who should have been less gullible" (Simons, MOTW 125). Simons's research culminated in The Meeting of the Waters: The Hindmarsh Island Affair (2003) as well as the creative writing component for her doctoral thesis of the same name, subtitled: An Exercise in Creative Non-fiction and Investigative Journalism. ${ }^{37}$ Despite this subtitle, Simons prefers the term "narrative journalism" to creative non-fiction for the absence of negatives (Joseph, "True Stories" 92). Throughout the narrative it becomes clear that Simons supports the case for secret women's business on the grounds that the dissident women did not have access to the oral narrative that gave birth to opposition to the bridge. This position attracted some criticism after publication, as will be discussed. Nevertheless, as Ricketson notes The Meeting of the Waters has been recognised as the most thorough, fair-minded and revelatory account of the Hindmarsh Island affair ("Ethical Issues" 92). It was shortlisted for four awards and won the Queensland Premier's Award for non-fiction in 2003.

Like Simons's book, Hooper's also explores the relationship between identity, stories, and the land, through the lens of civic conflict. The Tall Man (TM) covers an inquest into the death in custody of Cameron Doomadgee, an indigenous Australian and resident of Palm Island. Following the 1991 Royal Commission into Aboriginal Deaths in Custody, the suspicious circumstances surrounding Doomadgee's death and the following police investigation created a firestorm in the media nationwide. Essentially, public opinion was divided between support for the attending police officer, Senior Sergeant Chris Hurley, who claimed that the fatal injuries causing Doomadgee's death were the result of tripping over a step in the Palm Island police station, and those who believed that Cameron's injuries were maliciously inflicted by Senior Sergeant Hurley. ${ }^{38}$ These injuries included a black eye, four broken ribs, a ruptured portal vein, and a liver almost cleaved in two-damage that the inquiry found comparable to the effects of a high impact car accident. Doomadgee's death occurred on November $19^{\text {th }}, 2004$. On June $20^{\text {th }}, 2007$, after the case against Hurley 
had been dismissed and then reinstated, a Supreme Court jury acquitted Senior Sergeant Hurley of manslaughter and assault charges. Two years after the book's publication, the inquest was reopened; Hurley apologized to the Doomadgee family, but maintained he did not regret his actions on the day. At that inquest's conclusion, the coroner stated that he could not make a definitive finding due to the unreliability of police and aboriginal witnesses. While the first inquest and subsequent manslaughter charge form the core of The Tall Man, author Chloe Hooper notes that Doomadgee's death is just one such case in a chain of deaths in custody, and greater cycle of violence and oppression of Australia's indigenous people. As such, Hooper draws on historical sources: literary and historical figures such as Conrad's Kurtz, T. E. Lawrence, George Orwell and Robert "Uncle Boss" Curry, as well as indigenous mythology to tell Doomadgee's and Hurley's story, but also a wider story of colonial oppression and madness.

While many Australian practitioners of long-form literary journalism—such as David Marr, Guy Rundle, Paul McGeough, Fiona Harari and Jacquie Everitt - are currently practising daily mainstream journalists, Hooper is primarily a novelist. ${ }^{39}$ The recipient of a Fulbright scholarship, Hooper studied creative writing at Columbia University under Philip Roth and worked as an intern at the New Yorker, an experience that connected her to the US tradition of literary journalism. Hooper's 10,000-word essay on the death in custody of Palm Island Aborigine Cameron Doomadgee for The Monthly magazine won a Walkley_Australia's highest award for journalism — for magazine feature writing, and was later extended and published as The Tall Man: Death and Life on Palm Island (2008). In book form, The Tall Man garnered nine awards, and most recently a screen adaptation won a second Walkley for best longform journalism.

The most recent of the three texts analysed in this chapter, Into the Woods examines the issues involved in one of Australia's longest-running civic battles. For decades, mainstream journalists have covered the incremental developments in an ongoing dispute between loggers, politicians and environmentalists in Australia's smallest and southern-most state, but a particularly vicious outbreak of violence between loggers and environmental activists brings Anna Krien to the island. After viewing disturbing footage of the incident, Krien books a passage from her native Melbourne to 
Launceston, Tasmania's northern port city, where she begins what initially is a threeday investigation of the protest. Inevitably, three days stretches into a month, and one trip into four, as Krien is one of the literary journalists who, "[r]ather than hanging around the edges of powerful institutions ... attempt to penetrate the cultures that make institutions work" (Sims, Literary Journalists 3). Krien then immerses herself in the issues, interacting with players as diverse as loggers, politicians, activists, farmers, wood-workers, scientists and publicans. Beginning as a cover story for The Big Issue in 2009 , Krien says the initial essay "felt like ... the piece that everyone would have done. There were stereotypes; still a veil over everything" (Attwood). The essay was subsequently lengthened, and Into the Woods was published in 2010. To date the book has been shortlisted for five awards, winning both the Queensland Premier's award for Literary or Media Work Advancing Public Debate, and the 2011 People's Choice Award in Victoria. As indicated by these awards, the book has received an overwhelmingly positive reception from critics and Krien's growing readership.

Of the three practitioners represented in this chapter, epitextual evidence indicates Krien has the strongest link to an American tradition of literary journalism. Amanda Lohrey describes Krien as "the reincarnation of Hunter S. Thompson-in female form," asserting Krien has "suddenly come out of left-field to almost reinvent Gonzo journalism in Australia, the first attribute of which is fearlessness" (in Wessman). Similarly, writer and critic John Birmingham claims that Into the Woods would have been described as New Journalism if written in the 1960s (Birmingham). The link is astutely made as Krien notes Tom Wolfe and Joan Didion among her influences (Attwood), indicating that Krien identifies more with the US tradition than with Australian iconoclasts. In an epitexual online interview, she states that the best nonfiction uses the tools of fiction to tell a story in the tradition of Didion and Wolfe, whose non-fiction "you read ... and it's alive, and I find sometimes it's more alive [than fiction]" (Byrne, Author Anna Krien). Despite these influences, Krien writes with a distinctly Australian voice. She brings immediacy to her writing through fully reconstructed scenes and dialogue, vivid imagery, and present tense prose. It is perhaps her exposed subjectivity and the investigation-as-journey metaphor, however, that most closely links Krien with the New Journalists. Rather than the sustained lyricism of Truman Capote or metaphysical musings of Wolfe or Didion, Krien's style oscillates between highly evocative description of the natural world, personal 
introspection, Australian colloquialisms and dialogue, extended discursive passages and objective reporting.

\section{Epistemic Community and the Shaping of Australian Literary Journalism}

The nature of literary journalism's epistemic community in Australia is such that the roles of literary journalist, journalist, historian, writer, critic, academic, public intellectual and media commentator often overlap. A salient example from an earlier chapter can be found in the criticism of Garner's The First Stone; a representative selection of the book's critics include Kaz Cooke (novelist, cartoonist, non-fiction writer, columnist), Ann Curthoys (academic, historian, public intellectual), Mark Davis (writer, media commentator, public intellectual) and Inga Clendinnen (academic, historian, memoirist, public intellectual). The latter three, Curthoys, Davis and Clendinnen, have also been-and continue to be-important voices in the "history" and "culture wars" (see for example Ann Curthoys; Davis, Gangland; Davis, "Turf War"; Clendinnen, "Making Stories"; Clendinnen, “The History Question”). Consequently, the degrees of separation between literary journalist, colleague and critic are few indeed.

Conley reports in a 1998 study that since 1830, at least 168 Australian journalists have published novels (46). Simons also notes the anecdote that there are only two types of ambition in Australian journalism: "those who wanted to leave and write novels, and those who wanted to be editor of the [Melbourne broadsheet] Age. I was one of the former" (Fit to Print 4). Given the high degree of familiarity amongst Australia's epistemic community—or "community of knowers" (Code, ER 245)—combined with the lack of identifiable literary journalistic tradition, and distinct divides between the journalism and literary practices, Australian literary journalists are, to a large degree, risk takers. Simons, again, highlights this state in Fit to Print when recounting reactions to her heavily subjective essay published in the magazine Eureka Street. She writes that Sydney Morning Herald journalist Margo Kingston "warned me that there were a few people who might not want to talk to me again. '[Author, journalist and essayist] Laura Tingle is cross because she thinks you called her husband a has-been. She says you wrote it more like a novel than an article.' 'That was kind of the point,' I said" (Fit to Print 34). 
A combination of these factors: a relatively small, tightly-knit epistemic community, Australia's "history" and "culture wars" and national dialogue over the politics of representation conceivably influence the literary journalistic voices of Simons, Hooper and Krien. All three practitioners present themselves as "outsiders"; their initial narrative stance is one of "not knowing". In each case, an anxiety is evident over how they will be perceived as "knowers" by their subjects — and, implicitly, their readers. Consequently, all three texts are highly reflexive. Each practitioner is also concerned with the limits of their knowledge, which, for Code, "is a crucially important aspect of epistemic competence" (ER 176). But are these texts epistemically defensible? Unlike LeBlanc's and Cullen's books, the Australian texts are punctuated by self-questioning that rarely resolves. This anxiety is more resonant with Skloot's epitextual concerns over representation, but - unlike Skloot-Simons, Hooper and Krien use rhetorical questioning and reflexivity to propel their narratives forward. Further, this epistemic stance of "not knowing" is not limited to these practitioners. As noted in chapters three and four, Garner also crafts her narratives with deeply personal, introspective questioning that leads her to a privileged place of "knowing"- a stance that urges her readers to read her reflexivity as humility. Anna Funder's Stasiland (2003) has a similar approach; Lever observes that Garner and Funder "have expressed mutual admiration, and the books have in common the establishment of an authorial persona who asks both readers and interviewees to trust her observation, sensitivity, and moral strength" (1). ${ }^{40}$ This authorial persona is also evident in Simons's, Hooper's and Krien's literary journalism, indicating a nascent tradition-beginning with Garnermay be developing among these writers.

The "truth claims" in The Meeting of the Waters, The Tall Man, and Into the Woods are, consequently, heavily reliant on the truth of personal experience. As Giggs writes, "Truth, for many of these authors [including Garner, Simons, Hooper, and Krien], is a product of bodily experience. Of registering a fact that loosens something in the nervous system, only later made available for cerebral analysis" (71). This state is a clear departure from the truth claims found in the work of LeBlanc, Cullen and Skloot. Notwithstanding LeBlanc's disclaimer that the truth of Random Family is "her" truth (Boynton, The New New Journalism 247), each narrative analysed in the previous chapter displays a stronger reliance on observable, empirically verifiability to produce truth claims. While epistemic defence and verifiability are still concerns for the 
Australian practitioners, there is a fundamentally different process of production of truth claims: one that draws on a personal connection with the narrator-as-seeker, rather than narrator-as-knower. For these literary journalists, knowledge is personal, subjective, complex, subject to distortion, and to be critically evaluated at every point.

The telling of indigenous stories by non-indigenous practitioners also raises special epistemic challenges, as in the cases of Simons and Hooper. Seierstad's book, examined in chapter four, demonstrates some difficulties in representing different cultures, but an Anglo Australian representing Indigenous Australian subjects evokes different epistemic considerations again. A central issue here is a practitioner's epistemic responsibility towards subjects whose concepts of knowledge and truth are based on a fundamentally different epistemological foundation. Scholars such as Connery rightly assert that "verifiable detail is essential to the literary journalist" (Sourcebook 6). But how does a practitioner approach knowledge that seems unverifiable because it is based on what Anglo tradition would consider myth? For Code, this requires a value judgment: "When alternative ways of making sense of experience are allowed, we require some standard of value to guide our efforts toward reasonable choices of experts and authorities" (78). Believing that a purely objective assessment of empirically verifiable facts would unavoidably skew the investigation, Simons's and Hooper's task is not only to discover the "facts", but also to investigate and convey their subjects'-purely subjective-experience. Their selection of indigenous subjects as experts and authorities indicates recognition and value of an alternative epistemological foundation. Simons's and Hooper's efforts to understand and represent those differences play out the ethics of belief, and set their narratives in opposition to those who do not acknowledge knowledge that cannot be characterised as "the facts".

Despite this emphasis, or perhaps because of it, Simons's The Meeting of the Waters also demonstrates a strong commitment to disclosure transparency. A combination of competing - aggressive - media coverage, the book's alternative journalistic ambition and the threat of libel underpins its extensive peritext. Simons does have a personal website, but, unlike Skloot's or Cullen's, no framing information is given beyond the book's awards. The peritext is comprised of an author's note and acknowledgements (three pages); a "Prelude" (two pages); a "List of Characters" (eight pages); a timeline 
(seven pages); notes and references (25 pages); an index (11 pages); and a map. Here Simons highlights her investigative credentials while offering her readers the chance to cross-reference her sources. She also delimits the boundaries of her research: in both the author's note and list of characters she highlights subjects who declined to be interviewed. Simons raises the issue of epistemic as well as ethical limitations from the first page by acknowledging that she is a white woman - an outsider to indigenous beliefs and culture-representing sacred or taboo indigenous events (MOTW xi). Like Cullen in Columbine, Simons sets up her narrative in opposition to competing accounts, but Simons's truth claims are for journalistic integrity (see Ricketson, "Ethical Issues" 90) rather than a definitive version of events (Cullen, Columbine dust cover).

But such epistemically responsible practice has not protected the book from criticism. Anthropologist Ron Brunton has attacked Simons on the grounds of interpretation and omission, writing: "There are ways of assessing what [journalists] say-internal consistency; consistency with other seemingly reliable sources; the extent to which their statements ring true with our experiences and those of our fellows". He then cites examples of Simons's “interpretations" (160). Brunton also questions Simons's investigative credentials, asking why she did not check police files to establish anecdotal claims that she portrayed as evidence: "Strangely, this obvious program of research does not seem to have been undertaken by ... the investigative journalist. I cannot help but wonder why" (165). Brunton's criticism here is challenging Simons's intellectual integrity: she has been selective in her investigation to further her interpretation of the evidence, following "a long and unfortunate tradition whereby patronizing whites assimilate Aborigines into convenient and preconceived stereotypes" (161). Simons successfully refutes both of Brunton's criticisms, however, in a response to his article, referring to source information that had been edited out, official transcripts, as well as fully documented interview notes. ${ }^{41}$ What this sequence of criticism and defence demonstrates is the limitations of disclosure transparency. As demonstrated in the cases of McGinniss, Fuller, LeBlanc and Cullen, transparency can also increase criticism rather than understanding (Allen 323). Simons's case demonstrates that even in providing a "web of facticity" (Tuchman), practitioners must be selective about what can be included, and omissions can provide a target for criticism. 
Brunton's criticism is particularly interesting in light of Simons's effort to avoid "assimilat[ing] Aborigines into convenient and preconceived stereotypes" (Brunton 161). In the reconstruction of interviews, Simons employs extended characterization and dialogue in full to capture the complexity and individual "voices" of those stereotyped in mainstream media. Her first meeting with indigenous bridge opponent Henry Rankine, for example, facilitates this process. In this passage Simons expects a cultural stereotype: the "big and probably bearded, perhaps a little frightening" Aboriginal elder. The stereotype is dispelled, however, by the gentle act of a man "handing an elderly woman into a car," while the details of the "bouncy" Rankine with his baseball cap and running shoes lend the scene a feeling of levity - and indicate both Simons's relief and chagrin (MOTW 44). This passage is typical of characterisation throughout the narrative. Like Skloot's use of tiny details (such as bright nail polish and a discarded shoe), Simons employs facts-here the details of Rankine's appearance and actions - to move from ignorance to experience, a process fundamental to the deconstruction of stereotypes. She continues: "Henry Rankine begins almost any contentious conversation by emphasising that he does not want trouble. He still supports women's business but, he says, he has to be careful of his position" (MOTW 44). Present tense here creates a sense of immanence to the subject, while indirect discourse signals the reporter's presence. In this way Simons avoids reifying her subject: she places him in time at the moment of the interview, encouraging the reader to consider him as a subject rather than a character. This passage is typical in the sense that its construction appears calculated to break down stereotypes and resist imposing new ones. The level of detail authenticates the description, while the reader can infer that Simons is surprised, signalling a subtle shift in her attitude towards the Aboriginal elder.

An interesting counterpoint to this scene occurs a few pages later, where Simons reads to Henry Rankine's wife, Jean, from fellow journalist Chris Kenny's account of a meeting that took place in the Rankines' house. This meeting proves a crux in the competing narratives of the Hindmarsh Affair. Kenny's detailed account claims that Henry sat "cross-legged on a bean bag and Jean sat on a couch," to which Jean responds - with eyebrows shooting up - "I've never owned a bean bag," and that she does not remember being present at that meeting (MOTW 48). There is an implicit 
warning here: facts matter. That the "secret women's business" was not brought up at that meeting makes Jean's presence or absence significant, and these two disputed facts are seemingly resolved by a seemingly insignificant detail: Kenny was wrong about the beanbag, therefore wrong about Jean's presence. Juxtaposing scenes in this way may call into question Simons's own detailed account, or call Jean Rankine into question as a reliable witness, but a more likely result is the discrediting of Kenny's account, and reinforcement of the authority of Simons's narrative. Simons cannot verify Henry's account: as she notes, "to this day [the notes] of the meetings with the Rankines remain in storage somewhere in Norway" (MOTW 49), thus what happened at the meeting remains a contest of narratives, and the truth unresolved.

In Code's view, “standard justification and evidence-producing procedures" constitute an important aspect of epistemic responsibility, but are, finally, only one aspect (ER 71). For Code, when these standards fail to resolve knowledge claims, the onus falls on the intellectual character of the "knower" (ER 44). This is the crux of intellectual virtue, and the position to which, I argue, Simons, Hooper and Krien all default. Practitioners such as Cullen and Skloot emphasise the factual veracity of their texts and rely on these to build a coherent narrative. But, unable to verify details (which prove to be elusive in any case), Simons unsettles the foundational concept of fact, and positions herself as the point at which epistemic defence must rest. She writes epitextually: "I think this notion of a narrative voice, and the idea of the journalist being prepared to take on and wear the responsibility for the narrative is a big part of what I mean by acknowledging subjectivity" ("Facts" 29). Linking subjectivity with responsibility may perhaps initially seem paradoxical: invoking subjectivity can be seen as a way of side-stepping a journalist's responsibility to the truth, or bowing to an undermining of empiricism. But here Simons is expressing what she perceives as a more epistemically responsible position than objectivity, in order to produce a "richer" journalism, forcing the journalist to stand behind their work and defend their stance in relation to the facts ("Facts" 24). This is also Code's position. Indeed, the facts do matter for Simons; of the five other books analysed in chapters five and six of this thesis, the epistemic defence in the peritext is matched only by Cullen's. But, as demonstrated, contested factual details produce contesting narratives, thus epistemic responsibility is reoriented to the practitioner. 
Simons emphasises the fluidity of facts in The Meeting of the Waters. In the following passage, Simons interviews Steve Hemming, an anthropologist and expert on the Ngarrindjeri. Hemming believed that the "secret women's business" was entirely possible, and, after the Royal Commission, was forced to leave his job at the South Australian Museum as his position was "untenable" (MOTW 113). In this reflexive passage, Hemming reflects on the ethics of revealing culturally sensitive information, while Simons challenges notions of objectivity and a "stable" story:

Spaghetti sticks well to table tops. Steve Hemming was clearing up after his children's tea. ... I was sitting at the table, having cleared a tiny space from spaghetti debris for my notebook. I was trying to see in Steve Hemming the man who had been described to me. ... Hemming talked about anthropologists, and how "pissed off" he had become with the assumptions they made about their expertise. "How can anyone be expert on another people?" he said. "Some anthropologists can be so bloody arrogant." I remarked that journalism, too, was fraught with arrogance and assumptions about who did the reporting, and who the audience was, and who was reported upon. I had in mind the scene in front of me-Hemming and the washing up - and how it might appear in this book. "What are anthropologists anyway?" Hemming responded. He was still caught up in his own anger, and hadn't really heard me. "Some of them are just souped-up journalists. They just use people like some journalists use people." I opened my mouth and shut it again, and decided not to take professional offence. I had been a journalist all my working life. I made a note of what he had said, and of the state of his kitchen, and the now clearly asthmatic cough of his sleeping son. I was the journalist. He and his family were the subjects of my notes. This is how stories are written, and how the teller puts things together, and makes a difference (MOTW 113-116).

Simons here uses the technique of reporting her (own) direct dialogue as Skloot does in representing her altercation with Deborah. But the function is quite different. Engaging in a critique of objectivity on multiple levels, Simons invites the reader to consider the construction of her narrative by revealing - somewhat ironically-her thoughts during the interview of how the scene "might appear in the book". The dialogue overtly critiques objectivity in mainstream journalism: it matters "who did the reporting, and who the audience was, and who was reported upon". The irony is apparent in Hemming's statement that anthropologists are "just souped-up journalists", and that "journalists use people", notwithstanding the fact he is being interviewed by one in his kitchen. Simons uses the irony to her advantage, capitalising on the theme of the conversation in the final statement of the passage: "This is how stories are 
written, and how the teller puts things together, and makes a difference." In a strong critique, Simons here reinforces a central point of the narrative, first made in the peritext and recurring throughout the book: perception, selectivity, construction and perspective all contribute to the way a story is told. Simons is, at least ostensibly, warning readers to be wary of-even her-versions of "the truth". Underlying the playfulness of her reflexivity in this passage is not only Hemming's, but also her own, frustration at how stories are constructed, as well as the darker implication that "truth" is subject to construction. As Frus notes, this technique of emphasising the relationship between the subject, journalist and the reader works against reification of the text (180). While Simons risks undermining the authority of her narrative by conceding the limitations of her voice, this seems a risk she is willing to take to avoid reification and, ultimately, reinforce the authenticity and authority of her narrative.

The Meeting of the Waters provides answers to questions Pauly asks of North American literary journalism: "How could literary journalism report more effectively on group life? What stylistic or interpretive trade-offs would it have to make in order to do so?" ("Drama" 80) Simons's answers: trade complexity for simplicity, density for drama, and-her book is 512 pages long-analysis for length. Reflecting on narrative construction may be an unnecessary addition to the Hindmarsh story. But its value is in its epistemic defensibility, and the regular reiteration of a major theme in the book: the power and politics of storytelling.

Hooper's handling of disclosure transparency is quite different to Simons's. Firstly, the peritext is not as extensive. A list of sources following the narrative is organised under sub-headings, for example: The Island/The Death/The Investigation/Belief (TM 272). Quotes are attributed to their sources and Hooper's background reading is given here, but notes on reporting methods, reflections on limitations, or the construction of narrative are not explained. ${ }^{42}$ As proposed earlier, Hooper's uncertain narrative voice-like Simons's and Krien's - is arguably the book's strongest epistemic defence. This is, perhaps, understandable given that —unlike Simons, Krien, LeBlanc, Cullen and Skloot-Hooper is not a trained mainstream journalist. As Code writes, "in the communal aspect of the knowledge-seeking process, much depends on how epistemic authorities establish their credentials" (ER 35). But given the mainstream media's uniform coverage of Palm Island's riots, Hooper's "not knowing” is perhaps 
refreshing to the reader. She thus bases the "truth claims" of The Tall Man on the truth of her experience. "Truth claims" in this sense are subjectively constructed-definitive truth for Hooper is as elusive as the spirit of the Tall Man of the book's title. This epistemic stance is also partly necessary, as most readers would be aware that even after the third coronial enquiry a definitive finding was not possible, owing to unreliability of police and aboriginal witnesses (Schwarten).

The narrator's "outsider" status is introduced in the opening chapter. Hooper, a Melbournian and Southerner, recounts arriving on Palm Island where she immediately encounters two men stumbling around, leaning on each other. She is told by the mayor, "They're blind" to which Hooper replies, "Obviously" (7). The passage continues: "I assumed she meant blind drunk. One of the brothers then shook out a white cane and I saw that the men were connected with a piece of string, the man with the cane leading his brother by the wrist" (8). Here Hooper is "awkward", "out of place" and "unsure" (8). She also acknowledges: "Until I met [the Doomadgees' lawyer] Boe, I had never heard of Palm Island" (9). Like Skloot, Hooper begins from a place of "not knowing"; she has questions about a piece of her country's history, but, unlike Skloot, Hooper has a legal case through which to examine the causes of racial tension and the myth of national identity. While Skloot emphasises the factual verifiability of her narrative, Hooper relies on the authenticity of her desire to know the truth, no matter how complex and elusive it proves to be.

But this authenticity is complicated by the narrative's structure. Here issues of verifiable knowledge, lack of access and narrative representation intersect. In a public lecture at the University of Western Australia, Hooper stresses the importance of even-handedness in researching the events surrounding Doomadgee's death and the subsequent inquest:

I did try to be as sympathetic as I could be to Senior Sergeant Hurley ... [I]t would be much ... tidier for us to paint him as an ogre. I mean we literally like stories that are black and white, [but] I'd spoken to enough people who'd held him in high esteem to know that it was more complicated than that. So I feel that as a writer ... it's my job ... to extend my sympathy to him (Hooper, "Lecture"). 
As such, the possibility of Hurley's innocence echoes throughout the narrative. In one example Hooper explains: "I tried to look at things from every angle. I took each doubt I had and tried to explain it away, then put it back to test whether Cameron's death could have been just an accident. Was it possible that Hurley was innocent?" (TM 159). But despite her desire not to "paint him as an ogre", the narrative is bookended with a trope from indigenous mythology that undermines Hooper's stance. The Tall Man begins with a sequence that links Chris Hurley with the Tall Man of indigenous mythology who sneaks out at night to do evil and slides back into the cliffs by day. This image is reinforced in the final chapter, Hooper recounts the last time she saw Hurley. After a police parade, when Hooper looks for him, he has disappeared: "It was as if he'd dissolved into a long stream of blue" (TM 266), an allusion to the evil spirit slipping back into the cracks between the rocks. Throughout the narrative it is Hooper who creates and sustains this image of Hurley, an image at odds with her narrative stance; the "Tall Man" analogy is not made by any of the indigenous subjects in her book.

Lack of access also complicates Hooper's representation of - and subsequent truth claims about-Hurley. She states epitextually that one of her main goals was to avoid writing a book about issues, but rather to make it "be about people" (Warhaft, "Chloe Hooper"), and that "a story is best told through tiny human details" (Joseph, "True Stories" 85). But to a large extent the narrative itself dehumanises Hurley. He is initially in her estimation "the archetypal sheriff, clean-cut with deep-set eyes in a strong, handsome face, bristlingly physical and tall" (TM 19). This characterisation is distinctly at odds with Simons's detailed description of Henry Rankine, which deconstructs the archetype rather than reinforcing it. A uniquely American term, "sheriff" creates almost a caricature of Hurley, drawing on a Wild West narrative tradition that is easily accessible for readers but perhaps works against Hooper's aim to humanise her subjects. Following this physical description, Hooper uses leading language that extends the dehumanising process. As well as being "penned" in the witness box, Hooper writes of his remote placements: "This was now Hurley's natural environment ... He had become a creature of the Deep North, a specialist in places on the edges of so-called civilisation" (TM 20). The terms "creature" in its "natural environment" here are consistent with characterisation as the Tall Man, but 
inconsistent with Hooper's claims of even-handedness and an acknowledgement that part of her job is to extend sympathy.

This lack of access was due to the fact that Hurley refused to be interviewed by Hooper - or any media - at any time before or after the inquest and trial. Little compares Hooper's technique to Capote's characterisation of Perry Smith when she states: "Hooper is compelled to invent a similar line of 'knowing' with respect to the absent, yet always ever-present, antagonist, Senior Sergeant Chris Hurley" (54). ${ }^{43}$ Access to knowledge has been a matter of contention for Australian literary journalists in the past. As noted, Simons was denied access to the "dissident women" in the Hindmarsh Affair, prompting criticism about poor reporting practices. More famously, as outlined in chapter four, Garner was denied access to the plaintiffs in a case in 1995, and again in 2003. She attempted to overcome this hurdle by a combination of reflexivity and fine-or illuminating - detail of the individuals when she had access to them in the courtroom, with varying responses from critics. At this point Hooper's practice intersects with Garner's. Her research allows her to state: "Hurley liked dancing. He liked to party. He had a personality to match his outsize build. He'd swing girls over his shoulder, spinning them in the air. He'd stand in the centre of a crowd telling jokes: a cocky, exuberant larrakin" (TM 21). At other times, Hooper is less certain about her subject, causing her to invoke metaphor to capture her frustration - the truth of her experience:

The picture of Hurley was going in and out of focus. At moments his outline seemed sharp, clear. Then he blurred again. Blurred so much he seemed to be without edges, just a presence, a force hovering in the frame. ... He was good cop and bad cop. In all the tumult of miscommunication and legal sophistry, the real Chris Hurley had got away (TM 96-7).

Of course, the "force hovering in the frame" and that "the real Chris Hurley had got away" again evoke the enigmatic Tall Man of the preface, drawing Hooper's reader to her earliest judgement. But here Hooper is struggling with the limitations of her investigation. As previously contended, the distance between the facts of the case and the literary interpretation requires epistemic justification. At this point of the narrative Hooper acknowledges this distance, but without a peritextual statement to create expectations, the reflexivity is difficult to justify as epistemic defence. Interestingly, 
the criticism applied to Garner was not applied to The Tall Man; as noted by Fletcher and Ward, "Hooper won wide praise for her even-handedness in the book, which reveals Hurley to be a complex character. Despite Hurley refusing to speak to her, she created some vivid imagery in trying to get inside his mind" (Fletcher and Ward). While many academics are critical of Garner's propensity to be "long on atmosphere but light on relevant facts" (Ricketson, "Hitchhiking" 95), the same criticism has not been applied to Hooper in The Tall Man. Possible reasons for this can be drawn from Code's claims that where absolute uncertainty is taken to be impossible, a study of intellectual virtue and epistemic responsibility enhances confidence in knowledge claims (ER 67). Garner's history, outlined in chapter three, predisposed her later books to criticism; both Dever and Lever note that a number of academics refused to read Joe Cinque's Consolation given the controversial nature of The First Stone. Hooper, however, began with a clean slate. Nevertheless, it is perhaps anomalous that The Tall Man's truth claims did not receive more rigorous attention.

Another problem with its apparent roots in epistemology arises from Hooper's use of intertextuality. From interviews conducted with unnamed family friends and the Yanner family of Burketown, whose relationship with Hurley could be characterised as complex at best, Hooper reports that Hurley was ambitious, having told the family friend that he was "going all the way" (TM 80). He also appeared to be a proponent of summary justice-“cops doling out on-the-spot punishment with their fists" (TM 138) - which Hooper interprets as Hurley tending "to conceive of himself as the law" (TM 138). Such details and accompanying anecdotes, however, do not create a complete picture for Hooper: "ambition was only part of the explanation. These places can be addictive" (TM 81). She then supplements Hurley's motivations and character by intertextual allusions to Conrad's Mr Kurtz, the enigmatic T. E. Lawrence, and Palm Island's first superintendent, Robert "Uncle Boss" Curry. Curry was "a kind of Kurtz figure himself" (TM 82) whose authoritarian rule over the island climaxed in a rampage of murder. After dynamiting his house with his drugged children inside, shooting citizens and burning down buildings, Curry was finally brought down by Peter Prior, a young Aboriginal man, who was given a gun by white officials and told to shoot Curry. Hooper completes the passage by drawing the comparison: "Like Kurtz, Uncle Boss died in a land he had mistaken for his own" (TM 83). Problematically, here Hooper invests Hurley with the darkness of motive 
and psychology obvious in Kurtz, Curry and Lawrence. In a public lecture outlining the story, rationale and methodology underpinning her book, Hooper states: "It may be unfair of me to contrast the way these two Palm Island events, eighty years apart, were dealt with by the authorities of the day. But let me do it anyway" (Hooper, "Lecture"). This is presented as an ethical decision, but primarily concerning is the poor epistemic practice underpinning it. The "truth claims" here are again personal judgments embedded within a seamless narrative that guides the reader to unsubstantiated conclusions. If, as Code proposes, they are assessed on the epistemic responsibility of the "knower", the above quote might signal a cause for concern.

Thus, the narrative exhibits rhetorical strategies, structural decisions and intertextual allusions that stretch epistemic justification, and cast Hooper's narrative voice as a rhetorical stance rather than supporting the role of an authentic questioner. Interestingly, while Simons's strongly defended narrative came under fire from critics, Hooper has offered far less in the way of epistemic defence, and has been met with no criticism, scholarly or otherwise. This, again, may be accounted for by Hooper's position in the epistemic community; like Garner, Simons had caused some controversy - particularly with her move from journalist to media commentator, and her subsequent criticism of mainstream media arguably provided grounds for her book's mixed reception. A strong critique against Hooper's stance is also difficult given that-unlike MOTW - there are "knowable" facts, but these have been held back from the epistemic community by the people involved in the events surrounding Doomadgee's death.

Like The Tall Man, the peritext of Into the Woods provides little epitextual defence in the form of an author's note, reporting practices or even sources. Neither do Krien's personal website nor the book's promotional website offer any information to frame the text. In online interviews and reviews, however, Krien is critical of the notion of objectivity and its effects. She reflects on a sense that her reportorial persona was a key to obtaining information for Into the Woods: "I think people didn't mind chatting to me because ... I was happy to admit I wasn't all over the issues. ... I was happy to admit stupidity, and have them show me how to saw a log, and have them draw pictures for me, and we would end up having much larger conversations about their situations" (Attwood “Anna Krien”). Each of these elements and scenes is fully 
reconstructed in the book. Like Simons and Hooper, Krien therefore relies on a high level of correspondence between her experience of investigating and its representation in order to gain the reader's trust, and a narrative stance of "not knowing" that brings new eyes to a well-worn and much-publicised issue. The title, Into the Woods, foregrounds this authorial sensibility. Epitextually, Krien refers to herself as an "uncertain narrator", and suggests that her status as an "outsider" was a necessity to cover issues that seemed to be cut and dried (Wessman). Epistemic responsibility in the book is thus based as much upon transparency of self as a potential "knower" as transparency of process.

The literary journalistic form also allows Krien to use rhetorical questions to defend her reporting process while building trust with her readers. Hartsock demonstrates that the tendency of the style of mainstream news is to deny questioning by the reader, thus inhibiting reader participation (57). Krien leads her reader from one interview to the next with question and answer sequences that render her investigative process transparent but also model an inductive method of research. I proposed in the previous chapter that Cullen's cycle of questions and answers works as a selfverification mechanism. The effect in Into the Woods is different; rather than producing a compelling argument, Krien's questioning destabilises certainty and promotes reflexivity. This is possibly accounted for by the fact that Cullen is working to prove a theory; whereas, Krien lacks a theory at all. Moving between protestersor, as they call themselves "ratbags"-loggers, timber industry representatives and politicians, Krien weighs the information from her interviews against her research and experience before moving forward, often without resolution. She writes, for example: "The activists tread a fine line between drawing attention to threatened areas and provoking resentment that can ultimately backfire against the forest. Have ratbag actions taken their cause backwards rather than forwards?" before reporting the most recent results of their protests (32). Here Krien leads her readers through the issues while building their trust; her self-assigned role as an "uncertain protagonist" initiates the reader into the issues in the present tense, simulating their discoveries through her own. As in the following example, at times Krien's questioning does not advance her research process, but simply serves to reflect her thought processes and convey the sense of frustration she feels when trying to understand the conflict: 
How can so many people all be looking at the same thing and see it so differently? ... Of the older activists I've met who fought to save Tasmania's Lake Pedder forty years ago, many speak of their belief that if people could only see something, take their shoes off and wade into it, they would feel the same way. But are these feelings - the instinct for natural beauty - universal? Is a sunset beautiful to everyone, or just some? And what of the modern sunset, made peculiar and at times spectacular by smog and pollution, is that also beautiful? And just how marred are our perceptions by our desire to be (or seem) something other than what we are? (146-7)

Moving from the particular to the universal here, Krien widens the scope of her research to establish context and illuminate core issues. Rather than overtly answering such questions, Krien illustrates their complexity with anecdotes from her investigation. At an exhibition, for example, Krien finds herself at odds with the aesthetics of pieces crafted from Huon pine and writes: "I couldn't help thinking, why does it look so tacky? Isn't this meant to be 1000-year-old wood? Am I a snob, or is something dodgy seeping into this man's work?" (147) A feature of her practice is that her subjects answer such questions, with their variety of answers contributing to the complexity of the issue: “'Our aesthetics are vastly different,' says Gemma Tillack. 'We're attached to the aesthetics of an unmanned forest, whereas the loggers love the manned forest, because it's their manning. It's their work and they've created it"' (147). This environmentalist's view is followed by the responses of a former Labour premier of Tasmania, Liberal leader Robin Gray, Green party leader Bob Brown, and lecturer and author Pete Hay, resulting in a range of perspectives that is representative of the spectrum of opinions on aesthetics and logging. Krien acts as moderator, questioning perspectives and challenging assumptions. She does not, however, come to her own conclusion, preferring to retain an open stance towards her interviewees and the issues. While both Krien and Hooper use sequences of rhetorical questions to signal their balanced, searching approach to their subjects, a key difference between their narratives is that Hooper's narrative structure, employment of tropes and intertextual references contradict, to some extent, her "open" authorial stance; these techniques decidedly close the possibility for alternate representations of Hurley. And while Simons's narrative resists reification by exposing the constructed nature of all narratives, Krien is concerned about closing her narrative, thus avoids identifying herself with one faction. 
But as noted in the first chapter of this thesis, reflexivity and a questioning narrative stance cannot stand in for epistemic justification: "Propositions, set forth however 'reflexively', still contain a 'content' that calls out for assessment separate from the 'form' of their articulation" (Foley, "Politics" np). Appropriate epistemic questions here include: What is Krien's content? What does she consider viable "knowledge" on which to base her investigation? As the narrative draws to a close, Krien's emphasis on the factual increases as her subjectivity decreases. This is a result in part of lack of access to primary sources. Like the dissidents in The Meeting of the Waters and the Hurley camp in The Tall Man, representatives from the logging company Gunns Limited refused to speak to Krien. But, unlike Garner, who uses visceral reactions as knowledge; Hooper, who uses intertextuality to bridge gaps in content; and Simons, who destabilises foundationalism in narrative, Krien turns to the archives. Using such sources as media releases, environmental reports, numerous television programs, documentaries, and the Tasmanian parliament's Hansard, Krien steps out of the present to reconstruct the history of the conflict over Gunns's proposed pulp mill. The final section of Into the Woods entitled "The Mill" is far more grounded in fact, press quotes and statistics than the first four sections. Interestingly, here the tone also changes from uncertainty to self-assurance and, at times, irony, as Krien leads her readers through ten years of the proposed mill's history. After four chapters of historical reconstruction, Krien steps back into the narrative:

Each time I've sat down to type out the details about the pulp mill assessment, Gunns, Lennon and the complacency of state parliament, I've felt sick. It's so blatant. ... [S] inarticulate world of Lennon, [he believes] he's done the right thing. I cannot match the former premier's certainty. I agree a pulp mill might have been a success, a nice little earner, but not like this. Perhaps if the democratic process wasn't considered so pestilent in the state of Tasmania, I could see the pulp mill through Lennon's eyes (275-6).

Perhaps it is fitting, then, that in a final balancing act Krien returns to her experience in the Epilogue to synthesise the issues, but also to finally declare her allegiance. This, too, turns out to be more complex than she has anticipated. In a rally at the entrance to a coupe, Krien, part of the crowd, reflects on her participation. After explaining, "I've tried to balance my seesaw heart, carefully weighing up each argument. But there is something about this island that wants you to choose sides" (294), Krien finds herself making the choice: 
I see Pete Hay, his piercing blue eyes, white hair and weathered fisherman's face swaying with the push and pull. I catch his eye, we grin, and inside I say, fuck it. My hands against the back of the person in front of me, someone else's hands on mine, I feel the crowd start to move. We surge over the invisible line and into the forest (294).

Minutes later, this seeming declaration is complicated as, standing by the road, Krien sees a truck coming out of the coupe. Matthew, a logger she has previously interviewed, is sitting in the passenger seat. The tag-line of the paragraph reads: "Instinctively, we wave" (296), demonstrating the complex nature of her allegiance. Despite her identification with the environmentalist movement, Krien is still conflicted. Or, more accurately, the fact that she identifies with more than one party demonstrates the depth of her implication in the issues.

Into the Woods ends on an ambiguous note, with Krien sitting by a fire at Camp Florentine. She reflects: 'I'm more relaxed this time. I suspect I've the proprietorial air I accused the other activists of having. ... One day it will irk me that they have no idea whose roles they've stepped into, whose well-worn reins they're holding, whose slogans they've taken to chanting and whose enemies they've adopted without question. But tonight I'm just happy to be camping" (298). Krien here identifies herself with the ratbags through her "proprietorial air", as well as distancing herself through criticism. For a narrative guide who epitextually purports to be in control, flexible and open (Wessman), this disclosure acknowledges the journey resulting in the feeling of ownership of the camp, as well as resisting any firm conclusions. To the extent that online epitextual sources act as epistemic frame for Into the Woods, Krien defends her distrust of objectivity by challenging all arguments presented, as well as questioning her own ideological foundations and preconceptions.

The "truth claims" in Into the Woods are consequently reliant on Krien's questioning the nature of truth itself. Epitextually she explains that objectivity in mainstream journalism is used as "a disguise to hide behind", but that "there needs to be an underlying truth - not everyone can be right. And that was so frustrating on the island, because everyone has science on their side, which is impossible" (Atwood "Anna Krien"). For Krien, conclusions are elusive; the investigative process is "a journey 
through selective truths" (Into the Woods 118). In keeping with her narrative stance, the final words of the narrative body propose a "truth" in the form of a question:

Beyond all the figures, statistics and sums, the question remains: why are-were-John Gay, Robin Gray and their ilk so obsessed with the pulp mill? Why the strange phone calls to Gunns 20 defendants, Liberal leaders and a celebrity gardener? Why the bizarre opinion pieces? For an issue that they say is purely economic? Is it possible that, beyond all the carefully laid out arguments and the picking over of Gunns' financial carcass, these men are fuelled by something as simple, base and merciless - and so like a Grimms' fairytale — as hate? (279)

In this way Krien avoids the responsibility of definitive truth claims; rather, the reader is offered possible conclusions based on her journey of discovery. Reluctance to offer definitive conclusions is common to the three books analysed in this chapter, as are the conclusions inherently embedded in the narratives. For Krien, the spin has done its job: she is confused and does not know who to believe (149). But the facts that do not elude her are those that offer themselves to her senses; walking into a logged forest she finds: "It's gone. It's all gone. It feels as though I'm at the edge of the world. ... I feel like I am in the Swamp of Sadness from The Never-ending Story, the wet sucking me down, its sadness swallowing me" (288). Like Simons and Hooper, Krien finally offers herself as the place where responsibility falls. Hence, the journey towards knowledge is her epistemic justification for ignoring a police order, in the narrative's final pages, pushing on the back of the person in front of her, surging over an invisible line and into the woods (Krien 294) - an action she undoubtedly hopes the reader will take with her.

\section{Australia's New Gen: On "Being Australian"}

The news events investigated in these three books all involve multiple stakeholders from diverse sections of society. The building of a bridge, a death in custody, and a violent altercation between loggers and environmental protestors highlight discrepancies between the powerful and powerless for Simons, Hooper and Krien, a state at odds with Australia's proudly egalitarian national character. ${ }^{44}$ In each narrative the investigation of a hard news item inevitably gives way to an exploration of hegemonic, cultural and ideological differences between groups in a nation where access to fair and balanced media and judicial systems is assumed. Power relations underlie each narrative, thus a concern of the practitioners considered in this chapter 
is the relationship between the national character of Australia and the experience of its citizens.

Simons foregrounds this purpose in the "Prelude" that frames her narrative in the following way:

In the years since I began work on this book I have come to believe that there are many reasons why the story of the Hindmarsh Island bridge is one of the most important that can be told about Australia at the end of the last century and the beginning of all this. It can be seen as a tale of small town gossip and enmity. But as well, I think, it is one of those big, even archetypal, stories that tell us something about who we are (MOTW xvi).

Hooper has explained in a writer's panel that guiding questions for The Tall Man included: "What sort of country do we live in?" (Warhaft, "The Essay"). Similarly, she frames a lecture at the University of Western Australia by beginning: "Tonight I'd like to tell you a story about two men, which I hope will also tell us a story about Australia in the early $21^{\text {st }}$ century" (Hooper, "Lecture"). Civic conflict is limited to Tasmania in Into the Woods, but Krien also bookends her narrative with observations about Australia's colonial past and postcolonial present. Walking along the beach at twilight, her Tasmanian host points out the remains of middens; Krien shrugs at him in ignorance. After he explains they are on the site of an Aboriginal feast, her host muses: "We've had this land for generations ... But it's like I never saw it." She responds: "He's right. The middens I walked over without thinking now catch my eye, the sharpened stones like abandoned cutlery from another time" (2). This scene is mirrored at the end of the book where a friend takes Krien to the coast to look for broken porcelain pieces from settler times. Finding them embedded in rock pools and sand dunes, Krien reflects: "The broken plates looked like shells, just as curious and gentle, not like they don't belong at all. It is a relief to find beautiful traces of us" (282). These scenes frame the narrative with the themes of colonisation, belonging, and the indigeneity of the land, contextualising the battle in Tasmania in broader terms and allowing Krien to consider herself - a mainlander - in relation to the land. While not explicit in the same way as Simons and Hooper, Krien is also concerned with the meaning of Australians' relationship with the land, and how that is manifested through group conflict. 
That Australian national identity is so closely tied to issues of indigeneity is not surprising, considering the country's colonial past. For Simons and Hooper, conflict between Indigenous and Anglo Australians is a key to understanding "who we are" (MOTW xvi). Lehman points out that "recognizing that facts are always embedded in narrative does not excuse a writer or reader from trying to sort out those facts" (Matters 143-4); here this process of sorting is guided by what the facts say about Australians' experiences of reality. As Anglo writers, Hooper and Simons are also deeply concerned with casting a vision of an alternate-indigenous-experience of reality. Structure is employed to this end in both narratives. Perhaps the most vivid examples of this technique in The Meeting of the Waters are the juxtaposed extended metaphors of an opera and a Dreaming story. The opera metaphor is dominant, with the book structured in six parts, beginning with a "Prelude", and reaching its "crescendo" with the findings of the Royal Commission (MOTW 342). In a chapter entitled "Grand Opera", Simons writes: "And I drift back into sleep and when my dream returns it is like an opera. There are so many voices, all singing their own songs with such conviction. The emotions are huge, the narrative grand, almost everyone is infected with a sense of wounded righteousness, and sometimes it seems like a thousand small tragedies harnessed together" (341-2). As well as intimating a deeply European form of storytelling, the opera metaphor here signifies the impenetrability of the form by outsiders. Accessible only through initiation into "high culture", opera holds a different resonance to other, universally accessibly European forms of storytelling such as myth and fairytales. The chapter finishes, however, with the observation that the Hindmarsh Affair can also be seen as an indigenous creation narrative:

Like a Dreaming story, it tells us something about who we are. It tells us something about our culture. It is a story about cultures meeting. ... As in a Dreaming story, the meaning is not always clear. There are layers that can only be progressively revealed. Each episode of the story is partly opaque, and yet also resonant with meaning, saying something about how we connect with each other, and how we make our lives in this landscape understandable (MOTW 380).

In this passage Simons demonstrates how elements of the Hindmarsh affair contribute to identity formation: it "tells us something about who we are". The opera metaphor is useful in emphasising the polyphonic and emotive elements of the affair, but evokes a sense of closure. Dreaming stories have no beginning or end, only "layers that can be 
progressively revealed," each of which is "resonant with meaning, saying something about how we connect with each other." They construct knowledge, identity, and are continually undergoing a process of creation. By offering the two paradigms, Simons highlights the (in)accessibility of different types of cultural knowledge, as well as differences in their function. Simons here invites her-ostensibly Anglo-readers to see the affair through an unfamiliar worldview. The shift between metaphors also allows for comparisons to be made between Dreaming stories and the construction of "white men's" narratives, the stability and factual status of which Simons notes is incongruent with indigenous perceptions of story. While aiming to promote identification between her predominantly Anglo readership with indigenous subjects, this may also reinforce the differences between their experiences, distancing readers from their subject. However, casting facts in different narrative frames invites identification, and reinforces the irony of indigenous beliefs being tried in a "white man's" court.

Similarly, Hooper encourages her readers to broaden their understanding of events by considering alternate worldviews. From the opening chapters, indigenous notions of interconnectedness are invoked through imagery and symbolism. The narrative acknowledges dichotomies such as black/white, past/present, natural/supernatural and human/mythic, but Hooper seeks to destabilise rather than support them. At times such connections are simply stated: "Palm Island...is a place where history is so close to the surface, so omnipresent, it seems to run parallel with daily life" (TM 10), but more often Hooper transitions between the mythic and the everyday, infusing her descriptions of place with atmospheric weight. Reconstructing her first visit to Palm Island, Hooper writes that travelling to Palm Island "had been like a sequence in a dream" (TM 8), and notes the "pale green sea so luminous," with "moored small pristine islands" all around," where "mountains of forest met the palm-lined shore," but "Then the dream shifted" (TM 8). She continues: "In the tropics, buildings seem to ripen - then sag and wilt and rot. People spilled out of houses into yards, onto the street. We stopped at a beach, hemmed by the island's densely forested hills_ — ancient volcanoes. Two chestnut horses were foraging nearby, wild horses left over from the mission stockyards. They roamed the hills and township, grazing on nature strips and gardens" (TM 13). In these early descriptive passages, Hooper prefigures her central thematic and political concerns. Imbuing descriptions of the present with allusions to 
the past, both ancient and the more recent history of mission times, houses are like fruit that decomposes back into the landscape; groups of people are amorphous and, unrestricted by structures, naturally blend into the environment. The only restrictions, in fact, are imposed by nature itself, with the forested hills "hemming" the beach; animals are free to roam between the wild and the constructed. This description contrasts sharply with the representation of cities on the mainland, the effect being a picture of Palm Island that encompasses not only the physical but also the existential.

Later, Hooper asserts, "everything in the Aboriginal world view assumes a connection" (TM 126). Segueing into the appalling rates of alcohol-related crime and child abuse, she reports the "marked difference in the way parents treated their children in the wet season, when the roads were inaccessible and people couldn't leave to buy grog in Burketown. The children were better fed and were more likely to be at school than fishing" (TM 127). This logical, physical explanation is followed, however, by a Palm Island resident's explanation for social breakdown in indigenous communities:

"Nothing to do with grog, love, It's just the Dreamtime story dogs. We got it here. ...Y You look, young kids today about fourteen, fifteen, they all mum and dad here. Young fathers and young mothers who never look for the future." She sat staring in front of her. Lizzy Daylight had not taught her children her songs, had not wanted to pass them on to this broken new world. "This Law has been smashed like a chain smash. You know, when a chain break off your body" (TM 127).

Positioned at the end of a chapter, Aunty Betty's belief in a broken chain of law- the "power lines" of Simons's narrative - is left to resonate with readers. Those who are unfamiliar with indigenous worldviews are invited to "listen" to another perspective through direct quotation, while Hooper's layered narrative strategy is a more subtle invitation to consider a different vision of the same world.

Hooper deepens the interplay between the natural and supernatural with a motif that suggests that something larger than human interaction is at play. She offers her own "visionary portrait of well-known persons and events" (Lounsberry and Talese 30) in order to destabilise the familiar "trouble in paradise" cliché ubiquitously used in the intense media coverage (see Taylor 38). This "visionary portrait" initially manifests itself in the atmosphere of the island, and later on the mainland. Arriving on Palm 
Island, Hooper writes that she felt "like I was wearing the heat on my body. Like it was wearing me" (TM 15). Senses heightened, she continues: "Soon after dawn the cicadas resumed their electrical humming, as if releasing some live current into the air. I woke in a low single bed in a room whose walls had strange stains. This island was on some other frequency. Its element was different, like when you enter a hospital and the air changes" (TM 33). The atmosphere becomes increasing threatening: there are "Places where the streets, the days shimmered as if you were in a kind of fever-all of it, with its edge of menace, like some brilliant hallucination" (TM 20). The literary casting of the scene evokes the idea that Hooper has entered another sphere: one in which the natural and supernatural worlds are inseparable. This "edge of menace" becomes central as Hooper casts her vision of Hurley leading up to Cameron Doomadgee's death. Mediated by her sensibility, she projects her sense of atmosphere onto him: "perhaps his uniform was sticking to his skin in the heat and he could feel the sweat in the roots of his hair and this whole island was vibrating, the whole place out of control, and it was up to him to still it" (TM 24). These sensations - conceivably caused by the heat - are infused with a supernatural sense of menace that hovers around the edges. In the same way, Hurley himself is later presented in that dimension, "blurred so much he seemed to be without edges, just a presence, a force hovering in the frame" (TM 96). Here, reinforcing Aunty Betty's worldview, the natural and supernatural worlds are inextricably linked, and readers are positioned to see the unfolding events from an alternative paradigm.

Identification with her subjects' perspective is a complex negotiation for Krien; maintaining distance from her subjects and acknowledging her role as an observer is central rather than peripheral. Because of this, her relationship to the ratbags is implicated. Krien's friendship with activist Ula Majewski, for example, is the initial link to the story. She attempts to negotiate the potential bias in this connection with a combination of criticism and closely rendered detail. On her arrival in Tasmania, she makes her way to the "Pink Palace" - a house that acts as a home base for the ratbags. Her initial impression is one of chaos. Juxtaposing the picturesque surrounding scene with the house in front of her, Krien illustrates the evolution of the monikers "ratbag" and "feral" they use to describe themselves:

The house's pink weatherboards look as if they are bursting at the seams and a giant rat's nest of pillows, blankets and lengths of foam has 
formed on the verandah. The odd brown dreadlock sticks out like a tail. Stepping over the sleeping bodies, cables, axes, saws and D-locks, I walk tentatively through the wide-open front door. ... Wandering the entire length of the house, I'm spat out into a backyard strewn with newspapers, rotting fruit, empty cider bottles, ashtrays and fermenting tubs of Yakult. Some guys are parked on a couple of corduroy couches; the cushions are ripped open, and there are telltale clumps of foam around the jaws of two wrestling staffies. Beyond the chaos is an orderly veggie patch, healthy and green under a mulberry tree. ... Past the veggie patch is a cubby house. Someone's sleeping bag is poking out of it (18).

Krien's selection of details in her description of place prefigures the characterisation of her subjects. Initially confronted with the "rat's nest" on the verandah, Krien provides a picture of chaos and disorder, before noting the order beyond the chaos, a veggie patch, "healthy and green". In many ways this picture is symbolic of what Krien comes to understand about the ferals. At times she is critical of their presentation and techniques: "I shake my head. In a world of sound-bites and fivesecond grabs of footage, I can't help thinking that if they're going to go to the effort of living out here and getting the media to visit, they could smarten up" (43). She finds, however, a depth to their organisation and tactics that belies their appearance: "Later [Ula] shows me some of the work the group has produced. There are flora and fauna surveys, night footage of endangered species, marsupial hair samples, coupe documentation as well as two major reports ... I'm amazed at the amount of work and at the 'matter-of-fact' style the reports are written in. It's unexpected from this motley mob, who call themselves Still Wild Still Threatened" (21). Throughout the narrative Krien becomes more deeply concerned about the transience and disconnectedness of the protestors' lives. At times she openly confronts her friends, Ula and Wazza, about their goals, and the means they employ to reach them; at other times she is simply an outsider observing: "People breathe out, others are thinking hard. A sea of dirty dark hoodies, all accustomed to talk of the cops and bail and bunnies" (283). In this way Krien, like Simons and Hooper, destabilises the myth of "an" Australian experience: Krien presents herself as an outsider to the reality of even her friends, but employs the reporting process to demonstrate how understanding can build both understanding and empathy.

Place is also central to each of these texts in their consideration of national identity. Differing experiences of relationship to the land underlie the conflicts in Simons's and 
Krien's narratives, while Hooper contrasts the natural beauty of Palm Island with the social disorder and oppression of its citizens. Along with the subjective and reflexive elements of The Meeting of the Waters, the journalistic-or documentary-elements of the book are counterbalanced by sculpted literary passages that deepen the dimensions of the narrative. Simons imbues reconstructed settings with atmosphere, or, in Frus's terms, "transcends mere factuality" to give "the truth of experience" (26). Descriptions of the landscape are particularly purposeful in conveying the experience of a conflict fought over the ever-present, enigmatic landscape that seems to have a life of its own: "A gum tree leant over an outdoor table. The bark of the tree was somewhere between white and silver and there were clusters of bell-like gumnuts. It was the kind of tree you would expect to find in fairyland. We sat under it and Davey Thomason told me stories of protest and violence and blood and outrage and injustice" (MOTW 55). Here Simons juxtaposes the natural world with human nature, demonstrating the incongruent beauty and ugliness of each. Invoking the mythical quality of the title, the passage conveys the experiential sense of the conversation before the factual details. Alexander calls this "the disruptive strangeness of the literary," noting, "unlike facts, rhetorical figures are neither true nor false" (63).

If passages such as this are indeed disruptive or strange in non-fiction, they seem to be calculatedly so. As with the Dreaming metaphor, detail selection acts as a conduit to the indigenous understandings of the relationship with the land. Sliding between metaphors that anthropomorphise the land and narrativise the investigation, Simons invites her-predominantly anglicised - imagined readers to view and experience the story from a different perspective, an important point if readers are to identify with the indigenous protestors. While she recounts that British explorer Sturt wrote about the land in a way that dislocated any relationship between the two (MOTW 69), for the "proponent women", the connection was living and vital. Before making the decision whether or not to disclose "secret women's business" outside the Ngarrindjeri kinship network, the women stood together on the beach and sang, with one later recounting: "It was there on the beach really that the decision was made to tell Cheryl Saunders what we knew, and we didn't make it. The beach made it. The sky and the sea made it" (MOTW 215). For a case borne out in the Federal Courts of Australia, the discrepancy between the lived experience of the Ngarrindjeri women and the truth of 
empirical facts is enormous; the literary qualities of the narrative, however, allow Simons to go some way towards breaching the gap in worldviews for her readers.

Hooper eventually becomes comfortable with Palm Island and its citizens, but the same cannot be said of her return to the mainland. Juxtaposed against earlier passages where Palm Island is presented as ethereal, Hooper emphasises the materiality of the cities and marginalisation of nature to again underscore differences between Anglo and Indigenous experiences of the land. After journeying back to the mainland, Hooper writes:

The main streets of Townsville are lined with palm trees and emblems of colonial prosperity. Ornate urns and columns and wreaths swathe Victorian shopfronts which are still marked: TAILOR, STATIONERY, BANK. Hot-pink bougainvillea grows weed-like up wrought-iron lace to balconies with French doors flung open to the breeze. ... Townville's courthouse is a flat-roofed modernist building of weathered concrete. It rises amidst more palms and tropical fruit trees, with small square windows staring out from its façade (TM 147).

In this introduction to "white" Australia, order and boundaries are emphasised as colonial influences. Bougainvillea, the only unsubdued plant, is "weed-like" in the constructed environment, while the terms "Victorian" and "French" accentuate European dominance in the area. The concrete building seems to have subdued the surrounding vegetation; its "small square windows staring out from its façade" renders it at once soulless and secretive. But Hooper saves perhaps the most symbolic description for the "war room" of the Queensland Police Union. The Brisbane Broncos Leagues Club is the site for a police union meeting for its members who turn out in force to support Senior Sergeant Hurley:

The foyer of this club boasts a lush tropical water feature with a bronze bucking horse, and walls covered with blown-up action shots of mighty men in maroon, white and gold hugging a rugby ball with unrestrained ferocity. Their heads seemed to be fused with their necks as they ram each other with elbows, knees and shoulders, their faces contorted by the effort. ... On 1 February 2007, this room was filled with two thousand police officers in blue uniform, all gathered to protest the treatment of Chris Hurley. They were mainly men, white men in tight clusters, insignia on their shoulders indicating rank. What was most striking was their height. Until the late 1980 s, an officer had to be at least five-foot ten. This was a room of tall men, big men with tans or sunburn and close-cut hair (TM 197). 
Here the literal reality of the setting is imbued with a wider symbolism. The venue may indeed have been chosen for this purpose: Hooper implicitly parallels the "mighty men in maroon"- the Brisbane Broncos — with the "white men in tight clusters"- the police- to emphasise both the size and ferocity of the latter. The repetition in this passage further stresses their numbers and size, as well as signalling Hooper's discomfort amongst the "tall men". Her reconstruction of the Police Union meeting is not devoid of atmosphere, but the supernatural element has been replaced with a raw human quality: "The air was close, clammy with sweat and testosterone. The officers held their hats, some using them as fans, and chatted and laughed. ... We were in a pack. We could feel each other's animal warmth and sweat and breath — and it made me shiver" (TM 198). She saves perhaps her most explicit and scathing interpretation of the meeting, however, for the climax of the meeting:

The applause was thunderous. This felt like a revivalist meeting. Just as Cameron Doomadgee had become a martyr for Aboriginal Australia, Chris Hurley was now a martyr for anyone who felt blacks got too much from the system. ... This was real-life über-Australia up against insipid, politically correct, bullshit Australia. It was North against South. It was the cops, huddled close together, against those besieging them (TM 201).

The double narrative voice here signifies Hooper's view of the meeting and its aim. Slipping into free indirect discourse, the irony becomes apparent; Hooper clearly disagrees with the statements she appears to be making by voicing the police's perspective. But in doing so, Hooper dispenses with all attempts at "evenhandedness"; she becomes the judge, and all sympathy appears to be withdrawn.

In this passage Hooper relinquishes_or fulfils — her "quest" for the truth of Cameron Doomadgee's death, finding perhaps a greater truth about what initially fuelled the death in custody. The materiality and physicality of white Australian men - and their environment - is here most obviously juxtaposed against the spirituality and fluidity of the indigenous experience. It is apparent which group holds the power. The warring metaphor of men "huddled close together against those besieging them" strongly contrasts the atmosphere of Palm Island which "was vibrating, the whole place out of control" (TM 24, 161). Hooper represents two worlds, two ways of seeing, diametrically opposed and unequal in power. These representations of the incongruous 
white and indigenous experiences are strategically juxtaposed to lead readers to Hooper's central contention in the narrative: that the literal collision of black and white Australia in Doomadgee and Hurley is a "false battleground" (TM 243). She explicitly turns the reader to the synecdochal quality of the trial. In what is a climactic point of Hooper's narrative, she wonders what the point of justice for Cameron Doomadgee is, and comes to the realisation that

concentrating on a white man killing a black man took the nation back to its original sin, as if expurgation of this would stem the rivers of grog and the tides of violence drowning life in these communities. If we could absolve ourselves of this first sin we might be able to pretend that the later ones - the ones now killing a generation - happened in a realm beyond our reach and responsibility (243-4).

This passage shifts the perspective from a specific crime to the disparity of living conditions and safety outlined in the government's recently released "Little Children are Sacred" report. The centrality of this point has been prepared by the juxtaposition of environments, ideologies, and power structures, and readers are positioned to see the outcome of the case — in light of these elements — as inevitable.

The Court subsequently finds Hurley not guilty, a fact of which most readers would be aware. However, Hooper invites her readers to look beyond the legal system to see the mythic in the verdict: "The next morning [after the trial], it was raining so hard drivers turned their headlights on. Sirens rang out of the wet, long and angry. The Rainbow Serpent was whipping its tail, flashing its tongue" (TM 263). Perhaps the most powerful figure in Aboriginal mythology, the Rainbow Serpent is unexpectedly present in the streets of Townsville, but even its presence has failed to have an impact in favour of the minority it represents. Here Hooper's sense of powerlessness is tangible. While she herself is "incandescently white", she has identified with the indigenous community. Thus, their powerlessness becomes her own —and perhaps, by extension, the reader's.

Krien's rhetorical stance as the uncertain protagonist is all but abandoned in descriptive passages when she quite literally enters "into the woods". Following an observation that the risk is in "seeing a place" (56), Krien works to engage her readers emotionally through detailed description that evokes a fantasy world. The description 
begins: "By the main road, the morning shift is on, blue smoke ribbons rising up from their fire. At the end of the unfinished logging road, past unearthed roots and drying lichen the colour and consistency of tobacco, the forest glows green" (71). The blue smoke ribbons and forest glowing green here cast the scene in ethereal light, evoking the sense that - significantly - the forest is alive. Krien continues:

Stepping inside [the forest], it is difficult to be objective. ... Bright blue mushrooms huddle, and flames of orange fungi look like they've come off the side of a hotted-up V8. A red starfish mushroom stinks like rotten meat, making me retch. My favourite mushroom is the puffball, because it's interactive. A light tap on its side triggers a cloud of spores into the air. It makes me feel helpful. Leeches sucking secretly on my legs, I try to see this place as a merchant might. As commercially viable timber, as furniture, as beams that do not bow, the skeleton of houses, as toilet paper, as floorboards, chopping boards, boats, fruit bowls; as paper, crayfish pots, pencils, souvenir barometers and placemats. Most of all I imagine the forest disappearing behind me and turning up in the office photocopier, or wrapped around a present, or in this book perhaps. Every now and then I come across the odd giant tree, its base like the foot of a dinosaur. These eucalypts splinter up into the sky so high that I have to lean backwards to take it all in. It will grow back, I am told by Forestry. Like hair, like fingernails, like skin. It will grow back (71-2).

Krien's emotional engagement with the forest here is evident as she demonstrates the life and growth in the woods. The mushrooms are personified as they "huddle"; Krien draws a visual simile from her own experience between a hotted-up V8 and bright orange fungi; and the "interactive" puffball mushroom shows itself receptive to her touch. In this passage Krien demonstrates her connection to each element-whether visual, kinaesthetic or emotional. Juxtaposed against prosaic objects such as chopping boards, fruit bowls and placemats, the loss of life and the mystical is tangible. Perhaps paradoxically, Krien's attempt here to be objective heightens the emotional element of her experience, drawing the reader with her to the conclusion that-rendered in italics - appears to be devastating in spite of its pragmatic truth: It will grow back. In this passage Krien demonstrates the difficulty of being objective, but reflecting on her efforts to be balanced increases her authority as a reliable narrator and, perhaps, moral guide.

Experiencing "place" also offers Krien the opportunity to reflect on the relationship between perspective and identity. It is significant in the narrative-and the wider 
conflict - that warring factions are labelled according to their relationship with the land. The politicisation of labels and words then becomes an important narrative theme, as Krien connects "seeing" with "being". After waiting at the Pink Palace for her friend to return, Krien describes Majewski: "In Melbourne she was a rainbowwearing, beer and red goon-swilling student and poet. Now she is a jeans and T-shirt wearing, beer, cider and red goon-swilling activist. She is also, according to the forestry industry, an eco-militant, Trotskyist, industrial terrorist, guerrilla warrior and radical fundamentalist" (19). The juxtaposition of Krien's description against the forestry industry's is ironic, and effectively sides Krien against the industry. The irony is deepened by the clearly hyperbolic labels: Krien's description is playful, while the forestry industry's is aggressive. This passage is one of many that draws attention to the politicisation and power of words in the battle for Tasmania's forests, which is played out on the ground but also in the media. Krien does not draw back from engaging with the language of the conflict. At times this results in ironic humour, as with the above example, as well as calling Majewski the group's "media slut", and preferring "ferals" for "blockaders" (21). At other times Krien explicitly draws attention to the politicisation of terms. Early in the narrative she explains, "Working' forests are divided into coupes and then identified with codes such as SX10F. Ula says these labels have the effect of distancing the logging operations from the reality of levelling forests" (15). Later this information is invoked to produce a resonant truth that underscores the battle over labels:

Standing in the clear-fell, I suspect I'm no different from people all around the world, standing in places long gone, trying to feel the shape of a ghost, trying to feel something. In describing their sense of loss, the environmental movement can often seem melodramatic. Evoking napalm, Hiroshima and the holocaust to describe logging is manipulative, although it can be hard to find definitional error with such words. ... In SX10F I climb up onto the stump of a huge tree. What's left is mostly hollow. There's enough room for a tea party in there. Bridget climbs up with me. She points at its pithy insides and in a big blokey voice mimics a logger: "It's rotten up the inside, love! Dead anyway." We laugh. The sound echoes in the vast empty space (122).

Acknowledging that activists can be as guilty of manipulation as the forestry industry, Krien creates some distance between herself and the environmental movement. However, the universal scope becomes personal again as retrospection is outweighed 
by the truth of her experience. The dehumanising label SX10F is particularly incongruent here as Krien moves again from the coupe to an individual tree and observes it up close. Krien is enacting her new-found knowledge: "The risk, I realise as Bridget chews her walking whip beside me, maps fluttering around us, is in seeing a place" (56). She continues her theme of the politicisation of terms and their effects while reflecting on her background research:

The books, DVDs, brochures and pamphlets I receive from FT [Forestry Tasmania] are a journalist's nightmare. I find myself constantly trying to decipher new words. Nature needs 'disturbance,' logging is 'harvesting,' deforestation is 'afforestation,' burning woodchips for electricity is a form of 'bio-fuel' or 'renewable energy.' ... According to the timber industry, this means the forest has been 'disturbed' and can be classed as 'regrowth,' which, linguistically, makes it seem less sacred. It's easy to see how activists get cynical: you could piss in an ancient forest and have its status changed as a result (119).

Krien's main point here - that labels are employed to manipulate emotion-brings poignancy to her own use of terms, whether ironic or otherwise. Her use of inverted commas when using such terms as "greenie yuppies," "rednecks" and "Abos" signals by turn playfulness and anger at the use and misuse of such monikers. By exploiting this hurdle in her investigation and subsequent theme, Krien calls into question the war of words over the forests, effectively asking the reader to look beyond semantics to see the forests over which the battle is being fought — as well as the reality of the people who are fighting it.

Representing stakeholders in their complexity is another difficulty for reporters of group conflict. Pauly notes that narratives built around individual personalities deepen engagement with a subject, but may over-theorise the individual while undertheorising the group ("Drama" 79). Divided into five sections: Ratbags, Loggers, The Company, Groundswell and The Mill, Into the Woods maps the conflict through warring factions. The purpose of Krien's reflexive representation of stakeholders seems not to focus on her reactions as much as to contextualise the role of the individual within the larger, and quite complex, conflict. Simons similarly concludes The Meeting of the Waters with a drive back from Hindmarsh Island back to the 
mainland, and on to Melbourne — or, as she puts it, "the place I call home" (MOTW 461). On the journey she imagines the scene from above:

...a car crawling across the continent like an insect on skin. Eastward. Towards the future. But to get there I had to drive across country, and all around I could see the marks on the landscape. The roads, the towns, the big salt scars, the river's course, its lagoons and reaches, its taming locks. I wondered what myths might be told in the future about the ancestors who made these marks, and the great dream of settlement that drove their creation. Driving towards the sunset, yet always borne to the past (MOTW 461).

A sense of closure is produced here: for Simons at least, this journey is coming to an end. But the widening of perspective emphasises that this has been another mark on the landscape - one story within a longer narrative of the country's history that stretches into the future. That it may one day be told as a "myth" reinforces its function of revealing something to Australians about who they are, but also separates the end of Simons's journey from the Hindmarsh Affair: the larger story is not yet finished. Nevertheless, Simons is able to draw some conclusions about the meaning of the events. She writes:

I don't think it was Ngarrindjeri culture that was romanticised during the Hindmarsh Bridge Affair-or not only Ngarrindjeri culture. I think it was our own, by which I mean Western European culture. We believed in judicial process, and the ability to find the truth. We believed in books over the testimony of oral culture. We were very confident about our 'common sense' and where it might lead us. We like to think of our culture as open. We value transparency as a democratic virtue. This is one of the stories we tell about ourselves. But in fact, as this story shows, information is distributed unevenly and communicated when it suits people to do so. Information follows the lines of power. Aboriginal cultures make this explicit. Western European culture - and my own journalistic culture-like to pretend that it isn't necessarily so (MOTW 454).

While Simons's comments may initially seem hypocritical-after all, she has produced her own book on the subject - the narrative strategies she has used draw attention to the limitations of stories European cultures can tell about themselves, and the meanings produced by those forms. The inherent complexities of indigenous affairs and cultural perspectives often defy_or are denied — representation in forms of discourse essentially entrenched in Anglicized ways of perceiving the world. 
Embracing an alternative form of storytelling, Simons emphasises how culturally constructed narratives reinforce dominant ideologies and hegemonic structures. An achievement of The Meeting of the Waters, then, is an exposure of the gap between indigenous and white notions of truth, objectivity, perceptions of reality, and ideological differences - issues that were widely ignored or disregarded by the "intellectually respectable" cynicism of mainstream media coverage of the Hindmarsh Affair. Another achievement is in the narrative's explicit challenge to representation as a whole; consequently, it holds value beyond its content as news. The epistemic foundation of the narrative provides an alternative way for readers to see Simons and the subjects of the Hindmarsh Affair, the complexity of the issues, and the relationships between each of these elements, but it also creates a space for readers to see their own place in the story.

Closure in The Tall Man is more elusive. Hurley is acquitted of responsibility in regards to Doomadgee's death, but this brings no sense of completion. Hooper finds that the Hurley/Doomadgee conflict is a false battleground, one that overshadows the "great horror" exposed by Federal government's "Little Children Are Sacred" report. Meaning in this story, then, centres on Hurley's trial as an expurgation for past and current sins against indigenous Australians - a colonial history defining the nation's present consciousness. Without closure for the Doomadgee family or their supporters, Hooper-like Simons - uses her own journey of investigation to conclude the book. Hooper recounts the last time she saw Hurley, at the Queensland Police Union's inaugural Pride in Policing Day march. While greeting people, Hurley leans in toward a little girl, pretending to be a monster. She writes: “'Grrrr!' he cried, holding his hands like clawed paws in front of his face. There he was, the Tall Man" (TM 266). Later, when Hooper looks for him, he has disappeared: "It was as if he'd dissolved into a long stream of blue" (TM 266), an allusion to the Tall Man slipping back into the cracks between the rocks. Here the Senior Sergeant who bridged cultures has also found his way into mythology and the Dreaming stories of Aboriginal culture. The reader is left with a sense of the inevitability of the outcome in two dimensions: another chapter of history has been written on the disenfranchisement of Australia's indigenous peoples, and the Tall Man has proved himself the elusive spirit of Dreaming stories. 


\section{Conclusions}

In seeking to make sense of - and find meaning in - complex and often protracted conflicts, Australians arguably need more than the current lexicon and mainstream journalistic form to convey meaningful stories that embrace cultures, histories, ideologies and beliefs. Literary journalism has historically fulfilled this role, and contemporary Australian works continue to function in this way. The examples of book-length literary journalism analysed in this chapter resist the lines of dominant discourse in mainstream media, revealing instead narratives that are at once more nuanced and complex than their daily journalism counterparts. Importantly, each practitioner attempts to destabilise cultural stereotypes to re-engage their readers with the people behind the issues, the agendas behind the stories, and the reality behind the myths — with differing degrees of success.

The three texts analysed in this chapter deal with epistemic responsibility in different ways. For Simons, the "backyard effect" necessitates a high degree of epistemic justification. The extensive peritext of the book underscores her desire for disclosure transparency. This is supported by a highly reflexive narrative that draws attention to its own construction, which also functions as a critique of the motivations behindand construction of - competing narratives. For Hooper's readers familiar with the facts of Doomadgee's death, a narrative voice presuming to tell "the real story" would likely ignite scepticism and produce an unfavourable reaction. Hooper is well aware of the conditions under which she is writing, as she observes epitextually: "In nonfiction, it's important for the reader to feel they can trust the authorial voice-if they smell ideology or a political agenda the trust is blown" (Ruddock). As a result, Hooper presents herself as an ignorant outsider from the opening chapter, emphasising her role as a searcher for truth, although to some extent the structure of her narrative contradicts this epistemic stance. A similar danger exists for Krien, a mainlander investigating a decades-long conflict in which allegiances are paramount. She presents herself to both her subjects and her readers as the inexperienced reporter, relying on transparency at each stage of reporting and writing to maintain critical distance from highly emotive and politically charged issues. 
Consequently, anxiety over representation for all three practitioners manifests itself in an authorial stance of "not knowing", possibly best characterised as a colonial uncertainty in the context of their subject matter. As contended earlier, an "outsider" intentionally trespassing on occupied ground has deeply resonant overtones for a country struggling with race relations and power imbalances. This is particularly the case for Simons and Hooper who deal with issues of race, but is also relevant to Krien whose subject matter is the indigeneity of the land through old growth forests, and whose connection to the "ratbags" possibly prejudices her to favour a particular perspective. Again, it is interesting to note here that of the three practitioners, Simons offers the highest degree of epistemic defence, yet her book received the harshest criticism for its findings.

Along with epistemic defence, these texts are also structured in such a way as to resist closure at an institutional or political level, again taking into account readers' previous knowledge of events, and facilitating a journey from "not knowing" to an uncomfortable sense of completion for the writer, but not for the issue. In North American works which-perhaps apart from Columbine-deal with largely new information, the narrative arc is formed around events that reach a climax: Serena's $16^{\text {th }}$ birthday and pregnancy, the shootings at Columbine High School, and Deborah's reconciliation with her mother's past and her own future. To a great extent in the Australian texts, where the climax and outcome of the conflict is already known, the author's journey of discovery provides a parallel narrative arc to the events represented, and their desire to find "the truth" provides the narrative drive. This journey metaphor is central: Simons begins and ends her narrative with a road trip across central Australia; Hooper, the white southerner, flies to Palm Island, travels through the "deep north" and finishes her journey back on the mainland; and Krien takes the ferry across from her native Melbourne to Tasmania, a place she only dimly remembers visiting as a child. While complications rise from the sequence of events, equally important are the author's own reactions to the sense of menace they encounter, as well as doubts and dead ends during the investigative process. Indeed, each of these narratives is affected by limitations: Simons is denied access to the dissident women, Hooper is denied access to Hurley, and Krien is denied access to Gunns Ltd. This parallel narrative arc is significant as the resolution for each conflict is not found in real-world events, but the author's own conclusions about what the 
event signifies. At the end of each narrative the group conflicts are left unresolved; there is a sense of "unfinished business". The importance of the narrative, then, becomes its meaning rather than the resolution of events.

The civic focus of Australian literary journalism represented in this chapter has arguably grown out of economic necessity. As noted earlier, without the literary turn afforded by the New Journalism, Australian literary journalism has not received either the institutional or public recognition it has in the US. Consequently, the content of literary journalism is arguably consistent with Sims's assessment that international forms put more stress on social usefulness than artistry ("Problem" 10). Hooper's personal observations bear this out:

It seems there aren't more [Australian] authors in this area because traditionally there have not been the same publishing opportunities, nor the wide market, that, say, American non-fiction writers have enjoyed ... [T] here is a larger cultural opportunity cost in that Australian stories aren't researched and written at the same high level. Stories tell us who we are as a people. They can give us a more nuanced, sophisticated sense of our history and culture (Joseph, "Australian” 44).

This is a state that, as has been argued in this chapter, Hooper, Simons and Krien have sought to address. The civic conflicts that comprise the subjects of The Meeting of the Waters, The Tall Man, and Into the Woods open the door for complex, nuanced presentations of cultural concerns. As mentioned at the beginning of this chapter, Pauly asserts, "Literary journalism cannot be said to occupy the civic space that daily news once claimed as its own" ('Drama' 78). But Australian literary journalism demonstrates how a civic focus can carry out a role he perceives is missing in North American literary journalism; that is, to "make society as a whole available for analysis and conversation" ("Drama" 78). As such, Australian literary journalism has an important social role in influencing public debate (Ricketson, "Ethical Issues" 64, 235), as well as providing platforms from which the epistemic community can reflect on uniquely Australian issues and the ever-evolving consciousness of national identity. 


\section{The "New Gen": History Makers, Future Shapers}

During the late 1800s when the United States government began to recognise the need for additional land for processing on Ellis Island, a similar development was taking place in the nation's nascent journalism establishment. While work began to expand the now-famous landmark in the 1890s, a first wave of literary journalism was also gaining momentum (Connery, Sourcebook xii). Connery explains that "the realistic movement that had made the common and ordinary legitimate topics for writers had been at least partially fuelled by a cultural need to know and understand a rapidly changing world, and by a staunch faith that reality was comprehensible through printed prose" ("Third Way" 4). In this thesis I have argued that these two elementsthe need to know and understand a rapidly changing world, and faith that this is possible, if problematic, through descriptive narrative journalism - are still true for a new generation of literary journalists. This "New Gen" combines assiduous research with literary narrative prose to offer truths about life in the twenty-first century. But disputes over new territory, as exemplified by New York's and New Jersey's claims to Ellis Island, are not always solved with the passing of time. Despite the aims and claims of contemporary book-length literary journalism, there still exists an uneasy relationship between reality and its representation for many theorists, critics, readers, and, crucially, practitioners. As the analyses in chapters five and six demonstrate, discovery, exploration, consolidation, and occupation of other people's stories creates not only ethical but also complex epistemic situations to be negotiated by literary journalists. It has been, therefore, a central contention of this thesis that the epistemic imperative to "know well" is a primary concern in literary journalism scholarship.

The principles of epistemic responsibility are not new to the theory, practice or criticism of literary journalism. Throughout this thesis, practitioners such as Janet Malcolm, Helen Garner, Åsne Seierstad, Joe McGinniss, William Langewiesche, Dave Cullen and Margaret Simons have been shown to demonstrate critical reflection that suggests epistemic responsibility is a central concern in their practice. Similarly, reviews by Janet Maslin, Joanne Wypijewski, Timothy Mitchell and Jack Fuller exemplify incisive critique that pays attention to truth claims and considers epistemic concerns accordingly. What, then, does this thesis contribute to scholarship in this 
field? One answer emerges from a corollary observation to those already offered: consideration of epistemic responsibility does not inexorably lead to epistemically defensible practise. As the analyses of literary journalists-such as Richard Critchfield, Joe McGinniss and Helen Garner-show, problematic epistemic foundations are not easily identifiable. Epistemic "blind spots" are exactly that: opaque to those who carry them, and only discoverable with specific attention to the cognitive processes that organise knowledge and produce understanding. To appropriate Code's language once again, the quality of the literary journalist's action (in this case, making truth claims) is dependent upon their ability to understand situations rightly (ER 181). Concomitantly, constructive and productive criticism takes into account not only the action, but also the method of arriving at a belief; that is, not just the ethical, but also the epistemic foundation of a work of literary journalism.

The major part of my contribution to literary journalism scholarship, then, is to frame the discourse of literary journalism's truth claims with the approach and lexicon of Code's Epistemic Responsibility. I have argued, with Code, that a conflation of ethical and epistemic concerns often results in an obscuration of the latter, and that the two branches of enquiry should be held separately for the purposes of explication. While James Aucoin has previously identified the importance of Code's responsibilist approach to literary journalism, I have argued — again, with Code — that an assessment of knowledge and truth claims is incomplete without analysis that considers coherence and correspondence, as well as epistemic justification. Factual veracity of literary journalism is important, and where the discipline of verification fails, an epistemic responsibilist approach offers a standard to assess knowledge and truth claims that Code characterises as "stringent" without being impossible (ER 67). Such an assessment of epistemic responsibility primarily requires consideration of three elements: the subject (or literary journalist's) nature, environment, and the impact of their epistemic community (ER 50). In this thesis I have focused on the latter two to a great extent; the final discussion will emphasise the role of intellectual virtue in relation to the literary journalist.

Chapter two introduced the concept that the name of an author is a "constituent element" of a non-fiction author-reader contract. For Genette, an author's name 
fulfils a contractual function whose importance varies greatly depending on genre: slight or nonexistent in fiction, it is much greater in all kinds of referential writing, where the credibility of the testimony, or of its transmission, rests largely on the identity of the witness or the person reporting it. Thus we see very few pseudonyms or anonyms among authors of historical or documentary works, and this is all the more true when the witness himself plays a part in his narrative (Paratexts 41).

To apply Genette's assertion here, the practitioner's name is a key element of the literary journalistic contract. Indeed, it may be contended that the author's name is the key element in a negotiation of expectations. The truth claims of a text, finally, must rest on the integrity of the one who makes them. This is also a central point for Code: "prominent among my considerations in assessing a knowledge claim is evidence about whether the person at its source is in a position to know. That person's intellectual integrity counts as a significant part of the evidence in much the same way as, in moral matters, a person's moral integrity is a determining factor in decisions as to whether she or he should be trusted" (ER 39). Consequently, intellectual virtue-as distinct from, but in combination with, moral virtue - is a key characteristic of the literary journalist. For Code, "Virtues, both moral and intellectual, have more to do with ways of relating to the world than with the 'content' of particular actions or knowledge claims" (ER 53). The truth or knowledge claims made in a book-length work of literary journalism often appear to be the primary points of analysis, but any assessment that eludes empirical verification or assessment of whether a practitioner "is in a position to know" defaults to the intellectual virtue displayed by the purported "knower". Hersey put it this way: "We read journalism-or most of us still do, anyway - to try to learn about the external world in which our psyches have to struggle along, and the quality we most need in our informant is some measure of trustworthiness" (263).

This point has been evident throughout this thesis. Controversial cases particularly bear out the fact that practitioners producing multiple works of book-length literary journalism are often pre-judged, as evidenced in chapter four. In these cases the name of the practitioner alone sets a "horizon of expectations" which — fairly or unfairlyinfluences the reading of the text. Code's responsibilist approach indicates that it is not only fair, but also incumbent upon would-be knowers (in this case, readers) to 
assess the credentials of purported knowers (literary journalists). In cases where transparency disclosure is lacking, much can be accounted for by the illocutionary force of the literary journalist's name. Here I would add that paratextual links to literary journalistic traditions also carry some illocutionary weight. Code proposes that an epistemic responsibilist approach works primarily through example: "We see how the conduct of the [intellectually] virtuous shapes both the conduct of those aspiring to it and conceptions of virtue itself" (ER 63). This is, of course, an optimistic vision of epistemic agents, and one that Code recognises as problematicparticularly when it eschews questions of power and epistemic privilege ("Responsibility and Rhetoric" 6). But it is a salient point that paratextual allusions or endorsements that place a text "in the tradition of" a well-known figure of established epistemic virtue contribute towards a reader's horizon of expectations and subsequent assessment of truth claims. Here the assessment of epistemic responsibility reaches a full circle: analysis of narrative coherence and a literary journalist's intellectual character must be supported by the text's correspondence to reality where possible; these are the ideal conditions for an assessment of a text's truth claims.

For Code, those involved in progressive endeavours - such as literary journalismare subject to higher demands of epistemic responsibility and intellectual achievement than "those expected of persons simply as persons" (ER 62 emphasis in original). Contemporary literary journalists worldwide are consequently not only inheritors of a legacy; as leaders in their field they are also are responsible for shaping future standards of responsible enquiry. The analyses in chapters five and six of this thesis indicate that the future of literary journalism is in safe hands. The works of LeBlanc, Cullen, Skloot, Simons, Hooper and Krien are not unproblematic, but each of these practitioners demonstrates a strong commitment to epistemic responsibility, as well as traits of intellectual virtue. Each writer has undertaken many of the epistemic tasks identified as responsible practice. In Epistemic Responsibility, these include: sustaining an appropriate epistemic location (39); justifying knowledge and/or truth claims (42); evaluating the epistemic integrity of potential sources of knowledge (43); scrutinising self-knowledge and its impact on truth claims (57-8); defining the field of knowledge (59); being open to changing boundaries in this field of knowledge (59); acknowledging and pursuing doubts (59); acknowledging and assessing the impact of 
the epistemic community on knowledge (114); identifying and acknowledging limitations (136); and taking an objectivist approach to the subject (142-3).

These epistemic tasks should be considered indicators of epistemic responsibility rather than an exhaustive list of competencies. In fact, Code warns against producing a set of rules to apply in all situations: a theory of intellectual virtue can neither offer "any easy calculus for assessing knowledge and belief claims nor provide a decisionmaking scale against which specific knowledge claims can be measured for validity. Indeed, it cannot provide any definite and final answers. ... One could not responsibly write 'a guide for the recognition of responsible knowledge claims"' (ER 63-4). What an epistemic responsibilist approach can do, however, is offer principles to assess intellectually virtuous conduct. In doing so, individuals can acquire ways of discerning when claims to know are responsible, and when they are not (ER 64). To this end, Socratic questioning is useful. It narrows the field of irresponsible epistemic behaviour when claims to absolute knowledge or truth are impossible to justify. The epistemic tasks outlined above might be fulfilled by asking questions such as: Am I in a position-literal and metaphorical-to make these truth claims? Am I able to substantiate these truth claims on the basis of my research? Are my sources reliable and responsible "knowers"? How might my subjectivity impact the organisation of my research in problematic ways? What kind of self-knowledge is appropriate and necessary here? How much (more) do I need to know? What impact would further research have on the knowledge I already have? Is there more to discover? Have any changes occurred in the field since I began researching this subject? Is there anything here that does not fit coherently with the narrative I am constructing? If so, what is it? What might it mean? How has my subjects' knowledge shaped my own? What critical knowledge is impacting the way I shape my narrative? What are the limitations on my knowledge? Have I made claims that I cannot substantiate? What might the impact be of not acknowledging my limitations? Have I approached my subject with an agenda? And, finally, Have I tried to impose a structure on my subject that does not fit? Similarly, an epistemically responsible critic will take into account a text's correspondence with verifiable reality, its coherence, and also the known intellectual virtue of the literary journalist. The questions above are appropriate for the critic to ask, along with the questions: "Who knows?" and "Who cares?" which have been 
shown in this thesis to be important epistemic considerations when considering a text's truth claims.

An epistemic responsibilist approach has much to offer the theory and practice of literary journalism. Conley quotes Walter Lippmann when he writes: “"The function of news is to signalize an event. The function of truth is to bring to light the hidden facts, to set them in relation with each other, and make a picture of reality on which men can act.' The reporter gathers facts and opinions that often are in conflict and invites readers to determine "truth" (58). Indeed, the literary journalist goes beyond the gathering of facts to offer "truths" of their own. The responsibility inherent in this act of "making a picture of reality on which men can act" is heavy indeed. My intention in this thesis has been to make clearer the guidelines of epistemic responsibility, and to promote reflexive practice for both literary journalists and their epistemic community.

The link between ethics and epistemology is complex. It was noted in chapter four that the quest for truth is tightly linked to procedural matters such as fact checking and performing a wide range of research — these are primarily epistemic tasks. But, as Kieran writes, "Carelessness about such procedures is ... professionally culpable and, in this respect, constitutes a moral failure to live up to the responsibility of one's job" (152). Kieran's assessment is consistent with Code's approach, as she writes:

This task-demonstrating that these domains of enquiry must remain separate while, at the same time, benefitting from their evident overlap-is complex. The complexity arises because knowing well, preserving an appropriate degree of objectivity, thinking clearly, and being epistemically responsible are, in fact, moral matters. But they are not just moral matters; nor can they, as moral matters, be wholly subsumed under standard modes of ethical discussion (ER 68).

In this thesis I have consequently attempted to draw attention to the way literary journalism's knowledge and truth claims have invited moral or legal censure, and argue that a focus on epistemology, or the methods of arriving at a truth claim, can yield a more instructive, constructive analysis and critique. Like Code, my project has been to focus on an examination of process, or the efforts to achieve end-states, rather than the end-states alone ( $E R$ 8). Applying the lexicon of epistemic responsibility to the analysis, teaching and practice of literary journalism can, I contend, heighten 
awareness of epistemic issues, and thus produce better-informed, more responsible practice.

A secondary aim of this study has been to offer a characterisation of Australian literary journalism: that is, as a record of civic disputes that provide insight into the problematic nature of national identity. While the emphasis on civic matters is a key difference between Australian and US literary journalism, identity construction is a function they both perform. Pauly wrote in 1990 that writing and reading New Journalism affirmed a generational identity, but also "articulated a cultural identity" ("Politics" 119). This function is still evident: Pauly's 2011 keynote address to the International Association for Literary Journalism Studies stressed the embeddedness of identity within cultural concerns in contemporary literary journalism ("Drama" 77). Lehman similarly asserts that non-fiction of this kind is "literature whose historical assertions and representational intentions are by definition an effort to fix our identity within the world around us" (Matters 37). The texts analysed in chapter six, however, work less to capture a sense of generational identity, and more to question monolithic representations of national and cultural identity. While this is a central function of these texts, other works such as Helen Trinca's and Anne Davies's Waterfront: The Battle that Changed Australia (2000), Malcolm Knox's Secrets of the Jury Room (2005), Jacquie Everitt's The Bitter Shore (2008), and Sally Neighbour's The Mother of Mohammed (2010) in part rely on, and challenge, the character of Australia as an egalitarian, easy-going and welcoming nation-as represented in historical and political discourse. Like Marr's and Wilkinson's Dark Victory (2004), these booklength narratives have less of a literary intention than those analysed in this thesis, but in dealing with civic concerns they come into contact with cultural conflicts and often brush against issues regarding identity at local and national levels.

I have also endeavoured to characterise the current state of literary journalism in Australia. Ricketson's (2010) and Joseph's (2011) surveys indicate that the field of practising long-form literary journalists in Australia is small and fluid. Practitioners often do not identify themselves with the label "literary journalist", and, as noted earlier, they also report financial and time constraints on producing book-length literary journalism. Nevertheless, a survey of tertiary journalism programs further indicates that there is cause for optimism about literary journalism's future in 
Australia. In a 2007 census, 14 out of 20 university journalism departments (or $63.6 \%$ ) reported that literary journalism is a part of the curriculum. "Evocative description" and "use of writer's point of view" were the most widely taught narrative features, as evident in $81.8 \%$ of positive responses (Blair 20). The survey also showed that after feature articles, literary journalism was the most popular style of journalistic publication amongst academics. Blair explains that this may be accounted for by "the style's extensive history, its popularity (particularly during many of the respondents' youth in the 1960's and '70s) and [its] acceptance in the journalism world" (22). Respondents also identified constraints on a more extensive focus of creative styles, including the degree of difficulty needed to master the genres of literary journalism and creative non-fiction (22), and time pressures in already-crowded courses (24). Nevertheless, a new generation of Australian tertiary-educated journalists is gaining exposure to the alternative traditions of literary journalism. Rebecca Giggs also suggests that innovative forms of non-fiction, such as those represented in this thesis, are being "fostered by mid-tier presses rather than 'big end of town' [publishing] houses or the various funding bodies", and names Granta, Black Inc. and Scribe publishers as advocates for emerging non-fiction writers (in Zajac).

In light of these developments, book-length literary journalism does indeed have a strong future in Australia. Its powerful advocatory role for those who are under- or mis-represented in the mainstream media has already gained the attention of influential bodies. The Walkley Foundation-comparable to the Pulitzer Foundation for the Arts - for example, introduced The Walkley Book Award in 2005 in recognition of the increasing roles that long-form and literary journalism play in the Australian media. This recognition will conceivably continue to grow, as literary journalism is a particularly important alternative to mainstream journalism in this country. As of 2010, Young has identified highly concentrated media ownership, declining newspaper circulation, and increasing commercial pressures and economic goals as central characteristics of Australian media (622). The oligarchical influence on setting news and editorial agendas is beyond the scope of this thesis, but the freedom afforded literary journalists ensures readers have the option of wider, deeper, more contextual coverage of civic disputes. Further, as global mainstream journalism undergoes ideological, economic and technological crises, compounded by increasing disillusionment with the objectivity model, practitioners of literary journalism have 
much to offer an institution in the process of recalibration. The reliability required of daily journalists might conceivably be superseded by responsibility as "objective" news reports are increasingly replaced with commentary and opinion, and narrative forms take a stronger hold in mainstream journalistic practice.

I have argued in this thesis that epistemic responsibility is not solely the domain of the literary journalist; the epistemic community is also bound by its standards. "Knowing well" is indeed a virtue to which all participants in a society can aspire. This does not - and cannot - mean that the acquisition of knowledge is the greatest good. Rather, the principles of "knowing well" guide the process of translating knowledge into understanding, belief and, finally, truth. Code summarises this point in the following way:

[A]chieving intellectual goodness does not depend upon knowledge in any standard sense. It is a matter of learning from example, from persons of reason, integrity, and courage. The fact that exemplary people are often not recognized for what they are does not negate the importance of this claim. Socrates' death does not invalidate the principles for which he stood, any more than does Thomas More's or Martin Luther King's. This secular conception of moral and intellectual virtue leaves our appeals to reason and integrity without absolute foundations; yet they are founded in what we can best achieve within the scope of human potential. They are thus neither more nor less well founded than knowledge itself, where attempts to establish ultimate foundations have repeatedly failed (ER 194).

Contemporary literary journalists exemplify what it means to learn from intellectually virtuous predecessors to a great extent. Rather than the traditions of objectivity and reliability, current practitioners draw directly from the writings and examples of immersive journalism of practitioners from the 1890s onwards. If the first wave of literary journalists can be likened to the original 3-acre spot of land that was Ellis Island in 1891, the ensuing century of adding to that land has produced a vital point of transition for immigrants to a new world — or terra nullius - of journalistic inquiry. Contemporary literary journalists might well resist acquiescing to the sovereignty of a name. Their work, finally, is theirs alone. But this does not discount the fact that their place in history has as its foundation those who-like Hutchins Hapgood, George Orwell and James Agee - chose to harness the power of narrative and the techniques of storytelling to reveal truths about life in their generation. The intellectual integrity 
of many early literary journalists has shaped the standards of epistemic responsibility for subsequent generations of practitioners, who in turn shape the literary journalistic landscape for the future. For Code, intellectual goodness is "conducting one's moral and intellectual life so as to contribute to the creation and preservation of the best possible standards appropriate to the practices within which one lives" (ER 193); these are the demands of epistemic responsibility. And for practitioners-past, present and future-epistemic responsibility is the final bastion for the truth claims of literary journalism. 


\section{Endnotes}

${ }^{1}$ Code is critical of some aspects of her work in retrospect. She writes: "Despite my conviction that the central idea of Epistemic Responsibility is important and right, there are problems with the book, and some of the criticisms it has produced are well taken" ("Responsibility and Rhetoric" 5 emphasis in original). The primary deficiencies she observes are: the lack of boldness of a central thesis statement (5); the tacit—or perhaps uncritical-liberal humanism that informs the book, "where questions of power and epistemic privilege do not figure, and an honest, wellmeaning, transparently self-conscious epistemic agent who can make of her or his circumstances what she or he will is taken for granted as the central character of the story" ("Responsibility and Rhetoric" 6); "the book's ambiguous relation to the metaphysical requirements of the Anglo-American epistemological mainstream (an aspect external to the position I develop)" (6); and a "failure to spell out necessary and sufficient conditions for claiming or attributing epistemic responsibility (an aspect internal to the position)" (6). While these are areas that could and should be strengthened, I agree - with Code - that the central idea of Epistemic Responsibility is important and right. As such, it is my hope that this thesis opens not only a potential path of inquiry for literary journalism studies, but also refreshes the discussion over Code's important work.

2 In this thesis I distinguish between "mainstream" or "traditional" journalistic practices and literary journalism, but here I acknowledge that there is far more crossover than the nomenclature suggests. Paul McGeough, chief foreign correspondent for The Sydney Morning Herald, is one example of a current practitioner regularly publishing literary journalism in a daily newspaper. Recent research also shows that elements of literary journalism are increasingly being used in daily news reports in Australian newspapers, although the inverted pyramid is still the dominant model for reporting (see Johnston).

${ }^{3}$ Code notes of the ambivalent response to her book that it "might have been more approachable had it been packaged as intervention in a largely uncharted area of ethics, for the rites of passage there are different and perhaps in this respect less stringent" ("Responsibility and Rhetoric" 6). She does, however, cite a number of areas in which the responsibilist approach to epistemic theory has been employed in "gratifying, productive ways" (9). As well as finding a home in feminist theory, other areas include an adaptation of medical ethics in the area of informed consent; epistemic empowerment for women's and marginalized people's cognitive locations in social institutions; and epistemic responsibility issues in AIDS research (9). Here again I signal my intention and hope that this thesis is the beginning of a productive relationship between a "responsibilist" epistemic philosophy and literary journalism.

${ }^{4}$ Matthew Ricketson's study Ethical Issues in the Practice of Book-length Journalism (2009) makes a similar claim; indeed, these studies do overlap to a degree. One distinction between our approaches, however, is the critical move Code makes in separating ethics and epistemology: the greatest value of my thesis is arguably in making this distinction and applying a specifically epistemic responsibilist approach to literary journalism, rather than considering the equally important but broader categories of ethics and narrative journalism. 
${ }^{5}$ This statement reads: "At certain moments in the story, I describe the stream of a person's thoughts. In such instances, I am basing my narrative on interviews with the subjects in which they have recalled their thoughts often repeatedly, followed by factchecking sessions in which the subjects confirmed their recollections. If you ask a person, 'What were you thinking?' you may get an answer that is richer and more revealing of the human condition than any stream of thoughts a novelist could invent" (Preston xi).

${ }^{6}$ This statement comes from a wider discussion of what Foley terms the "spectrum argument", representing a view that fictional and nonfictional discourse cannot be qualitatively distinguished. Foley argues that it "conflates the necessary recognition of historical shifts in the mimetic contract with the impossibility of logical classification, thereby precluding any inquiry into the historically varying epistemological bases of generic distinctions" (Telling the Truth 32). The quote in full reads: "The spectrum argument ends up treating generic categorization as a framework imposed a posteriori by literary critics, ruling out the possibility that it may constitute a necessary basis for the contracts formed between actual writers and readers" (Telling the Truth 32).

${ }^{7}$ Dolezel also takes up this point. He uses possible worlds theory to identify four distinctions in the "macrostructural" properties of fictional and historical texts that reassert fundamental distinctions between the two types of narrative. They are as follows: 1) Historical worlds are restricted to the physically possible; 2) The cast of agents in the historical world is determined by the set of agents involved in the past event(s); 3) The persons of historical worlds - as well as their events, settings, etc. have to bear documented properties; 4) The gaps in historical worlds are epistemological, given by the limitations of human knowledge (258-259).

${ }^{8}$ There are some important studies that particularly focus on texts whose practitioners consciously blend invented material with real events; Barbara Lounsberry's study is of Norman Mailer's practice and Daniel Lehman's writing on Tim O'Brien in Matters of Fact: Reading Nonfiction Over the Edge (1997) are both good examples here. The analyses in this thesis, however, concern texts that explicitly claim and defend their status as non-fiction, where no intention of "blending" fact with invention is signalled in good faith.

9 Australian author Helen Darville's The Hand that Signed the Paper illustrates Genette's assertion that the name of the author is indeed a constituent element of the contract and has an effect that blends with the effects of other elements. While neither literary journalism nor non-fiction, Darville's case illustrates how paratextual elements such as an author's name can have illocutionary force. The book was first published in 1994 under the pseudonym of Helen Demidenko. It was marketed as a novel, but the author, Helen Darville, falsely claimed to be of Ukranian ancestry. From the book's first publication, she dressed in national costume, assumed an accent, and implied that the story was an oral history, passed through her family, about her uncle's experiences during the Holocaust. Before the scandal broke, the book won the Australian/Vogel Literary Award for young authors, the prestigious Miles Franklin Award, and, after the scandal was revealed, the Gold Medal of the Australian Literature Society. Jill Kitson told the Sydney Morning Herald that "many Vogel manuscripts were autobiographical", which may have contributed to the belief that the book was non-fiction (Knox, "The Darville Made Me Do It"). Michael Owen-Brown 
writes: "Darville says she used the pseudonym for two reasons. She wanted to protect the identity of a death camp guard living in Australia, whom she had interviewed. She also feared the book would not be viewed as legitimate unless the author was thought to come from a Ukrainian background" (np). As a result, the book was widely received as an oral history, and thus discredited when Darville's true identity was made public. Paradoxically, in these cases where the illocutionary force of the contract was perhaps most powerful because of the author's assumed authority over the content, market forces did little to pass judgement on the authors. For Darville, however, the peritext was altered in subsequent editions to renegotiate, or refine, the author-reader contract. In this case, the peritext of the third edition of the bookpublished after her true identity was revealed-was significantly altered. As expected, the book was republished under her real name rather than the intentionally misleading pseudonym "Demidenko", but critical praise and the publisher's logo were also removed from the dustcover, biographical information was altered to disclose Darville's true ancestry, and acknowledgements were added (Darville), ostensibly to remove the association of her novel as an oral history and clarify its fictional status.

10 The use of the term "contract" to describe the negotiation between author and reader has been critiqued on the grounds that it "can lead critics astray by implying too many similarities between how we read and how we construct and enforce legal contracts" (Heyne, "Fiction Meets Nonfiction" 326). But this is a relevant observation. The legal arena is, in fact, a site where readers and subjects can and do contest narrative representations in works of literary journalism. Epistemic defenceor its absence - can take on the power of a legal contract when an author claims nonfiction status for a text. The implications here will be more fully explored in chapter four.

${ }^{11}$ John Hartsock takes a slightly more nuanced approach when characterising literary journalism scholarship. He cites the English/Journalism divide (6), but also recognises the cultural studies approaches of John J. Pauly, David Eason, and Shelley Fisher Fishkin; the closely associated post-modern Marxist scholarship of Phyllis Frus; and "other efforts that do not fall comfortably into any of the categories" (258), including Mas'ud Zavarzadeh's Mythopoeic Reality (1980) and Eric Heyne's “Toward a Theory of Literary Nonfiction" (1987). The dual traditions recognised by Aucoin, however, are relevant to this discussion framed in the context of "truth claims". To this end, Aucoin places both Heyne and Zavarzadeh with the "genre of literature" scholarsnot unproblematically, I would argue.

${ }^{12}$ Interestingly, a scholar's academic background does not necessarily determine their stance on such standards; Aucoin is one example of a scholar with a background in journalism who argues that its standards of verification are too narrow for literary journalism (8). Conversely, Barbara Lounsberry, a literary scholar, argues forcefully for verification in the journalistic tradition (xiii).

13 This contention is supported by Kovach and Rosenstiel's research, in which they report: "In our survey of journalists about core values, eight out of ten journalists working in national outlets, and more than seven out of ten working in local outlets, said they felt "there is such a thing as a true and accurate account of an event" (47) 
${ }^{14}$ Code differentiates her "responsibilist" position from Ernest Sosa's "reliabilist" position. She acknowledges that for a person or their knowledge to be reliable establishes "a closer connection with truth and warrantability than responsibility can establish" (ER 51 in footnote). However, in her view, "a knower/believer has an important degree of choice with regard to modes of cognitive structuring, and is accountable for these choices; whereas a "reliable" knower could simply be an accurate, and relatively passive, recorder of experience" (ER 51). Here a distinction can be made between mainstream and literary journalism: the degree of choice available to a daily journalist when reporting an event is considerably less than that afforded a literary journalist. Hence, a daily journalist is more likely to be judged on their reliability according to established protocol and procedures, whereas literary journalists are not bound by the same rules of cognitive structuring, and thus have a much stronger mandate for responsibility. Code writes: "A person can be judged responsible or irresponsible only if she/he is clearly regarded as an agent (in this case a cognitive agent) in the circumstances in question. An evaluation of human knowledge-seeking in terms of responsibility is instructive precisely because of the active, creative nature of the endeavour" (ER 51). Clearly, in an epistemic sense, responsibilism is just as binding on a daily journalist as a literary journalist; the point here is that literary journalism highlights practitioners' responsibility, whereas the objectivity standard obscures it.

15 Barbara Foley makes a similar point. Writing in 1986, she reflects on the divergence of contracts invoked in works of fiction and (new) journalism:

Turning to what I could learn about the responses of other readers to contemporary works of journalism and fiction, I found my own reactions provisionally confirmed. None of the reviewers of Ragtime complained that Doctorow had distorted the historical record; they may have quarrelled with him on various scores, but they appear to have acceded to his play with facts on the grounds that he was simply writing a novel. By contrast, many readers of works such as In Cold Blood, The Executioners Song, and Roots have stated that the credibility of the narrative collapsed for them when they discovered that certain details had been invented of significantly changed to enhance the thematic patterning of the text. Clearly these readers did not feel that the writers' disregard for information existing in the historical record represented support for the proposition that contemporary reality is weird and unknowable; they simply felt that they had been deceived. I found, in other words, that even in works asserting the "significance of nonsignificance," the idea that history is a fiction has been asserted in conventionally novelistic, journalistic, and autobiographical ways (Telling the Truth 15).

${ }^{16}$ The passage in full reads:

I take a bottle of water from the cooler. "Was it ethnic violence?" I ask. "No," says Sam. "My father was a Shiite and he was murdered by a Shiite. A thief." I nod. According to an article in the New Republic, the next war in Iraq will be between Shiites and Shiites. "And then?" I ask. "My father's killer lived in our neighborhood. I went to him and I killed 
him." I take a drink of water and ask Sam whether he wants one as well, but he doesn't. "But you were six- teen," I say. "Shouldn't someone else have done that instead? An older brother? Or an uncle?" (in Andeweg 62)

${ }^{17}$ Margaret Simons's approach to her subjects in The Meeting of the Waters is arguably objectivist, but the narrative relies on an exploitation of subjectivity in order to emphasise the nature of perception and reality. As such, it "appears" to be subjectivist, and has been criticised on this point. These issues are dealt with further in chapter six.

18 Two further statements made at a 2012 conference go some way towards illuminating Garner's approaches to literary journalism. Garner asserted that: "The story does not exist as a story until the writer makes it. A story is not an object that's been dropped on the ground ... What you stumble on is a mess of fragments. It's your task as a writer - indeed, your duty, your sole function in the universe - to do the labour of shaping inchoate matter into some meaningful, pain-relieving and aesthetically pleasing form." In the same speech, Garner also stated: "Until I make the form, or rather sense one rising from the material as I helplessly brood over it, the things I want to say aren't even things. ... If I try to force the unborn thing into some clever shape my bossy intellect thrusts at me, I'll deafen and blind myself to what's going on around me" ("An Evening"). These responses perhaps reveal an underlying epistemic conflict at the heart of Hayden White's theory: does nature reveal an underlying form and meaning (rising from the material as the writer helplessly broods over it), or are these imposed by a process of creation-for White, imagination (the labour of shaping inchoate matter into some form)? Garner's comments suggest she understands the process to be both passive and active: she is at once duty-bound to do the labour of shaping, and wary of forcing into some clever shape. These seemingly contradictory statements perhaps give some insight into Garner's conflicted epistemic foundation, and place her approach closer to the subjectivist than objectivist end of an epistemological spectrum.

${ }^{19}$ Another interesting example that bears out this point is Dave Eggers's Zeitoun (2009). Eggers's book-length work of literary journalism reconstructs Abdulrahman Zeitoun's experience of Hurricane Katrina in August 2005, and the following days where he used his canoe to rescue neighbours, feed and animals and navigate the flooded city of New Orleans. During this time Zeitoun was wrongfully arrested and spent 23 days detained as a suspected terrorist. Robbie Brown of the New York Times observes that Eggers's book turned Zeitoun into "a New Orleans hero". However, "in recent years, the stable, loving relationship between Mr. Zeitoun and his wife, Kathy, that was described in the 2009 best seller has taken a series of dark turns. The couple divorced last year after he was convicted of assaulting her. And on Wednesday, the New Orleans police charged him with plotting to have Kathy Zeitoun, her son and another man murdered. ... In an interview with the New Orleans Times-Picayune, Ms. Zeitoun said the book had accurately portrayed their relationship at the time. But she said her ex-husband had since grown angrier and more violent and his Islamic views had become more "radical"' (Brown). The understanding that end-states of knowledge necessarily signify given moments in time, then, should moderate charges of reification. Zeitoun is written in third-person narration, and as such, eschews 
reflexivity. This, and the tangible — although uneasy — sense of closure in the text may contribute to reification of its subjects, but readers arguably also have a responsibility to acknowledge that non-fiction narratives represent moments in time, as practitioners have an epistemic responsibility to consider and acknowledge the limitations of their knowledge where appropriate.

${ }^{20}$ As of 2012, the Australian Press Council is the principle body that receives and adjudicates media complaints. Its website states that the APC's jurisdiction "extends to all the print publications and related digital outlets of its constituent bodies, which collectively account for about $98 \%$ of all print media sales in Australia" (see "Complaints").

${ }^{21}$ For the SPJ's code of ethics, see http://www.spj.org/ethicscode.asp. The MEEA's code of ethics can be found at http://www.alliance.org.au/code-of-ethics.html

${ }^{22}$ For a full list of "constituent bodies" over which the APC has jurisdiction, see http://www.presscouncil.org.au/constituent-bodies/

${ }^{23}$ See Forde's discussion of Walter Lippman and John Dewey's dialogue about the role of the press in a democracy in Literary Journalism on Trial: Masson v. New Yorker and the First Amendment (72-86). Forde concludes: "While Lippmann (and Masson) suggested that one should protect the quality of public discourse so as to enable human freedom, Dewey (and Malcolm and the New Yorker) suggested that one should protect the freedom of public discourse so as to enable communities to arrive at truth (even contingent truths) on which to base their decisions and beliefs (86).

${ }^{24}$ Forde observes that the U.S. Supreme Court justices "failed to question is whether readers of the New Yorker actually believed that multiparagraph and even multipage quotations in the magazine's fact writing were reported verbatim." She asks rhetorically, "Did readers understand that some kind of convention was at work other than the daily journalism standard of reporting short, often partial verbatim quotations?" (45), the implication being that this indeed was likely the case.

25 Jack Shafer notes that Shawn expressed regret over allowing Capote's In Cold Blood to be serialised in the New Yorker decades after its publication. Shawn had marked up the galley proofs and identified problem areas to discuss with the author, but "the story ran in the magazine without addressing Shawn's queries" (2012).

${ }^{26}$ The similarities between the cases are interesting: Boynton observes that Malcolm's case grew beyond a mere libel suit to become a signifier for some of (US) society's "most bitterly fought cultural battles, about the press, psychoanalysis, the roles of men and women" (Boynton, "Till Press"). A similar statement could be made of The First Stone controversy, in which the roles of the media, patriarchy, feminism and the Academy were vigorously scrutinised and debated in the public domain.

${ }^{27}$ Boynton notes that in The Silent Woman: Sylvia Plath and Ted Hughes (1994), Malcolm's "typically cool, literary reserve is replaced by skittishness", and that "The Silent Woman sometimes reads like a response to her critics. As if to reassure suspicious readers that no scenes were concocted she tells us exactly where everything happens" ("Till Press" np). Joe Cinque's Consolation explicitly acknowledges the effects of the previous drama in the second chapter: "Four years 
earlier I had published a book of reportage called The First Stone ... The parallels between that story and this one were like a bad joke. No way was I going back out there" (13). It is evident to the reader that she did, of course, and her second offering again attracted criticism, although it was less controversial than The First Stone.

28 There is a discrepancy here between dates; see pp 20, 616. While a minor inaccuracy, for some readers this kind of error may call into question even McGinniss's journalistic integrity as dates are verifiable and as such, are central to authorial claims of accuracy.

${ }^{29}$ As stated in chapter two, a key indication of a text's non-fiction status is that it is open to contestation. This case exemplifies the importance of this point. Rais published his own book in response to Seierstad's: Once Upon a Time There Was a Bookseller in Kabul (2007), opening Seierstad's version to the process of narrative contestation.

${ }^{30}$ In an interview regarding the lawsuit, Seierstad stated:

I agree now that it is not possible to write a neutral story. ... I don't criticise the society with my words in the book but I agree, it's there in the text anyway. It's not an open critique but it is a critique. ... If I write a book in future, I may decide to take the precaution of going back to every person I interview, reading their quotes back to them and asking them to sign a letter, saying it is accurate ... Journalism is moving into a different world where we are held to almost impossible standards. In everything I write, ever again, I need to make sure I am 100\% accurate. A journalist can get away with this sort of controversy once, but I can't survive it again (Hill).

${ }^{31}$ Clark makes this point in relation to John Berendt's Midnight in the Garden of Good and Evil (1994). The author's note at the end of the book reads: "Though this is a work of nonfiction, I have taken certain storytelling liberties, particularly having to do with the timing of events. Where the narrative strays from strict nonfiction, my intention has been to remain faithful to the characters and to the essential drift of events as they really happened" (Berendt np). Clark writes of this passage: "The second sentence is no justification for the first. Authors cannot have it both ways, using bits of fiction to liven up the story while desiring a spot on the New York Times nonfiction list" (np). Wyatt also notes the author's note is "tucked away" at the end of the book where it essentially functions as a postface (np). Genette's observations about peritextual placement are salient here:

$[\mathrm{P}]$ laced at the end of a book and addressed to a reader who is no longer potential but actual, the postface certainly makes more logical and more relevant reading for that reader. But for the author, and from a pragmatic point of view, the postface is much less effective, for it can no longer perform the two main types of function we have found the preface to have: holding the reader's interest and guiding him by explaining why and how he should read the text.... Given the postface's location and type of discourse, it can hope to fulfil only a curative, or corrective, function (Paratexts 238-39). 
Clark compares Berendt's ambiguous disclosure with that of G. Wayne Miller, who begins King of Hearts (2010) with the statement: "This is entirely a work of nonfiction; it contains no composite characters or scenes, and no names have been changed. Nothing has been invented. The author has used direct quotations only when he heard or saw (as in a letter) the words, and he paraphrased all other dialogues and statements-omitting quotation marks-once he was satisfied that these took place" (np). Clark concludes: "Because, by definition, what goes on in the head is invisible, the reporting standards must be higher than usual. When in doubt, attribute" (np).

32 See Merritt's and Brown's No Easy Answers: The Truth Behind Death at Columbine (2002); and Kass's A True Crime Story, a Victim, the Killers and the Nation's Search for Answers (2009).

${ }^{33}$ See Rundle's Down to the Crossroads: On the Trail of the 2008 US Presidential Election (2008); McGeough's In Baghdad: A Reporter's War (2003); Manhattan to Baghdad: Despatches from the Frontline in the War on Terror (2003); Kill Khalid (2009); and Knox's Secrets of the Jury Room (2005).

34 "Goolwa", the closest town to the site of the proposed bridge, is also translated as "meeting of the waters" in the Ngarrindjeri dialect.

${ }^{35}$ These women were "dissident" in relation to the claims made about the sacredness of the site.

${ }^{36}$ The title of Kenny's book, It Would Be Nice if There Was Some Women's Business: The Story Behind the Hindmarsh Island Affair (1996) was taken from an anthropologist's quote around the time the dispute began. However, it captures the ironic stance held by the mainstream media at the time. Conversely, Simons's title, The Meeting of the Waters: The Hindmarsh Island Affair, highlights the mythic, archetypal dimensions that brought about the issue, and prefigures the narrative patterns of the book. Both titles carry out the dual function identified by Symes, who writes that the title "looks inward to the artifact, providing it with a privileged set of interpretations; but it also looks outward to the marketplace, where artifacts compete for critical acclaim and appeal" (19).

${ }^{37}$ As well as the exegetical component of her thesis focusing on the issues raised in researching and writing the book, Simons has also published a number of articles and speeches that question and challenge the forms and fundamentals of journalism. These include Fit to Print (1999), in which Simons draws on her own experience and observations of the Canberra press gallery to reflect on and critique the institution from an outsider's perspective; an essay recounting a conversation with Helen Garner on journalism, narrative and non-fiction ("Helen Garner: The Woman with the Hammer in the Kitchen Drawer"); a speech at the Sydney Institute ("Facts, Projection, Politics and the Objective Journalist"); and a journal article tracing journalism's relationship with anthropology ("The Hindmarsh Island Affair and Australian Anthropology"). My rationale for identifying MOTW as Simons's first work of book-length literary journalism is based primarily on the literary focus of her project. I acknowledge that Fit to Print (1999) also exhibits some of the characteristics evident in literary journalism as defined in this thesis, and marks a transitional period in Simons's career from journalist to media commentator. 
38 This event was the central point of contention in the court case. Initially, in an official police report, Hurley claimed that Doomadgee had punched him as he stepped out of the police van. Hurley then dragged him into the police station, and they both tripped on the step, falling in through the door next to each other. When the coroner found Doomadgee's injuries inconsistent with this version of events, Hurley then claimed that he must have fallen on Doomadgee, but maintained that he had no recollection of that. The Court found that it was unable to definitively rule whether the injuries were sustained intentionally or accidently.

${ }^{39}$ See Harari's A Tragedy in Two Acts: Marcus Einfeld and Teresa Brennan (2011) and Everitt's The Bitter Shore: An Iranian's Escape to Australia and the Hell They Found at the Border of Paradise (2008).

40 The dust cover of The Tall Man features critical praise from Garner: "Life springs from every page of this enthralling book. Australians will weep over it. It is first-class reportage, meticulously researched, studded with superbly observed human detailand all the more moving for its intense restraint." Similarly, the front cover of Into the Woods features the following from Chloe Hooper: "Anna Krien's intimate, urgent book pulsates with life and truth." Rebecca Giggs asks of an interview with Anna Krien if there is an implied contention of "a mentorship dynamic that could account for the boom in journalistic essay ands and books being written by women? $\mathrm{Ha}$ [s] the category of nonfiction subtly shifted to include more intuitive, emotional or psychological writing? Or could it simply be said that after so many years of pioneering feminist thought, women were finally learning to write politically about issues of national concern, to demonstrate complex and noteworthy opinions on industry, business, labour and civics?" (66). Giggs's article makes a strong point that the area of genre and gender in Australian non-fiction writing is a rich area for future research.

${ }^{41}$ Brunton's criticisms were published in "The Sydney Papers", a publication by The Sydney Institute - a privately funded not-for-profit current affairs forum - shortly after MOTW was published. Simons's rebuttal was printed in the same issue: she meets each of his points in the notes section of her article. (See "Hindmarsh and Australian Anthropology".)

42 A small number of online epitextual sources give some insight into Hooper's epistemic foundation; however, when compared to intratextual claims, they raise a number of issues to do with representation, as discussed later in the chapter.

${ }^{43}$ Little is critical of Capote but not Hooper. Evidently her criticism is based on the belief that "for Capote, ingratiating himself with the two murderers in the Clutter family was a means to an end, a way of building a book out of a crime, and an experiment with the non-fiction novel that made him a literary star". Whereas, Hooper's book "is as much a disclosure of her own position as a once comfortably unaware white Australian woman as it is a story of why what happened at Palm could never be handled by hard news alone - and was in effect misrepresented by it" (54).

${ }^{44}$ Useful discussions of Australian national identity which cite egalitarianism as a characteristic can be found in: "The History Question: Who Owns the Past?" 
(Clendinnen); "Cultivating Identity" (Keneally); and "Great Expectations: Government, Entitlement and an Angry Nation" (Tingle). 


\section{List of Works Cited}

Abbott, H. Porter. The Cambridge Introduction to Narrative. Cambridge University Press, 2008. Print.

Agee, James, and Walker Evans. Let Us Now Praise Famous Men: Three Tenant Families. Boston: Houghton Mifflin, 1988. Print.

AgendaStevePaikin. "Rebecca Skloot: The Story of HeLa." Online Video Clip. YouTube. YouTube, 7 May 2010. Web. 16 Nov. 2011.

Al Yafai, Faisal. "The Ruling Against Bookseller of Kabul Author Asne Seierstad." The National. Online Newspaper. 20 Aug. 2010. Web. 27 June 2012.

Alexander, Robert. “'My Story Is Always Escaping into Other People': Subjectivity, Objectivity, and the Double in American Literary Journalism." Literary Journalism Studies 1.1 (2009): 57-66.

Allen, David S. "The Trouble With Transparency." Journalism Studies 9.3 (2008): 323-340.

Andeweg, Agnes. "Searching for Truth: Arnon Grunberg's Literary Journalism." World Literature Today 86.2 (2012): 60-63. EBSCOhost. Web.

Attwood, Alan. “Anna Krien.” Online Video Clip. YouTube. YouTube, Sept. 2010. Web. 30 Jan. 2012.

Aucoin, James L. "Epistemic Responsibility and Narrative Theory." Journalism 2.1 (2001): 5-21.

Bak, John S. "Introduction." Literary Journalism Across the Globe: Journalistic Traditions and Transnational Influences. Ed. John S. Bak \& Bill Reynolds. Amherst, MA: University of Massachusetts Press, 2011. 1-22. Print.

Bak, John S., and Bill Reynolds, eds. Literary Journalism Across the Globe: Journalistic Traditions and Transnational Influences. Amherst, MA: University of Massachusetts Press, 2011. Print.

Bakhtin, Mikhail. The Dialogic Imagination: Four Essays. Austin: University of Texas Press, 1981. Print.

Bartley, Aryn. "The Citizen-Witness and the Politics of Shame." Literary Journalism Studies 1.2 (2009): 23-42.

Bedell, Geraldine. "Eleven Years in the Bronx." The Guardian. Online Newspaper. 19 Oct. 2003. Web. 25 Oct. 2011.

Beebee, Thomas O. The Ideology of Genre: A Comparative Study of Generic Instability. Philadelphia, PA: Penn State Press, 1994. Print.

Bennett Jones, Owen. "The Bookseller of Kabul: Author Loses Legal Case." BBC World Service. Media Broadcaster. 2 Aug. 2010. Web. 24 Oct. 2012.

Berendt, John. Midnight in the Garden of Good and Evil: A Savannah Story. New York: Random House. Print.

Bergner, Daniel. Soldiers of Light. London: Allen Lane, 2004. Print.

Berkowitz, Dan. "Doing Double Duty: Paradigm Repair and the Princess Diana What-a-story.” Journalism 1.2 (2000): 125-143. 
Berlatsky, Eric. "Lost in the Gutter: Within and Between Frames in Narrative and Narrative Theory." Narrative 17.2 (2009): 162-187. Print.

Berning, Nora. "Narrative Journalism in the Age of the Internet." textpraxis. Digital Journal. Web. 2 Nov. 2011.

“Best Sellers.” The New York Times 4 Dec. 2011. Web. 4 Dec. 2011.

Bhatia, V. Worlds of Written Discourse: A Genre-based View. London: Continuum, 2004. Print.

Birmingham, John. "'Into the Woods: The Battle for Tasmania's Forests' by Anna Krien.” The Monthly. Online Magazine. Sept. 2010. Web. 29 Jan. 2012.

Blair, Molly. "Uncovering the Place of Creative Non-fiction in Australian Journalism Departments." Asia Pacific Media Educator 18 (2007): 17-30. Print.

Borden, Sandra L. "Empathetic Listening: The Interviewer's Betrayal." Journal of Mass Media Ethics 8.4 (1993): 219-226. Print.

Boyer, Paul S. By the Bomb's Early Light: American Thought and Culture at the Dawn of the Atomic Age. New York: Pantheon, 1985. Print.

Boynton, Robert. The New New Journalism: Conversations with America's Best Nonfiction Writers on Their Craft. New York: Vintage Books, 2005. Print.

---. "Till Press Do Us Part: The Trial of Janet Malcolm and Jeffrey Masson." Robert S. Boynton. Personal Website. Web. 20 Aug. 2012.

Brown, Robbie. "Celebrated Hero in 'Zeitoun' Book Faces Murder Charges in New Orleans.” The New York Times 9 Aug. 2012. NYTimes.com. Web. 9 Oct. 2012.

Brunton, Ron. "The Meeting of the Waters and the Problem of the Barrages." The Sydney Papers 15.2 (2003): 160-6. search.informit.com.au. Web. 16 Jan. 2012.

Bryson, John. Evil Angels. Ringwood: Penguin Books, 1986. Print.

Burrough, Bryan. "Death in Wyoming." The New York Times 8 June 2008. NYTimes.com. Web. 19 July 2011.

Byrne, Jennifer. “Author Anna Krien.” Online Video Clip. First Tuesday Book Club. ABC. 4 Oct. 2011. Web. 12 Jan. 2012.

Byrne, Jennifer. "Helen Garner in Conversation with Jennifer Byrne." Online Video Clip. Slow TV. The Monthly. Mar. 2010. Web. 24 Jan. 2012.

Capote, Truman. In Cold Blood. New York: Random House, 1966. Print.

Carey, John. The Faber Book of Reportage. New Edition. London: Faber and Faber, 1996. Print.

Cavanaugh, Amy. "Rebecca Skloot, Author of The Immortal Life Of Henrietta Lacks.” A.V. Club. Onion Inc. 18 May 2011. Web. 17 Nov. 2011.

Chandrasekaran, Rajiv. Imperial Life in the Emerald City: Inside Iraq's Green Zone. New York: Knopf Doubleday, 2007. Print.

chuckpalahniukcult. Interview W/ "Columbine" Author Dave Cullen, Part 3 (4) "The Media”. Online Video Clip. YouTube. 01 Sep. 2010. Web. 23 Aug. 2011. 
Clark, Roy Peter. "The Line Between Fact and Fiction.” Poynter.org. 2 Mar. 2011. Web. 23 Oct. 2012.

Clendinnen, Inga. "Making Stories, Telling Tales: Life, Literature, Law." The Lionel Murphy Foundation. 17 Nov. 2004. Web. 4 Oct. 2012.

---. “The History Question: Who Owns the Past?” Quarterly Essay 23 (2006): 1-72. Print.

Code, Lorraine. Epistemic Responsibility. London: Brown University Press, 1987. Print.

---. "Responsibility and Rhetoric." Hypatia 9.1 (1994): 1-20.

---. "Who Cares? The Poverty of Objectivism for a Moral Epistemology." Rhetorical Spaces: Essays on Gendered Locations. New York: Routledge, 1995. 103119. Print.

“Complaints.” Australian Press Council. 2011. Web. 24 July 2012.

Conley, David. "Birth of a Novelist, Death of a Journalist." Australian Studies in Journalism 7 (1998): 46-73. Print.

Connery, Thomas B., ed. A Sourcebook of American Literary Journalism: Representative Writers in an Emerging Genre. New York: Greenwood Press, 1992. Print.

---. "A Third Way to Tell the Story: American Literary Journalism at the Turn of the Century." Literary Journalism in the Twentieth Century. Ed. Norman Sims. New York: Oxford University Press, 1990. 3-20. Print.

Cooper, Thomas W. "Review Essay: Lorraine Code's Epistemic Responsibility, Journalism, and the Charles Stuart Case." Business \& Professional Ethics Journal 12.3 (1993): 83-106. Print.

Cowlishaw, Gillian. "Arbiters of the Past.” Blak Times. Ed. Peter Minter. Vol. 65.1. Carlton: Meanjin, 2006. 208-212. Print.

Cramer, Richard Ben. How Israel Lost: The Four Questions. London: Free Press, 2004. Print.

Critchfield, Richard. Shahhat: An Egyptian. New York: Syracuse University Press, 1978. Print.

Cryle, Denis. "New Journalism Post-War and Australia Media Traditions: A Case Study of Nation Review." ejournalist 1.2 (2001): n. pag. Web. 13 Apr. 2012.

Cullen, Dave. Columbine. New York: Twelve, 2009. Print.

---. “Columbine Online.” DaveCullen.com. Web. 20 Oct. 2011.

Cunningham, Brent. "Re-thinking Objectivity." Columbia Journalism Review 42.2 (2003): 24. ProQuest. Web. 23 Oct. 2012.

Curran, James. "The Future of Journalism." Journalism Studies 11.4 (2010): 464-476. CrossRef. Web. 4 Dec. 2011.

Curthoys, Ann. "Feminism, Citizenship and National Identity." Feminist Review 44.1 (1993): 19-38. CrossRef. Web. 30 Nov. 2012.

Curthoys, Anne. "Where Is Feminism Now?" Bodyjamming. Ed. Jenna Mead. Milsons Point, NSW: Vintage Books, 1997. 189-212. Print. 
Cutter, Weston. "Doubling Down: An Interview with John D'Agata and Jim Fingal." The Kenyon Review. 23 Feb. 2012. Web. 1 Aug. 2012.

D’Agata, John, and Jim Fingal. The Lifespan of a Fact. New York: W. W. Norton \& Company, 2012. Print.

Darrel, Mansell. 'Unsettling the Colonel's Hash: 'Fact' in Autobiography." Literary Journalism in the Twentieth Century. Ed. Norman Sims. New York: Oxford University Press, 1990. 261-280. Print.

Darville, Helen. The Hand That Signed the Paper. 3rd ed. St Leonards, NSW: Allen \& Unwin, 1994. Print.

Dash, Leon. Rosa Lee: a Mother and Her Family in Urban America. New York: BasicBooks, 1996. Print.

"Dave Cullen's Biography." Red Room: Where the Writers Are. 2011. Web. 20 Sept. 2011.

Davis, Mark. Gangland: Cultural Elites and the New Generationalism. St Leonards, NSW: Allen \& Unwin, 1997. Print.

---. “Turf War.” The Age 19 May 2007. The Age. Web. 30 Nov. 2012.

Derrida, Jacques. “The Law of Genre.” Critical Inquiry 7.1 (1980): 55-81. Print.

Dever, Maryanne. "Hanging Out for Judgement." Australian Women's Book Review 16.2 (2004): n. pag. Web. 31 Jan. 2012.

Dimock, Wai Chee. "Introduction: Genres as Fields of Knowledge." PMLA 122.5 (2007): 1377-1388. CrossRef. Web. 7 Feb. 2011.

Dow, William. "A Literature of Urgency." Prose Studies: History, Theory, Criticism 33.2 (2011): 132-153. Print.

Dubrow, Heather. Genre: The Critical Idiom. London: Methuen, 1982. Print.

Eason, David. "The New Journalism and the Image-World." Literary Journalism in the Twentieth Century. Ed. Norman Sims. New York: Oxford University Press, 1990. 191-205. Print.

Eggers, Dave. Zeitoun. London: Penguin Books, 2011. Print.

Eisenhuth, Susie, and Willa McDonald. The Writer's Reader: Understanding Journalism and Non-fiction. Port Melbourne: Cambridge University Press, 2007. Print.

Everitt, Jacquie. The Bitter Shore: An Iranian Family's Escape to Australia and the Hell They Found at the Border of Paradise. Sydney: Pan Macmillan, 2008. Print.

Fakazis, Elizabeth. "Janet Malcolm: Constructing Boundaries of Journalism." Journalism 7.1 (2006): 5-24. Print.

Farley, Amy. "In the Family Way." The Village Voice. Online Magazine. 28 Jan. 2003. Web. 4 Dec. 2011.

Finlayson, Iain. "The Legend of Colton H. Bryant by Alexandra Fuller." The Times. Online Newspaper. 20 June 2008. Web. 19 July 2011.

Fletcher, Jay, and Mat Ward. "New Doco on Black Death in Custody Denied Footage." Green Left Weekly 29 Jan. 2012. Web. 27 Apr. 2012. 
Foley, Barbara. Telling the Truth: The Theory and Practice of Documentary Fiction. Ithaca: NY: Cornell University Press, 1986. Print.

---. "The Politics and Poetics of Journalistic Narrative: The Timely and the Timeless." Modern Fiction Studies 41.2 (1995): 344-346. Project MUSE. Web. 7 Mar. 2011.

Forde, Kathy Roberts. Literary Journalism on Trial: Masson V. New Yorker and the First Amendment. Amherst, MA: University of Massachusetts Press, 2008. Print.

Forna, Aminatta. "A Modern Cowboy Story." The Telegraph. Online Newspaper. 6 July 2008. Web. 21 July 2011.

Frank, Russell. "These Crowded Circumstances: When Pack Journalists Bash Pack Journalism." Journalism 4.4 (2003): 441-458. Print.

---. “'You Had to Be There' (And They Weren't): The Problem With Reporter Reconstructions." Journal of Mass Media Ethics 14.3 (1999): 146-158. Print.

Frow, John. Genre. London: Routledge, 2006. Print.

---. "Reproducibles, Rubrics, and Everything You Need: Genre Theory Today." PMLA 122.5 (2007): 1626-1634. CrossRef. Web. 7 Feb. 2011.

Frus, Phyllis. The Politics and Poetics of Journalistic Narrative: The Timely and the Timeless. Cambridge: Cambridge University Press, 1994. Print.

Fuller, Alexandra. Don't Let's Go to the Dogs Tonight: An African Childhood. New York: Random House, 2003. Print.

---. Scribbling the Cat: Travels with an African Soldier. New York: Penguin Press, 2004. Print.

---. The Legend of Colton H. Bryant. London: Simon and Schuster, 2008. Print.

Fuller, Jack. News Values: Ideas for an Information Age. Chicago, Ill.: University Of Chicago Press, 1997. Print.

---. “What Is Happening to News?” Daedalus 139.2 (2010): 110-118. Print.

Gans, Herbert J. "News \& The News Media in the Digital Age: Implications for Democracy." Daedalus 139.2 (2010): 8-17,152. Print.

Garfield, Bob. "Lawrence Weschler on the Fiction of Non-Fiction: Transcript." On the Media. 24 Dec. 2010. Web. 25 June 2012.

Garner, Helen. “An Evening with Helen Garner.” NonfictioNow Conference. RMIT University, Melbourne. 2012. Keynote Address.

---. Joe Cinque's Consolation. Sydney: Picador, 2004. Print.

---. “The Art of a Dumb Question.” True Stories. Melbourne: Text Publishing, 1996. Print.

---. The First Stone: Some Questions About Sex and Power. Sydney: Picador, 1995. Print.

Garness, Kati. “An Interview with Rebecca Skloot." The Daily Cardinal. Online Newspaper. 25 Oct. 2010. Web. 16 Nov. 2011.

Genette, Gérard. Fiction \& Diction. Ithaca: NY: Cornell University Press, 1993. Print. 
---. Paratexts: Thresholds of Interpretation. Cambridge: Cambridge University Press, 1997. Print.

Giggs, Rebecca. "Imagining Women." Overland 208 (2012): 66-71. Web. 2 Dec. 2012.

Giles, Fiona. "Review of 'Bodyjamming': A Collection of Essays Edited by Jenna Mead." Australian Humanities Review 8 (1997): n. pag. Web. 19 Oct. 2012.

Harari, Fiona. A Tragedy in Two Acts: Marcus Einfeld and Teresa Brennan. Carlton: Melbourne University Publishing, 2011. Print.

Harbers, Frank. "Between Fact and Fiction: Arnon Grunberg on His Literary Journalism." Literary Journalism Studies 2.1 (2010): 75-83. Print.

Harrington, Walt. “The Writer's Choice." River Teeth: A Journal of Nonfiction Narrative 5.2 (2004): 77-89. Print.

Hartsock, John. A History of American Literary Journalism: The Emergence of a Modern Narrative Form. Amherst, MA: University of Massachusetts Press, 2000. Print.

Heinze, Ruediger. "Violations of Mimetic Epistemology in First-Person Narrative Fiction." Narrative 16.3 (2008): 279-98. Print.

Hellmann, John. Fables of Fact: New Journalism as New Fiction. Urbana: University of Illinois Press, 1981. Print.

Henry, Erin. "Henrietta Lacks: Author Rebecca Skloot Answers Your Questions." Simply Stated. Online Magazine. 3 May 2011. Web. 21 Aug. 2011.

Hersey, John. "The Legend on the License." Killing the Messenger: 100 Years of Media Criticism. New York: Columbia University Press, 1989. 247-267. Print.

Heyne, Eric. "Toward a Theory of Literary Nonfiction." Modern Fiction Studies 33.3 (1987): 479-490. Print.

---. "Where Fiction Meets Nonfiction: Mapping a Rough Terrain." Narrative 9.3 (2001): 322-33. Print.

Hill, Amelia. "Bookseller of Kabul Author Åsne Seierstad: 'It's Not Possible to Write a Neutral Story'." The Guardian. Online Newspaper. 31 July 2010. Web. 27 June 2012.

Hirst, Martin. "Journalism Education 'Down Under'." Journalism Studies 11.1 (2010): 83-98. Print.

Hollowell, John. Fact and Fiction: The New Journalism and the Nonfiction Novel. Chapel Hill, NC: University of North Carolina Press, 1977. Print.

Hooper, Chloe. "Public Lecture." The University of Western Australia. Alexander Lecture Theatre, Perth. 12 Aug. 2008. Guest Lecture.

---. The Tall Man: Death and Life on Palm Island. Camberwell: Hamish Hamilton, 2008. Print.

Horst, Claire. "Interview with Adrian Nicole LeBlanc." Aviva. Online Magazine. 27 Apr. 2009. Web. 24 Oct. 2011. 
Jauss, Hans Robert, and Elizabeth Benzinger. "Literary History as a Challenge to Literary Theory." New Literary History 2.1 (1970): 7-37. JSTOR. Web. 9 Feb. 2011.

Johnston, Jane. "Turning the Inverted Pyramid Upside Down: How Australian Print Media Is Learning to Love the Narrative." Asia Pacific Media Educator 18 (2007): 1-15. Print.

Joseph, Sue. "Australian Creative Non-fiction: Perspectives and Opinions." ejournalist 11.2 (2011): 31-52. Print.

---. “Telling True Stories in Australia.” Journalism Practice 4.1 (2010): 82-96.

---. "What If Tom Wolfe Was Australian?" Creativity and Uncertainty Conference. Australasian Association of Writing Programs. University of Technology, Sydney. 2008. Conference Paper.

Josephi, Beate, and Christine Muller. "Differently Drawn Boundaries of the Permissible in German and Australian Literary Journalism." Literary Journalism Studies 1.1 (2009): 67-76. Print.

Karlsson, Michael. "Rituals of Transparency." Journalism Studies 11.4 (2010): 535545. CrossRef. Web. 14 Dec. 2011.

Kass, Jeff. Columbine: A True Crime Story, a Victim, the Killers and the Nation's Search for Answers. Denver, CO: Ghost Road Press, 2009. Print.

Keeble, Richard Lance. "The 2011 Keynote: An Appreciation.” Literary Journalism Studies 3.2 (2011): 83-7. Print.

Keeble, Richard Lance, and John Tulloch, eds. Global Literary Journalism: Exploring the Journalistic Imagination. New York: Peter Lang Publishing, 2012. Print.

Keneally, Thomas. "Cultivating Identity.” Meanjin 70.3 (2011): 20-31. Print.

Kerrane, Kevin, and Ben Yagoda. The Art of Fact: A Historical Anthology of Literary Journalism. New York: Scribner, 1997. Print.

Kieran, Matthew. "The Regulatory and Ethical Framework for Investigative Journalism." Investigative Journalism: Context and Practice. Ed. Hugo De Burgh. London: Routledge, 2004. 156-76. Print.

Knox, Malcolm. Secrets of the Jury Room. Sydney: Random House Australia, 2005. Print.

---. “The Darville Made Me Do It.” Sydney Morning Herald 9 July 2005. Sydney Morning Herald. Web. 15 July 2011.

Kornstein, Daniel J. “Twisted Vision: Janet Malcolm's Upside down View of the 'Fatal Vision Case'." Cardozo Studies in Law and Literature 1.2 (1989): 127 156.

Kovach, Bill, and Tom Rosenstiel. The Elements of Journalism: What Newspeople Should Know and the Public Should Expect. New York: Three Rivers Press, 2001. Print.

Krakauer, Jon. Under the Banner of Heaven: A Story of Violent Faith. New York: Doubleday, 2003. Print. 
Kramer, Mark. "Breakable Rules for Literary Journalists." Literary Journalism: A New Collection of the Best American Nonfiction. Ed. Norman Sims \& Mark Kramer. New York: Ballantine Books, 1995. 21-34. Print.

Krien, Anna. Into the Woods: The Battle for Tasmania's Forests. Melbourne: Black Inc., 2010. Print.

Lake, Thomas. “About This Story.” Atlanta. Online Magazine. May 2009. Web. 20 Dec. 2012.

---. "The Last Heavy Footfalls of Doc Hullender." Atlanta. Online Magazine. May 2009. Web. 26 June 2012.

Langewiesche, William. American Ground: Unbuilding the World Trade Center. New York: North Point, 2003. Print.

LeBlanc, Adrian Nicole. Random Family: Love, Drugs, Trouble, and Coming of Age in the Bronx. New York: Scribner, 2004. Print.

Lehman, Daniel. Matters of Fact: Reading Nonfiction over the Edge. Columbus, $\mathrm{OH}$ : Ohio State University Press, 1997. Print.

---. "Mining a Rough Terrain: Weighing the Implications of Nonfiction." Narrative 9.3 (2001): 334-342. JSTOR. Web. 28 Jan. 2011.

Lever, Susan. “Against Forgetting: Anna Funder's Stasiland and Helen Garner's Joe Cinque's Consolation." Academia.edu. 2006. Web. 1 Dec. 2012.

Little, Janine. "Journalism, Creative Non-fiction and Australia's Black History: The Tall Man and Cross-Cultural Source Relationships." Australian Journalism Review 32.2 (2010): 47-58. Print.

Lodge, David. Modern Criticism and Theory: A Reader. London: Longman, 1988. Print.

Lounsberry, Barbara. The Art of Fact: Contemporary Artists of Nonfiction. New York: Greenwood Press, 1990. Print.

Lounsberry, Barbara, and Gay Talese. The Literature of Reality: Writing Creative Nonfiction. New York: HarperCollins, 1996. Print.

MacDonald, Dwight. "Parajournalism, or Tom Wolfe and His Magic Writing Machine." The New York Review of Books. Online Magazine. 26 July 1965. Web. 19 Apr. 2011.

Maddow, Rachel. “The Rachel Maddow Show.” MSNBC. Web. 18 Aug. 2011.

Maguire, Miles. "Richard Critchfield: 'Genius' Journalism and the Fallacy of Verification.” Literary Journalism Studies 1.2 (2009): 9-21. Print.

Malcolm, Janet. The Journalist and the Murderer. 6th ed. New York: Vintage Books, 1990. Print.

---. "Women at War: A Case of Sexual Harassment." The New Yorker 7 July 1997 : 73-75. Print.

Marr, David, and Marian Wilkinson. Dark Victory. Crows Nest, NSW: Allen \& Unwin, 2004. Print.

Marsh, Charles. "Deeper Than the Fictional Model." Journalism Studies 11.3 (2010): 295-310. CrossRef. Web. 
Maslin, Janet. "School Day When Hell Came Knocking.” The New York Times 6 Apr. 2009. NYTimes.com. Web. 4 Dec. 2011.

Matheson, Donald. "Hans-Georg Gadamer's Philosophical Hermeneutics and Journalism Research.” Journalism Studies 10.5 (2009): 709-718. Print.

McDonald, Willa. "Creditable or Reprehensible? The Literary Journalism of Helen Garner." Literary Journalism Across the Globe: Journalistic Traditions and Transnational Influences. Ed. John S. Bak \& Bill Reynolds. Amherst, MA: University of Massachusetts Press, 2011. 260-275. Print.

McGeough, Paul. In Baghdad: a Reporter's War. Crows Nest, NSW: Allen \& Unwin, 2003. Print.

---. Kill Khalid: Mossad's Failed Hit ... and the Rise of Hamas. New York: New Press, 2009. Print.

---. Manhattan to Baghdad: Despatches from the Frontline in the War on Terror. Crows Nest, NSW: Allen \& Unwin, 2003. Print.

McGinniss, Joe. The Last Brother: The Rise and Fall of Teddy Kennedy. London: Warner Books, 1995. Print.

McKay, Jenny. "Åsne Seierstad and the Bookseller of Kabul." Global Literary Journalism: Exploring the Journalistic Imagination. Ed. Richard Lance Keeble \& John Tulloch. New York: Peter Lang Publishing, 2012. 175-190. Print.

---. "Reportage in the U.K.: A Hidden Genre?" Literary Journalism Across the Globe: Journalistic Traditions and Transnational Influences. Ed. John S. Bak \& Bill Reynolds. Amherst, MA: Massachusetts Press, 2011. 47-60. Print.

Mead, Jenna. "The First Stone: Feminism and Non Fiction." Sydney Papers 7.4 (1995): 120-131. search.informit.com.au.helicon.vuw.ac.nz. Web. 19 Oct. 2012.

Mehta, Suketu. Maximum City: Bombay Lost and Found. 1st ed. New York: Knopf, 2004. Print.

Merritt, Rob, and Brooks Brown. No Easy Answers: The Truth Behind Death at Columbine. New York: Lantern Books, 2002. Print.

Meyers, Christopher. 'Judgment, Accountability, and 'Information': A Response to Machamer and Boylan.” Business \& Professional Ethics Journal 14.2 (1995): 77-92. JSTOR. Web. 23 Aug. 2012.

Miller, G. Wayne. King of Hearts: The True Story of the Maverick Who Pioneered Open Heart Surgery. New York: Crown, 2010. Print.

"Mission Statement." International Association for Literary Journalism Studies. Web. 12 June 2012.

Mitchell, Timothy. "The Invention and Reinvention of the Egyptian Peasant." International Journal of Middle East Studies 22.2 (1990): 129-150. JSTOR. Web. 23 Oct. 2012.

Mordue, Mark. "Is the Novel Dead?" Sydney Morning Herald. Online Newspaper. 25 Jan. 2003. Web. 18 Dec. 2012. 
Naughtie, James. "Bookclub: Asne Seierstad." BBC Radio 4. Media Broadcaster. 10 July 2008. Web. 25 Oct. 2012.

O'Grady, Carrie. "Review: The Legend of Colton H. Bryant by Alexandra Fuller." The Guardian. Online Newspaper. 18 Apr. 2009. Web. 21 July 2011.

Orlean, Susan. The Orchid Thief: A True Story of Beauty and Obsession. New York: Random House, 1998. Print.

Orwell, George. Down and Out in Paris and London. London: Harper \& Brothers, 1933. Print.

Owen-Brown, Michael. "Writing Wrongs." The Advertiser. Online Newspaper. 16 Nov. 2002. Web. 21 July 2011.

Pauly, John J. "Literary Journalism and the Drama of Civic Life." Literary Journalism Studies 3.2 (2011): 73-82. Print.

---. "The Politics of The New Journalism." Literary Journalism in the Twentieth Century. Ed. Norman Sims. New York: Oxford University Press, 1990. 110129. Print.

PENamericancenter. "Writing Inside, Writing Outside." Online Video Clip. YouTube. YouTube, 28 May 2010. Web. 23 Nov. 2011.

Pether, Penny. "The Prose and the Passion: Searching for an Australian 'Constitutional Epic' in Our Recent Literature and Cinema." Meanjin 66.3 (2007): 43-48. Print.

Phelan, James. "Toward a Rhetorical Reader-Response Criticism: The Difficult, the Stubborn, and the Ending of Beloved." Modern Fiction Studies 39.3\&4 (1993): 709-728. Print.

Pitzer, Andrea. "Rebecca Skloot on Narrating History." Nieman Storyboard. 16 July 2010. Web. 22 Aug. 2011.

Plaisance, Patrick Lee. "Transparency: An Assessment of the Kantian Roots of a Key Element in Media Ethics Practice." Journal of Mass Media Ethics 22.2-3 (2007): 187-207. Web. 28 Oct. 2012.

Preston, Richard. The Hot Zone: A Terrifying True Story. New York: Anchor Books, 1994. Print.

“Publisher's Note.” Internet Archive. Web. 4 Oct. 2012.

Pyrhönen, Heta. "Genre." The Cambridge Companion to Narrative. Ed. David Herman. Cambridge: Cambridge University Press, 2007. 109-123. Print.

Rabinowitz, Peter. "'Betraying the Sender': The Rhetoric and Ethics of Fragile Texts." Narrative 2.3 (1994): 201-213. Print.

Rais, Shah Muhammad. Once Upon a Time There Was a Bookseller in Kabul. Kabul: Shah M Book Co, 2007. Print.

Reynolds, Bill. "A Metaphor for the World: William Langewiesche, John Vaillant and Looking for the Story in Long-form." Asia Pacific Media Educator 18 (2007): 58-71.

Ricketson, Matthew. "Ethical Issues in the Practice of Book-Length Journalism." Sept. 2009 : n. pag. Print. 
---. "Helen Garner's 'The First Stone': Hitchhiking on the Credibility of Other Writers." Bodyjamming. Ed. Jenna Mead. Milsons Point, NSW: Vintage Books, 1997. Print.

---. "The Vibrant State of Book-Length Journalism in Australia." Australian Journalism Review 32.1 (2010): 67-79. Print.

---. "True Stories: The Power and Pitfalls of Literary Journalism." Journalism: Theory in Practice. Ed. Suellen Tapsall \& Carolyn Varley. Melbourne: Oxford University Press, 2001. 149-165. Print.

Rimmon-Kenan, Shlomith. Narrative Fiction: Contemporary Poetics. New York: Routledge, 2002. Print.

Rooney, Brigid. "The Sinner, the Prophet, and the Pieta: Sacrifice and the Sacred in Helen Garner's Narratives." Antipodes: A North American Journal of Australian Literature 19.2 (2005): 159-165. Print.

Ruddock, Sam. "In Converation With: Chloe Hooper." Vulpes Libris. Literary Blog. 2 June 2010. Web. 24 Jan. 2012.

Rundle, Guy. Down to the Crossroads: On the Trail of the 2008 US Presidential Election. Melbourne: Penguin Books, 2008. Print.

Ryan, Marie-Laure. Narrative as Virtual Reality: Immersion and Interactivity in Literature and Electronic Media. Baltimore, MD: Johns Hopkins University Press, 2001. Print.

---. "Postmodernism and the Doctrine of Panfictionality." Narrative 5.2 (1997): 165187. JSTOR. Web. 28 Jan. 2011.

---. "Towards a Definition of Narrative." The Cambridge Companion to Narrative. Ed. David Herman. Cambridge: Cambridge University Press, 2007. Print.

Schudson, Michael. "Political Observatories, Databases \& News in the Emerging Ecology of Public Information.” Daedalus 139.2 (2010): 100-109,154. Print.

---. “The Objectivity Norm in American Journalism.” Journalism 2.2 (2001): 149170. Print.

Schwarten, Evan. "Coroner Slams Cops Over Doomadgee Death." The Sydney Morning Herald. Online Newspaper. 14 May 2010. Web. 2 Dec. 2012.

Seierstad, Åsne. The Bookseller of Kabul. 1st ed. Little, Brown and Company, 2003. Print.

Shafer, Jack. "Dismantling the Capote Myth." Reuters Blogs 14 Mar. 2012. Web. 23 Oct. 2012.

Silverman, Craig. "The Lifespan of a Fact' Blends Fiction with Nonfiction to Explore Nature of Truth.” Poynter.org. 5 Mar. 2012. Web. 1 Aug. 2012.

Simons, Margaret. "Facts, Projection, Politics and the Objective Journalist." The Sydney Papers 12.3 (2000): 22-30. search.informit.com.au. Web. 16 Jan. 2012.

---. Fit to Print: Inside the Canberra Press Gallery. Sydney: UNSW Press, 1999. Print.

---. "Helen Garner: The Woman with the Hammer in the Kitchen Drawer." The Best Australian Essays 2001. Ed. Peter Craven. Melbourne: Black Inc., 2001. Print. 
---. "The Hindmarsh Island Affair and Australian Anthropology." The Sydney Papers 15.2 (2003): 150-9. Print.

---. The Meeting of the Waters: The Hindmarsh Island Affair. 1st ed. Sydney: Hodder Headline Australia Pty Ltd, 2003. Print.

Sims, Norman, ed. Literary Journalism in the Twentieth Century. 2nd ed. New York: Oxford University Press, 2008. Print.

---, ed. The Literary Journalists. 1st ed. New York: Ballantine Books, 1984. Print.

---. "The Problem and the Promise of Literary Journalism Studies." Literary Journalism Studies 1.1 (2009): 7-16. Print.

---, ed. True Stories: A Century of Literary Journalism. Evanston Illinois: Northwestern University Press, 2007. Print.

Sims, Norman, and Mark Kramer, eds. Literary Journalism: A New Collection of the Best American Nonfiction. New York: Ballantine Books, 1995. Print.

Skloot, Rebecca. "Book Special Features.” Rebecca Skloot. 2011. Web. 22 Nov. 2011.

---. The Immortal Life of Henrietta Lacks. New York: Crown Publishers, 2010. Print.

Smith, Kathy. "John McPhee Balances the Act.” Literary Journalism in the Twentieth Century. Ed. Norman Sims. New York: Oxford University Press, 1990. 206227. Print.

State of New Jersey v. State of New York. 523 US 767. Supreme Court of the United States. 1998. Lexis. Web. 20 Jul. 2012.

Steffens, Lincoln. The Shame Of The Cities. New York: Hill and Wang, 1904. Print.

Strainchamps, Anne. "Transcript for John D'Agata and Jim Fingal on 'The Lifespan of a Fact'." To The Best of Our Knowledge. Wisconsin Public Radio. 2012. Web. 2 Aug. 2012.

Swales, John M. "Worlds of Genre - Metaphors of Genre." Genre in a Changing World. Ed. Charles Bazerman. Fort Collins, CO: Parlor Press, 2009. Print.

Symes, Colin. "You Can't Judge a Book by Its Cover: The Aesthetics of Titles and Other Epitextual Devices." Journal of Aesthetic Education 26.3 (1992): 1726. Print.

Talese, Gay. Fame and Obscurity. New York: World, 1971. Print.

Taylor, Cheryl. “"This Fiction, It Don't Go Away': Narrative as an Index to Palm Island's Past and Present." Queensland Review 16.1 (2009): 35-67. Print.

“The CNF Foundation.” Creative Nonfiction. 2005. Web. 17 Feb. 2011.

“The Lifespan of a Fact." W. W. Norton \& Company, Inc. Publisher Website. 2012. Web. 1 Aug. 2012.

Tingle, Laura. "Great Expectations: Government, Entitlement and an Angry Nation." Quarterly Essay 46 (2012): 1-64. Print.

Todorov, Tzvetan. Genres in Discourse. Cambridge: Cambridge University Press, 1990. Print. 
Topping, Alexandra. "The Bookseller of Kabul Author Cleared of Invading Afghan Family’s Privacy.” The Guardian. Online Newspaper. 13 Dec. 2011. Web. 27 June 2012.

Tuchman, Gaye. Making News: A Study in the Construction of Reality. New York: Free Press, 1978. Print.

Ulin, David. “Dave Cullen's Writer's Channel." Online Video Clip. YouTube. YouTube. 11 Jun. 2010. Web. 20 Oct. 2011.

Vaillant, John. The Golden Spruce: A True Story Of Myth, Madness, And Greed. New York: W. W. Norton \& Company, 2005. Print.

Van der Wurff, Richard, and Klaus Schonbach. "Between Profession and Audience." Journalism Studies 12.4 (2011): 407-422.

Van Tuyll, Debra Reddin. “The Past Is Prologue, Or.” Journalism Studies 11 (2010): 477-486. CrossRef. Web. 5 Dec. 2011.

Vare, Robert. "The State of Narrative Nonfiction Writing." Nieman Foundation. Fall 2000. Web. 16 Feb. 2011.

Warhaft, Sally. "Chloe Hooper in Conversation with Sally Warhaft About The Tall Man.” Online Video Clip. Slow TV. The Monthly. Jul. 2008. Web. 13 Feb. 2012.

Warhaft, Sally. "The Essay: Nicolas Rothwell, Gideon Haigh, Chloe Hooper \& Sally Warhaft." Online Video Clip. Slow TV. The Monthly. Aug. 2008. Web. 24 Jan. 2012.

Weber, Ronald. The Literature of Fact: Literary Non-Fiction in American Writing. Columbus, OH: Ohio University Press, 1985. Print.

Weingarten, Marc. The Gang That Wouldn't Write Straight: Wolfe, Thompson, Didion, and the New Journalism Revolution. New York: Crown, 2005. Print.

Wessman, Ralph. "North to Garradunga." Famous Reporter 42 (2011): n. pag. Web. 30 Jan. 2012.

Westoll, Andrew. The Riverbones: Stumbling After Eden in the Jungles of Suriname. Toronto: Emblem Editions, 2008. Print.

White, Hayden. "Narrativity in the Representation of Reality." The Content of the Form. Baltimore, MD: Johns Hopkins University Press, 1987. Print.

---. "The Question of Narrative in Contemporary Historical Theory." The Content of the Form. Baltimore: Johns Hopkins University Press, 1987. Print.

---. Tropics of Discourse: Essays in Cultural Criticism. Baltimore, MD: Johns Hopkins University Press, 1978. Print.

Whitt, Jan. Settling the Borderland: Other Voices in Literary Journalism. Lanham, MD: University Press of America, 2008. Print.

WKNOPBS. "A Conversation with Rebecca Skloot." Online Video Clip. YouTube. YouTube, 11 Nov. 2010. Web. 17 Nov. 2011.

Wolfe, Tom. The New Journalism. New York: Harper \& Row, 1973. Print.

---. "The New Journalism: A La Recherche Des Whichy Thickets." New York Magazine. Online Magazine. 21 Feb. 1972. Print. 
Wyatt, Edward. "His Blockbuster on Shelves, He Tempts Fate With Fire." The New York Times 21 Sept. 2005. NYTimes.com. Web. 14 July 2011.

Wypijewski, JoAnn. "No Way Out." Guardian. Online Newspaper. 13 Dec. 2003. Web. 21 Aug. 2011.

Young, Sally. "The Journalism 'Crisis'.” Journalism Studies 11.4 (2010): 610-624. CrossRef. Web. 1 Dec. 2011.

Zajac, Bec. "Women and Nonfiction." Overland. Online Literary Journal. 18 Sept. 2012. Web. 13 Dec. 2012.

Zavarzadeh, Mas'ud. Mythopoeic Reality: The Postwar American Nonfiction Novel. Urbana: University of Illinois Press, 1980. Print. 